Human Health Risk

Comparisons for Environmental

Management Baseline

Programs and Integration

Opportunities (Discussion Draft)

S. A. Eide

J. L. Jones

o

T. E. Wierman

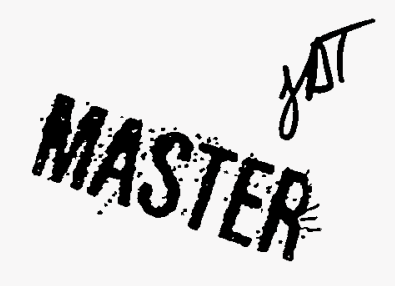

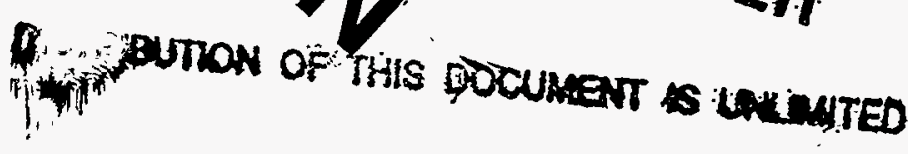




\title{
Human Health Risk Comparisons for Environmental Management Baseline Programs and Integration Opportunities (Discussion Draft)
}

\author{
S. A. Eide \\ J. L. Jones \\ T. E. Wierman
}

Published February 1998

Idaho National Engineering and Environmental Laboratory Environmental Management Integration Department

Lockheed Martin Idaho Technologies Company Idaho Falls, Idaho 83415

Prepared for the

U.S. Department of Energy

Assistant Secretary for Environmental Management

Under DOE Idaho Operations Office

Contract DE-AC07-94ID13223 



\section{DISCLAIMER}

This report was prepared as an account of work sponsored by an agency of the United States Government. Neither the United States Government nor any agency thereof, nor any of their employees, makes any warranty, express or implied, or assumes any legal liability or responsibility for the accuracy, completeness, or usefulness of any information, apparatus, product, or process disclosed, or represents that its use would not infringe privately owned rights. Reference berein to any specific commercial product, process, or service by trade name, trademark, manufacturer, or otherwise does not necessarily constitute or imply its endorsement, recommendation, or favoring by the United States Government or any agency thereof. The views and opinions of authors expressed herein do not necessarily state or reflect those of the United States Government or any agency thereof. 


\section{DISCLAIMER}

Portions of this document may be illegible in electronic image products. Images are produced from the best available original document. 


\begin{abstract}
This report documents the process and results of human health risk assessments of the U.S. Department of Energy (DOE) complex-wide programs for high-level waste, transuranic waste, low-level waste, mixed low-level waste, and spent nuclear fuel. The DOE baseline programs and alternatives for these five material types were characterized by disposition maps (system flow diagrams) and supporting information in the May 1997 report A Contractor Report to the Department of Energy on Environmental Baseline Programs and Integration Opportunities (Discussion Draft). Risk analyses were performed using the Simplified Risk Model (SRM), developed to support DOE Environmental Management (EM) integration studies. The SRM risk analyses consistently and comprehensively cover the entire programs for the five material types, from initial storage through final disposition. Risk results are presented at several levels: DOE complex-wide, material type program, individual DOE sites, and DOE site activities.
\end{abstract}




\section{SUMMARY}

In July 1996, the U.S. Department of Energy (DOE) Assistant Secretary for Environmental Management (EM) chartered a government contractor-led effort to develop a suite of technically defensible, integrated alternatives that meet the EM mission. The contractor team was challenged to "think outside the box" for solutions that cross traditional site boundaries and enable the programs to get the job done at an earlier date and at a lower cost. The results of that effort are summarized in the May 1997 report $A$ Contractor Report to the Department of Energy on Environmental Baseline Programs and Integration Opportunities (Discussion Draft). In that report are presented DOE complex-wide baseline programs and alternatives for six areas: high-level waste (HLW), transuranic waste (TRUW), low-level waste (LLW), mixed low-level waste (MLLW), spent nuclear fuel (SNF), and waste generated from environmental restoration activities (ER).

This report documents a related effort, the development of simplified human health risk models for the baseline programs and alternatives. The simplified risk models were developed to:

- provide a consistent, comprehensive, and quantitative human health risk picture for all of the important activities involved in the baseline programs and alternatives

- evaluate the alternative program risks relative to the baseline program risks

- provide a simplified risk model that can be exercised to answer stakeholder questions about risk.

The Simplified Risk Model (SRM) was developed to fulfill these types of needs. The technical basis for the SRM is documented in the September 1996 report A Simplified Method for Quantitative Assessment of the Relative Health and Safety Risk of Environmental Management Activities. Use of the SRM is explained in the October 1996 report User's Guide for the Simplified Risk Model (SRM). The SRM models in an approximate, quantitative manner the human health risk from radionuclide and chemical exposure from both accidents and normal, incident-free operation. Exposure pathways include airborne (inhalation) and groundwater (ingestion).

Human health risk results (person-rem) for the DOE complex-wide programs -- HLW, TRUW, LLW, MLLW, and SNF -- are presented in this report for both the baseline programs and alternatives. ER is not covered. The human health risk analyses consistently and comprehensively cover risk from initial storage through final disposal or disposition. Results are presented at the complex, program, DOE site, and site activity levels of detail. Risk results are also broken down into accident versus normal, incidentfree operation, and worker/site versus public.

Risk results from all five material types -- HLW, TRUW, LLW, MLLW, and SNF -- indicate a total DOE complex risk of approximately 26,000 person-rem for both the baseline programs and the alternatives. Therefore, at the complex level, there is no significant difference in human health risk from radionuclides and chemicals between the baseline and alternative programs.

A breakdown of the risk by material type is presented in Figure S-1. For the baseline programs, TRUW contributes the most risk (11,600 person-rem). The next highest risk material type is LLW (6,700 person-rem), followed by HLW (4800 person-rem). SNF (1750 person-rem) and MLLW (1,600 person-rem) have the lowest risk. The alternative programs result in slightly different risks, but the order of the material types is unchanged except for SNF and MLLW. The comparison of risks between material 
type programs, shown in Figure S-1, is appropriate because all five material types were analyzed in a consistent and comprehensive manner. Risk modeling assumptions were applied consistently across all of the analyses. Also, the complex-wide programs for each material type cover present storage conditions up through final disposal or disposition, and also include newly-generated material.

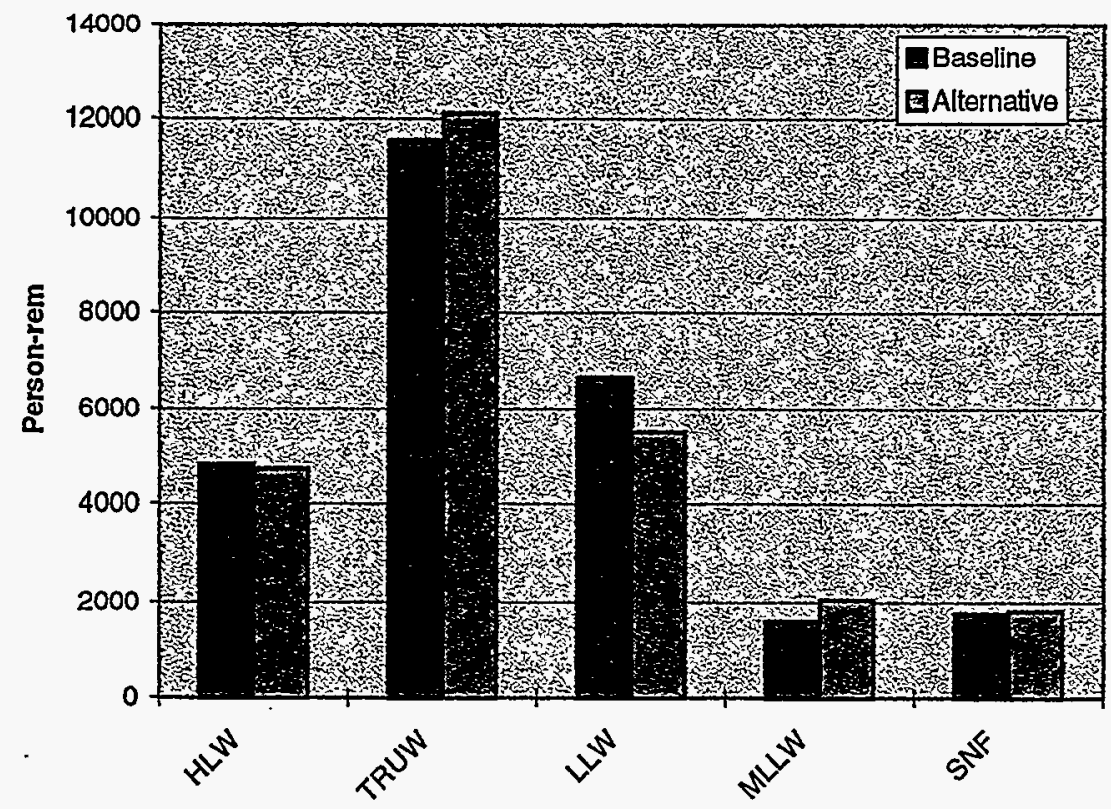

Figure S-1. DOE complex-wide risk results by material type.

Figure S-2 presents the risk results by site for the baseline programs. (The results for the alternative are similar.) Shown in the figure are $12 \mathrm{DOE}$ sites, one combined "site" representing off-site transportation, three disposal sites, and one commercial treatment site. As shown in Figure S-2, off-site transportation contributes the most risk. The transportation risk is dominated by TRUW shipments. Among the DOE sites, the Savannah River Site (SRS), Rocky Flats Environmental Technology Site (RFETS), Hanford, and the Idaho National Engineering and Environmental Laboratory have the highest risks. Each site has a different composition of material type risks, with SRS dominated by HLW and RFETS dominated by TRUW. Disposal sites are only minor contributors to risk, compared with most of the other sites.

Comparisons of these SRM risk predictions with other more detailed risk assessments, such as those in Environmental Impact Statements (EISs), have indicated that the SRM results are reasonably accurate. In particular, the SRM predictions for transportation match EIS risk predictions, when consistent sets of assumptions are used, such as total miles traveled, amount of material type carried by each truck or rail shipment, and the mrem per hour at one meter from the shipping containers. Risk results from other types of activities modeled with the SRM, such as storage, treatment, and handling, have also indicated that the SRM predictions are reasonably accurate. 


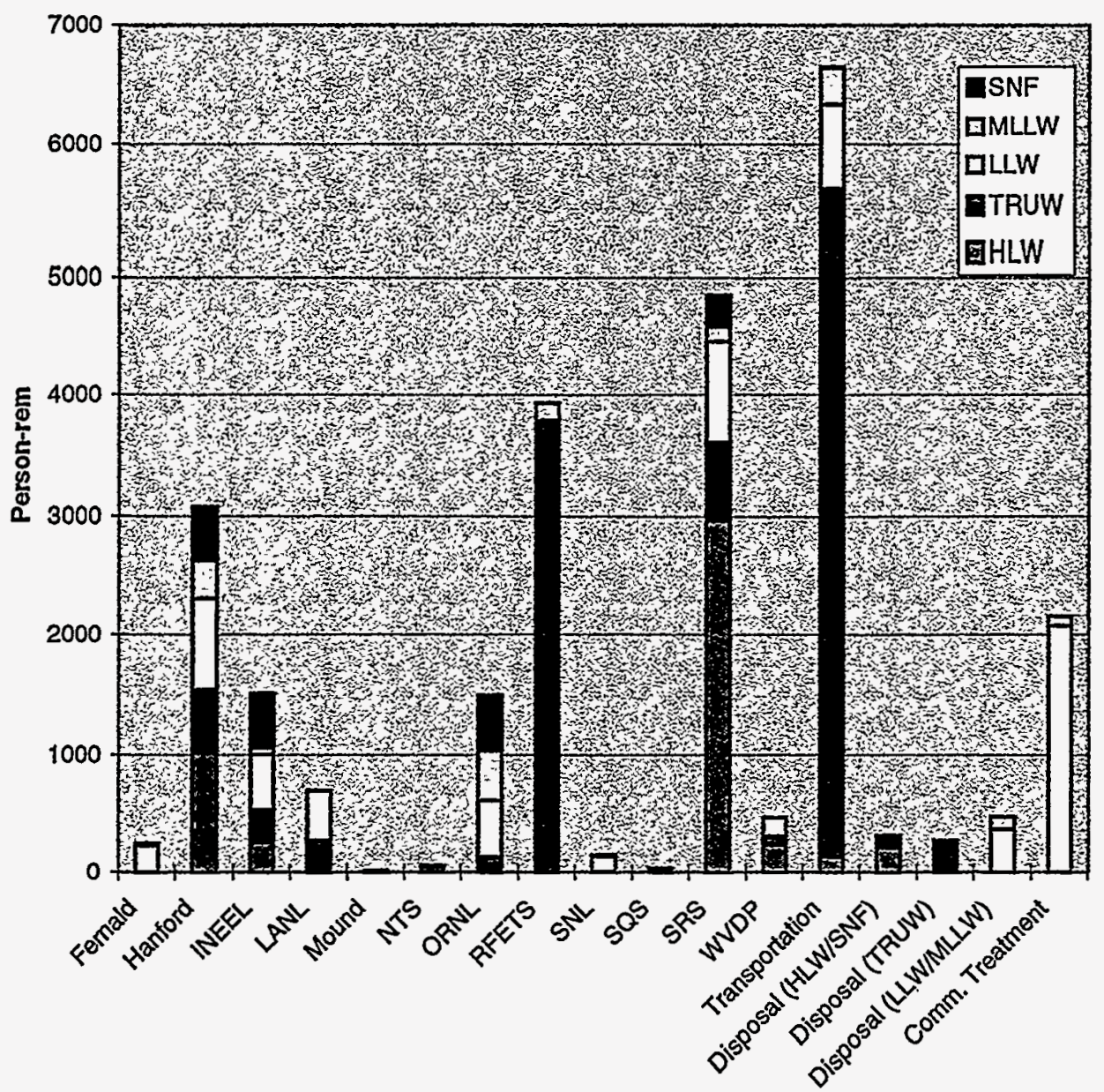

Figure S-2. DOE risk results by site and material type (baseline).

The DOE complex-wide SRM models for HLW, TRUW, LLW, MLLW, and SNF are EXCEL ${ }^{\mathrm{TM}}$ spreadsheets. These spreadsheets contain detailed risk information on many different types of human health risk contributions, including the following: accident risk (airborne pathway) to workers, site personnel, and the public, broken down into contributions from actinides, nonactinides, and chemicals; groundwater ingestion risk to the public from actinides, nonactinides, and chemicals; offgas risk (airborne pathway) to site personnel and the public, broken down into contributions from actinides, nonactinides, and chemicals; normal exposure (direct radiation) to workers; and normal and accident risk to the crew and public for transportation. All of these risk contributors were included in the SRM because they have been shown to be significant in one or more of the activities typically modeled. All of these contributors (applicable to the activity in question) are summed in order to estimate the total risk. 


\section{ACKNOWLEDGMENTS}

The authors would like to acknowledge several contributions to the development of the SRM. The precursor to the SRM was the risk modeling performed by G. A. Beitel and T. H. Smith as part of the 1995 systems engineering effort documented in the report Integration of EM Activities at the INEL. Following that effort, T. H. Smith initiated the development of the SRM and contributed significantly to almost all aspects of the model. R. G. Peatross and I. E. Stepan also contributed significantly to portions of the SRM.

Also, the authors would like to acknowledge the support of the material type subject matter experts located at the various DOE sites. Without their help in collecting information associated with the disposition maps, the SRM analyses could not have been performed.

Finally, initial reviews of a preliminary version of the SRM by Sandia National Laboratories and Oak Ridge National Laboratory helped to improve the structure and content of the SRM. 


\section{CONTENTS}

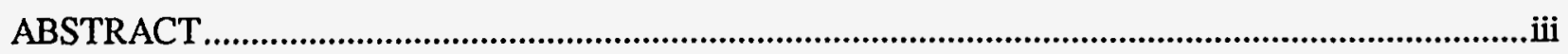

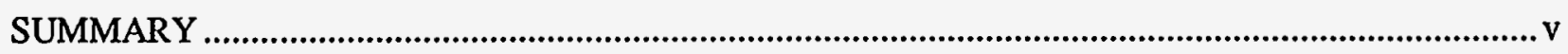

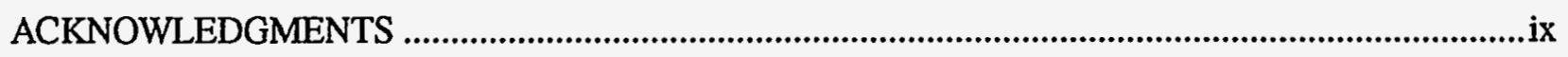

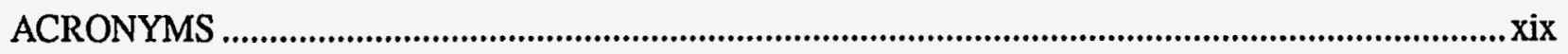

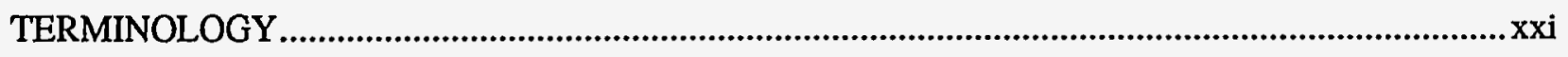

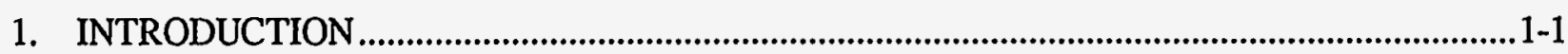

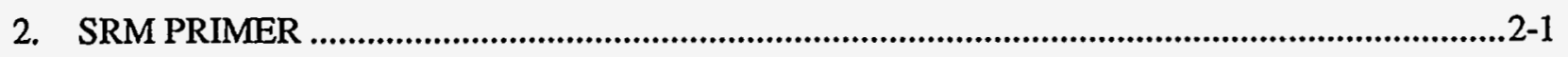

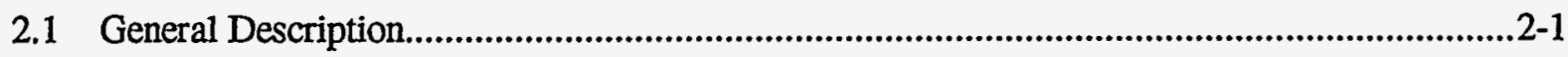

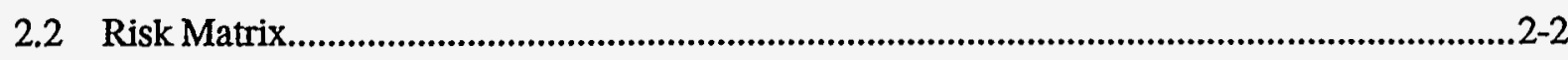

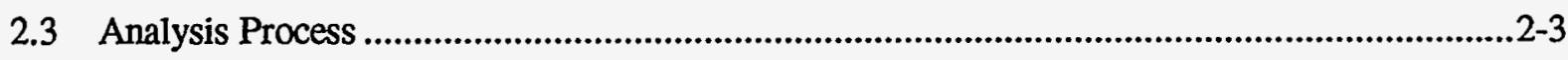

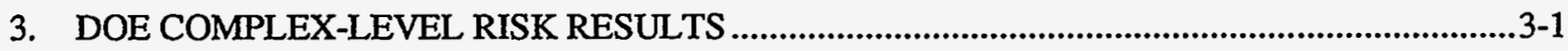

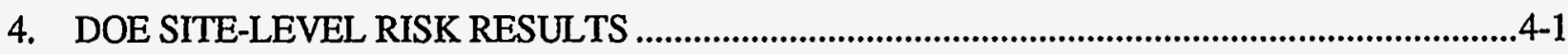

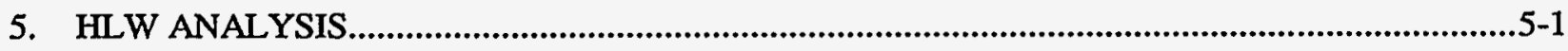

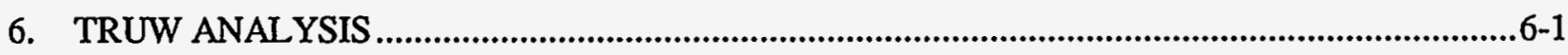

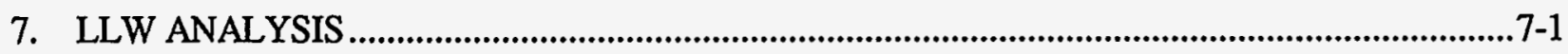

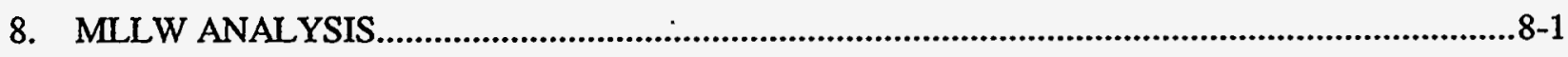

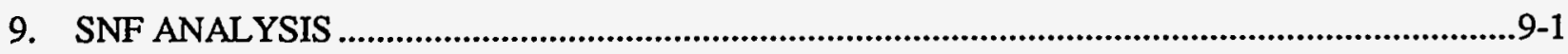

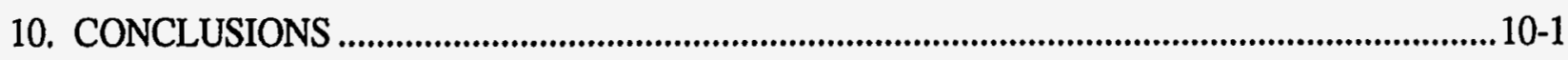

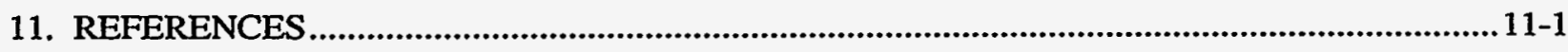

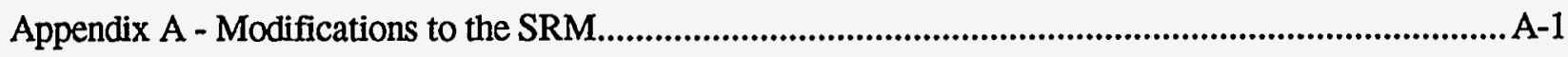

Appendix B - SRM Activity Risk Matrices for HLW ........................................................................ B-1

Appendix C - SRM Activity Risk Matrices for TRUW ..........................................................................

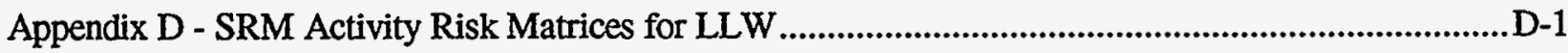




\section{FIGURES}

S-1. DOE complex-wide risk results by material type ................................................................. vi

S-2. DOE risk results by site and material type (baseline) .............................................................. vii

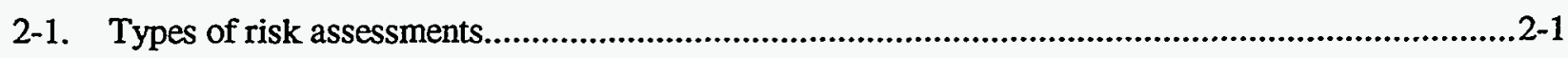

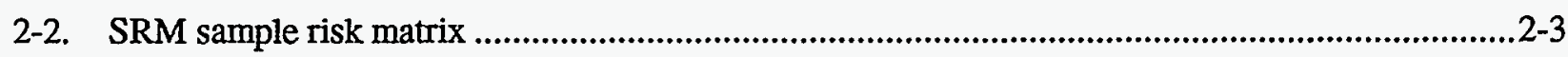

3-1. DOE complex-wide risk results for HLW, TRUW, LLW, MLLW, and SNF ..............................3-1

3-2. DOE complex-wide risk results (worker/site versus public) .................................................3-2

3-3. DOE complex-wide risk results (accident versus normal) ...................................................... 3-2

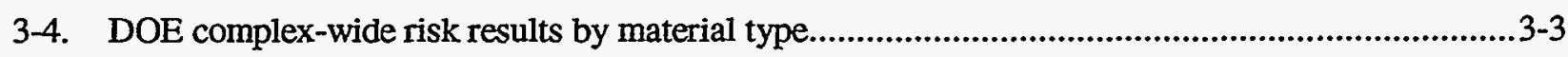

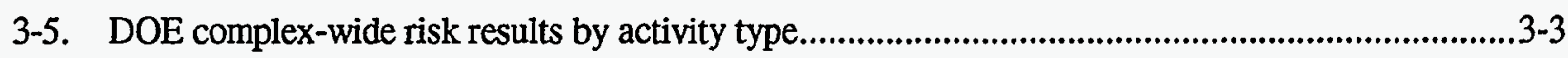

4-1. DOE risk results by site and material type (baseline) .....................................................

4-2. DOE risk results by site and material type (alternative) .......................................................4-2

5-1. Hanford HLW disposition maps (baseline and alternative) ..................................................5-2

5-2. INEEL HLW disposition maps (baseline and alternative) ......................................................

5-3. SRS HLW disposition maps (baseline and alternative) ........................................................5-4

5-4. WVDP HLW disposition maps (baseline and alternative) .........................................................5-5

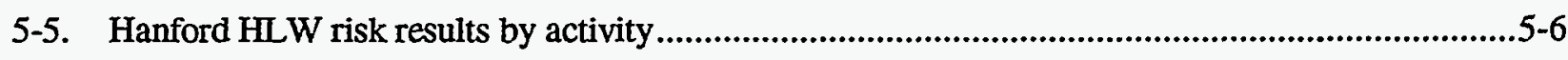

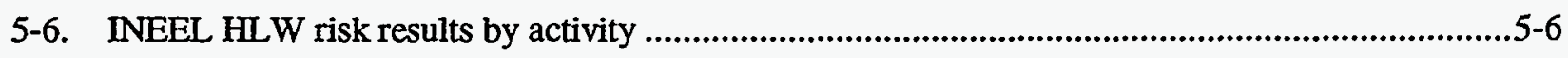

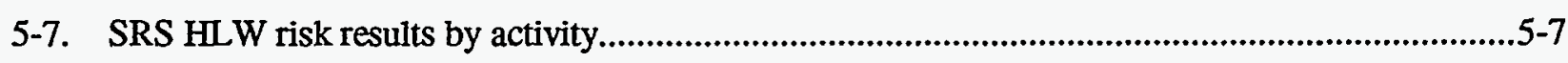

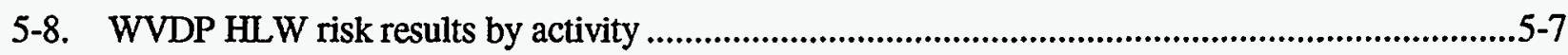

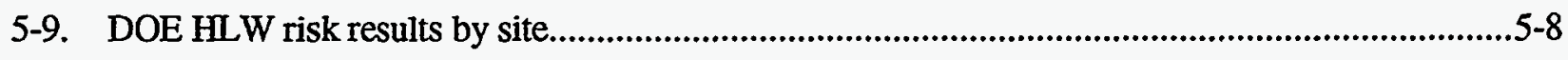

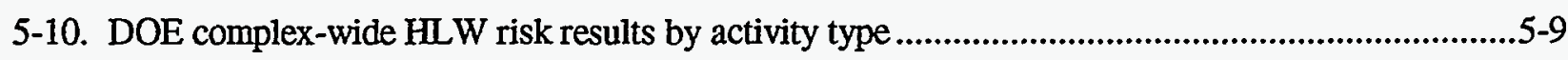


5-11. DOE complex-wide HLW risk results

5-12. DOE HLW risk results by site (worker/site versus public)

5-13. DOE complex-wide HLW risk results by activity type (worker/site versus public)......................5-10

5-14. DOE complex-wide HLW risk results (worker/site versus public) $5-11$

5-15. DOE HLW risk results by site (accident versus normal). 5-12

5-16. DOE complex-wide HLW risk results by activity type (accident versus normal) 5-12

5-17. DOE complex-wide HLW risk results (accident versus normal) 5-13

6-1. Hanford TRUW disposition maps (baseline and alternative). .6-3

6-2. INEEL TRUW disposition maps (baseline and alternative) ......................................................6-4

6-3. LANL TRUW disposition maps (baseline and alternative) .....................................................6-5

6-4. Mound TRUW disposition maps (baseline and alternative) ....................................................6-6

6-5. NTS TRUW disposition maps (baseline and alternative) ..........................................................6-7

6-6. ORNL TRUW disposition maps (baseline and alternative) ...................................................6-8

6-7. RFETS TRUW disposition maps (baseline and alternative)....................................................6-9

6-8. SNL TRUW disposition maps (baseline and alternative) ........................................................6-10

6-9. SRS TRUW disposition maps (baseline and alternative) ........................................................6-11

6-10. WVDP TRUW disposition maps (baseline and alternative) ...................................................6-12

6-11. Hanford TRUW risk results by activity ...............................................................................6-13

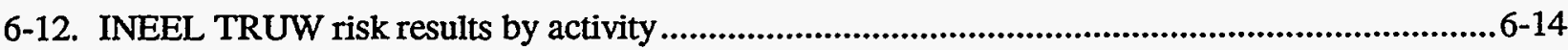

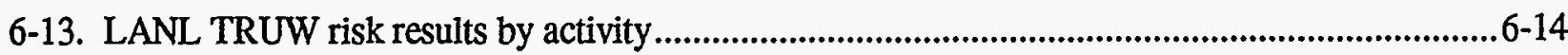

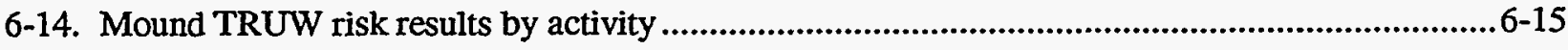

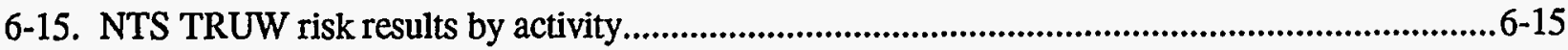

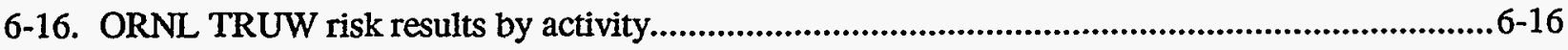

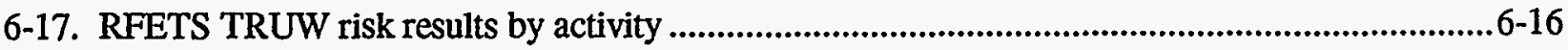

6-18. Small Quantity Sites TRUW risk results by activity..........................................................17 
6-19. SNL TRUW risk results by activity.

6-20. SRS TRUW risk results by activity 6-18

6-21. WVDP TRUW risk results by activity. $6-18$

6-22. Commercial TRUW risk results by activity.

6-23. WIPP TRUW risk results by activity.

6-24. DOE TRUW risk results by site

6-25. DOE complex-wide TRUW risk results by activity type.

6-26. DOE complex-wide TRUW risk results.

6-27. DOE TRUW risk results by site (worker/site versus public).

6-28. DOE complex-wide TRUW risk results by activity type (worker/site versus public).

6-29. DOE complex-wide TRUW risk results (worker/site versus public).

6-30. DOE TRUW risk results by site (accident versus normal)

6-31. DOE complex-wide TRUW risk results by activity type (accident versus normal)

6-32. DOE complex-wide TRUW risk results (accident versus normal)

7-1. Fernald MLLW disposition maps (baseline and alternative)

7-2. Hanford MLLW disposition maps (baseline and alternative) 7-3

7-3. INEEL MLLW disposition maps (baseline and alternative) ....................................................

7-4. LANL MLLW disposition maps (baseline and alternative) ................................................. 7-6

7-5. RFETS MLLW disposition maps (baseline and alternative) .....................................................7-7

7-6. ORNL MLLW disposition maps (baseline and alternative) ....................................................7-8

7-7. SNL MLLW disposition maps (baseline and alternative)......................................................... 7-9

7-8. SRS MLLW disposition maps (baseline and alternative) ....................................................11

7-9. WVDP LLW disposition maps (baseline and alternative) $7-13$

7-10. Fernald LLW risk results by activity 
7-11. Hanford LLW risk results by activity

7-12. INEEL LLW risk results by activity

7-13. LANL LLW risk results by activity.

7-14. RFETS LLW risk results by activity $7-16$

7-15. ORNL LLW risk results by activity. 7-16

7-16. SNL LLW risk results by activity. 7-17

7-17. SRS MLLW risk results by activity 7-17

7-18. WVDP LLW risk results by activity .7-18

7-19. DOE LLW risk results by site 7-19

7-20. DOE complex-wide LLW risk results by activity type... 7-19

7-21. DOE complex-wide LLW risk results $7-20$

7-22. DOE LLW risk results by site (worker/site versus public) $7-20$

7-23. DOE complex-wide LLW risk results by activity type (worker/site versus public) . 7-21

7-24. DOE complex-wide LLW risk results by site (worker/site versus public). .7-21

7-25. DOE LLW risk results by site (accident versus normal). 7-22

7-26. DOE complex-wide LLW risk results by activity type (accident versus normal) 7-22

7-27. DOE complex-wide LLW risk results (accident versus normal). 7-23

8-1. Fernald MLLW disposition maps (baseline and alternative) 8-3

8-2. Hanford MLLW disposition maps (baseline and alternative) $8-4$

8-3. INEEL MLLW disposition maps (baseline and alternative) .8-5

8-4. LANL MLLW disposition maps (baseline and alternative). 8- 6

8-5. NTS MLLW disposition maps (baseline and alternative) .8-7

8-6. ORNL MLLW disposition maps (baseline and alternative) $.8-8$

8-7. RFETS MLLW disposition maps (baseline and alternative). $.8-9$

8-8. SNL MLLW disposition maps (baseline and alternative) . 8-10 
8-9. SRS MLLW disposition maps (baseline and alternative)

8-10. Fernald MLLW risk results by activity

8-11. Hanford MLLW risk results by activity

8-12. INEEL MLLW risk results by activity.

8-13. LANL MLLW risk results by activity

8-14. NTS MLLW risk results by activity

8-15. ORNL MLLW risk results by activity

8-16. RFETS MLLW risk results by activity

8-17. SNL MLLW risk results by activity

8-18. SRS MLLW risk results by activity.

8-19. Commercial MLLW risk results by activity

8-20. National MLLW risk results by activity.

8-21. Transportation MCLW risk results by activity

8-22. Repository MLLW risk results by activity

8-23. DOE MLLW risk results by site

8-24. DOE complex-wide MLLW risk results by activity type

8-25. DOE complex-wide MLLW risk results.

8-26. DOE MLLW risk results by site (worker/site versus public)

8-27. DOE complex-wide MLLW risk results by activity type (worker/site versus public).

8-28. DOE complex-wide MLLW risk results by site (worker/site versus public)

8-29. DOE MLLW risk results by site (accident versus normal).

8-30. DOE complex-wide MLLW risk results by activity type (accident versus normal)

8-31. DOE complex-wide MLLW risk results (accident versus normal)

9-1. Hanford SNF disposition maps (baseline and alternative) 
9-2. INEEL SNF disposition maps (baseline and alternative) ....................................................

9-3. ORNL SNF disposition maps (baseline and alternative) .........................................................

9-4. SRS SNF disposition maps (baseline and alternative) ........................................................6

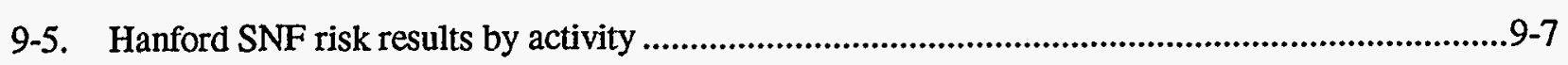

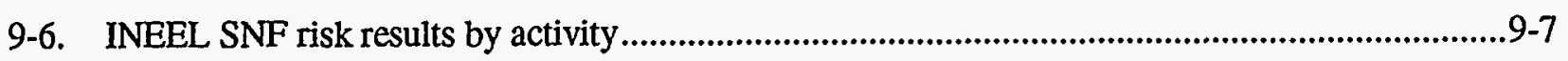

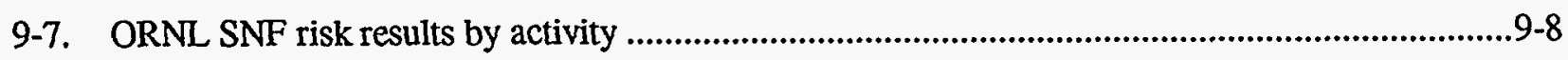

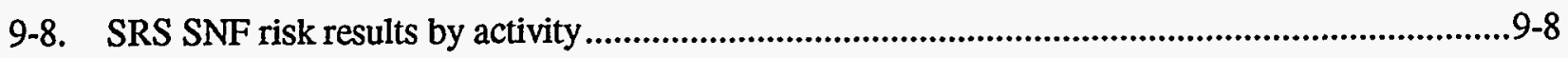

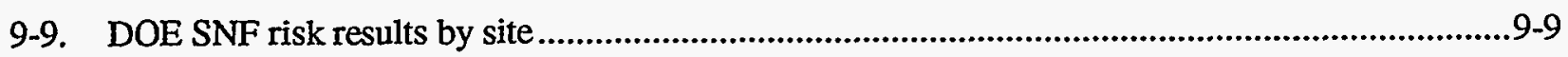

9-10. DOE complex-wide SNF risk results by activity type...........................................................9-10

9-11. DOE complex-wide SNF risk results ................................................................................

9-12. DOE SNF risk results by site (worker/site versus public) ........................................................9-11

9-13. DंOE complex-wide SNF risk results by activity type (worker/site versus public) ......................9-11

9-14. DOE complex-wide SNF risk results (worker/site versus public) ................................................9-12

9-15. DOE SNF risk results by site (accident versus normal) .....................................................12

9-16. DOE complex-wide SNF risk results by activity type (accident versus normal)..........................9-13

9-17. DOE complex-wide SNF risk results (accident versus normal) ...............................................9-13

\section{TABLES}

5-1. DOE site HLW radiological and chemical inventory estimates ...............................................5-1

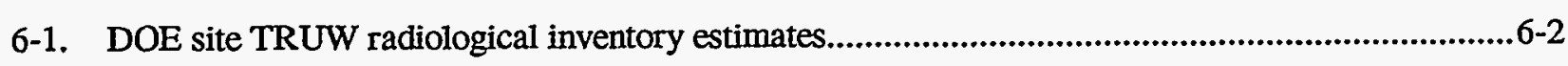

6-2. Comparison of SRM risk results with other sources...........................................................6-25

7-1. DOE site LLW radiological and chemical inventory estimates..................................................7-1

8-1. DOE site MLLW radiological inventory estimates .................................................................. $8-2$

9-1. DOE site SNF radiological and chemical inventory estimates..................................................9-1

9-2. Summary of EIS risk results (Planning Basis Alternative) ...................................................14 
xviii 


\section{ACRONYMS}

BRA Baseline risk assessment (CERCLA)

CERCLA Comprehensive Environmental Response, Compensation, and Liabilities Act

DOE Department of Energy (U.S.)

ER Environmental restoration

HLW High-level waste

INEEL Idaho National Engineering and Environmental Laboratory

LANL Los Alamos National Laboratory

LLW Low-level waste

MLLW Mixed low-level waste

NTS Nevada Test Site

ORNL Oak Ridge National Laboratory

PA Performance assessment

PRA Probabilistic risk assessment

RFETS Rocky Flats Environmental Technology Site

SNF Spent nuclear fuel

SNL Sandia National Laboratories

SRM Simplified risk model

SRS Savannah River Site

TRUW Transuranic waste

WIPP Waste Isolation Pilot Plant

WSSA Weapon system safety assessment

WV West Valley Demonstration Plant

WVDP West Valley Demonstration Plant 



\section{TERMINOLOGY}

Absolute risk -- A quantitative expression of risk in terms of specified effects, such as person-rem or rate of cancer incidence.

Actinide -- Alpha-emitting radionuclides (atomic number $\geq 89$ ) with half-lives $>20$ years, and any existing decay products.

Activity -- A basic waste management activity or facility at a site, such as storage, treatment, or disposal, . An activity can also involve transportation within a site or between sites.

Disposition map -- A system flow chart showing the disposition of a material type. The disposition map for each material type and U.S. DOE site starts with the initial storage of the material, indicates flows to processes such as treatment and/or repackaging, and shows the final disposal or disposition of the material.

High-level waste - Highly radioactive material resulting from the reprocessing of SNF.

Low-level waste - Radioactive waste not classified as HLW, MLLW, TRUW, or SNF.

Material type -- High-level waste, transuranic waste, low-level waste, mixed low-level waste, or spent nuclear fuel. The first four material types are considered waste. Spent nuclear fuel may or may not be considered waste.

Mixed low-level waste - Radioactive waste containing both low-level radioactivity and hazardous chemicals.

Nonactinide -- All radionuclides that are not actinides.

Radioactivity - The property of spontaneous emission of alpha or beta particles (or gamma rays) by the disintegration of the nuclei of atoms

Radionuclide -- A radioactive nuclide.

Relative risk -- A qualitative or quantitative expression of risk comparison.

Risk -- The quantitative or qualitative expression of possible loss that considers both the probability that a hazard will cause harm and the consequences of that event.

Site -- A location, such as a U.S. Department of Energy laboratory. Within a site can be located various facilities to store, treat, and dispose of the various material types.

Spent nuclear fuel - Irradiated fuel discharged from a nuclear reactor.

State -- A basic waste management activity or facility at a site, such as storage, treatment, or disposal. A state can also involve transportation within a site or between sites.

Transuranic waste - Radioactive waste that contains more than $100 \mathrm{nCi} / \mathrm{g}$ of alpha-emitting isotopes with atomic numbers greater than 92 and half-lives greater than 20 years. 


\section{Human Health Risk Comparison for Environmental Management Baseline Programs and Integration. Opportunities (Discussion Draft)}

\section{INTRODUCTION}

In July 1996, the U.S. Department of Energy (DOE) Assistant Secretary for Environmental Management (EM) chartered a government contractor-led effort to develop a suite of technically defensible, integrated alternatives that meet the EM mission. The contractor team was challenged to "think outside the box" for solutions that cross traditional site boundaries and enable the programs to get the job done at an earlier date and at a lower cost. The results of that effort are summarized in the May 1997 report $A$ Contractor Report to the Department of Energy on Environmental Baseline Programs and Integration Opportunities (Discussion Draft). ${ }^{1}$ In that report are presented DOE complex-wide baseline programs and alternatives for six areas: high-level waste (HLW), transuranic waste (TRUW), low-level waste (LLW), mixed low-level waste (MLLW), spent nuclear fuel (SNF), and waste generated from environmental restoration activities (ER).

This report documents a related effort, the development of simplified human health risk models for the baseline programs and alternatives. The simplified risk models were developed to:

- provide a consistent, comprehensive, and quantitative human health risk picture for all of the important activities involved in the baseline programs and alternatives

- evaluate the alternative program risks relative to the baseline program risks

- provide a simplified risk model that can be exercised to answer stakeholder questions about risk.

The Simplified Risk Model (SRM) was developed to fulfill these types of needs. The technical basis for the SRM is documented in the September 1996 report A Simplified Method for Quantitative Assessment of the Relative Health and Safety Risk of Environmental Management Activities. ${ }^{2}$ Use of the SRM is explained in the October 1996 report User's Guide for the Simplified Risk Model (SRM). ${ }^{3}$ The SRM models in an approximate manner the quantitative human health risk from radionuclide and chemical exposure from both accidents and normal, incident-free operation. Exposure pathways include airborne (inhalation) and groundwater (ingestion).

SRM results for five of the six areas listed above are presented in this report. The broad area of ER is not covered. Section 2 of this report contains a brief description of the SRM approach to modeling human health risk. Section 3 summarizes the risks from the five material types at the DOE complex level. Site results are summarized in Section 4. The individual material type SRM analyses are discussed in Sections 5 through 9. Conclusions are presented in Section 10. Finally, references are presented in Section 11.

In addition, there are six appendices to this report. The appendices are included in a separate

volume. Appendix A summarizes the changes made to the SRM for this effort. Appendices B through F contain the detailed SRM risk matrices for each site and activity for each of the five material types. 


\section{SRM PRIMER}

\subsection{General Description}

Risk is defined in DOE Order 5480.23, Nuclear Safety Analysis Reports as "... the quantitative or qualitative expression of possible loss that considers both the probability that a hazard will cause harm and the consequences of that event." ${ }^{4}$ Types of risk that may be addressed in risk analyses include human health and safety, environmental impact, and programmatic impact. However, most risk assessments are focused on human health and safety. Risk analyses can range from simple qualitative estimates obtained within hours or days to detailed, quantitative studies requiring years to complete, as shown in Figure 2-1. Risk analyses can also be relative or absolute, with the absolute analyses resulting in human health risk measurements such as person-rem or cancer fatalities.

\begin{tabular}{|c|c|c|c|c|}
\hline Type of Results & Qualitative & \multicolumn{3}{|c|}{ Quantitative } \\
\hline Level of Detail & Simplistic & Simplistic & Moderately Detailed & Very Detailed \\
\hline Purpose (typical) & $\begin{array}{l}\text { Relative risk } \\
\text { estimation for } \\
\text { prioritization studies }\end{array}$ & $\begin{array}{l}\text { Absolute or relative } \\
\text { risk estimation of } \\
\text { multiple options } \\
\end{array}$ & $\begin{array}{l}\text { Absolute risk } \\
\text { estimation of } \\
\text { multiple options }\end{array}$ & $\begin{array}{l}\text { Absolute risk } \\
\text { estimation of } \\
\text { facility/activity, to } \\
\text { compare with } \\
\text { requirements }\end{array}$ \\
\hline Duration (typical) & Hours to days & Weeks & Months to years & Years \\
\hline Example & $\begin{array}{l}\text { DOE prioritization } \\
\text { studies using high/ } \\
\text { medium/low risk } \\
\text { estimates }\end{array}$ & DOE management & $\begin{array}{l}\text { Environmental } \\
\text { impact statement } \\
\text { (EIS) studies }\end{array}$ & $\begin{array}{l}\text { Comprehensive } \\
\text { Environmental } \\
\text { Response, } \\
\text { Compensation, and } \\
\text { Liability Act } \\
\text { (CERCLA) baseline } \\
\text { risk assessments } \\
\text { (BRAs) } \\
\text { DOE performance } \\
\text { assessments (PAs) } \\
\text { Nuclear reactor } \\
\text { probabilistic risk } \\
\text { assessments (PRAs) } \\
\\
\text { Department of } \\
\text { Defense weapon } \\
\text { system safety } \\
\text { assessments } \\
\text { (WSSAs) }\end{array}$ \\
\hline
\end{tabular}

Figure 2-1. Types of risk assessments.

The SRM was developed to fulfill a need for a simple, absolute, and quantitative risk assessment methodology that could be used to generate risk estimates within weeks, as indicated by the shaded area in Figure 2-1. A quantitative risk assessment method was desired to maximize consistency in risk estimations covering a wide variety of material types, facilities and activities, and accident and normal exposure risks. 
Also, an absolute risk methodology was desired in order to compare results with more detailed risk assessments. Such comparisons are necessary to establish the credibility of the SRM. Finally, because the EM integration studies cover a variety of options for handling material types across the entire DOE complex, a simplistic risk assessment methodology was needed to provide efficient and timely support.

The SRM covers human health and safety risk from normal, incident-free operations and accidents involving radionuclides and/or chemicals. Environmental impact and programmatic impact risk are not covered. Also, within the area of human health and safety, risk from standard industrial accidents (injuries and deaths) is not presently covered. Simplistic additions to the SRM are planned to cover standard industrial accidents and environmental impact. However, such risks are presently not covered by the SRM.

SRM pathways for radionuclides and/or chemicals to affect human health and safety include airborne (inhalation) and groundwater (ingestion), as well as direct radiation from radionuclides. DOE site work force and surrounding population information is contained within the SRM, as well as representative DOE site airborne and groundwater dispersion characteristics.

As presently developed, the SRM is applicable to DOE waste management activities involving HLW, TRUW, LLW, MLLW, and SNF. Additional development would be required to comprehensively model ER or decontamination and decommissioning (D\&D) activities.

\subsection{Risk Matrix}

The basic building block of the SRM is the risk matrix, shown in Figure 2-2. This matrix is filled out for each of the basic EM activities, such as storage, treatment, transportation, and disposal. The sample risk matrix shown in Figure 2-2 is for a five-year storage of liquid $\mathrm{HLW}$ at the Idaho National Engineering and Environmental Laboratory (INEEL).

The basic equation for accident risk from both radionuclides and chemicals, upon which the matrix was developed, is the following:

\begin{tabular}{|c|c|c|c|}
\hline & Risk & $=$ & $\left(E_{1 a}\right)\left(E_{1 a \text { decay }}\right)\left(E_{1 b}\right)\left(E_{2 a}\right)\left(E_{2 b}\right)\left(E_{3 a}+E_{3 b}\right)\left(E_{4 * 5 a-\text {-ac }}+E_{4 * 5 a-s i t e}+E_{4 * 5 b}\right)\left(E_{6}\right)$ \\
\hline \multirow[t]{11}{*}{ where } & $\mathrm{E}_{\mathrm{la}}$ & $=$ & Total curies (radionuclides) or kgs (chemicals) associated with state in question \\
\hline & $\mathrm{E}_{\text {la decay }}$ & $=$ & Fractional decay of curies (radionuclides only) \\
\hline & $\mathrm{E}_{1 \mathrm{~b}}$ & $=$ & Toxicity of mix of radionuclides or chemical (rem/Ci for radionuclides) \\
\hline & $\mathrm{E}_{2 a}$ & $=$ & Release fraction for material at risk \\
\hline & $\mathrm{E}_{2 \mathrm{~b}}$ & $=$ & $\begin{array}{l}\text { Effectiveness of containment (probability of containment failure, or fraction of } \\
\text { released material that enters the atmosphere or groundwater) }\end{array}$ \\
\hline & $\mathrm{E}_{3 \mathrm{a}}$ & $=$ & $\begin{array}{l}\text { Combined frequency times material-at-risk fraction for natural phenomena } \\
\text { accidents (1/year) }\end{array}$ \\
\hline & $\mathrm{E}_{3 \mathrm{~b}}$ & $=$ & $\begin{array}{l}\text { Combined frequency times material-at-risk fraction for operational accidents } \\
\text { (1/year) }\end{array}$ \\
\hline & $E_{4 * 5 a-f a c}$ & $=$ & Combined dispersion and facility worker exposure factor (airborne) \\
\hline & $E_{4 * 5 a-s i t e}$ & $=$ & Combined dispersion and site worker exposure factor (airborne) \\
\hline & $\mathrm{E}_{4 * 5 \mathrm{~b}}$ & $=$ & $\begin{array}{l}\text { Combined dispersion and off-site population exposure factor (airborne or } \\
\text { groundwater) }\end{array}$ \\
\hline & $\mathbf{E}_{6}$ & $=$ & Time duration (year). \\
\hline
\end{tabular}


$\begin{array}{llrl}\text { Site: } & \text { INEEL } & \text { Waste HLW, } & \text { Date: } \\ \text { State: } & \text { Storage (tanks, liquid) } & \text { Stream: liquid } & \text { Name: }\end{array}$

\begin{tabular}{|c|c|c|c|c|c|c|c|c|c|c|c|c|c|c|c|c|c|c|}
\hline \multirow{2}{*}{$\begin{array}{c}\text { Type of } \\
\text { Risk }\end{array}$} & \multirow{2}{*}{$\begin{array}{l}\text { Exposure } \\
\text { Pathway }\end{array}$} & \multirow[t]{2}{*}{ Waste Type } & \multicolumn{11}{|c|}{ Equation Elements } & \multirow[t]{2}{*}{ DR } & \multirow{2}{*}{$\begin{array}{l}\text { Worker } \\
\text { Risk } \\
\text { Facility }\end{array}$} & \multirow{2}{*}{$\begin{array}{l}\text { Worker } \\
\text { Risk } \\
\text { Site }\end{array}$} & \multirow{2}{*}{$\begin{array}{l}\text { Public } \\
\text { Risk }\end{array}$} & \multirow[t]{2}{*}{ Risk } \\
\hline & & & $1 a$ & 1a Decay & 16 & $2 a$ & $2 b$ & $3 a$ & $3 \mathrm{~b}$ & $\begin{array}{l}4 \times 5 a- \\
\mathrm{Fac}\end{array}$ & $\begin{array}{c}4 \times 5 a- \\
\text { Site }\end{array}$ & $4 \times 5 b$ & 6 & & & & & \\
\hline \multirow{9}{*}{ Accident } & \multirow{5}{*}{ 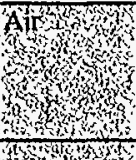 } & Actinide & $2.7 \mathrm{E}+04$ & $1.0 \mathrm{E}+00$ & $3.5 \mathrm{E}+02$ & $3.0 \mathrm{E}-03$ & $1.0 \mathrm{E}-02$ & $1.0 \mathrm{E}-04$ & $2.0 \mathrm{E}-05$ & $3.0 \mathrm{E}+00$ & $3.0 \mathrm{E}+00$ & $5.0 \mathrm{E}+00$ & $5.0 \mathrm{E}+00$ & - & $5.1 \mathrm{E}-01$ & $5.1 \mathrm{E}-01$ & $8.4 \mathrm{E}-01$ & $1.9 \mathrm{E}+00$ \\
\hline & & Nonactinide & $5.3 \mathrm{E}+06$ & $1.0 \mathrm{E}+00$ & $1.5 \mathrm{E}-01$ & $3.0 \mathrm{E}-03$ & $1.0 \mathrm{E}-02$ & $1.0 \mathrm{E}-04$ & $2.0 \mathrm{E}-05$ & $3.0 \mathrm{E}+00$ & $3.0 \mathrm{E}+00$ & $5.0 \mathrm{E}+00$ & $5.0 \mathrm{E}+00$ & - & $4.3 \mathrm{E}-02$ & $4.3 \mathrm{E}-02$ & $7.2 \mathrm{E}-02$ & $1.6 \mathrm{E}-01$ \\
\hline & & Chiemiáli I & $0,0 \mathrm{E}+00$ & $B^{2} x^{2}, 4$ & 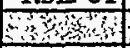 & 3ind & ats & 3. & 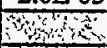 & $y^{2} x^{2}$ & Sists & 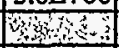 & 3.6. & 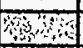 & $0.0 \mathrm{E}+00$ & $0.0 \mathrm{E}+00$ & $0.0 \mathrm{~B}+00$ & $0.0 \mathrm{E}+00$ \\
\hline & & Chemuchl 2 ; & $0.0 \mathrm{E}+00$ & Bit & $4 x+2$ & $x_{n}^{2}=w_{1}$ & Wh & pos & 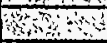 & wat & (n) & - 6 & 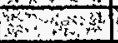 & ton & $0.0 \mathrm{E}+00$ & $0.0 \mathrm{~B}+00$ & $000 \mathrm{E}+00$ & $0.0 \mathrm{E}+100$ \\
\hline & & & & & & & & & & & & & & & & & & \\
\hline & \multirow{4}{*}{ 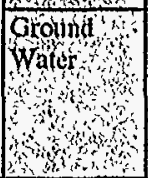 } & Actinide & N/A & N/A & N/A & N/A & N/A & N/A & N/A & N/A & N/A & N/A & N/A & - & $0.0 \mathrm{E}+00$ & $0.0 \mathrm{E}+00$ & $0.0 \mathrm{E}+00$ & $0.0 \mathrm{E}+00$ \\
\hline & & \begin{tabular}{|l|} 
Nonactinide \\
\end{tabular} & $\mathrm{N} / \mathrm{A}$ & $N / A$ & $\mathrm{~N} / \mathrm{A}$ & $N / A$ & N/A & N/A & $\mathrm{N} / \mathrm{A}$ & N/A & N/A & N/A & N/A & - & $0.0 \mathrm{E}+00$ & $0.0 \mathrm{E}+00$ & $0.0 \mathrm{E}+00$ & $0.0 \mathrm{E}+00$ \\
\hline & & Greninical 1 , & $\mathrm{N} / \mathrm{A} \cdot \mathrm{i}, \mathrm{n}$ & $x+4 y$ & $\mathrm{NiA}, \mathrm{O}$ & $\mathrm{N} / \mathrm{A}, \mathrm{s}, \mathrm{y}$ & N/A & N/A $14 \times$ & $N / A^{2}$ & N/A & N/A & $\mathrm{N} / \mathrm{A}, \mathrm{A}$ & NIA & righ & $0.0 \mathrm{E}+00$ & $60.0 \mathrm{E}+00$ & $60.0 \mathrm{E}+00$ & $0.0 \mathrm{E}+00$ \\
\hline & & Chemicall 2 ; & $\mathrm{N} / \mathrm{A} / \mathrm{W}$ & 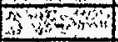 & $\mathrm{N} / \mathrm{A}+\mathrm{m}$ & $\mathrm{N} / \mathrm{A}^{\mathrm{s}} \mathrm{k}$ & $\mathrm{N} / \mathrm{A}, \mathrm{m}$ & $\mathrm{N} / \mathrm{A}, \mathrm{y}, \mathrm{s}$ & N/A & N/A & N/A & NAA & N/ASO & 3\% & $0.0 \mathrm{E}+00$ & $0.0 \mathrm{E}+00$ & $0.0 \mathrm{E}+00$ & $0,0 \mathrm{~B}+60$ \\
\hline & & & & & & & & & & & & & & & & & & \\
\hline \multirow{6}{*}{$\begin{array}{l}\text { Normal } \\
\text { Incident } \\
\text { Free }\end{array}$} & \multirow{5}{*}{ 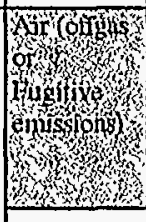 } & Actinide & $\mathrm{N} / \mathrm{A}$ & $\mathrm{N} / \mathrm{A}$ & N/A & N/A & N/A & - & - & - & N/A & N/A & - & $\overline{-}$ & - & $0.0 \mathrm{E}+00$ & $0.0 \mathrm{E}+00$ & $0.0 \mathrm{E}+00$ \\
\hline & & Nonactinide & N/A & N/A & $\overline{\mathrm{N} / \mathrm{A}}$ & N/A & $\widehat{N / A}$ & - & - & - & N/A & N/A & - & - & - & $0.0 \mathrm{E}+00$ & $0.0 \mathrm{E}+00$ & $0.0 \mathrm{E}+00$ \\
\hline & & Grićnicillil & 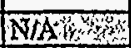 & Bups, & 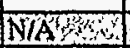 & $\mathrm{N} / \mathrm{A} ; \mathrm{s}$ & $\mathrm{N} / \mathrm{A}_{\mathrm{W}}$ & Bownons & Woms & ons & N/A & N/A & 3 & Wost & ing & $10.0 \mathrm{E}+00$ & 10.08\%00 & $0.0 E+00$ \\
\hline & & Cheinical 2 y & (I) A 3 & $3, y+40$ & 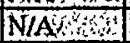 & N/A & N/A & $40 \rightarrow \infty$ & $\cos 64$ & tons & N/A $Q$ & $\mathrm{~N} / \mathrm{A}+\mathrm{S}, \mathrm{m}$ & when & किष & 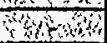 & $0.0 \mathrm{E}+00$ & $0.0 \mathrm{O}+00$ & $0.0 \mathrm{E}+00$ \\
\hline & & & & & & & & & & & & & & & & & & \\
\hline & \multicolumn{2}{|c|}{ Direct Radigtioli } & - & - & - & - & - & - & - & $1.5 \mathrm{E}-01$ & $0.0 \mathrm{E}+00$ & $0.0 \mathrm{E}+00$ & $5.0 \mathrm{E}+00$ & \begin{tabular}{|c|} 
In \\
$4 * 5$ \\
terms
\end{tabular} & $7.5 \mathrm{E}-01$ & $0.0 \mathrm{E}+00$ & $0.0 \mathrm{E}+00$ & $7.5 \mathrm{E}-01$ \\
\hline
\end{tabular}

Note - The risk results are presented in terms of person-rem.

\begin{tabular}{|l|l|l|l|l|}
\hline Total State Risk & $1.3 \mathrm{E}+00$ & $5.5 \mathrm{E}-01$ & $9.2 \mathrm{E}-01$ & $2.8 \mathrm{E}+00$ \\
\hline
\end{tabular}

Figure 2-2. SRM sample risk matrix. 
As indicated in the risk matrix in Figure 2-2, for accidents, the air and groundwater pathways are modeled separately. Also, radionuclides are divided into two categories: actinides and nonactinides. Chemicals are modeled by selecting several dominant chemicals and modeling each of those separately. (No chemicals have been included in the sample risk matrix in Figure 2-2.)

Normal, incident-free operational risk is estimated for two cases, as shown in Figure 2-2: airborne exposure to offgas or fugitive emissions, and direct radiation. The model for offgas of fugitive emissions is a variation of that used for accidents, with the assumption that some fraction of the curie or chemical inventory will escape into the atmosphere with the offgas. The model for direct radiation is based on the number of facility workers working directly with the hazardous materials and estimates of annual exposures for such work.

The risk results for each activity, as indicated in Figure 2-2, are estimated separately for up to 35 distinct cases (combinations of actinide, nonactinide, or chemical; pathway; normal or accident; and receptor). For example, the facility worker risk resulting from accidents releasing actinides into the atmosphere is 0.51 person-rem. (The risk matrix in Figure 2-2 has been calibrated to predict person-rem as the risk measure.) Similarly, the public risk is 0.84 person-rem. The total risk for this state (last column in risk matrix) is 2.8 person-rem, comprised of into 1.9 person-rem from accidents (actinide contribution), 0.16 person-rem from accidents (nonactinide contribution), and 0.75 person-rem from direct radiation exposure of workers resulting from periodic surveillances. Breaking down the risk another way (bottom row of risk matrix), 1.3 person-rem is incurred by facility workers, 0.55 person-rem by DOE site workers, and 0.92 person-rem by the public. This level of detail in modeling is necessary in order to cover all potentially important contributors to risk and to allow for risk results to be broken down into various types of categories (e.g., worker risk versus public risk or accident risk versus normal, incident-free operations risk).

The SRM has look-up tables to assist the risk analyst in determining values for all of the elements in the risk matrix except for $\mathrm{E}_{1 \mathrm{a}}$, the curie and/or chemical inventory, and $\mathrm{E}_{6}$, the time duration. ${ }^{3}$ However, the risk analyst must collect a certain amount of information for each activity, such as the characteristics, size, and location (DOE site) of the facility or process and the form of the material being processed or stored, in order to select the appropriate values from the look-up tables.

\subsection{Analysis Process}

A typical SRM analysis consists of seven steps:

1. information collection

2. development of a system flow diagram (disposition map)

3. breakdown of the system flow diagram into more basic SRM states (e.g., storage of specific materials, various treatment processes, on-site and off-site transportation, loading and unloading, and disposal)

4. characterization of curie and/or chemical flows through the system

5. development of SRM risk matrices for states 
6. combining of individual risk matrix results into system risk results

7. comparison of SRM risk estimates with more detailed analyses (if available).

The seven-step SRM analysis process is documented for each of the five material types in Sections 5 through 9 of this report. For these analyses, part of step 1 and all of step 2 had already been performed as part of the EM integration study. ${ }^{1}$

The SRM analysis process outlined above can take days to months to complete, depending upon the complexity of the system to be modeled, the difficulty in obtaining the necessary information (especially curie and/or chemical flow information), and the number of sites and states to be modeled. The SRM risk analyses discussed in Sections 5 through 9 in this report, covering DOE complex-wide programs for HLW, TRUW, LLW, MLLW, and SNF, each required approximately six weeks to complete. 


\section{DOE COMPLEX-LEVEL RISK RESULTS}

SRM human health risk results (person-rem) for HLW, TRUW, LLW, MLLW, and SNF are summarized at the DOE complex level in this section. Figure 3-1 presents the total person-rem from all five material types for both the baseline programs and the alternatives. (The baseline programs and alternative programs are discussed in Sections 5 through 9 of this report.) Figure 3-2 presents the same risk results, broken down into accident and normal, incident-free operation risk contributions. Figure 3-3 presents the breakdown by public and worker/site contributions. The total DOE complex risk is approximately 26,500 person-rem for the baseline programs. The risk from the alternative programs is $0.1 \%$ smaller. This small difference in person-rem totals is insignificant compared with the uncertainties in the risk modeling. Therefore, the alternatives outlined in the May 1997 report A Contractor Report to the Department of Energy on Environmental Management Baseline Programs and Integration Opportunities (Discussion Draft) are considered to be risk neutral at the DOE complex-wide level, compared with the baseline programs.

As shown in Figure 3-2, the normal, incident-free operation contribution to the overall human health risk is approximately $67 \%$, while the accident contribution is $33 \%$. Breaking down the risk differently, Figure 3-3 shows that the worker/site risk is also approximately $67 \%$, while the public risk is $33 \%$.

The DOE complex-wide risks for each of the five material type programs are presented in Figure 3-4. As shown in the figure, TRUW has the highest risk (approximately 11,600 person-rem), and MLLW has the lowest risk (approximately 1,600 person-rem).

Finally, Figure 3-5 presents the risk results by type of activity: storage, handling, treatment, transportation, and disposal. Handling and transportation activities account for the most risk, followed by treatment and storage. Disposal risk is much lower than the other activities.

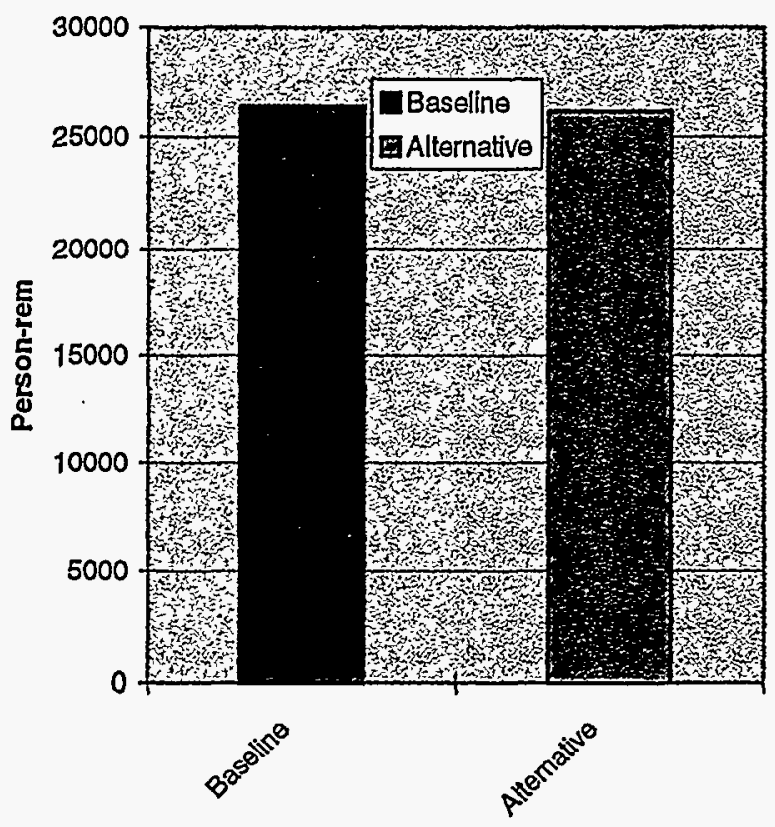

Figure 3-1. DOE complex-wide risk results for HLW, TRUW, LLW, MLLW, and SNF. 


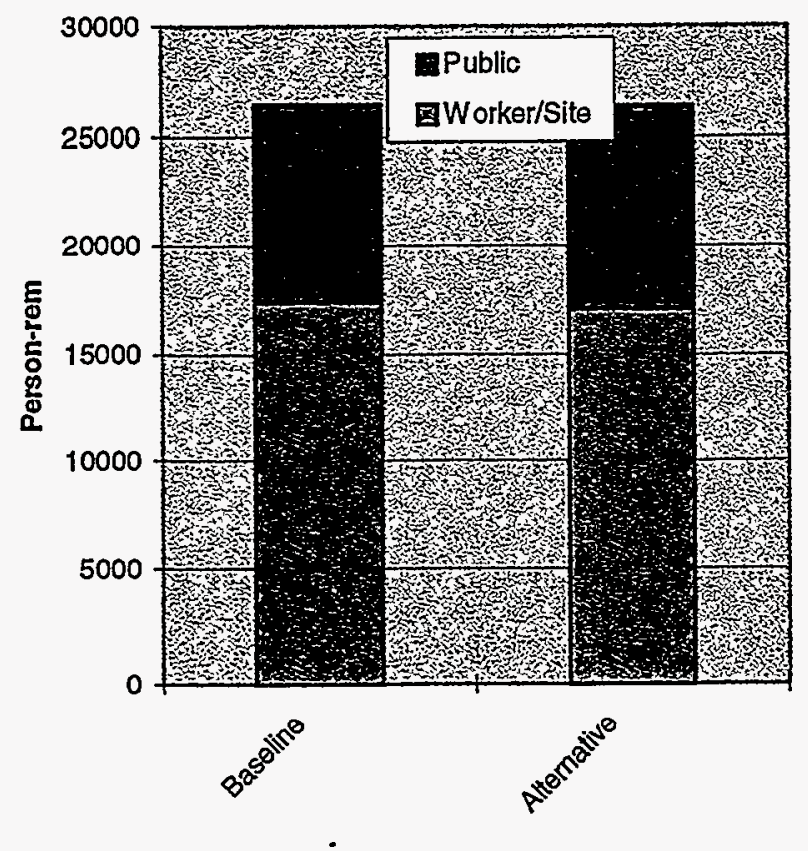

Figure 3-2. DOE complex-wide risk results (worker/site versus public).

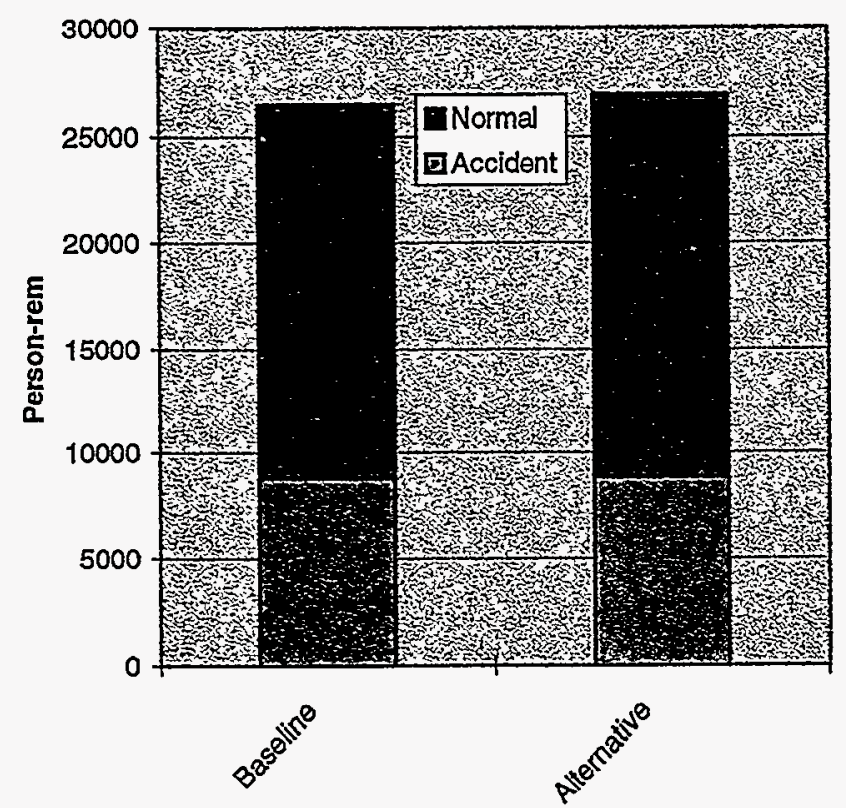

Figure 3-3. DOE complex-wide risk results (accident versus normal). 




Figure 3-4. DOE complex-wide risk by material type.

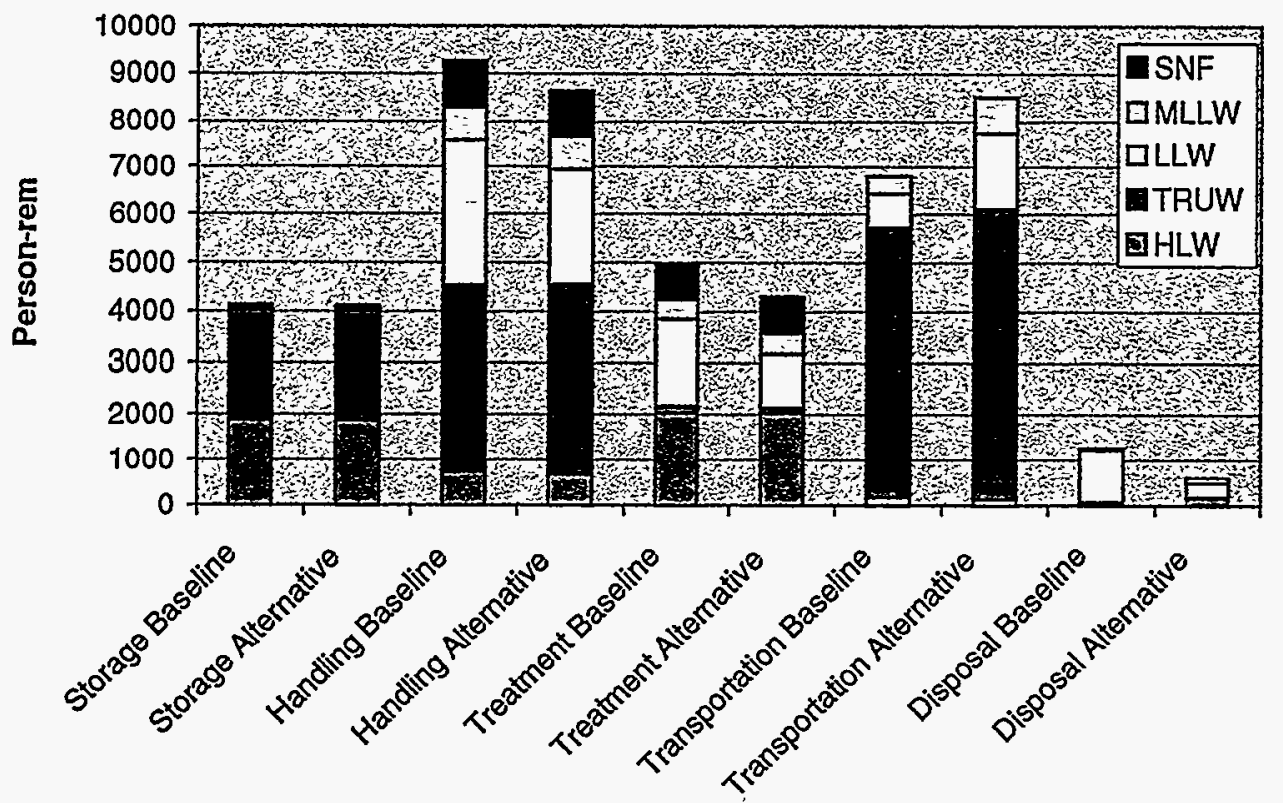

Figure 3-5. DOE complex-wide risk by activity type. 


\section{DOE SITE-LEVEL RISK RESULTS}

Figures 4-1 and 4-1 present the DOE risk results by site for the baseline and alternative programs, respectively. Included are $12 \mathrm{DOE}$ sites, one "site" covering all off-site transportation, three disposal sites not located at the 12 DOE sites (TRUW, HLW/SNF, and LLW/MLLW), and a commercial treatment site. The highest risk for both the baseline and alternative programs is off-site transportation, with TRUW contributing approximately $75 \%$ to the total off-site transportation risk. Among the DOE sites, SRS, RFETS, Hanford, and the INEEL have the largest risks. Each site has a different composition of material type risks, with SRS dominated by HLW and RFETS dominated by TRUW. Disposal risk is a minor contributor to the overall risk.



Figure 4-1. DOE risk results by site and material type (baseline). 


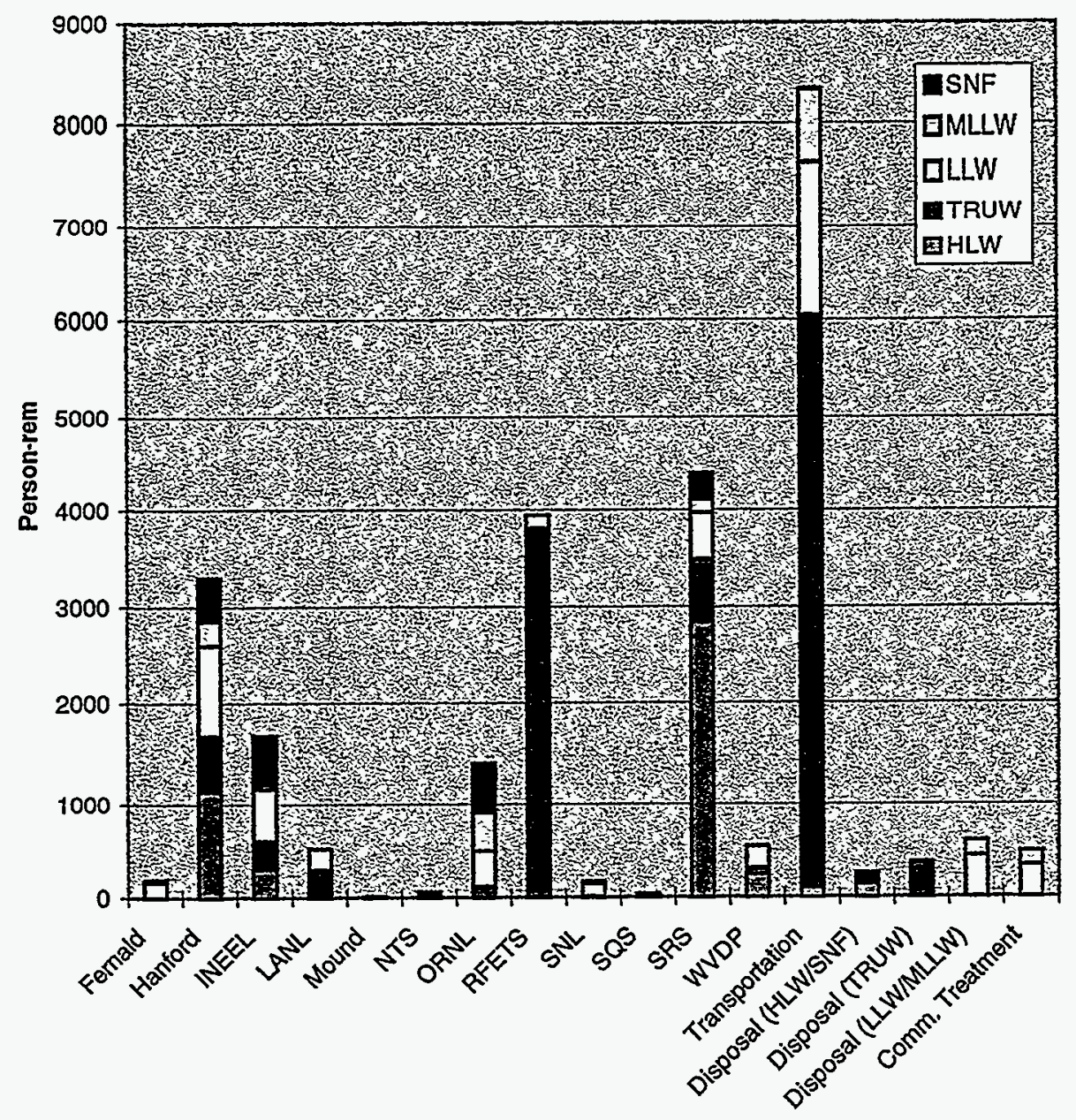

Figure 4-2. DOE risk results by site and material type (alternative). 


\section{HIGH-LEVEL WASTE ANALYSIS}

DOE HLW is presently stored at four sites: Hanford, INEEL, Savannah River Site (SRS), and West Valley Demonstration Plant (WVDP). DOE plans to stabilize this waste, mostly liquid and sludge stored in underground tanks, and ultimately dispose of the stabilized HLW in a repository such as Yucca Mountain. The baseline program and alternative for HLW for each of the four sites are outlined in the disposition maps presented in Figures 5-1 through 5-4. The baseline disposition maps for the four sites show the process by which the stored HLW is retrieved, stabilized, and sent for disposal. The alternatives involve additional separations activities, transport of HLW to other sites for processing or interim storage, schedule changes, and other activities.

The SRM HLW model was developed by subdividing the disposition map boxes into activities (risk states) such as storage, retrieval, loading and unloading, on-site and off-site transport, various types of waste processing steps, and disposal. The subdivision of the disposition maps into activities is shown in Figures 5-1 through 5-4, where the numbers in parentheses refer to specific activities for the site in question. Figures 5-5 through 5-8 list the specific activities for each site.

The SRM requires knowledge of the radionuclide curie and chemical flow through the disposition maps. The curie information was generally obtained from the report Integrated Data Base Report - 1995: U. S. Spent Nuclear Fuel and Radioactive Waste Inventories, Projections, and Characteristics. ${ }^{5}$ Initial curie totals for each of the four sites are shown in Table 5-1. Additional information required for the SRM, such as the waste form (liquid, sludge, grout, glass, etc.), characteristics of storage and processing facilities, types of on-site and off-site transport, and schedules were obtained from the site subject matter experts. In cases where such information was not available, assumptions were made.

Table 5-1. DOE site HLW radiological and chemical inventory estimates.

\begin{tabular}{llll}
\hline \multicolumn{1}{c}{ Site } & \multicolumn{1}{c}{ Actinides (Ci) } & Nonactinides (Ci) & Chemicals (kg) \\
\hline Hanford & $2.0 \mathrm{E}+5$ & $3.5 \mathrm{E}+8$ & $1.1 \mathrm{E}+8^{\mathrm{a}, \mathrm{b}}$ \\
INEEL & $2.6 \mathrm{E}+5$ & $5.2 \mathrm{E}+7$ & Not modeled \\
SRS & $2.5 \mathrm{E}+6$ & $5.0 \mathrm{E}+8$ & Not modeled \\
WV & $9.6 \mathrm{E}+4$ & $2.4 \mathrm{E}+7$ & Not modeled \\
a. Assumed to be nitric acid. & & \\
b. Additional 1.06E+8 kg of nitric acid added for phase 2 dissolution in the alternative (activity 26). \\
\hline
\end{tabular}

Chemicals in the HLW and chemicals used for dissolution of the HLW were modeled only for the Hanford HLW case. For the other sites, no chemicals were modeled because of a lack of available information.

SRM human health risk results (person-rem) for activities at each of the four DOE sites are presented in Figures 5-5 through 5-8. Each figure shows the baseline program and the alternative. Examination of the results indicates that for $\mathrm{HLW}$, the initial storage (liquid and sludge) in underground storage tanks and the treatment of HLW are generally high risk activities relative to other activities such as transportation and final disposal. It should be noted that the activities modeled for each site represent all of the important steps in the baseline program (or alternative), from initial storage through final disposal. 
HLW Alternative Disposition Map

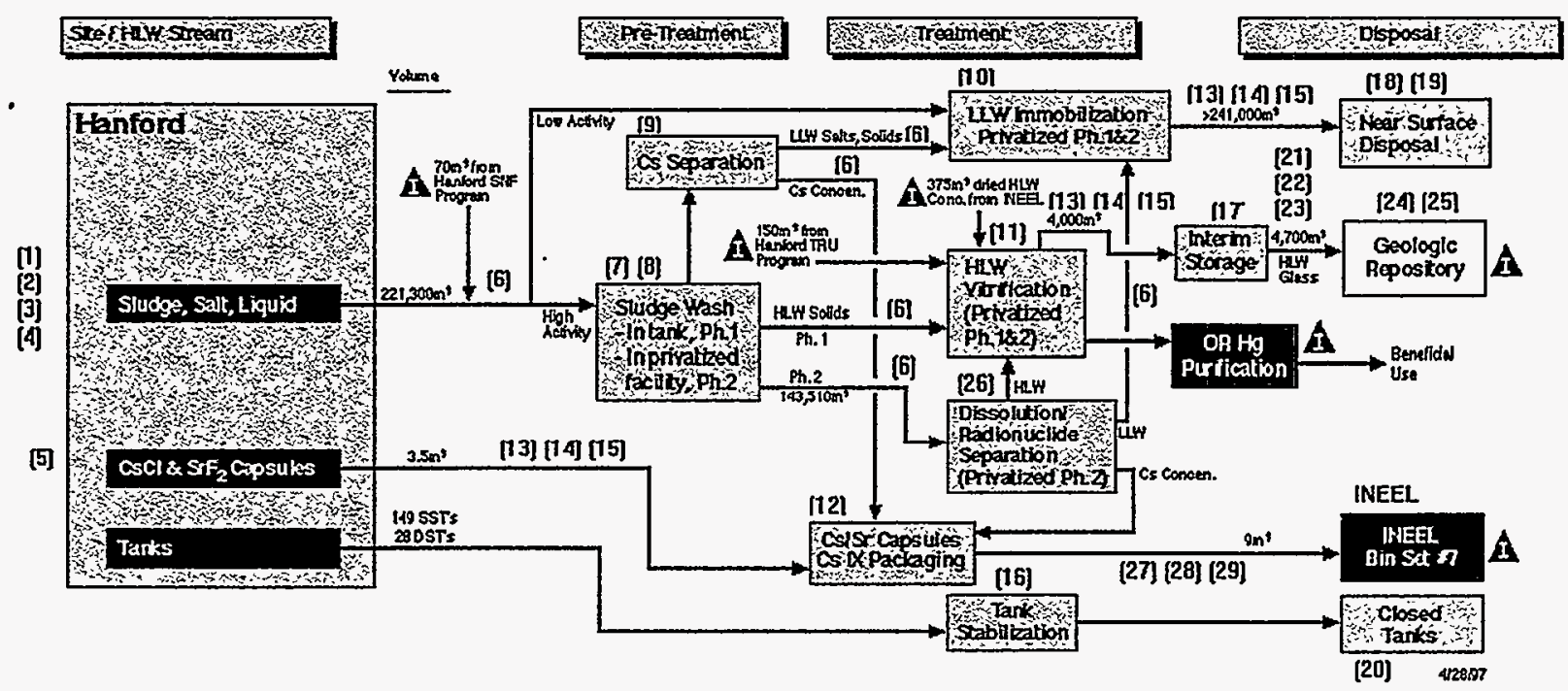

HWW Baseline Disposition Map

Sietriksien

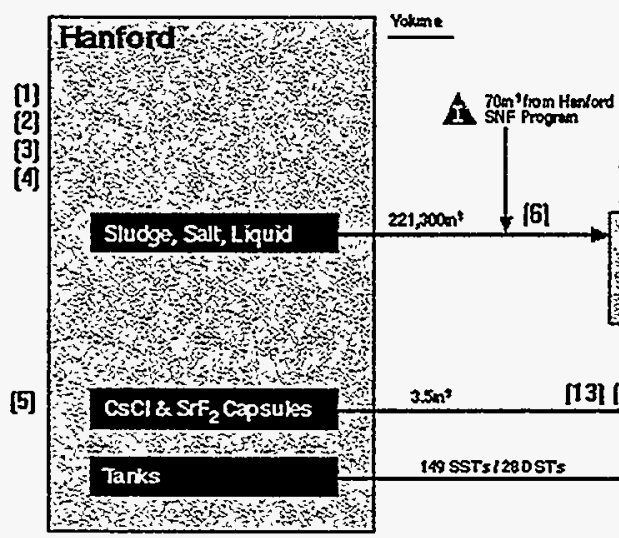

PREDECISIONAL DRAFT

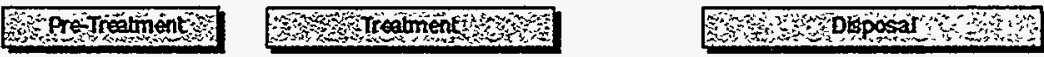


HLW Alternative Disposition Map

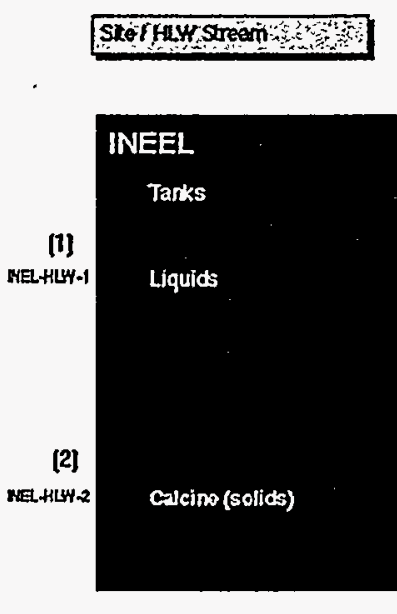

PREDECISIONAL DRAFT

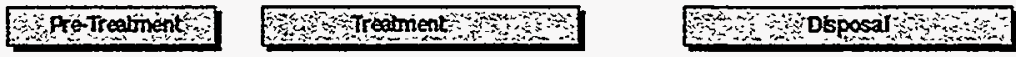

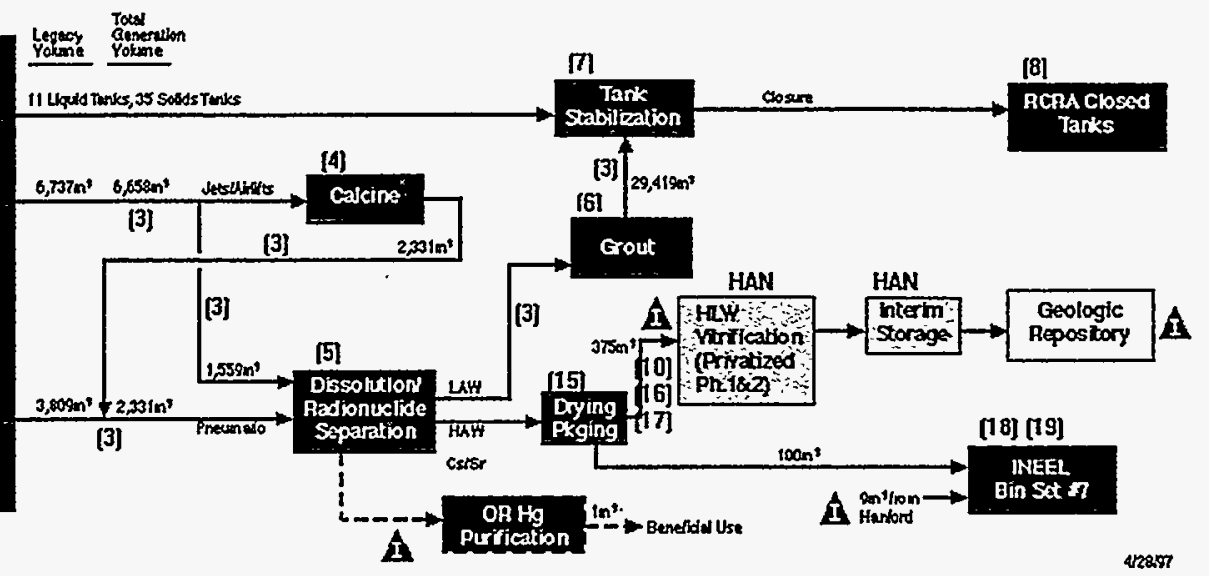

HLW Baseline Disposition Map

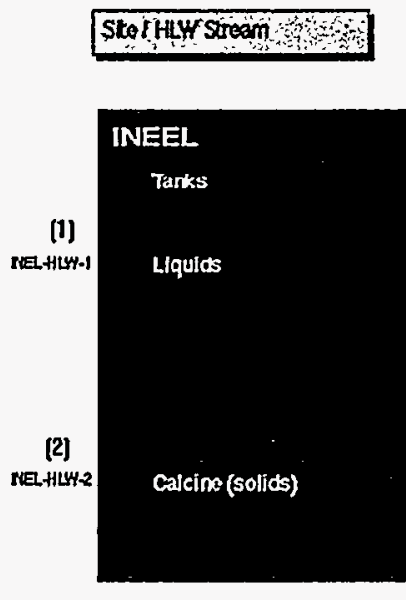

PREDECISIONAL DRAFT

spietralínent

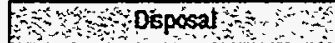

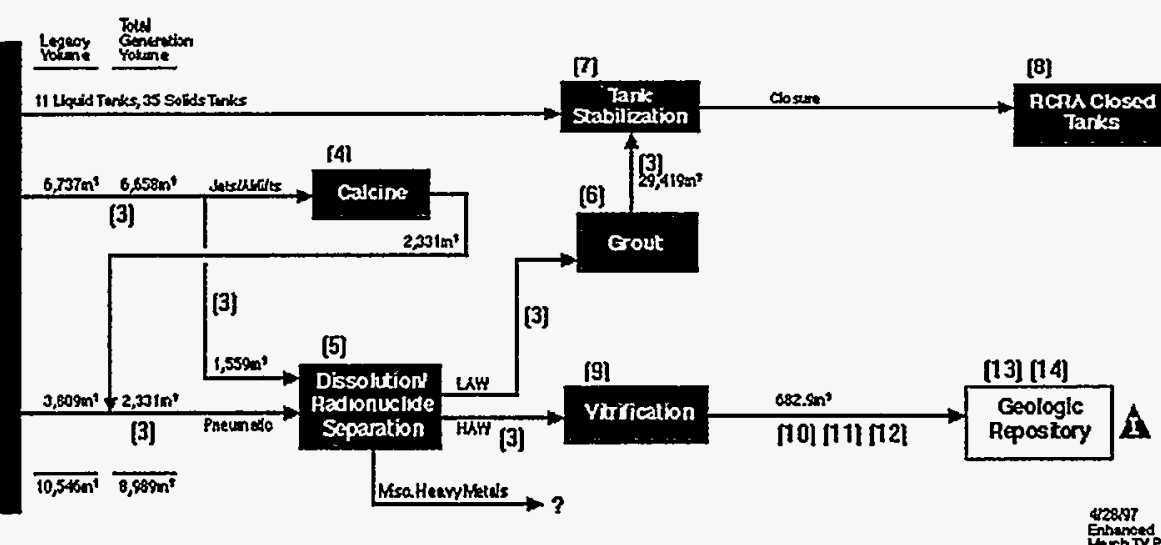

Figure 5-2. INEEL HLW disposition maps (baseline and alternative). 
HLW Alternative Disposition Mep

StolHLFTim,
PREDECISIONAL DRAFT

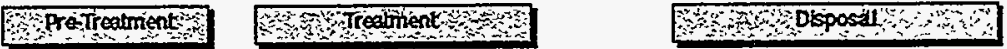

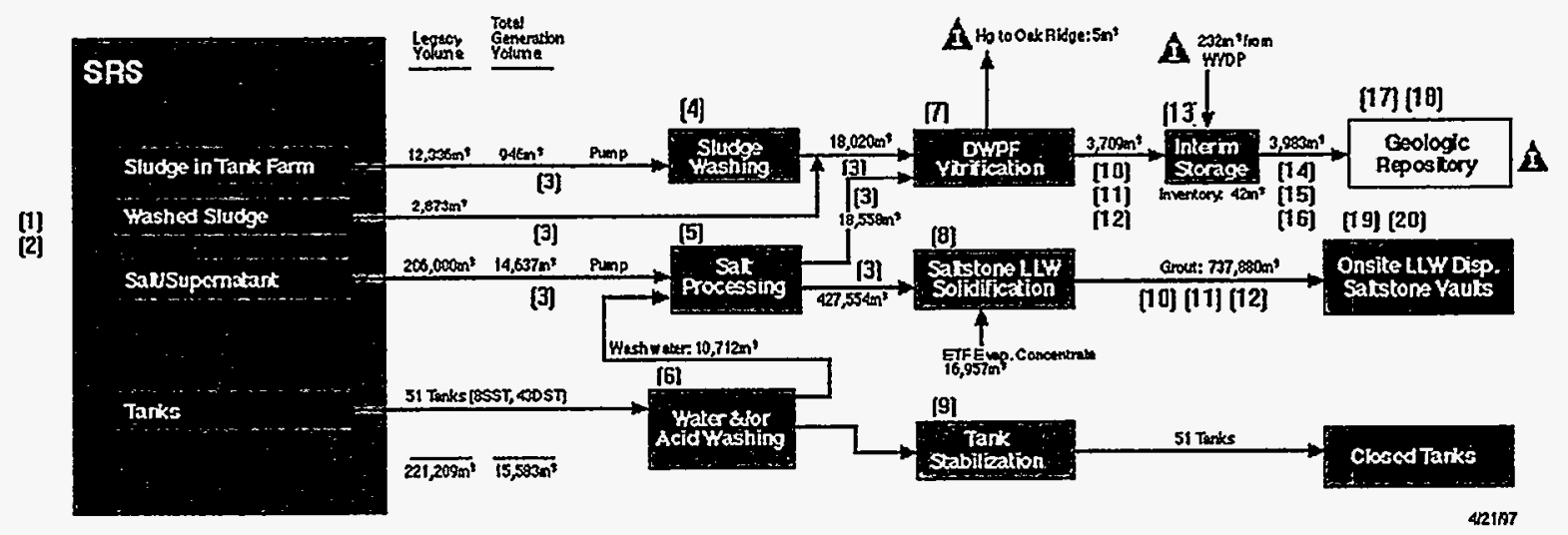

HLW Baseline Disposition Map

PREDECISIONAL DRAFT

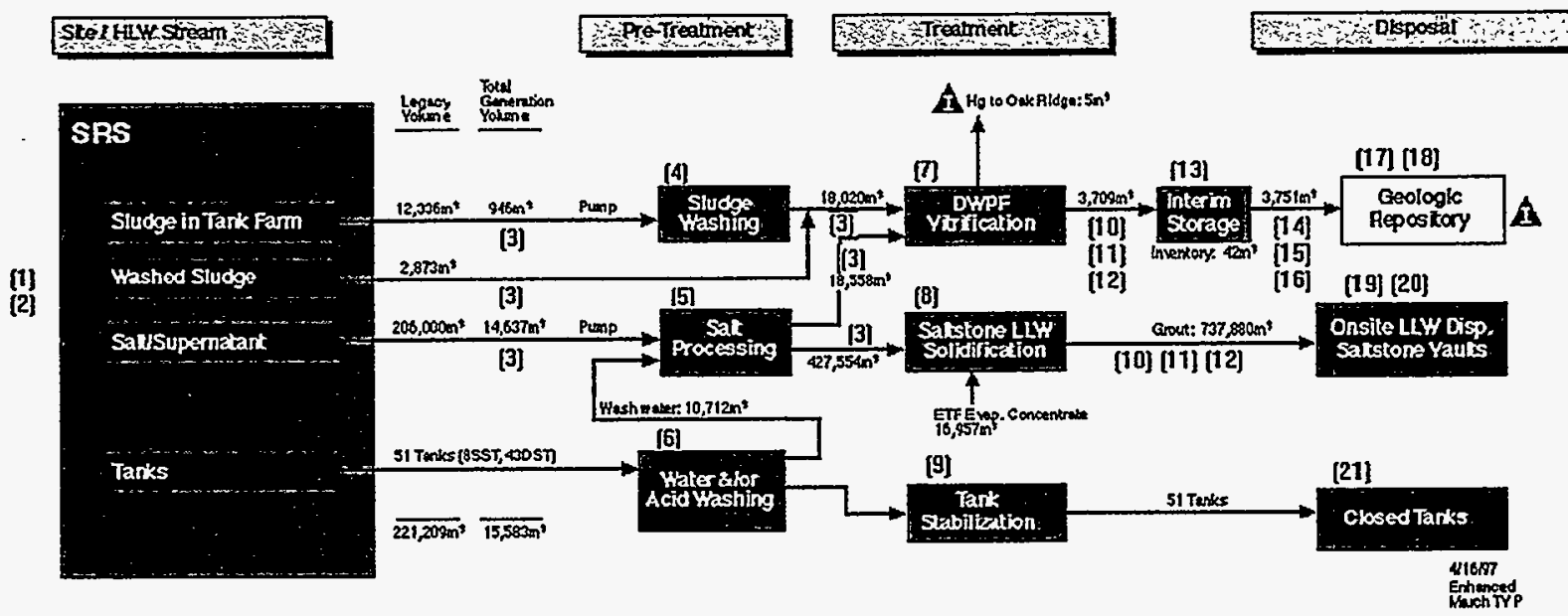

Figure 5-3. SRS HLW disposition maps (baseline and alternative). 


\section{HLW Alternative DIsposition Map}

StelHEW Strean:

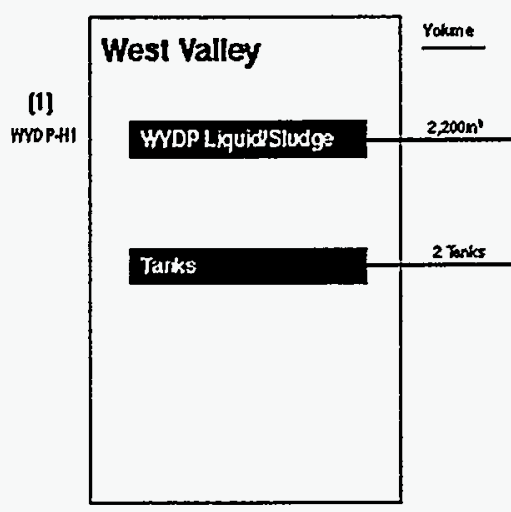

vane

\section{PREDECISIONAL DRAFT}

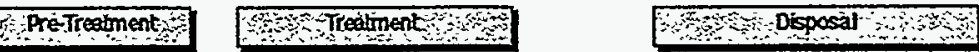

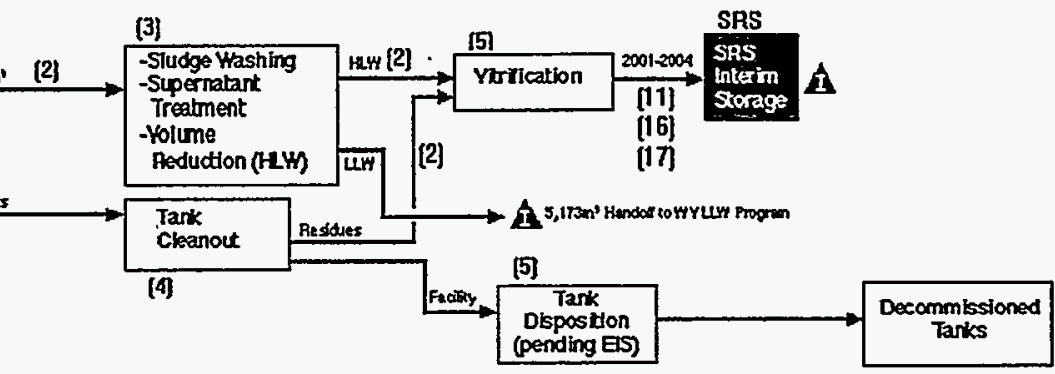

42197

HLW Baseline Disposition Map

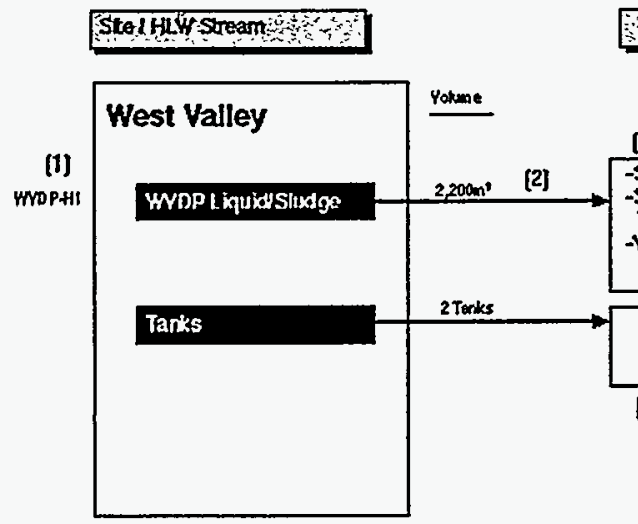

\section{PREDECISIONAL DRAFT}

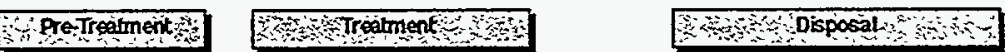

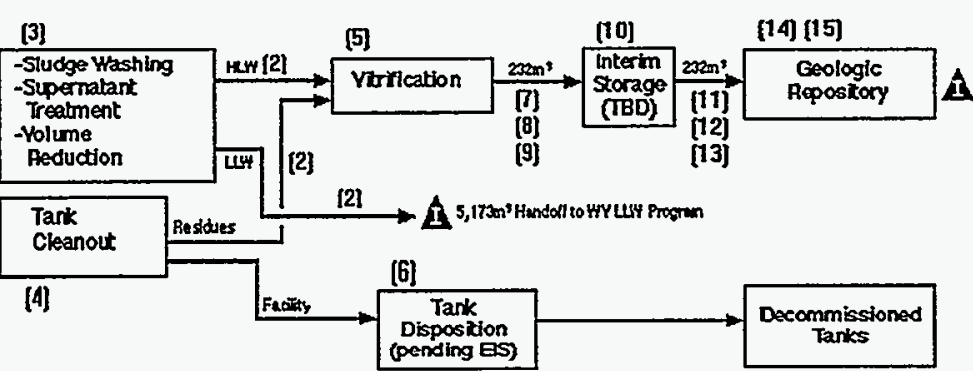

41697

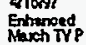

Figure 5-4. WVDP HLW disposition maps (baseline and alternative). 


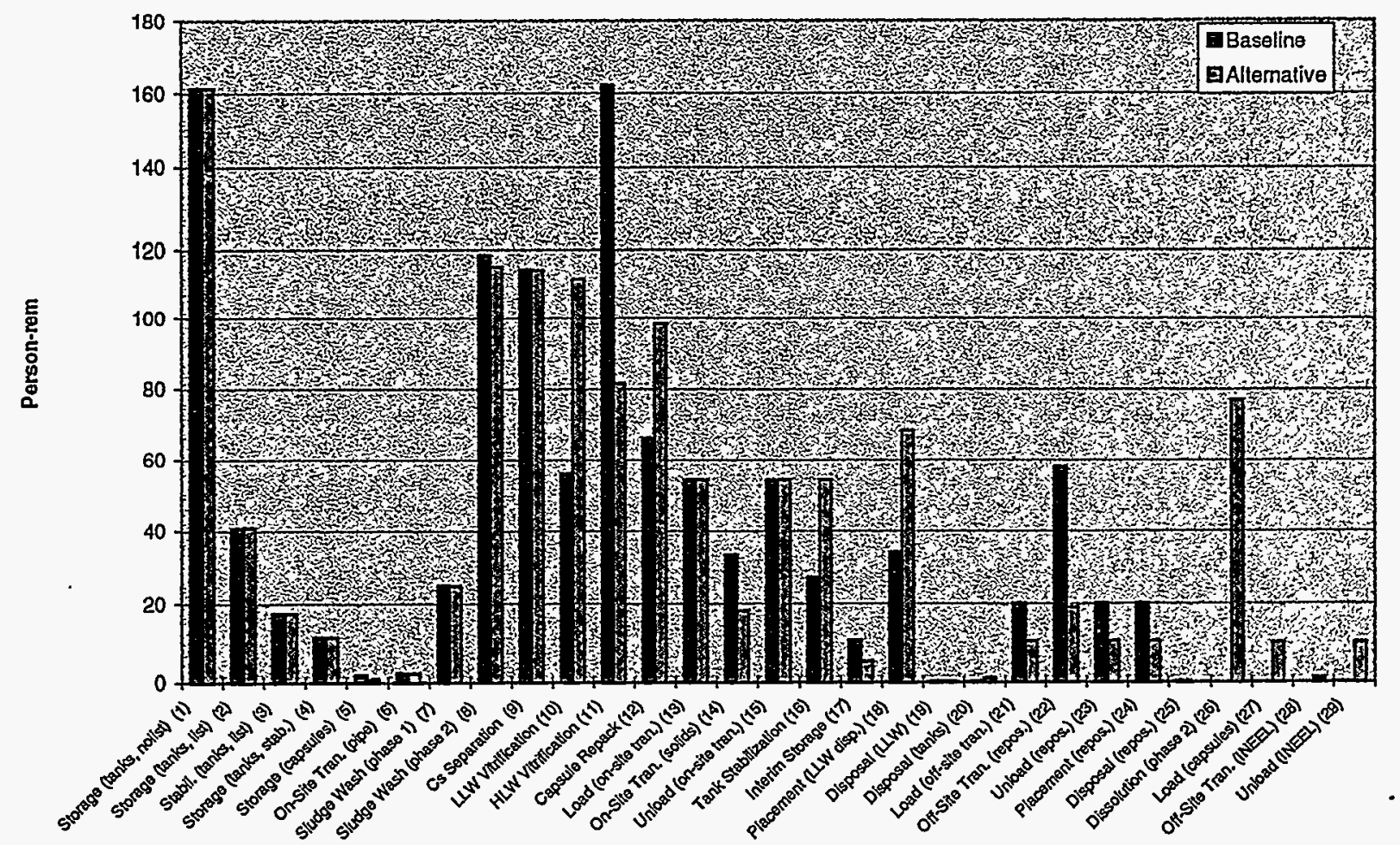

Figure 5-5. Hanford HLW risk results by activity.

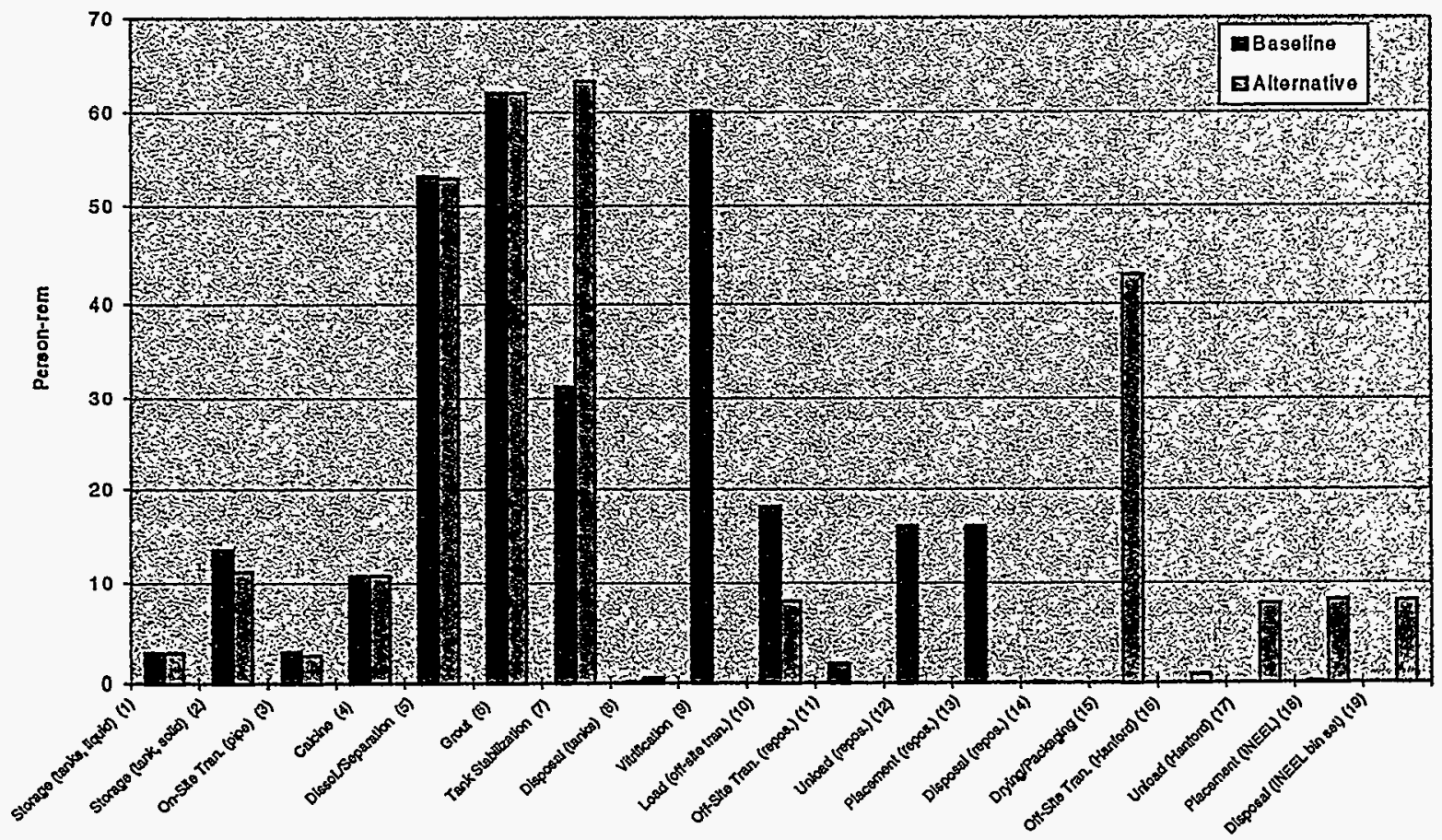

Figure 5-6. INEEL HLW risk results by activity. 


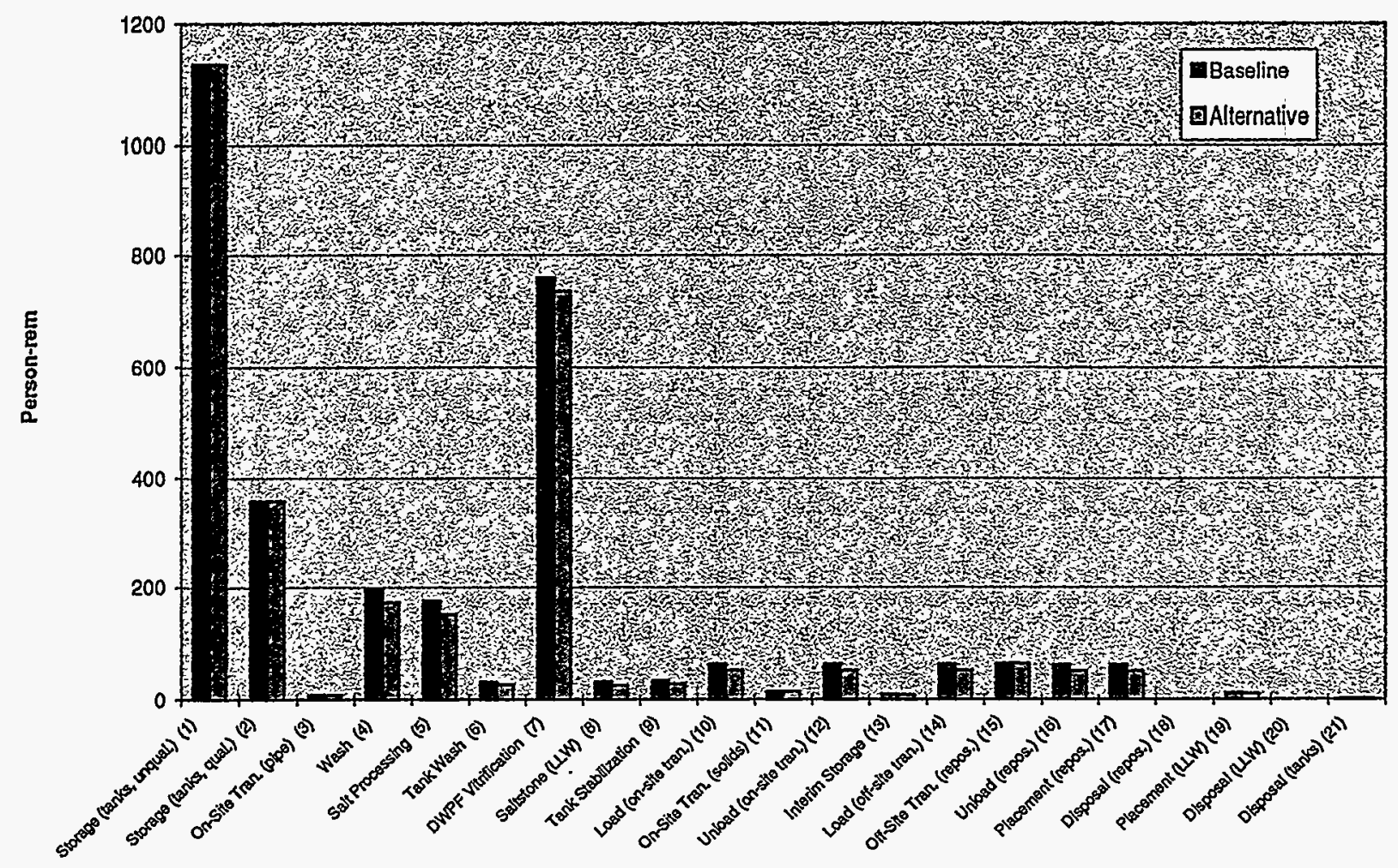

Figure 5-7. SRS HLW risk results by activity.

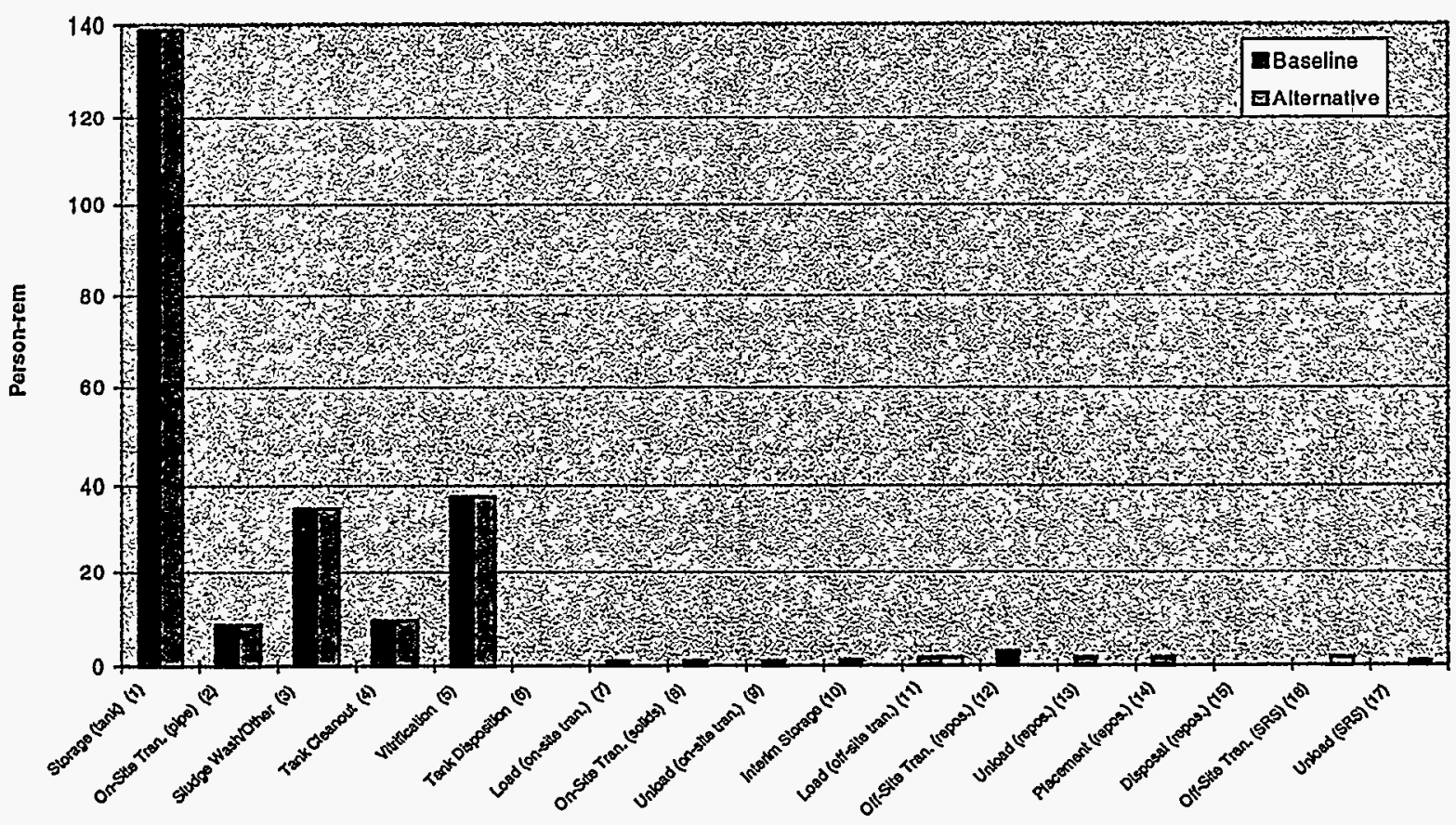

Figure 5-8. WVDP HLW risk results by activity. 
Figure 5-9 is a summary of the total risk (person-rem), baseline program and alternative, for each of the four sites, plus off-site transportation and final disposal (at Yucca Mountain). The SRS site has the most risk because it has the most curies, especially actinides, and it has a higher off-site population density than the INEEL or Hanford.

Figure 5-10 summarizes the DOE complex-wide HLW risk results by type of activity: storage, handling, treatment, transportation, and disposal. Treatment of HLW is a significant contributor to the overall HLW risk. Storage of HLW, mainly in its initial state, also contributes significantly. The other three types of activities are smaller contributors.

Figure 5-11 presents the total DOE complex-wide HLW risk for the baseline program and alternative. The total risk for the HLW baseline program is approximately 4800 person-rem, while the alternative case is approximately 4700 person-rem. This small drop in risk for the opportunity is negligible, given the accuracy of the SRM. Therefore, both the baseline program and the alternative are considered to have the same risk at the DOE complex-wide level.

Figures 5-12 through 5-14 are similar to Figures 5-9 through 5-11, but show the breakdown of risk into public and worker/site contributions. Overall, the worker/site risk is greater than the public risk.

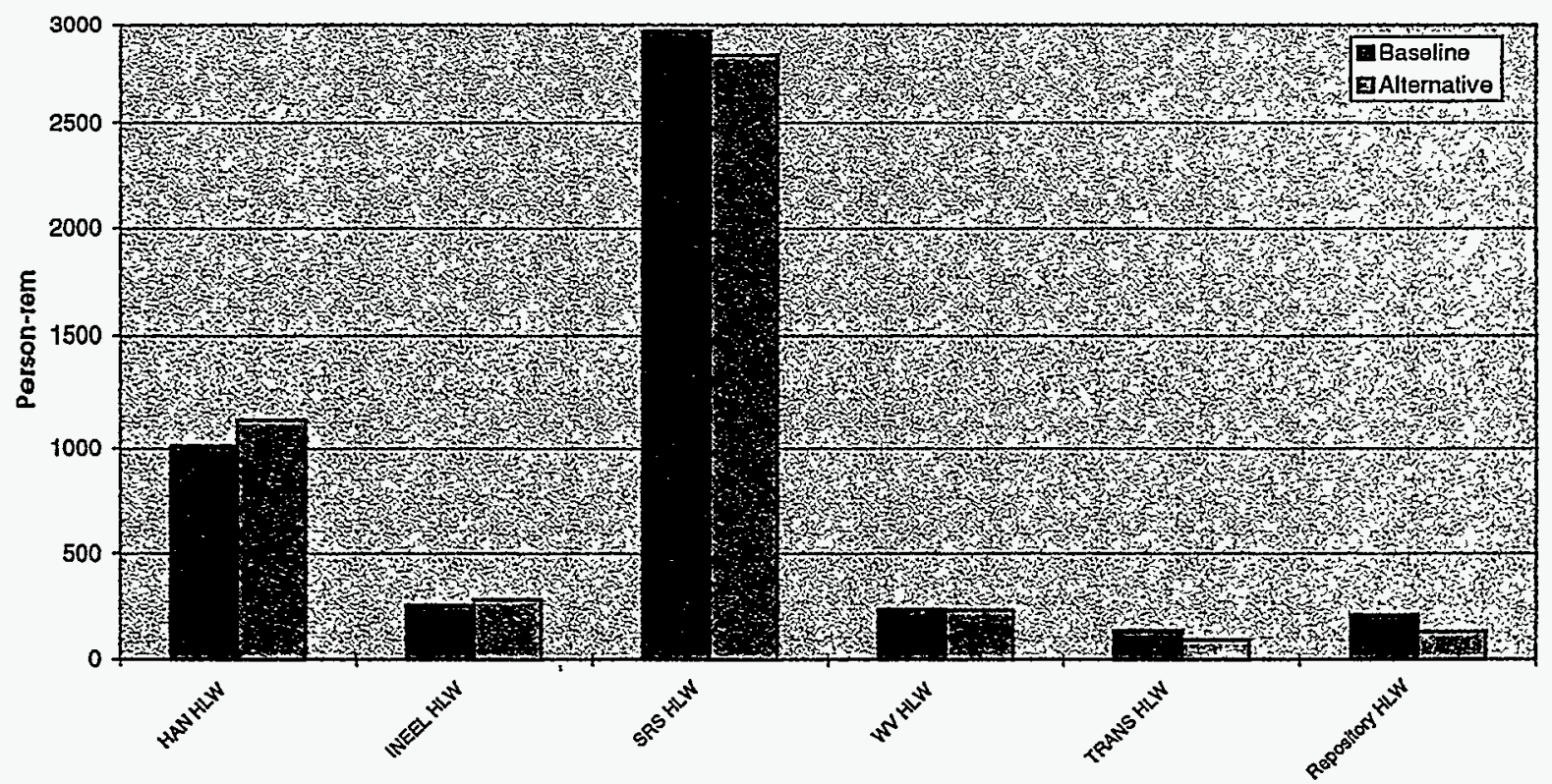

Figure 5-9. DOE HLW risk results by site. 


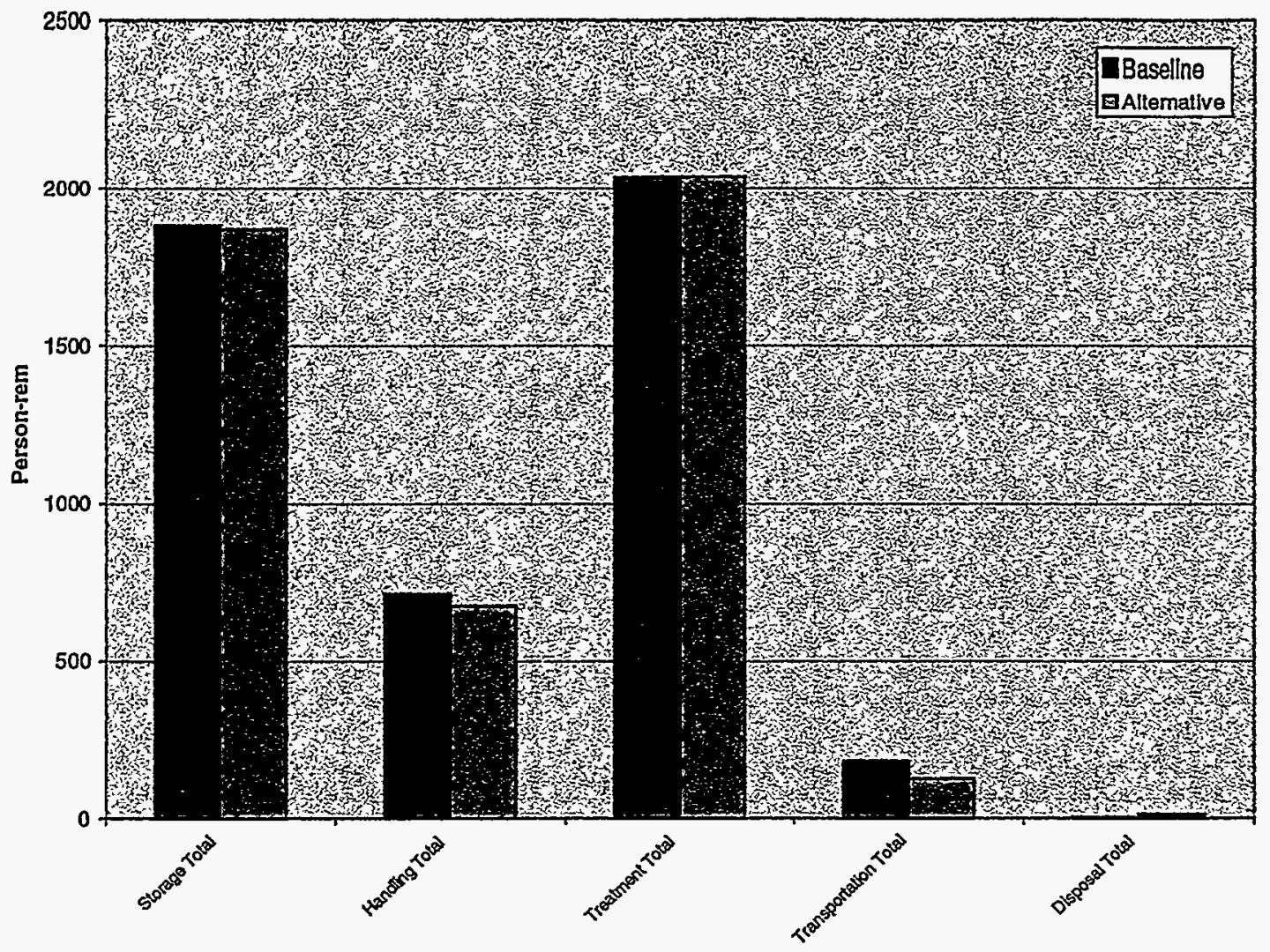

Figure 5-10. DOE complex-wide HLW risk results by activity type.

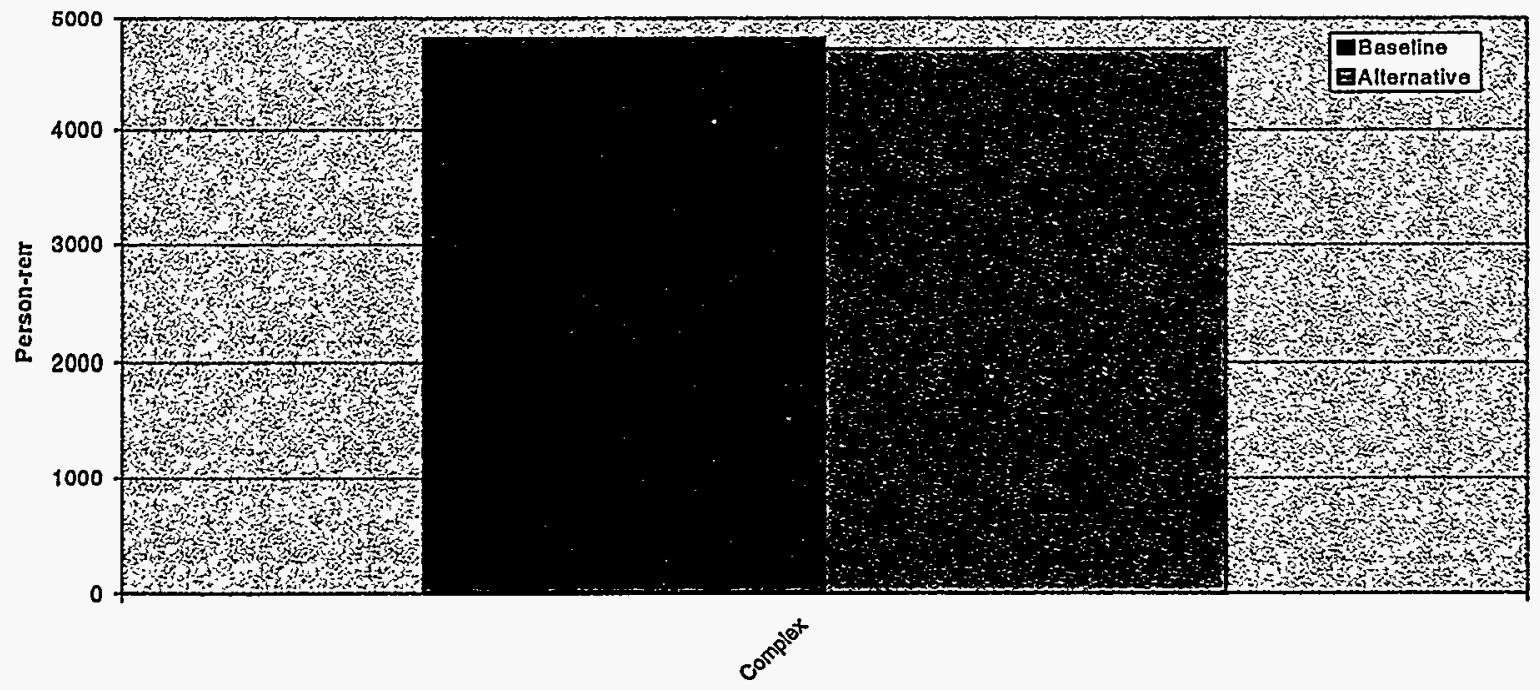

Figure 5-11. DOE complex-wide HLW risk results. 


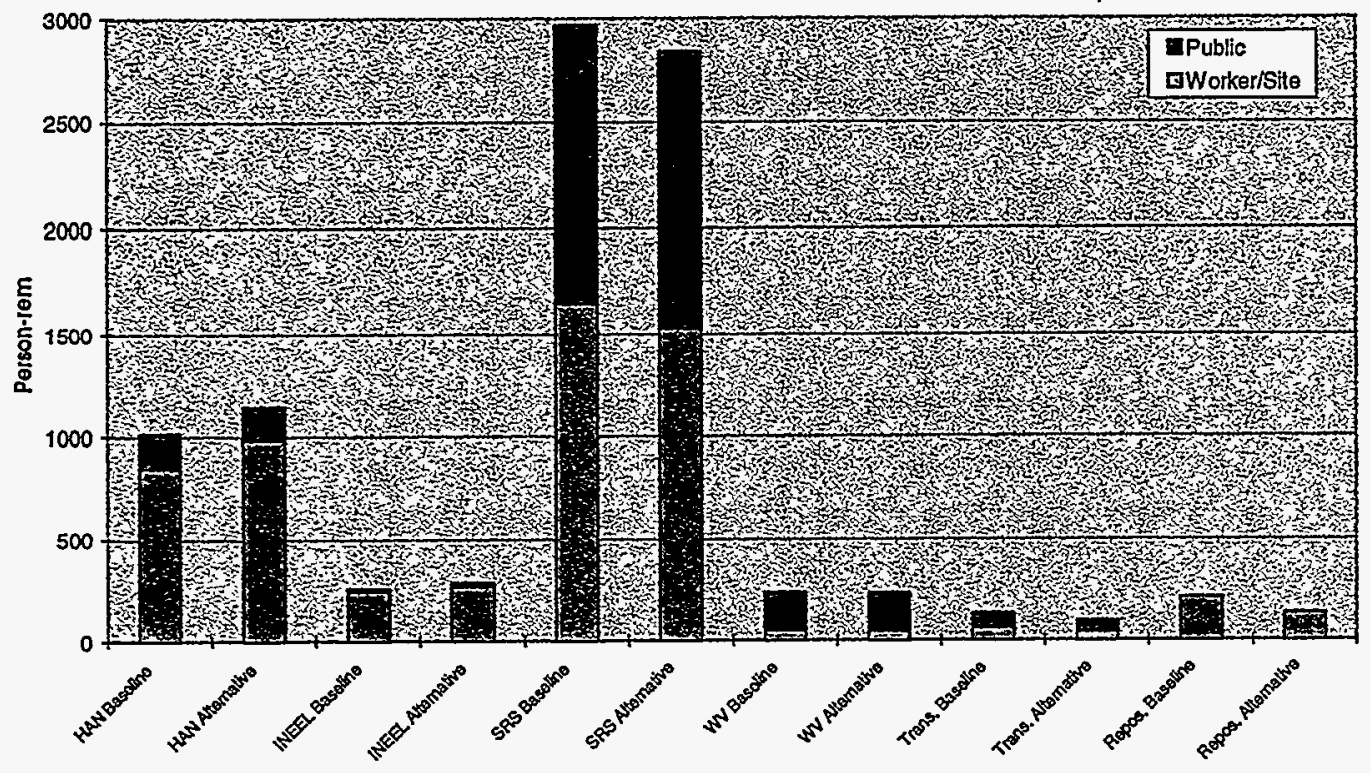

Figure 5-12. DOE HLW risk results by site (worker/site versus public).

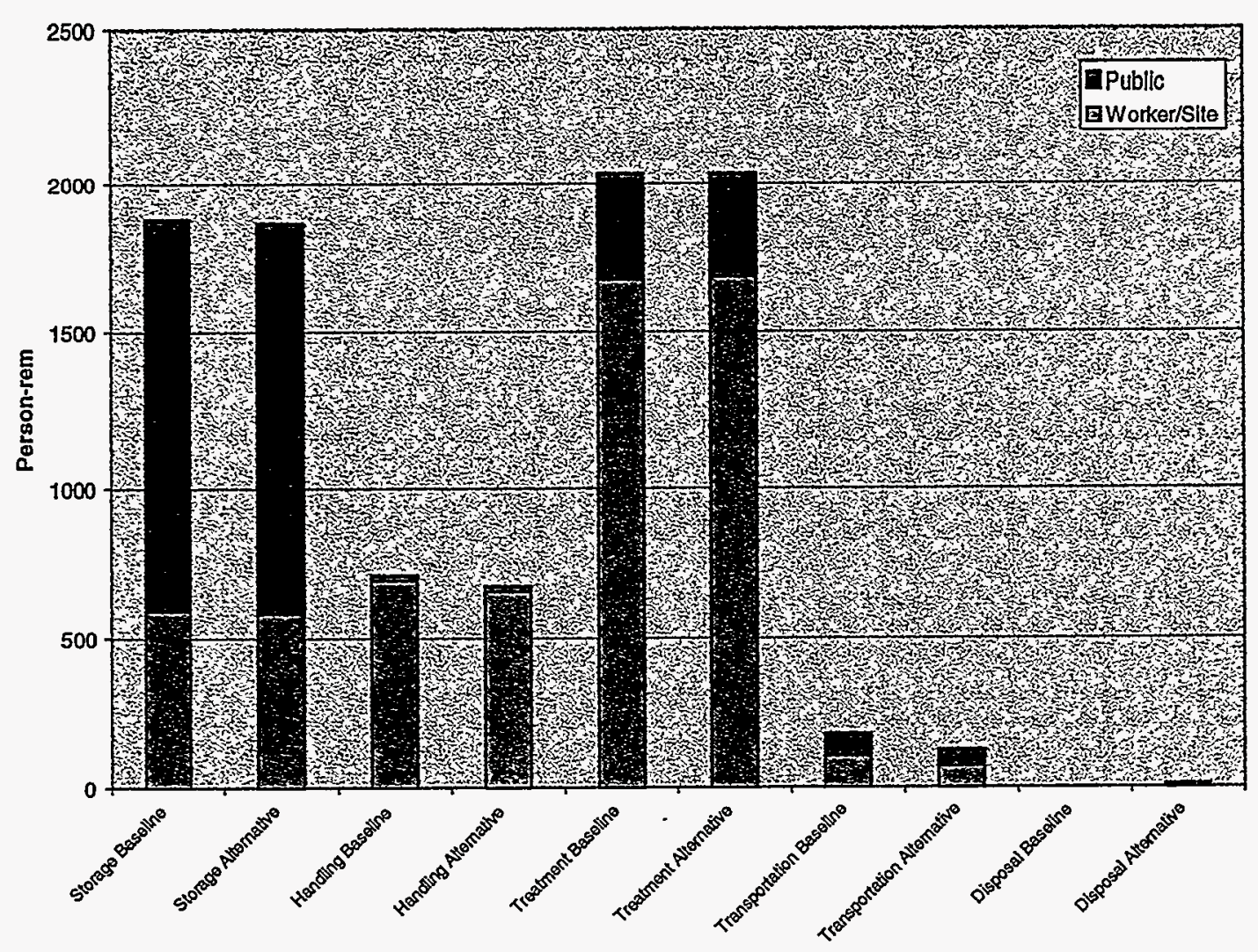

Figure 5-13. DOE complex-wide HLW risk results by activity type (worker/site versus public). 


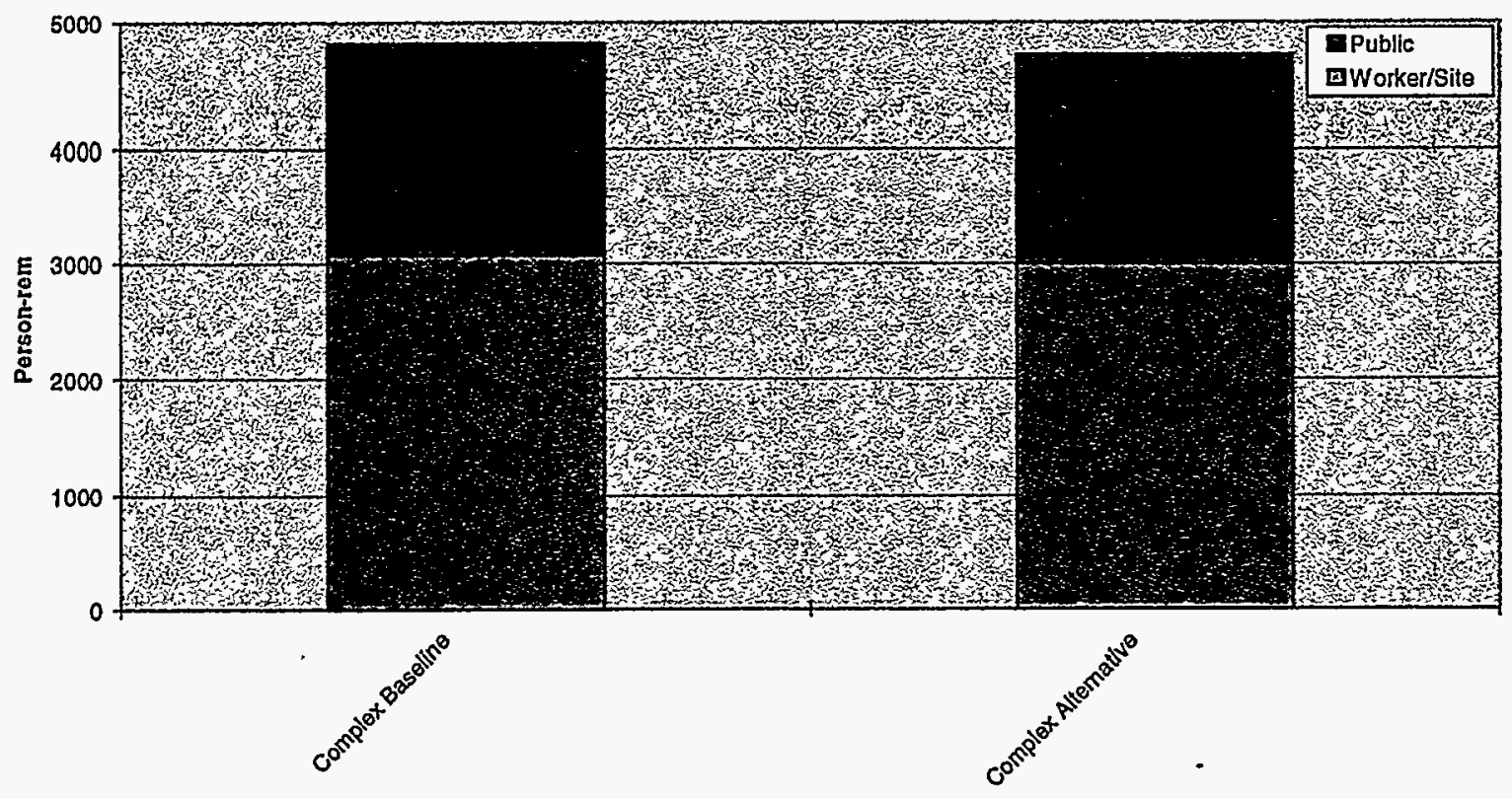

Figure 5-14. DOE complex-wide HLW risk results (worker/site versus public).

Finally, Figures 5-15 through 5-17 are similar to Figures 5-9 through 5-11, but show the breakdown of risk from accidents and normal, incident-free operation. Overall, the risk from normal, incident-free operation is comparable to the risk from accidents.

The Hanford HLW model includes the effects of chemicals in the HLW and chemicals used for processing. The contribution to risk from the chemicals is approximately $3 \%$ of the total risk. Because of the approximate manner in which the chemicals were modeled, this may be an upper bound contribution from chemicals.

The complete SRM HLW model is an EXCEL ${ }^{\text {TM }}$ workbook, with separate spreadsheets for each of the activities summarized in Figures 5-5 through 5-8. The spreadsheets contain detailed risk information on the following: accident risk (airborne) to workers, DOE site personnel, and the public, broken down into contributions from actinides, non-actinides, and chemicals; groundwater ingestion risk to the public from actinides, non-actinides, and chemicals; offgas risk (airborne) to DOE site personnel and the public, broken down into contributions from actinides, non-actinides, and chemicals; normal exposure (direct radiation) to workers; and normal and accident risk to the crew and public for transportation. All of these contributors (applicable to the activity in question) are summed in order to estimate the total risk from the activity.

Because the SRM HLW model is computerized, sensitivity studies can be performed relatively easily. Also, if more opportunities are identified in the future, the SRM analyses can be performed efficiently. Finally, existing SRM HLW results can be broken down in many different ways to respond to questions from stakeholders. 


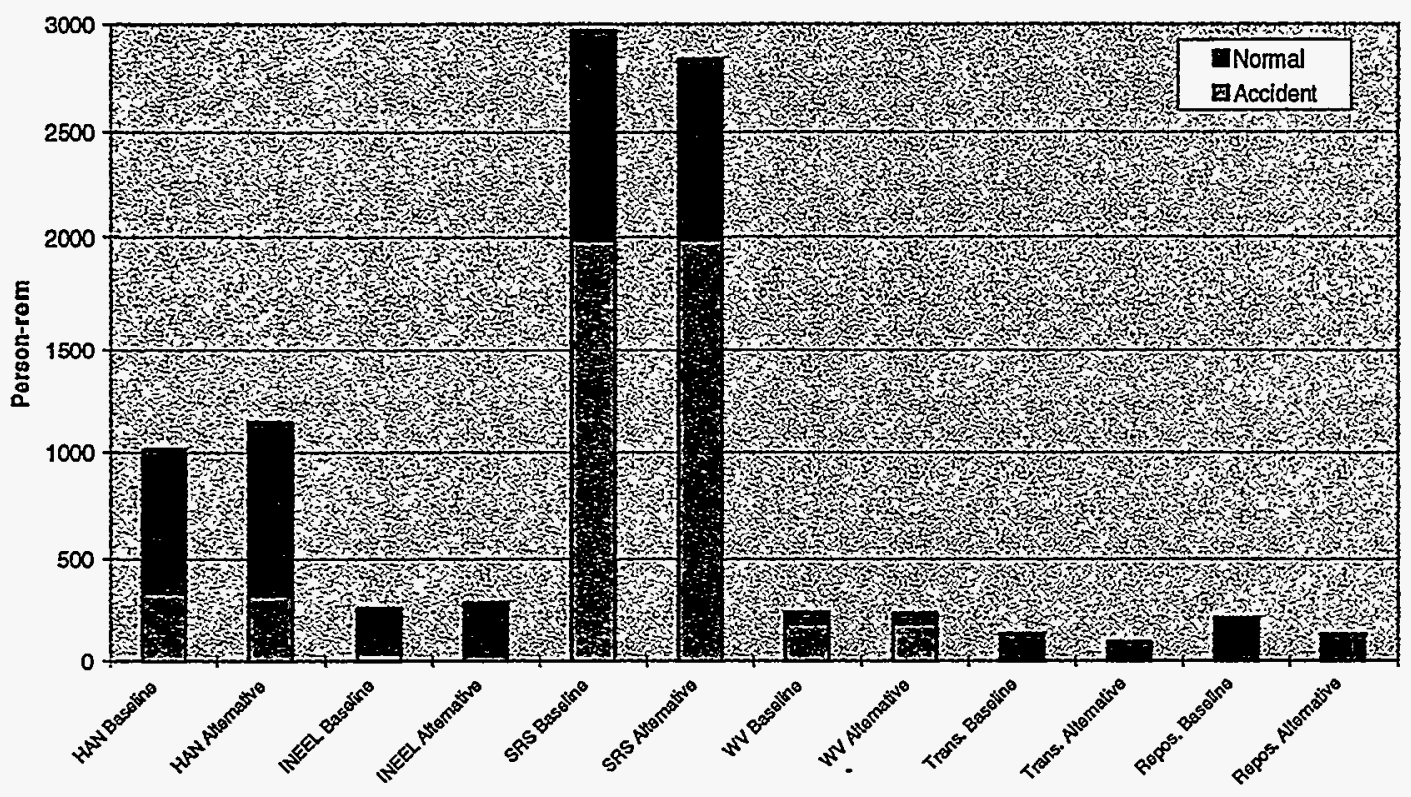

Figure 5-15. DOE HLW risk results by site (accident versus normal).

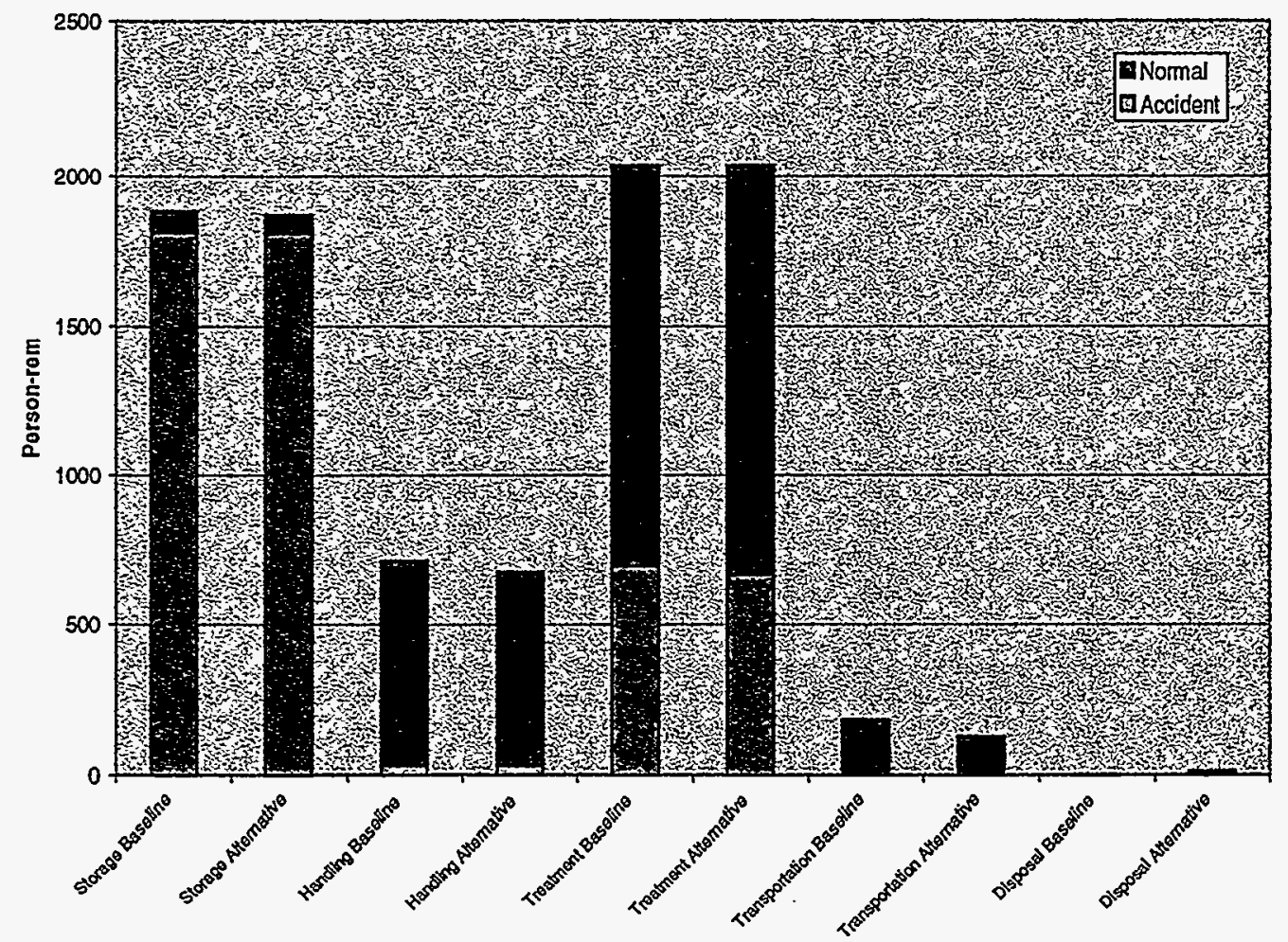

Figure 5-16. DOE complex-wide HLW risk results by activity type (accident versus normal). 


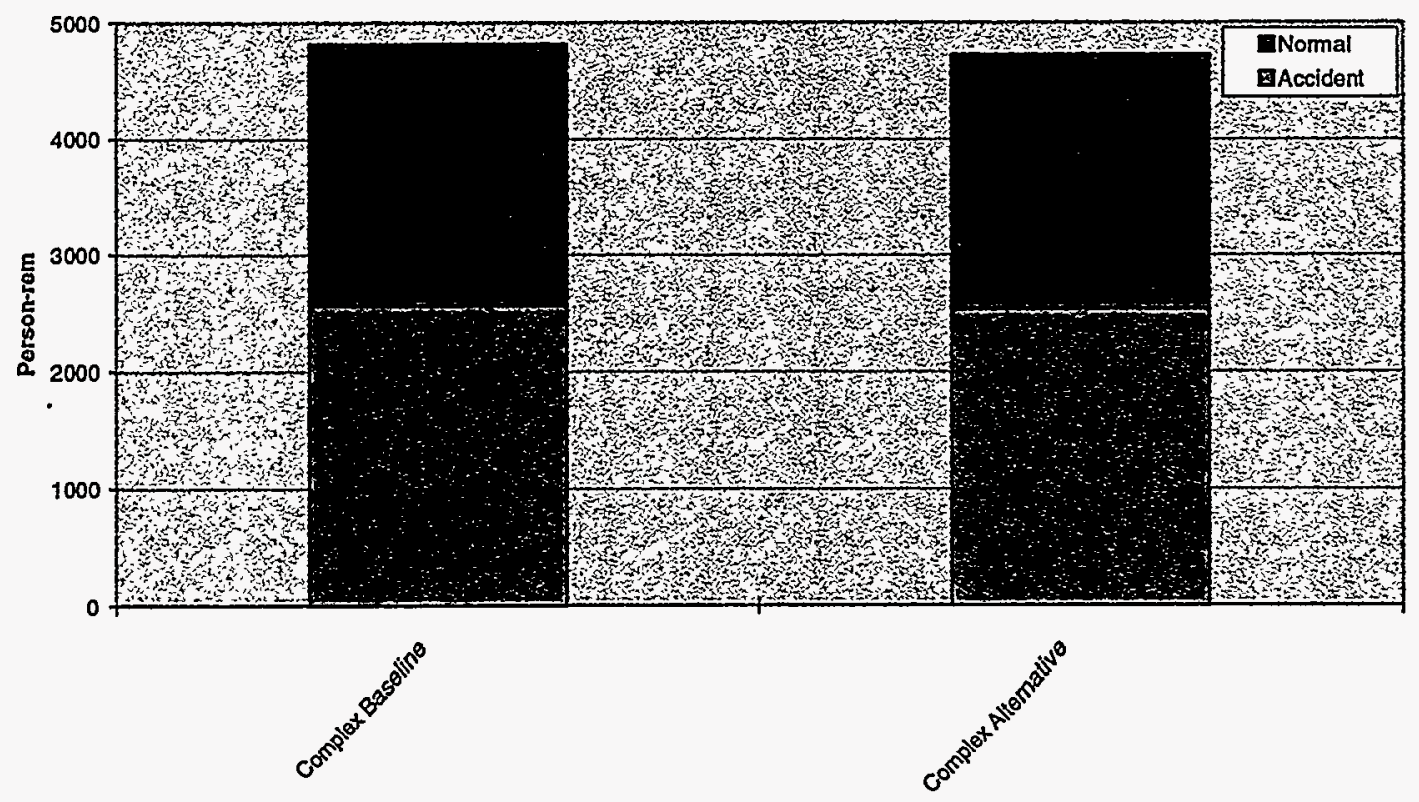

Figure 5-17. DOE complex-wide HLW risk results (accident versus normal).

The SRM risk results were compared with other risk estimate sources to ensure that the risk predictions are consistent with more detailed analyses. Comparisons were made, if possible, with results from the Final Waste Management Programmatic Environmental Impact Statement (WM-PEIS) ${ }^{6}$, individual site Environmental Impact Statements (EISs), historical exposure data from sites, and other detailed risk assessments. However, for HLW, the WM-PEIS modeled only interim storage of vitrified HLW (after processing) and transport to the final repository (assumed to be Yucca Mountain). Therefore, the WM-PEIS HLW risk results do not represent the total risk from the HLW baseline program and cannot be compared with the SRM HLW total risk results. The WM-PEIS does present risk results for off-site transportation of HLW (p. E-57), which can be compared with the SRM results. The WM-PEIS off-site transportation risk is 161 person-rem for the crew (rail) and 175 person-rem for the public. Those risk results are based on a conservative estimate of approximately $14 \mathrm{mrem} / \mathrm{h}$ at one meter $(10 \mathrm{mrem} / \mathrm{h}$ at two meters) for shipping casks. The SRM off-site transport risk for the baseline program is 59 person-rem for the crew and 73 person-rem for the public, based on a more realistic estimate of $5 \mathrm{mrem} / \mathrm{h}$ at one meter. Because the risk estimates are approximately linear with the $\mathrm{mrem} / \mathrm{h}$ at one meter assumption, the WM-PEIS results would be 58 person-rem for the crew and 63 person-rem for the public, assuming 5 $\mathrm{mrem} / \mathrm{h}$ at one meter. These estimates agree well with the SRM results. Therefore, the SRM off-site transportation model for HLW corresponds well with the WM-PEIS model; with the SRM results being lower because of a more realistic assumption concerning the $\mathrm{mrem} / \mathrm{h}$ at one meter for the shipping cask.

The report Savannah River Site Waste Management Final Environmental Impact Statement ${ }^{7}$ presents three risk estimates that can be compared with the SRS HLW results. Overall tank farm operations (H-Area) have resulted in 32.8 person-rem/year (p. E-44) of normal exposure. If these operations were to extend for 33 years (the SRM baseline program assumption), then there would be 1082 
person-rem for the workers. The SRM result is approximately 700 person-rem for the workers. Given the accuracy of the SRM, this is considered to be reasonable agreement. Also, for vitrification, the SRS EIS (p. E-46) lists offgas exposure to the public of 293 person-rem for alternative C (full treatment). The SRM result is 182 person-rem, which is again considered to be reasonable agreement. Finally, the SRS EIS (p. F-18) indicates 1.5 person-rem/year to the public for the worst HLW facility accident. If this is multiplied by 33 years, the result is 49.5 person-rem. The SRM result (for vitrification) is 61 person-rem to the public, which agrees well with the SRS EIS.

WVDP worker exposure data indicate 121.2 person-rem over the period 1989 through $1996 .^{8}$ The corresponding SRM result is 24 person-rem to the workers. This is a significant underprediction of actual worker exposure, and probably is the result of "dirtier" than normal operations associated with processing the HLW.

Finally, the report Probabilistic Safety Assessment for Hanford High-Level Waste Tanks indicates an accident risk of 8.7 person-rem/year for the public and 0.2 person-rem/year for site personnel from existing tank storage of HLW. ${ }^{9}$ The corresponding SRM result (for listed tanks) is 2.2 person-rem/year for the public and 0.22 person-rem/year for the site. The SRM site result agrees closely with the detailed risk assessment result, while the SRM public result is approximately $25 \%$ of the detailed risk assessment result.

In general, the limited comparisons discussed above indicate that the SRM is adequately predicting HLW human health risk. However, the comparisons do not cover all parts of the SRM. An important contributor to SRM HLW risk is the exposure (radiological and chemical) of workers if accidents occur. Little information is available from more detailed risk assessments, so the SRM results in this area are not validated. Also, there is no detailed risk assessment of the entire DOE HLW baseline program, so no overall comparison can be made with the SRM results. 


\section{TRANSURANIC WASTE ANALYSIS}

DOE TRUW is presently stored at a number of sites: Hanford, INEEL, Los Alamos National Laboratory (LANL), Mound, Nevada Test Site (NTS), Oak Ridge National Laboratory (ORNL), Rocky Flats Environmental Technology Site (RFETS), Sandia National Laboratory (SNL), SRS, and WVDP. In addition, many smaller sites are combined into the class designated as Small Quantity Sites (SQS). Two disposal sites are included in the model that currently have no waste, Waste Isolation Pilot Plant (WIPP) and an as yet unnamed Commercial MLLW Disposal Site.

DOE plans to stabilize this waste, which is mostly in solid form (e.g., items such as protective clothing, paper rags, glass, miscellaneous tools, and equipment). Some TRUW is in the form of sludges or liquids resulting from chemical processing for recovery of plutonium or other transuranic elements. Some of the liquids have been solidified, and some of the sludges dewatered. All sludge and liquid waste scheduled for disposal at the WIPP will be solidified prior to their shipment to meet current WIPP waste acceptance criteria. The baseline program and alternative for TRUW for each of the sites are outlined in the disposition maps presented in Figures 6-1 through 6-10. The baseline disposition maps for the DOE sites show the process by which the stored TRUW is retrieved, stabilized, and sent for disposal. The alternatives involve additional separations activities, transport of TRUW to other sites for processing or interim storage, schedule changes, and other activities.

The SRM TRUW model was developed by subdividing the disposition map boxes into activities (risk states) such as storage, retrieval, loading and unloading, on-site and off-site transport, various types of waste processing steps, and disposal. The subdivision of the disposition maps into activities is shown in Figures 6-1 through 6-10, where the numbers in parenthesis refer to specific activities for the site in question. Figures 6-11 through 6-24 indicate the word description associated with each number.

The SRM requires knowledge of the radionuclide curie and chemical flow through the disposition maps. The curie information was generally obtained from the report Integrated Data Base Report - 1995: U. S. Spent Nuclear Fuel and Radioactive Waste Inventories, Projections, and Characteristics. ${ }^{5}$ Table 6-1 lists the curie totals for each site. In the table, the curie information is broken down into contact handled $(\mathrm{CH})$ and remote handled $(\mathrm{RH}) \mathrm{TRUW}$. Also, the table lists the existing curie estimates, as well as estimates of additional TRUW that will be generated in the next 20 years. Additional information required for the SRM, such as the waste form (liquid, sludge, grout, glass, etc.), characteristics of storage and processing facilities, types of on-site and off-site transport, and schedules were obtained from the site subject matter experts. In cases where such information was not available, assumptions were made.

SRM human health risk results (person-rem) for activities at each of the DOE sites are presented in Figures 6-11 through 6-24. Each figure shows the baseline program and the alternative. It should be noted that the activities modeled for each site represent all of the important steps in the baseline program (or alternative), from initial storage through final disposal.

Examination of the results indicates that for TRUW, the transportation of the RH TRUW comprises the highest normal operations single risk contributor. The RH TRUW contribution is 
due to the higher number of trips (one trip for every three 55-gallon drums) and the higher dose rate from the transport packages (seven mrem/hour at one meter from the shipping casks), compared with CH TRUW (three mrem/hour at one meter).

Table 6-1. DOE site TRUW radiological inventory estimates.

\begin{tabular}{|c|c|c|c|c|c|c|c|}
\hline Site & $\begin{array}{l}\text { Legacy } \\
\text { /New }\end{array}$ & $\mathrm{CHCi}$ & $\begin{array}{l}\text { Actinides } \\
\text { (Ci) }\end{array}$ & $\begin{array}{c}\text { Nonactinides } \\
\text { (Ci) }\end{array}$ & $\mathrm{RHCi}$ & $\begin{array}{l}\text { Actinides } \\
\text { (Ci) }\end{array}$ & $\begin{array}{l}\text { Nonactinides } \\
\text { (Ci) }\end{array}$ \\
\hline \multirow[t]{3}{*}{ Hanford } & Legacy & 155,000 & 153,450 & 1,550 & 31,500 & 1,260 & 30,240 \\
\hline & New & 66,000 & 65,340 & 660 & - & - & - \\
\hline & Total & 221,000 & 218,790 & 2,210 & 31,500 & 1,260 & 30,240 \\
\hline \multirow[t]{3}{*}{ INEEL } & Legacy & 490,000 & 485,100 & 4,900 & 7,150 & 644 & 6,507 \\
\hline & New & - & - & - & - & - & - \\
\hline & Total & 490,000 & 485,100 & 4,900 & 7,150 & 644 & 6,507 \\
\hline \multirow[t]{3}{*}{ LANL } & Legacy & 202,000 & 201,798 & 202 & 516 & 72 & 444 \\
\hline & New & - & - & - & - & - & - \\
\hline & Total & 202,000 & 201,798 & 202 & 516 & 72 & 444 \\
\hline \multirow[t]{3}{*}{ Mound } & Legacy & 1,560 & 1,544 & 16 & - & - & - \\
\hline & New & 97 & 96 & 1 & - & - & _ \\
\hline & Total & 1,657 & 1,640 & 17 & - & - & - \\
\hline \multirow[t]{3}{*}{ NTS } & Legacy & 3,500 & 3,465 & 35 & 155 & 16 & 140 \\
\hline & New & 16 & 16 & 0 & - & - & - \\
\hline & Total & 3,516 & 3,481 & 35 & 155 & 16 & 140 \\
\hline \multirow[t]{3}{*}{ ORNL } & Legacy & 92,708 & 92,708 & - & 111,000 & 1,110 & 109,890 \\
\hline & New & 38,000 & 37,620 & 380 & 1,510 & 15 & 1,495 \\
\hline & Total & 130,708 & 130,328 & 380 & 112,510 & 1,125 & 111,385 \\
\hline \multirow[t]{3}{*}{ RFETS } & Legacy & $1,160,000$ & $1,148,400$ & 11,600 & - & - & - \\
\hline & New & 60,300 & 59,697 & 603 & - & - & - \\
\hline & Total & $1,220,300$ & $1,208,097$ & 12,203 & - & - & - \\
\hline \multirow[t]{3}{*}{ SQS } & Legacy & 454 & 449 & 5 & 241 & 24 & 217 \\
\hline & New & - & - & - & - & - & - \\
\hline & Total & 454 & 449 & 5 & 241 & 24 & 217 \\
\hline \multirow[t]{3}{*}{ SNL } & Legacy & 167 & 165 & 2 & 14 & 2 & 12 \\
\hline & New & 105 & 104 & 1 & - & - & - \\
\hline & Total & 272 & 269 & 3 & 14 & 2 & 12 \\
\hline \multirow[t]{3}{*}{ SRS } & Legacy & 690,400 & 689,710 & 690 & - & - & - \\
\hline & New & - & - & - & - & - & - \\
\hline & Total & 690,400 & 689,710 & 690 & - & - & - \\
\hline \multirow[t]{3}{*}{ WVDP } & Legacy & 37 & 36 & 0 & 143 & 14 & 129 \\
\hline & New & 19 & 18 & 0 & - & - & - \\
\hline & Total & 55 & 55 & 1 & 143 & 14 & 129 \\
\hline
\end{tabular}

The largest contributing activities to the accident risk at DOE sites are all located at RFETS. RFETS has the largest curie loading and waste volume of the sites by approximately an order of magnitude, which directly affect the results. The high-risk activities at RFETS include, in order of importance: (1) aboveground storage, and (2) load and unloading activities for both on-site shipping and off-site shipping.

Other activities that show high accident risk rankings include aboveground storage at other sites, retrieval at sites with underground storage, and load and unload activities. The aboveground 
storage risk is driven by the assumed type of the waste form, the higher probability of a fire compared with underground storage event, and the assumption that there is only one level of confinement to the storage.

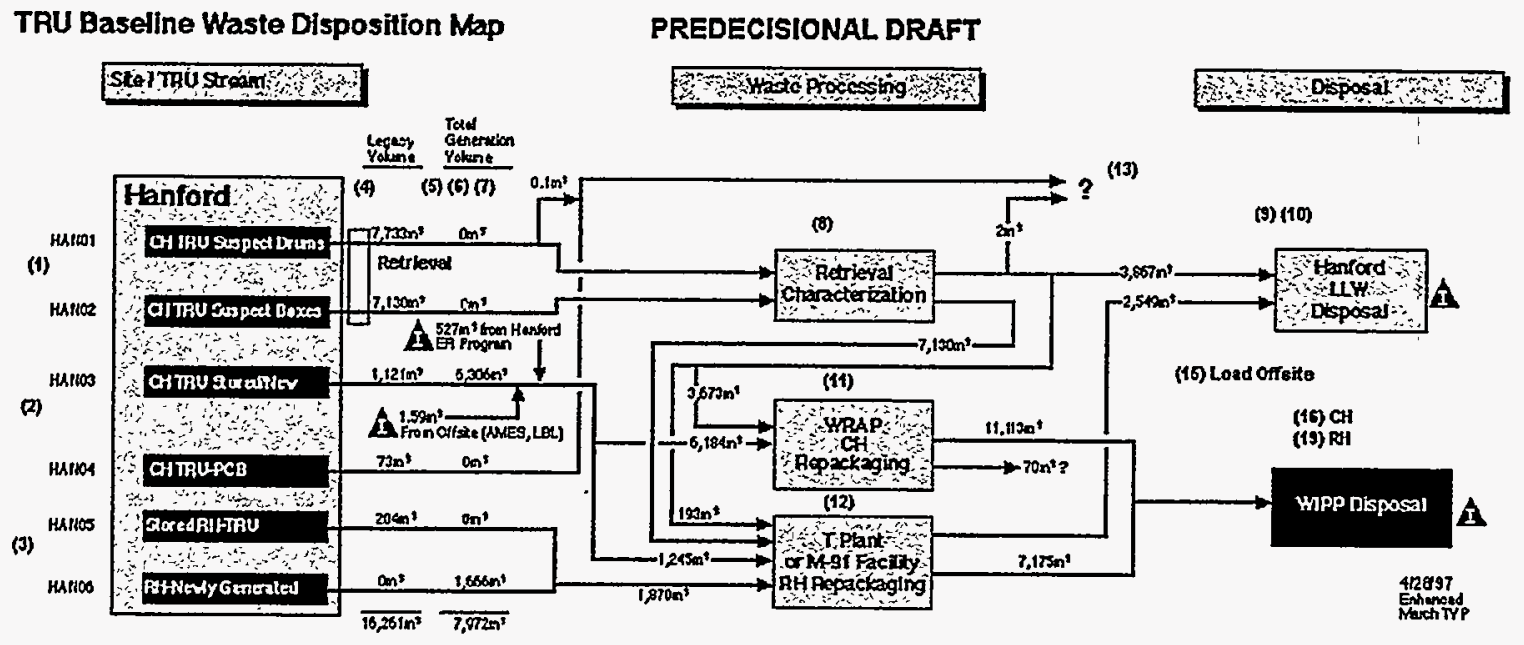

TRU Alternative Waste Disposition Map

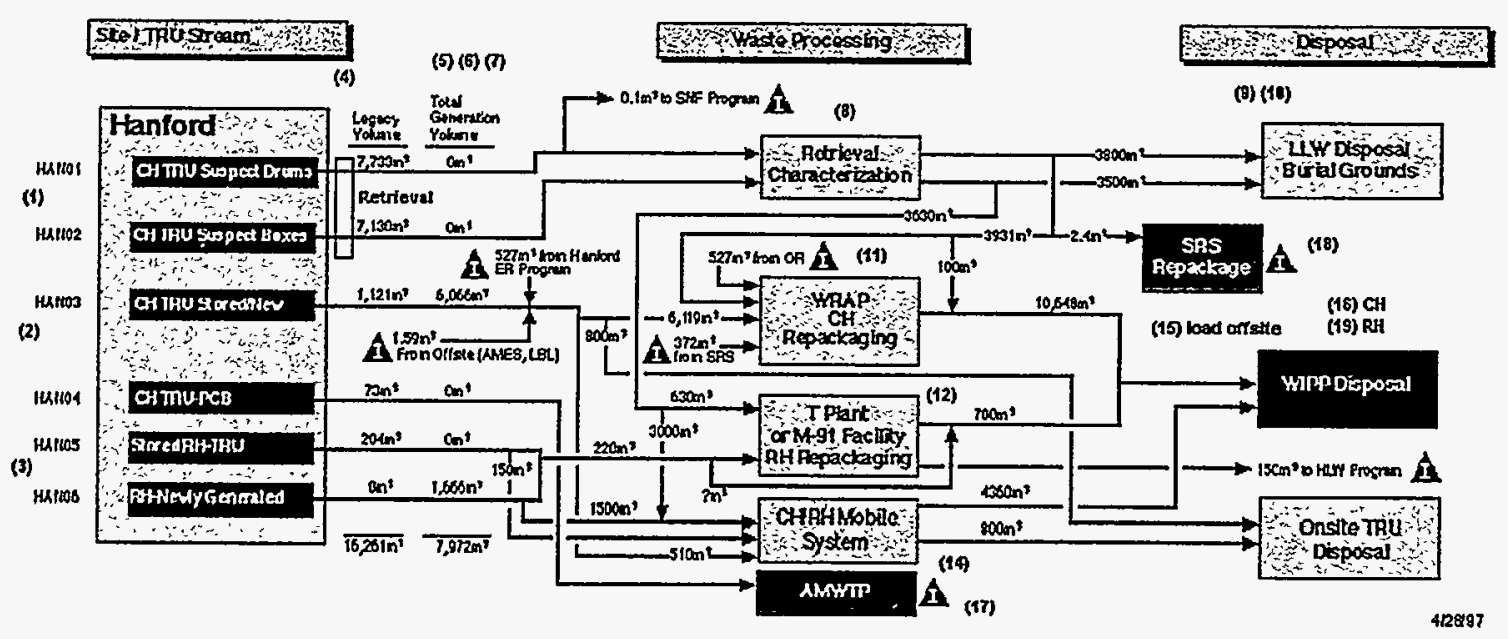

Figure 6-1. Hanford TRUW disposition maps (baseline and alternative). 
TRU Baseline Waste Disposition Map

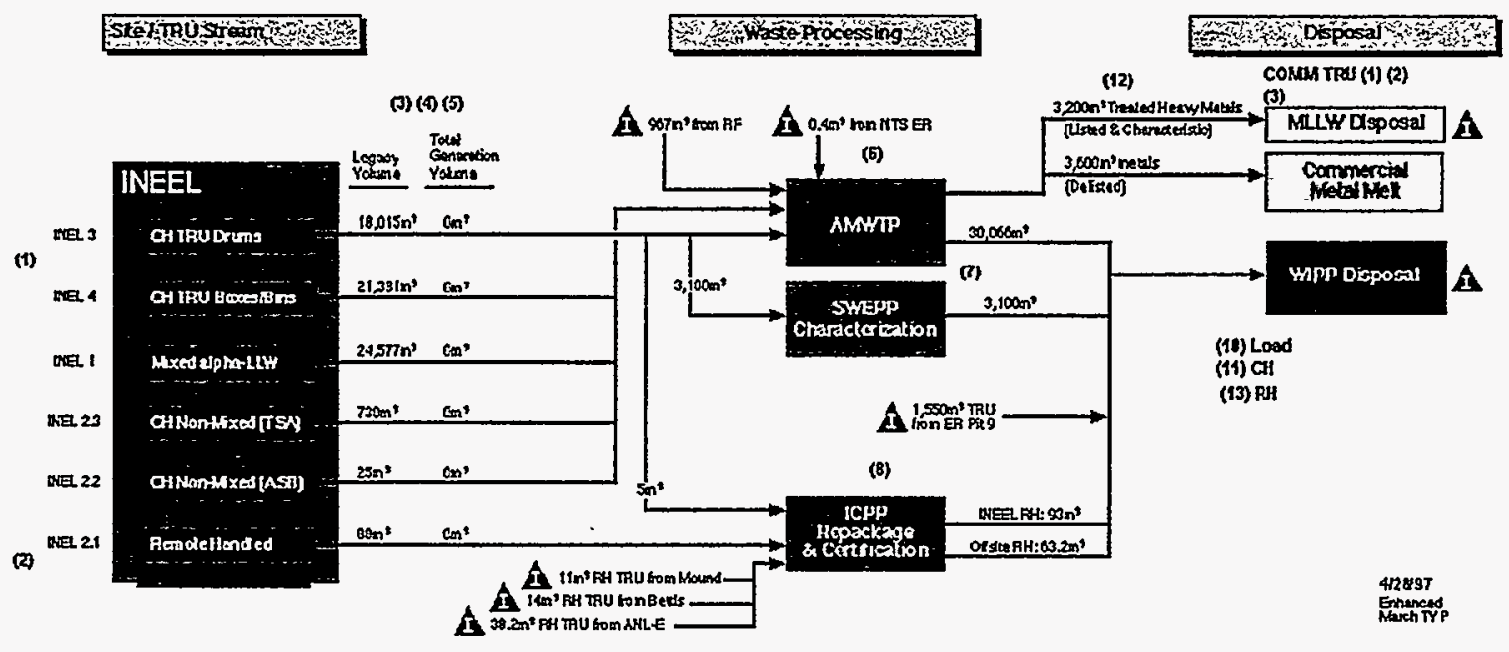

TRU Alternatlve Waste Disprosition Map

StafThustom

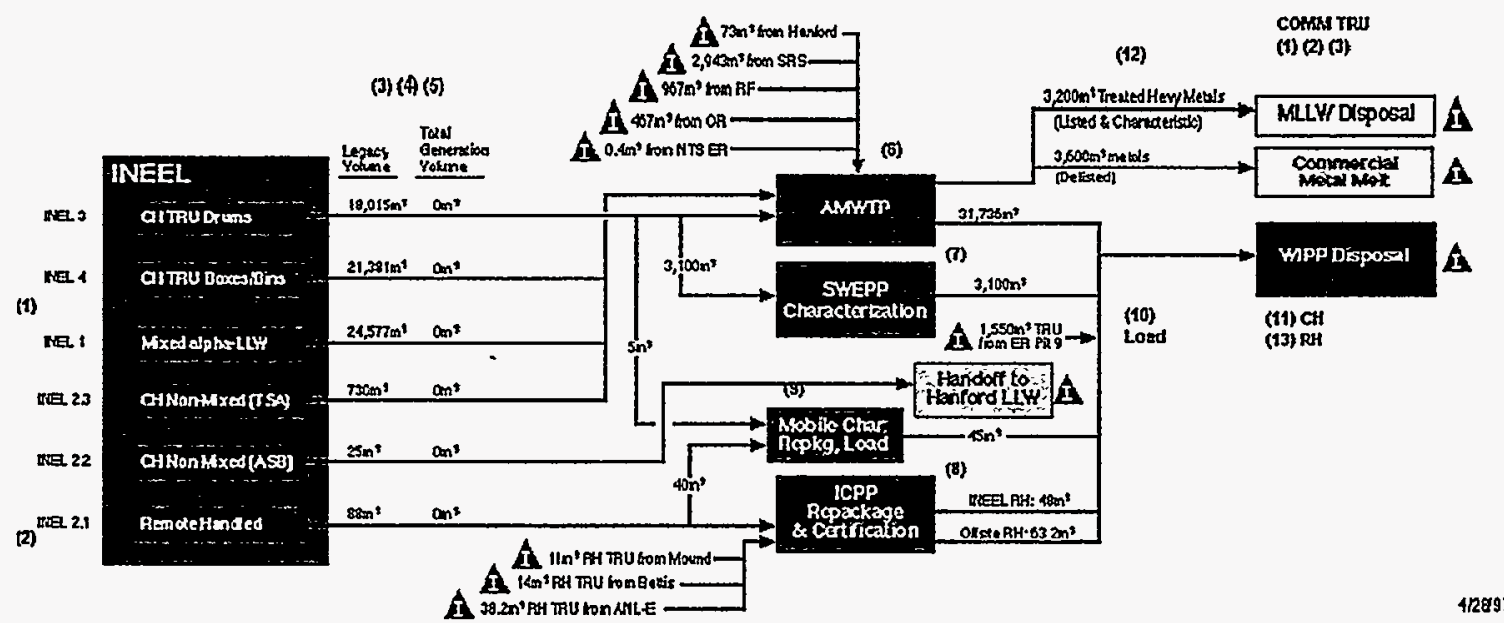

Figure 6-2. INEEL TRUW disposition maps (baseline and alternative). 
TRU Baseline Waste Disposition Map

PREDECISIONAL DRAFT

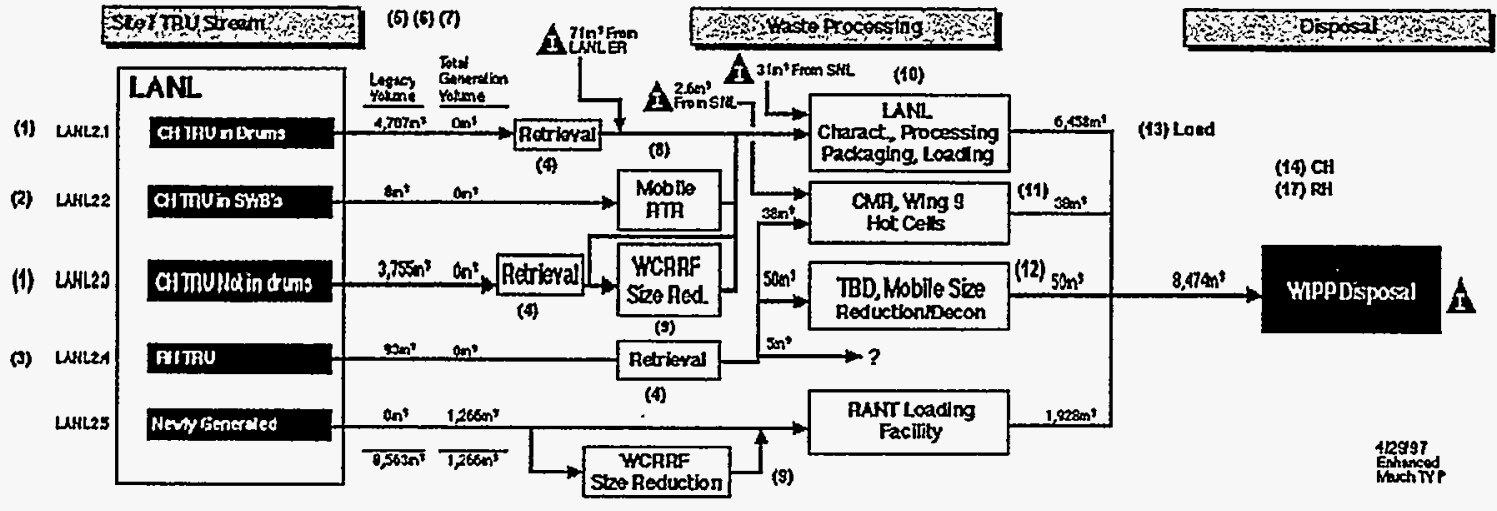

TRU Alternative Waste Disposition Map

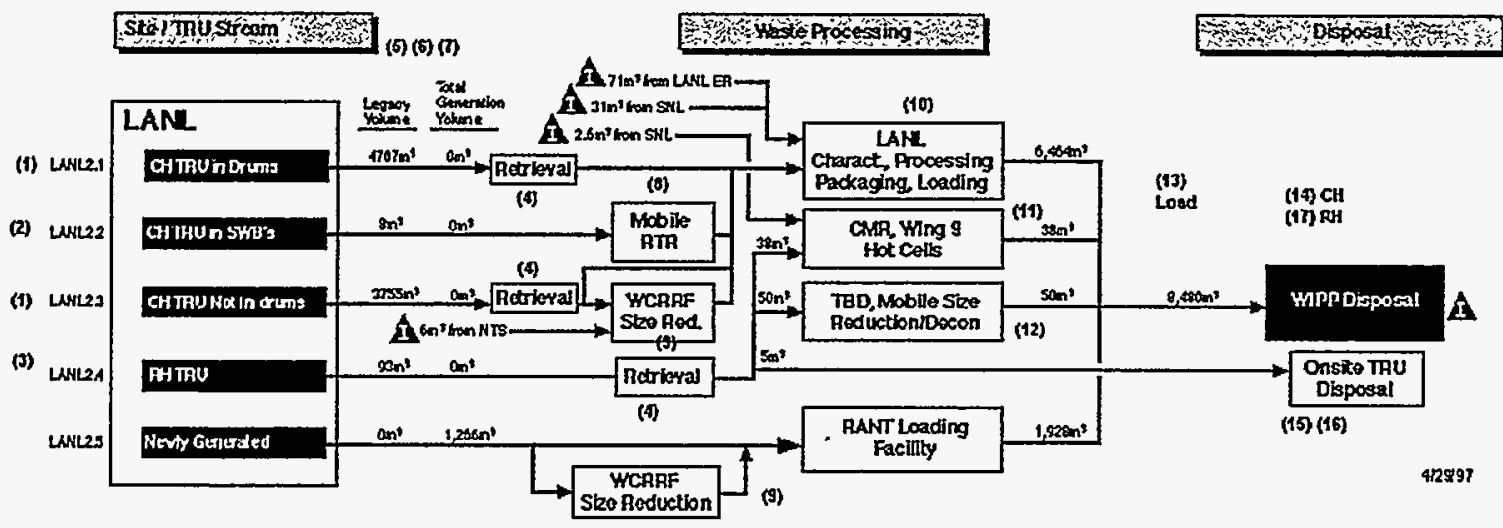

Figure 6-3. LANL TRUW disposition maps (baseline and alternative). 
TRU Baseline Waste Disposition Map

Stexpusiring

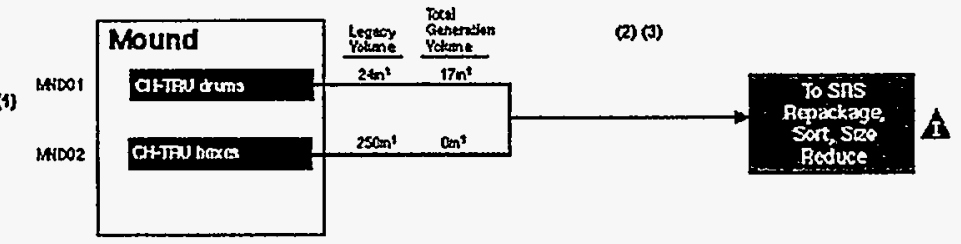

TRU Alternative Waste Disposition Map

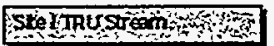

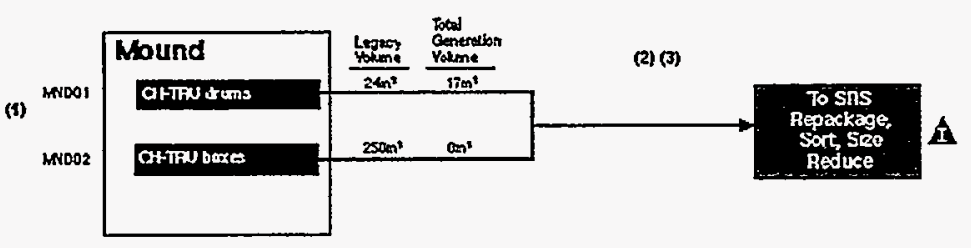

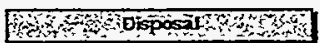

42997

Emhateces

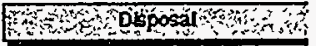

Figure 6-4. Mound TRUW disposition maps (baseline and alternative).

42\%97 
TRU Baseline Waste Disposition Map

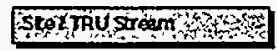

PREDECISIONAL DRAFT

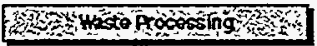

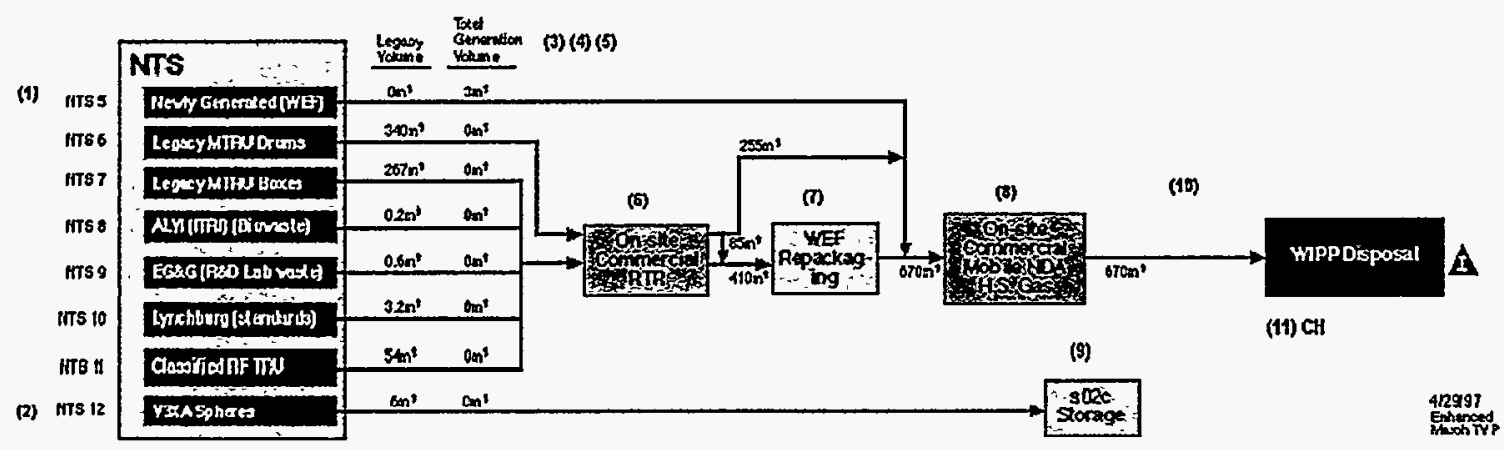

Figure 6-5. NTS TRUW disposition maps (baseline and alternative). 


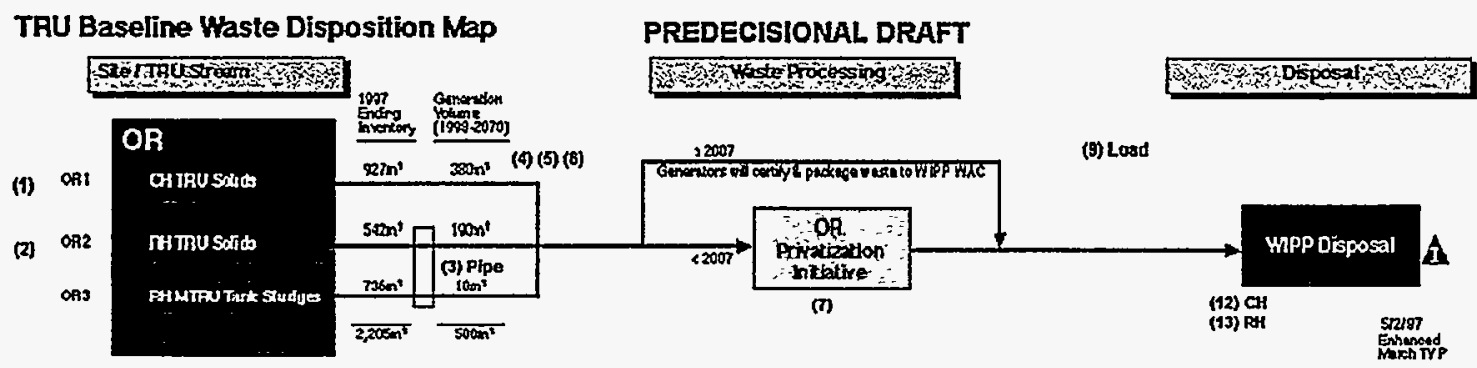

TRU Alternative Waste Dispasitton Map

Sropinusrom

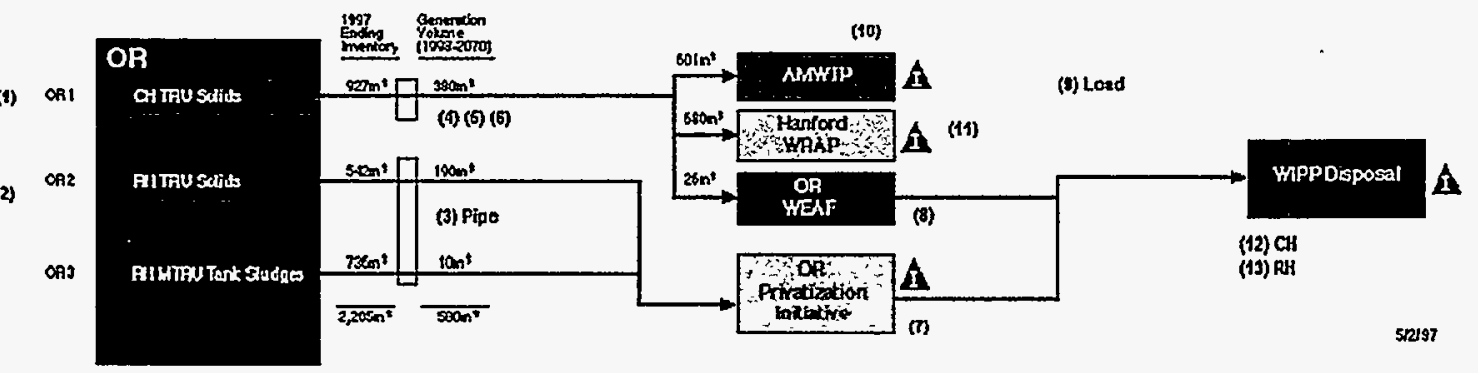

Figure 6-6. ORNL TRUW disposition maps (baseline and alternative). 


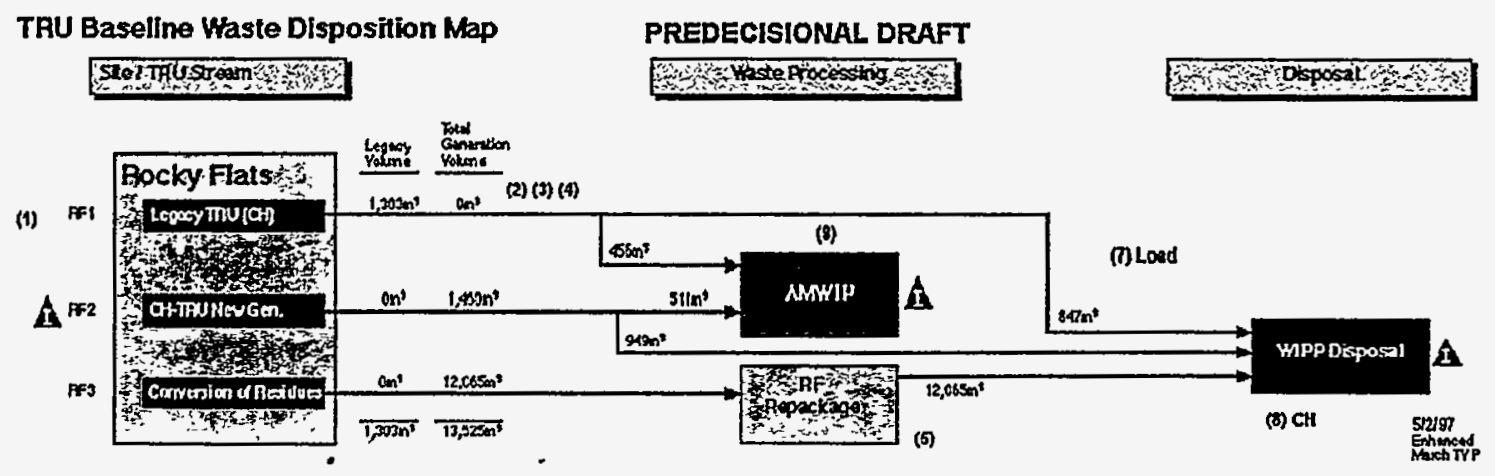

TRU Alternative Waste Disposition Map

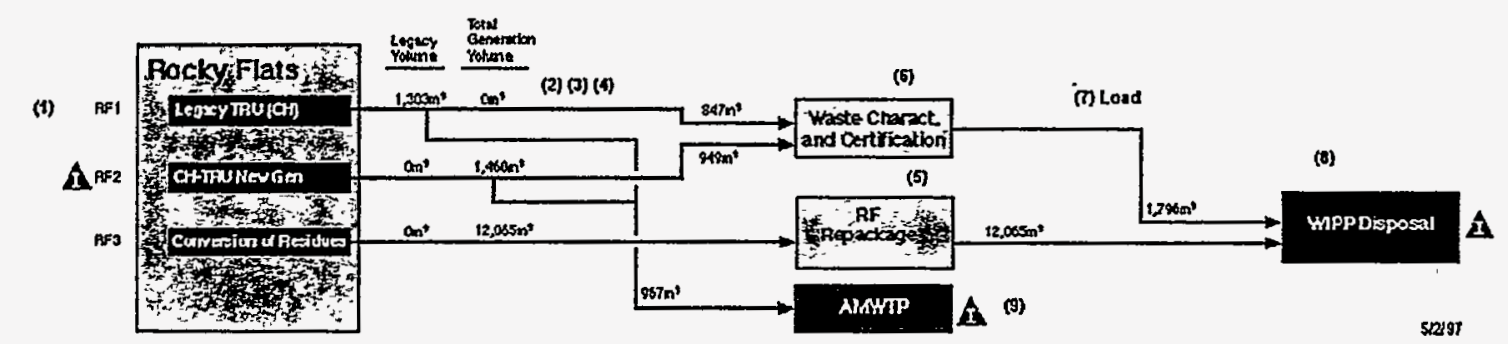

Figure 6-7. RFETS TRUW disposition maps (baseline and alternative). 
TRU Baseline Maste Disposition Map

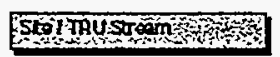

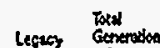

(1) anL1

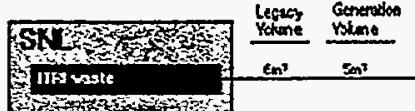

SNL2

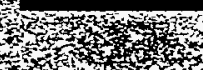

Fin

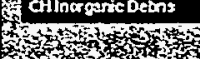

(2) sins

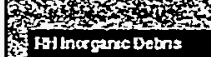

Finotyerebetns

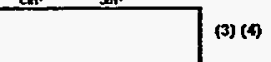

(3) (3)

(n)

TRU Altematlye Waste DIsposition Map

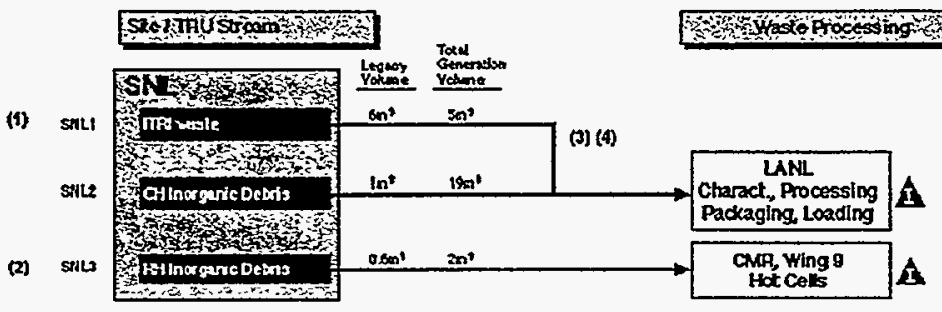

LANL

Craract, Processing 1
Packaging. Loading

OMR, Whing

Hot cells

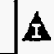

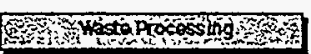

52197 - Emenosd

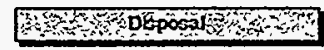

42697

Figure 6-8. SNL TRUW disposition maps (baseline and alternative). 


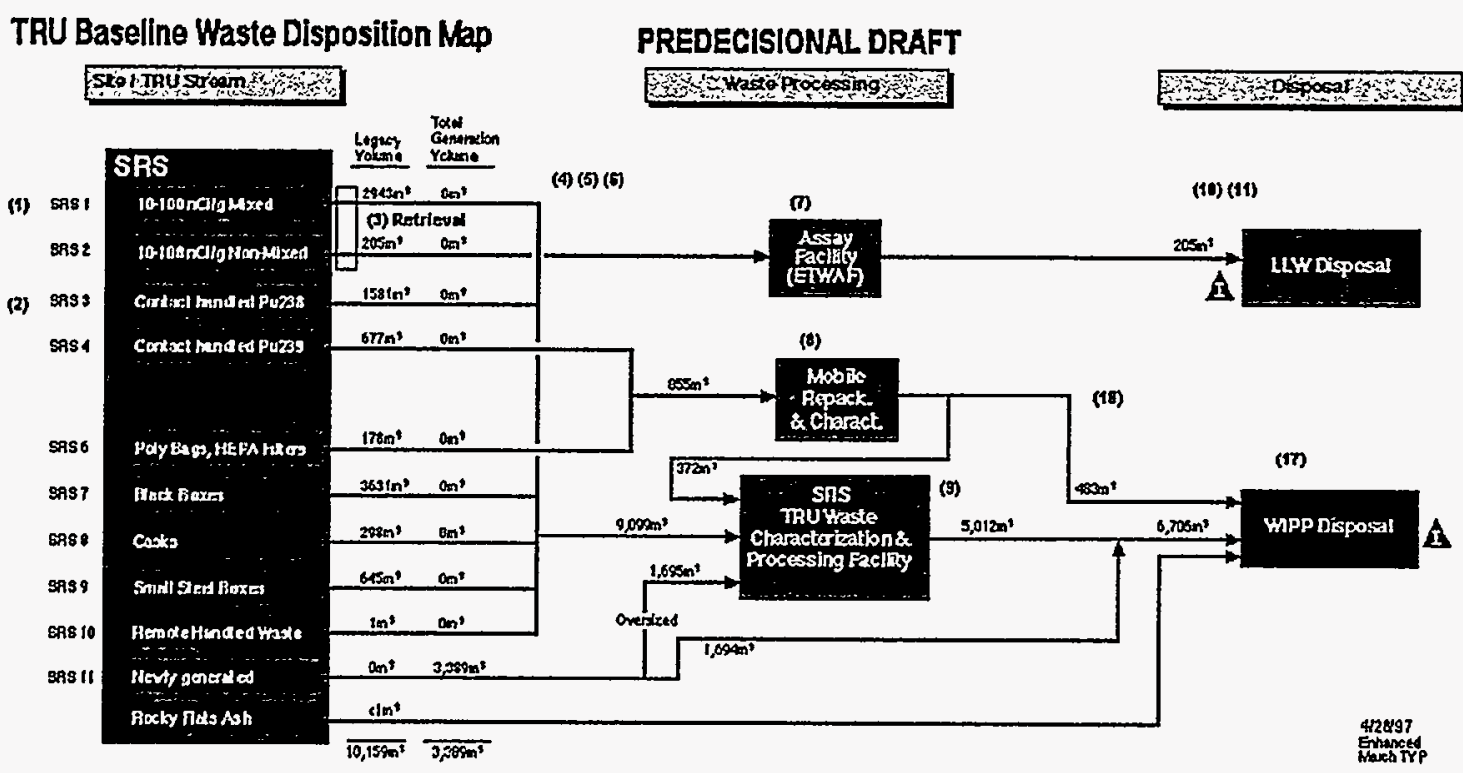

IRU Alternative Waste Disposition Map Stontustom

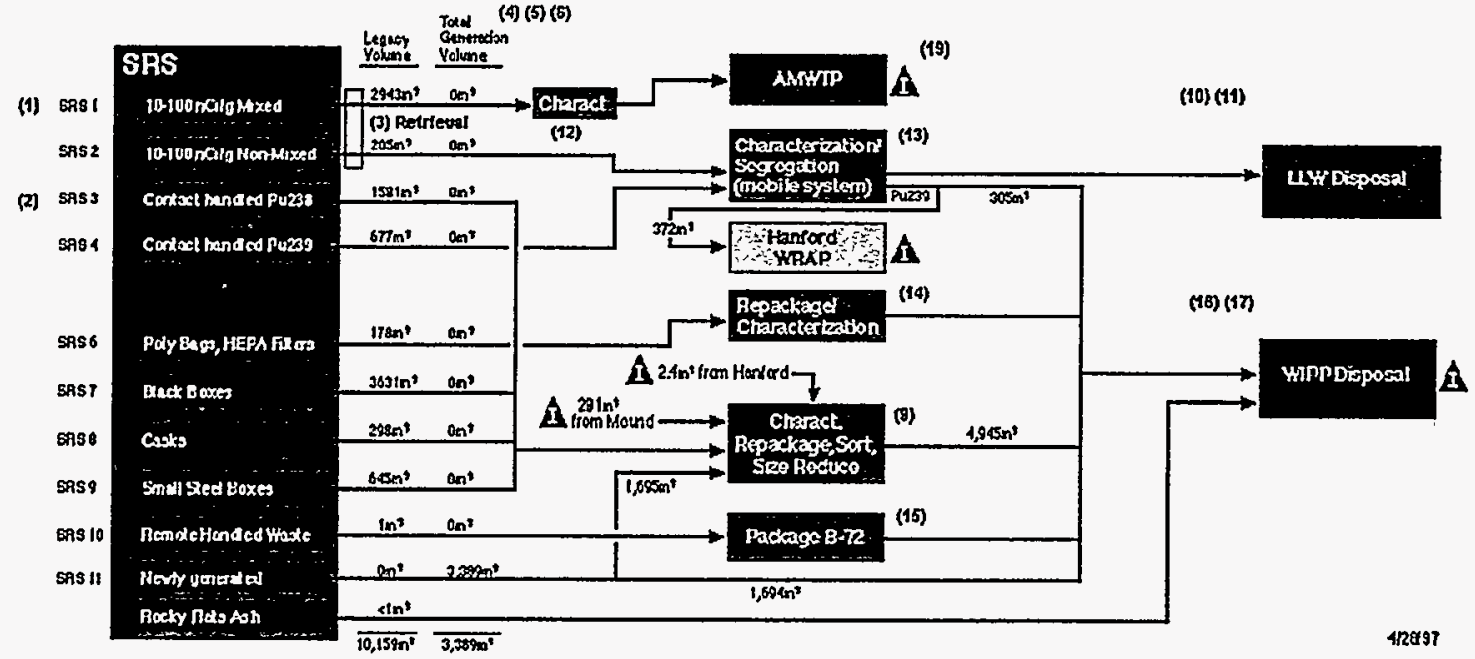

Figure 6-9. SRS TRUW disposition maps (baseline and alternative). 

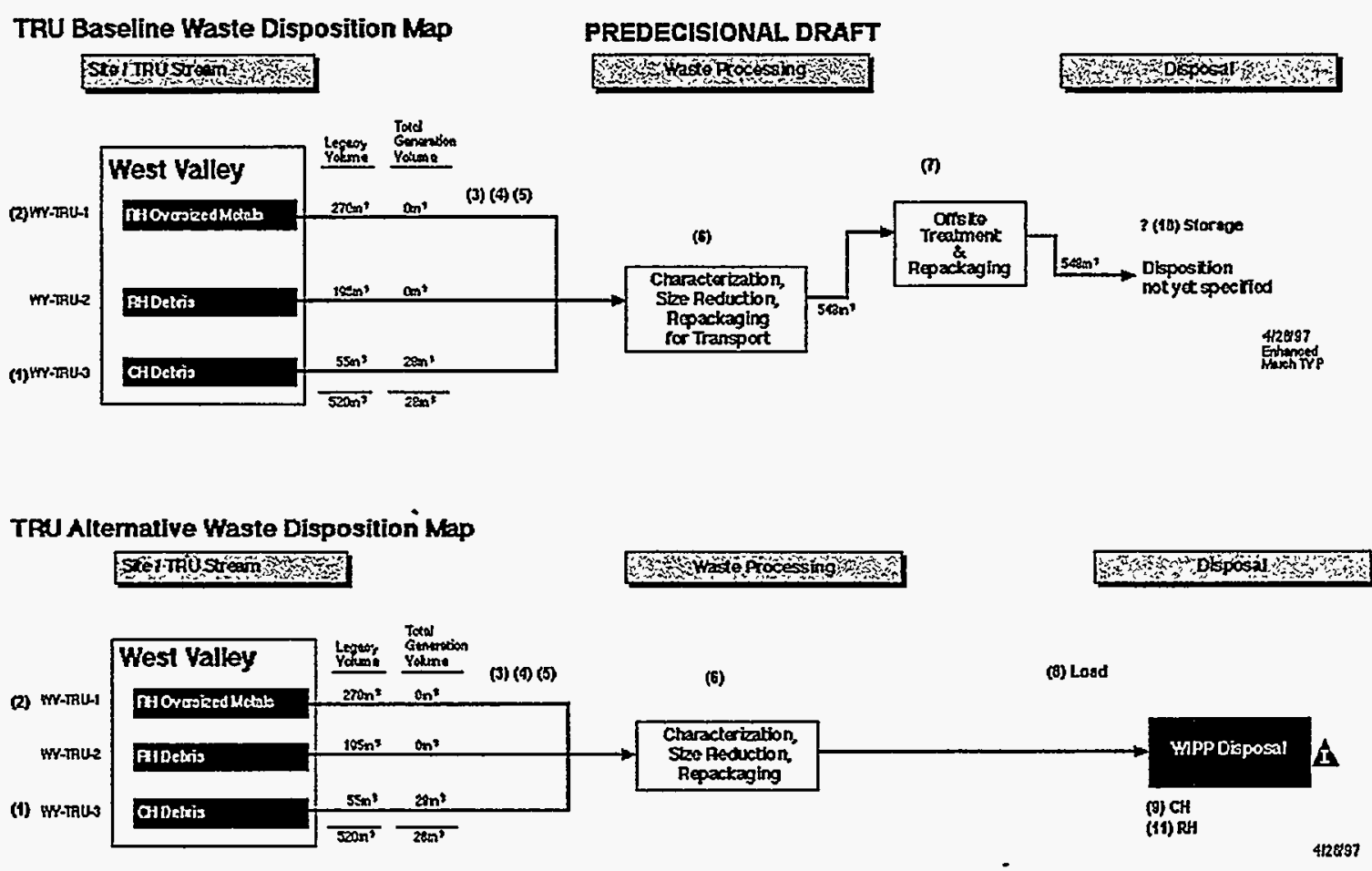

Figure 6-10. WVDP TRUW disposition maps (baseline and alternative).

Other notable activities include repackaging, sorting, treatment and retrieval. These activities have large numbers of workers and support personnel who are exposed to the radiation levels for extended periods.

Figure 6-24 is a summary of the total risk (person-rem), baseline program and alternative, for each of the sites, plus off-site transportation and final disposal (at WIPP).

Figure 6-25 presents the DOE complex-wide TRUW risk results by type of activity: storage, handling, treatment, transportation, and disposal. Transportation and handling of TRUW are significant contributors to overall TRUW risk. Storage of TRUW, mainly in its initial state, also contributes significantly. The other types of activities are much smaller contributors.

Figure 6-26 presents the total DOE complex-wide TRUW risk for the baseline program and alternative. The total risk for the TRUW baseline program is approximately 11,600 person-rem, while the alternative case is approximately 460 higher. This is a small increase in risk, given the accuracy of the SRM. Therefore, both the baseline program and the alternative are considered to have comparable risks.

Figure 6-27 through Figure 6-29 show the breakdown of risk into public and worker/site contributions. 
Finally, Figure 6-30 through Figure 6-32 show the breakdown of risk from accidents and normal, incident-free operation. Overall, the risk from normal, incident-free operation is much more compared to the risk from accidents, but if the contribution from transportation were set aside, the risk would be largely due to accidents.

The complete SRM TRUW model is an EXCEL TM workbook, with separate spreadsheets for each of the activities summarized in Figure 6-11 through Figure 6-23. The spreadsheets contain detailed risk information on the following: accident risk (airborne) to workers, DOE site personnel, and the public, broken down into contributions from actinides, non-actinides, and chemicals; groundwater ingestion risk to the public from actinides, non-actinides, and chemicals; offgas risk (airborne) to DOE site personnel and the public, broken down into contributions from actinides, non-actinides, and chemicals; normal exposure (direct radiation) to workers; and normal and accident risk to the crew and public for transportation. All of these contributors (applicable to the activity in question) are summed in order to estimate the total risk from the activity.

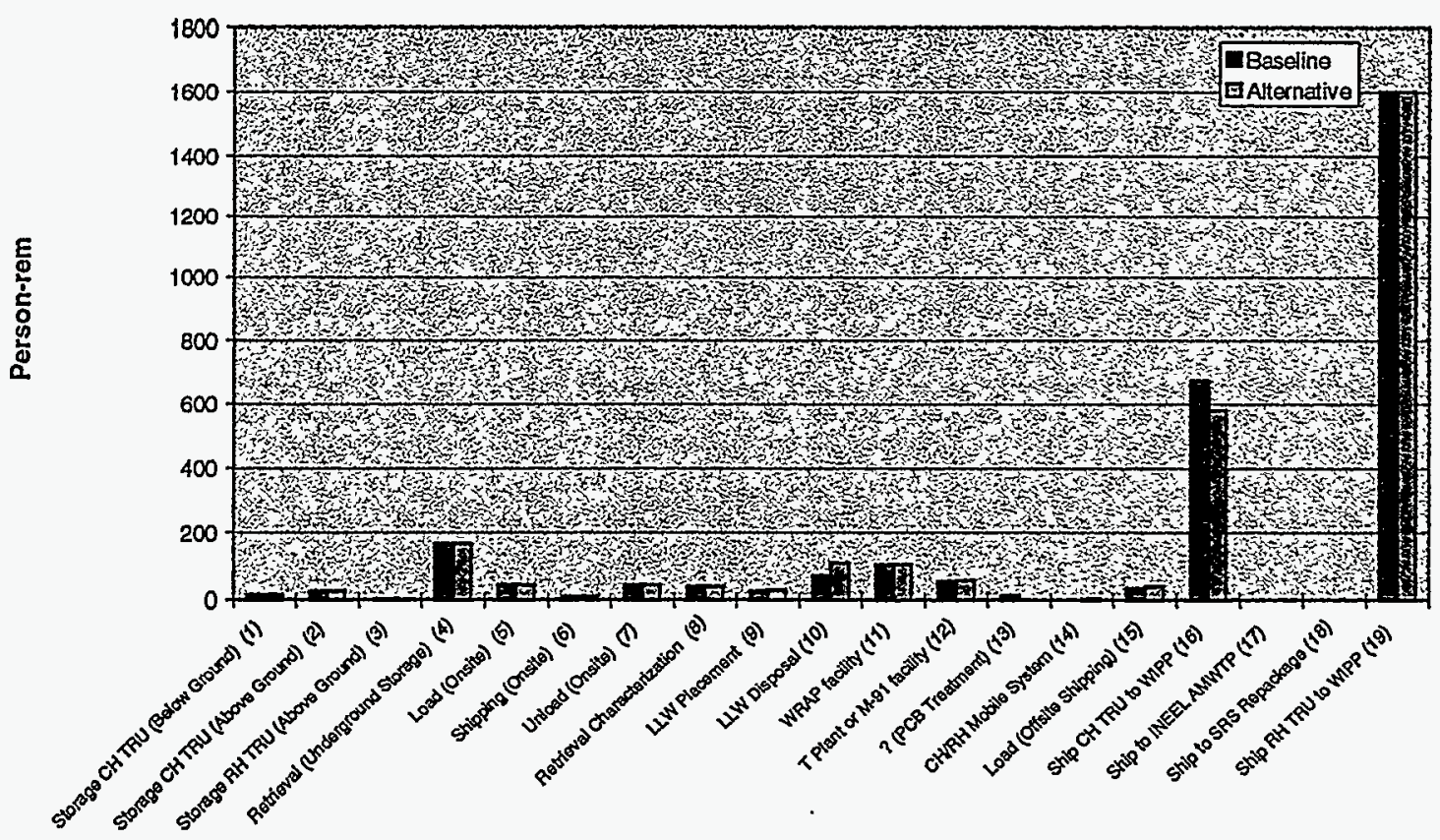

Figure 6-11. Hanford TRUW risk results by activity. 


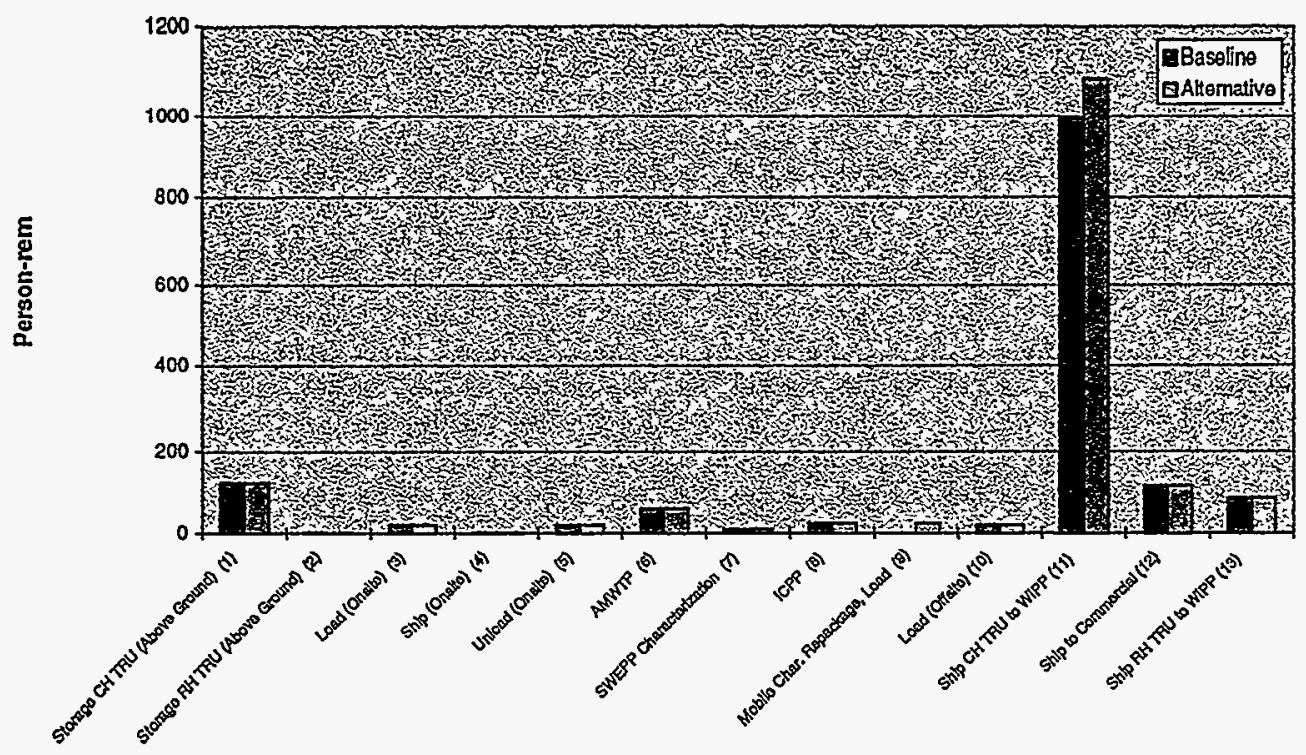

Figure 6-12. INEEL TRUW risk results by activity.

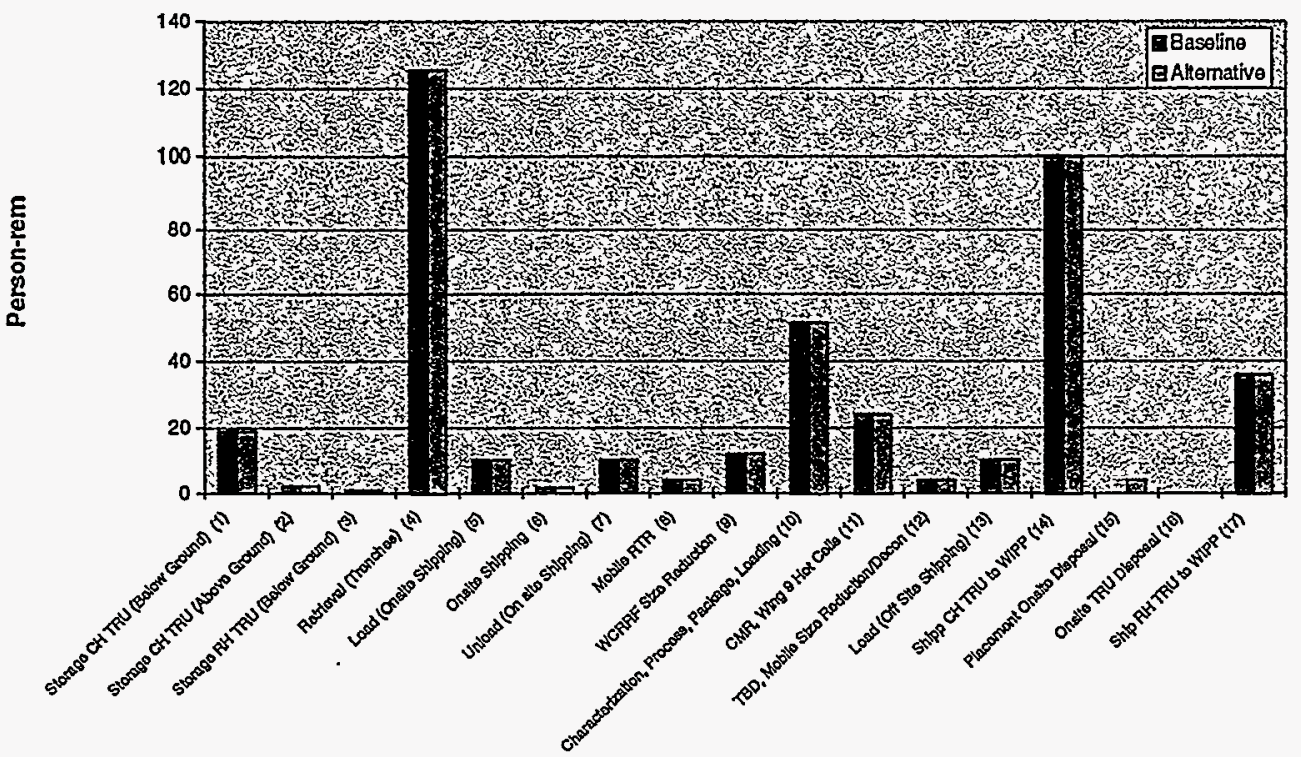

Figure 6-13. LANL TRUW risk results by activity. 


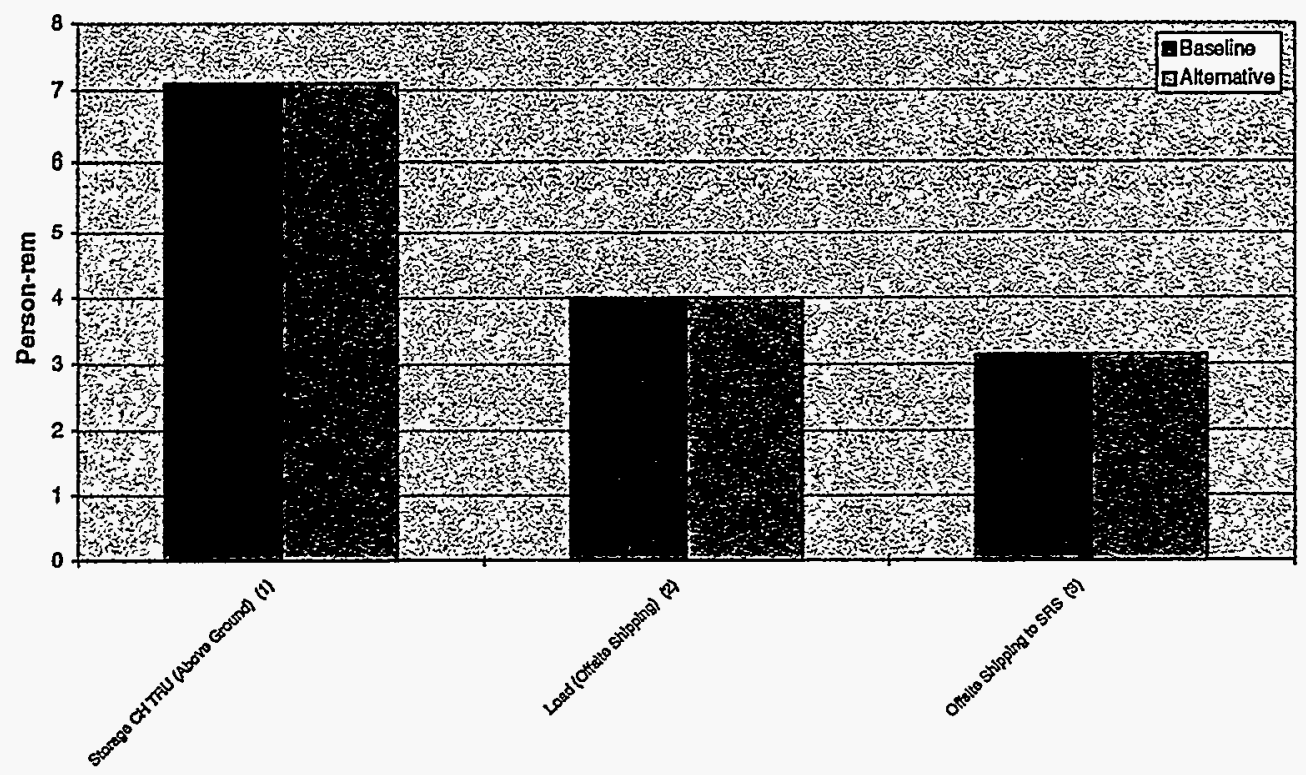

Figure 6-14. Mound TRUW risk results by activity.

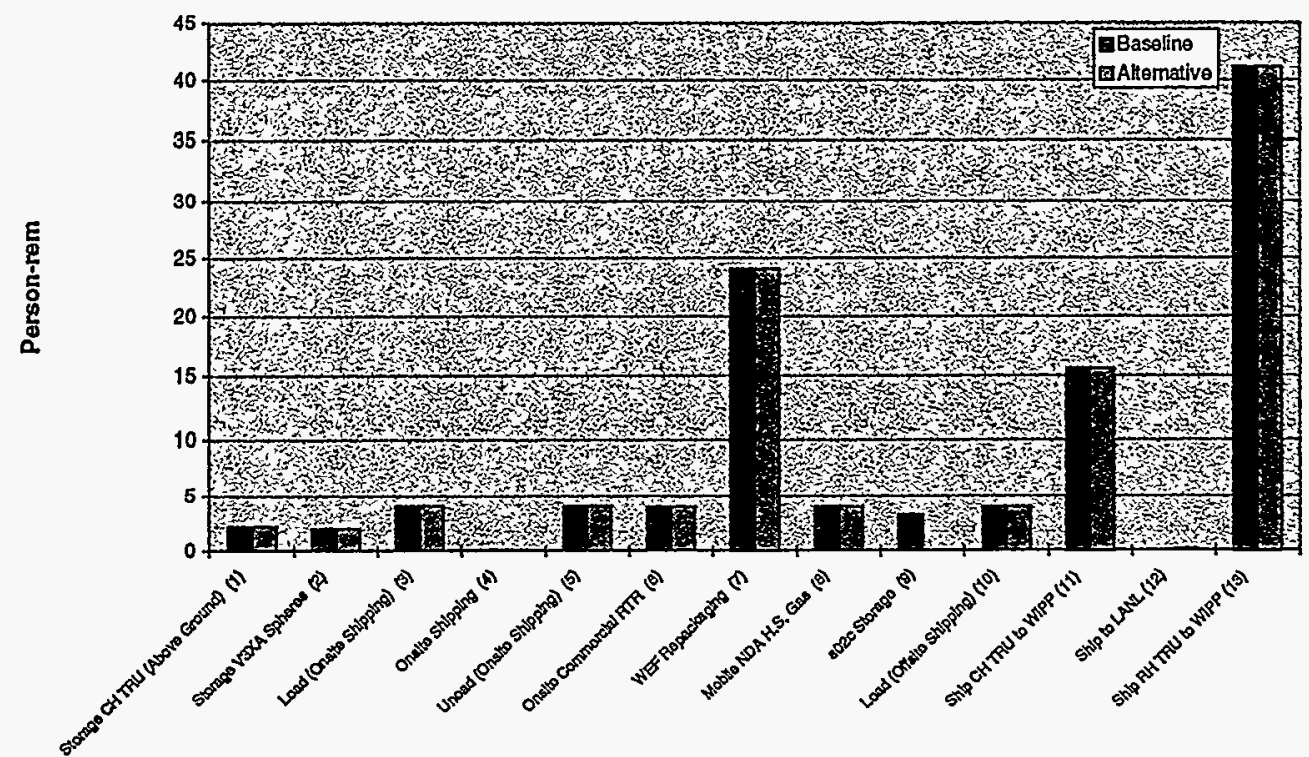

Figure 6-15. NTS TRUW risk results by activity. 


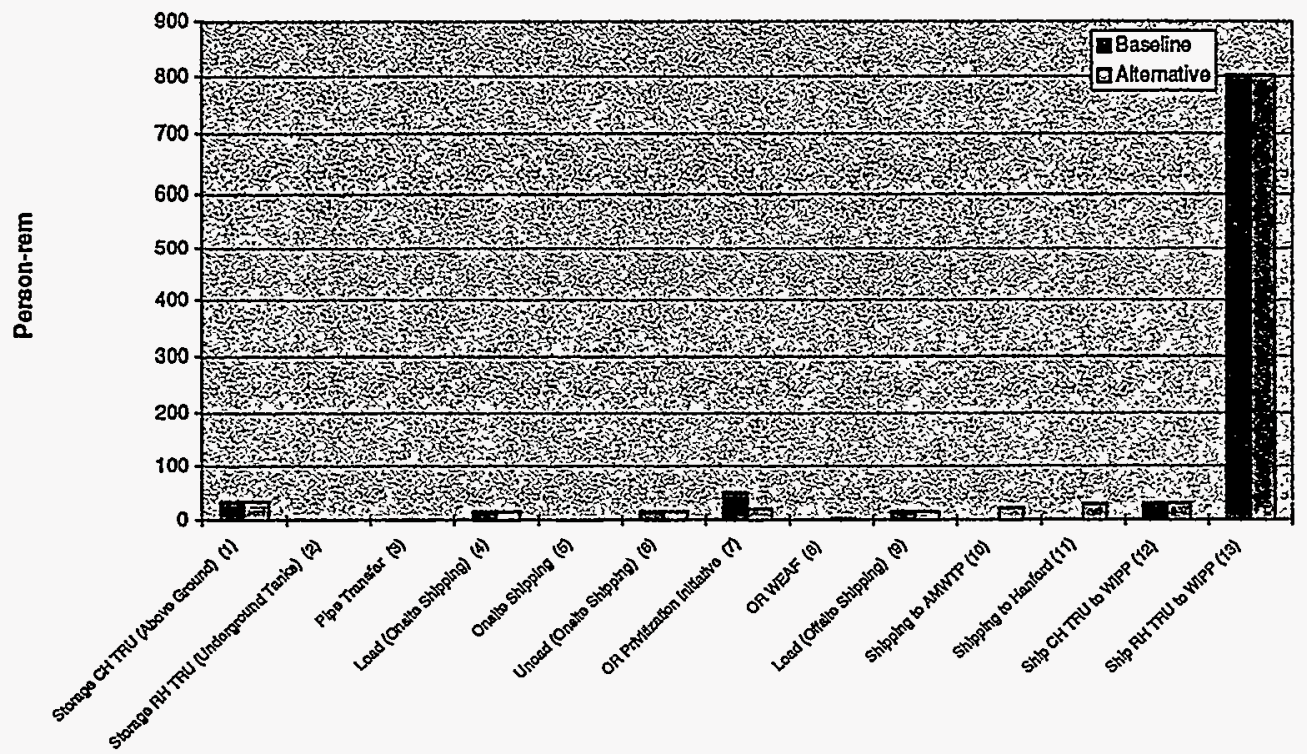

Figure 6-16. ORNL TRUW risk results by activity.

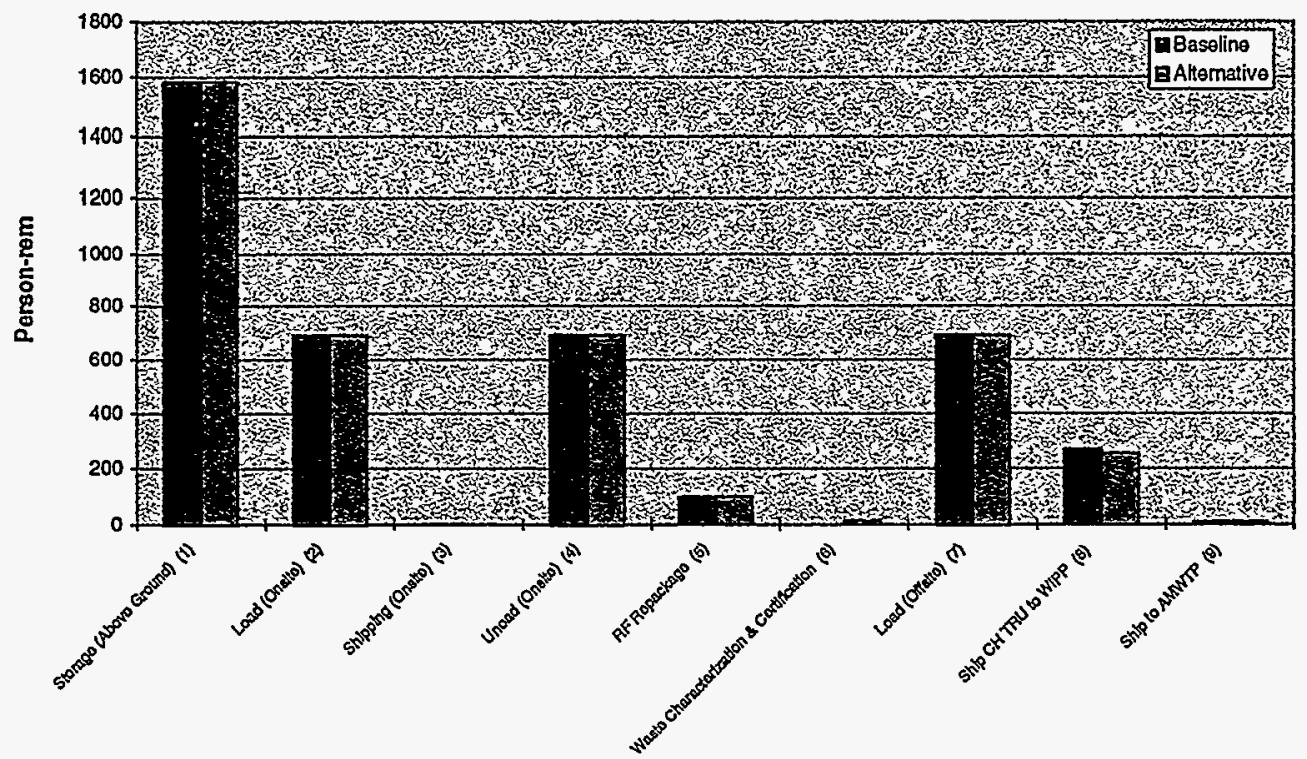

Figure 6-17. RFETS TRUW risk results by activity. 


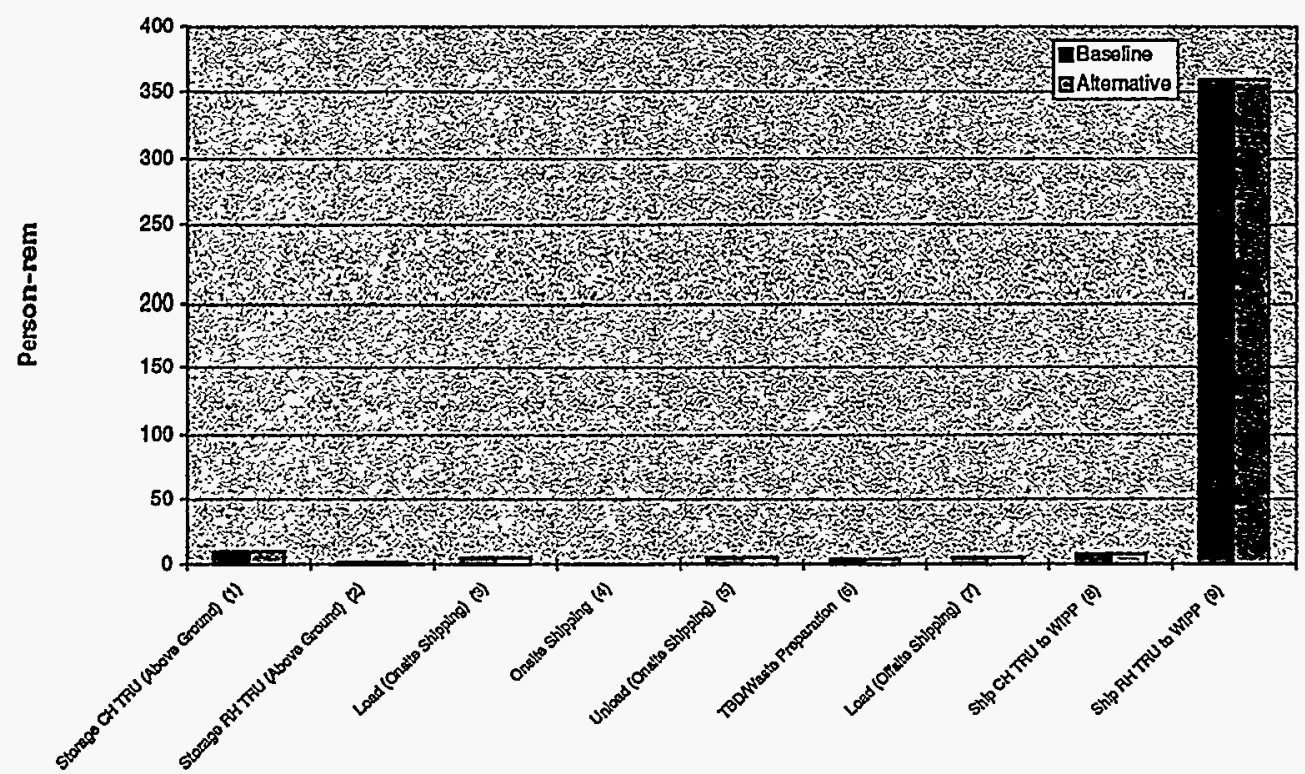

Figure 6-18. SQS TRUW risk results by activity.

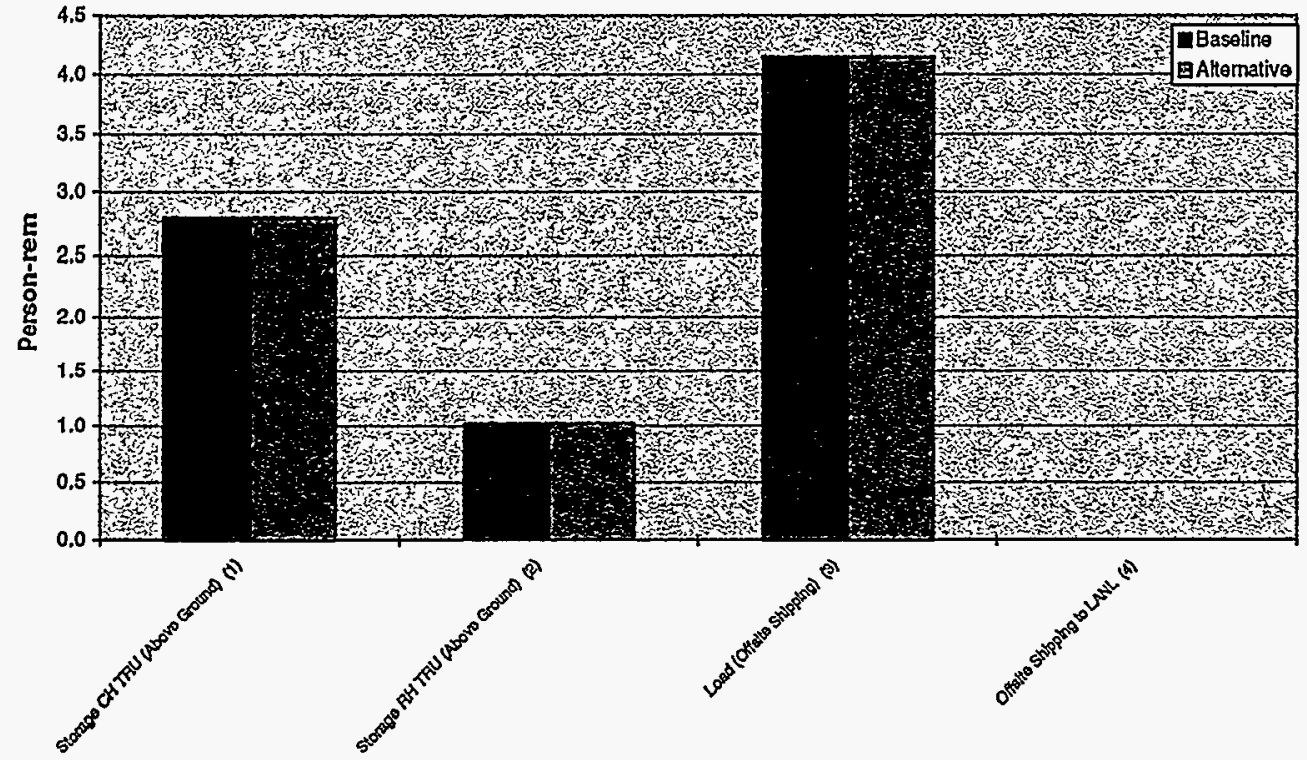

Figure 6-19. SNL TRUW risk results by activity. 


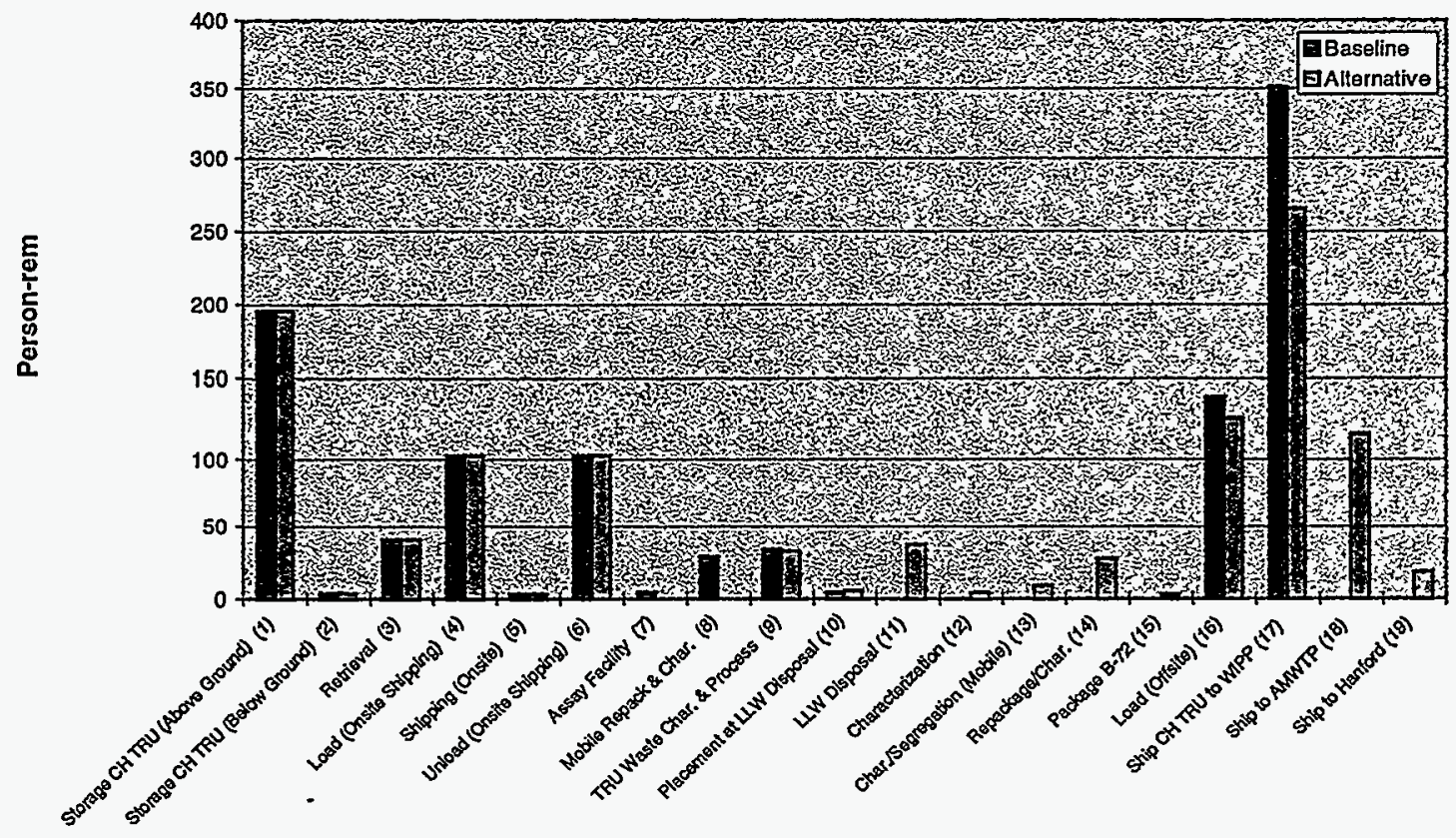

Figure 6-20. SRS TRUW risk results by activity.

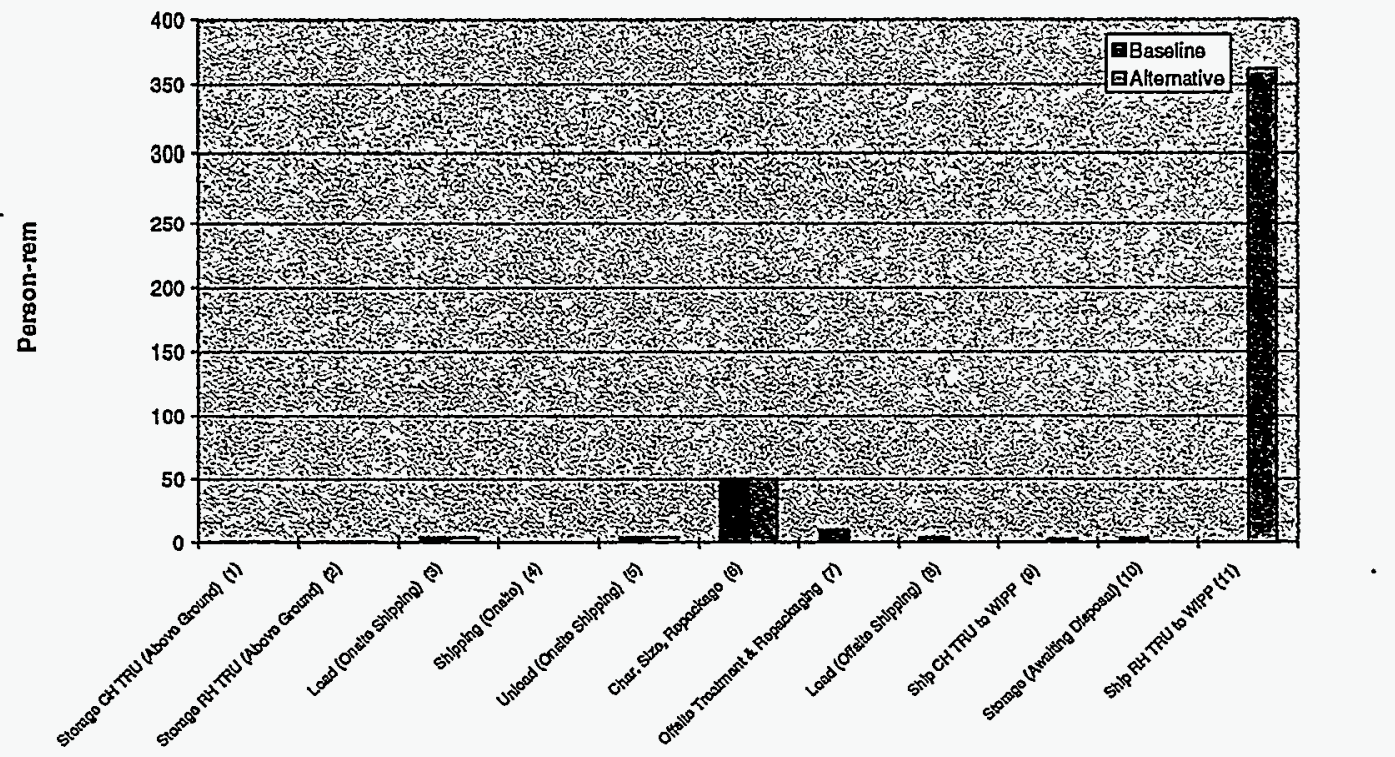

Figure 6-21. West Valley TRUW risk results by activity. 


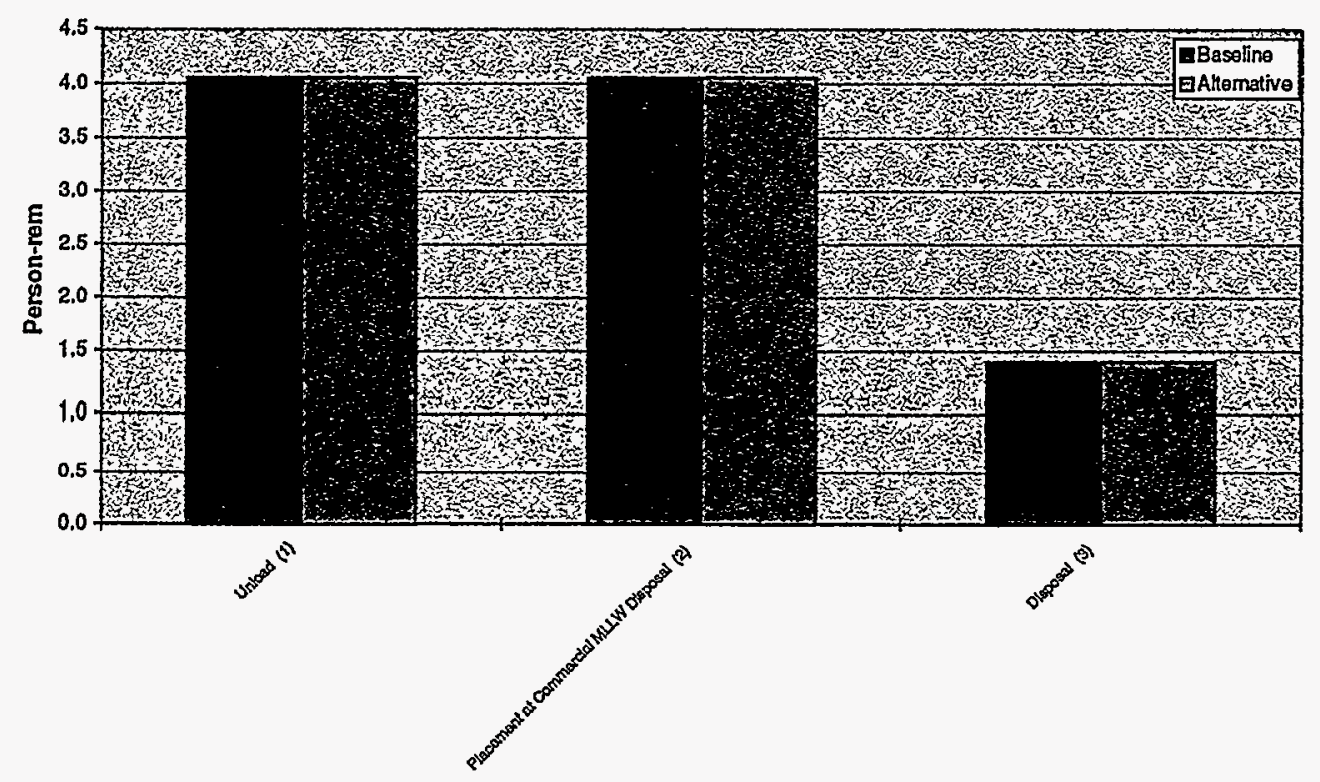

Figure 6-22. Commercial TRUW risk results by activity.

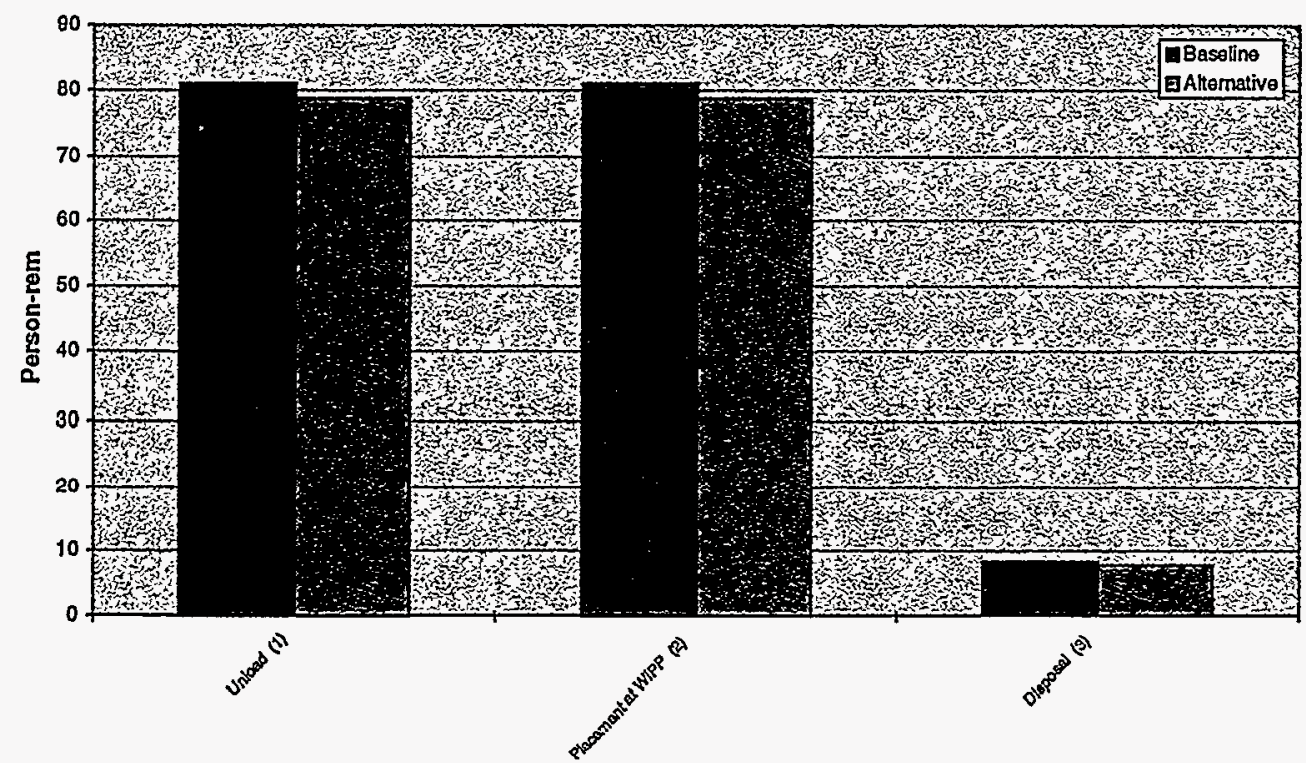

Figure 6-23. WIPP TRUW risk results by activity. 


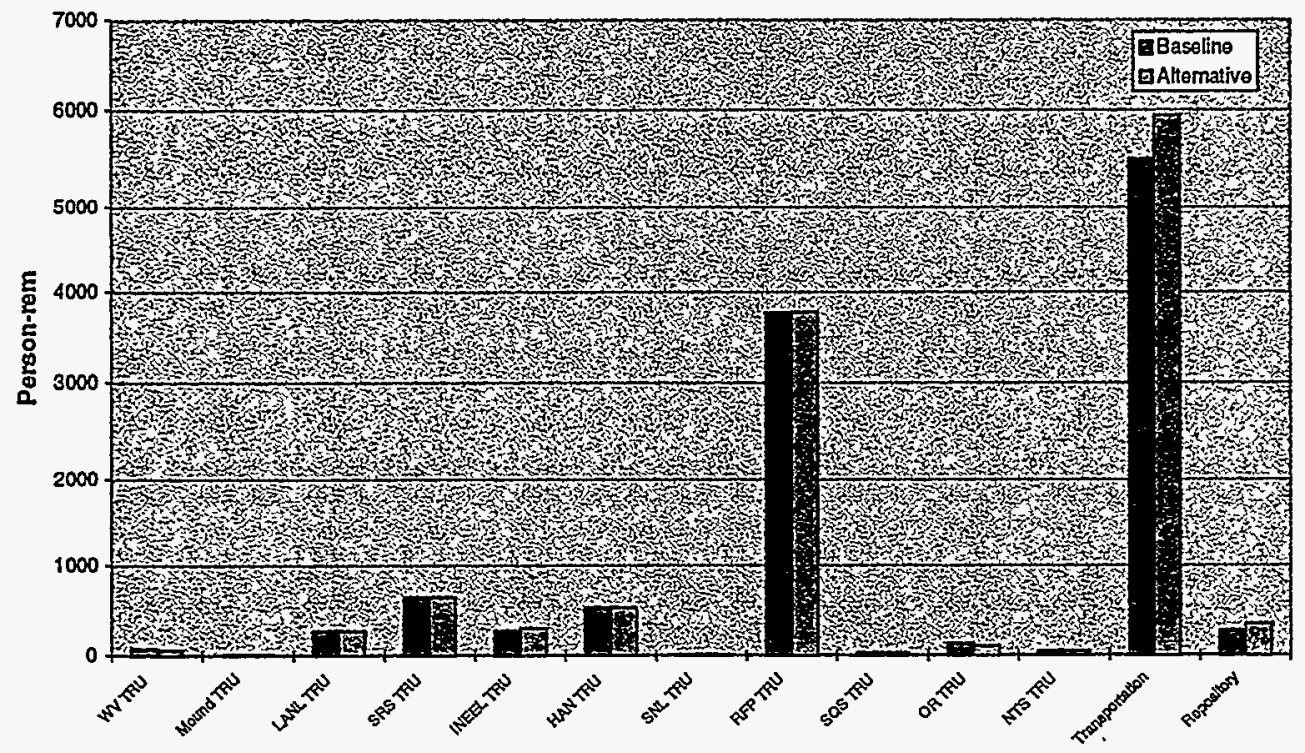

Figure 6-24. DOE TRUW risk results by site.

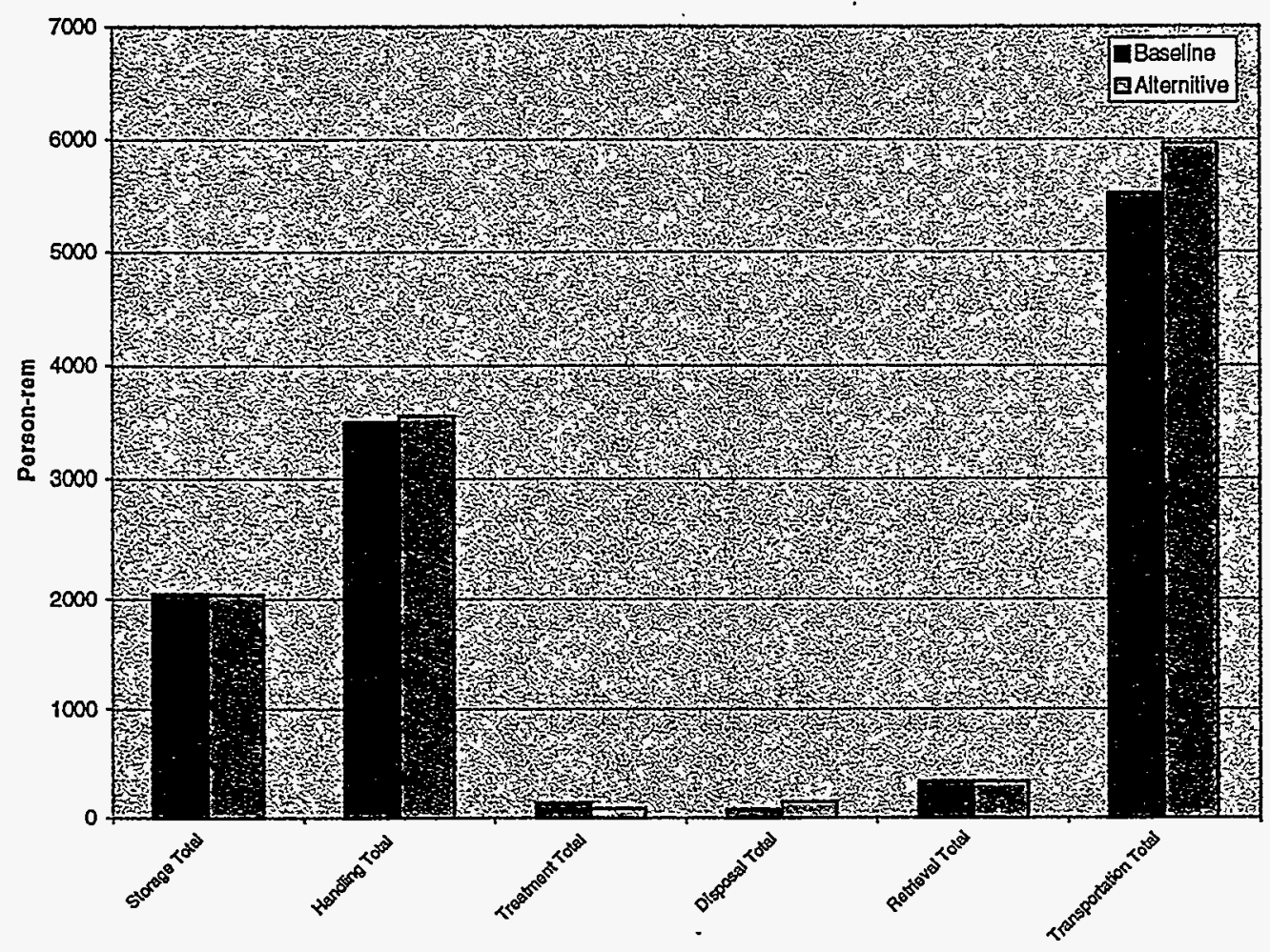

Figure 6-25. DOE complex-wide TRUW risk results by activity type. 


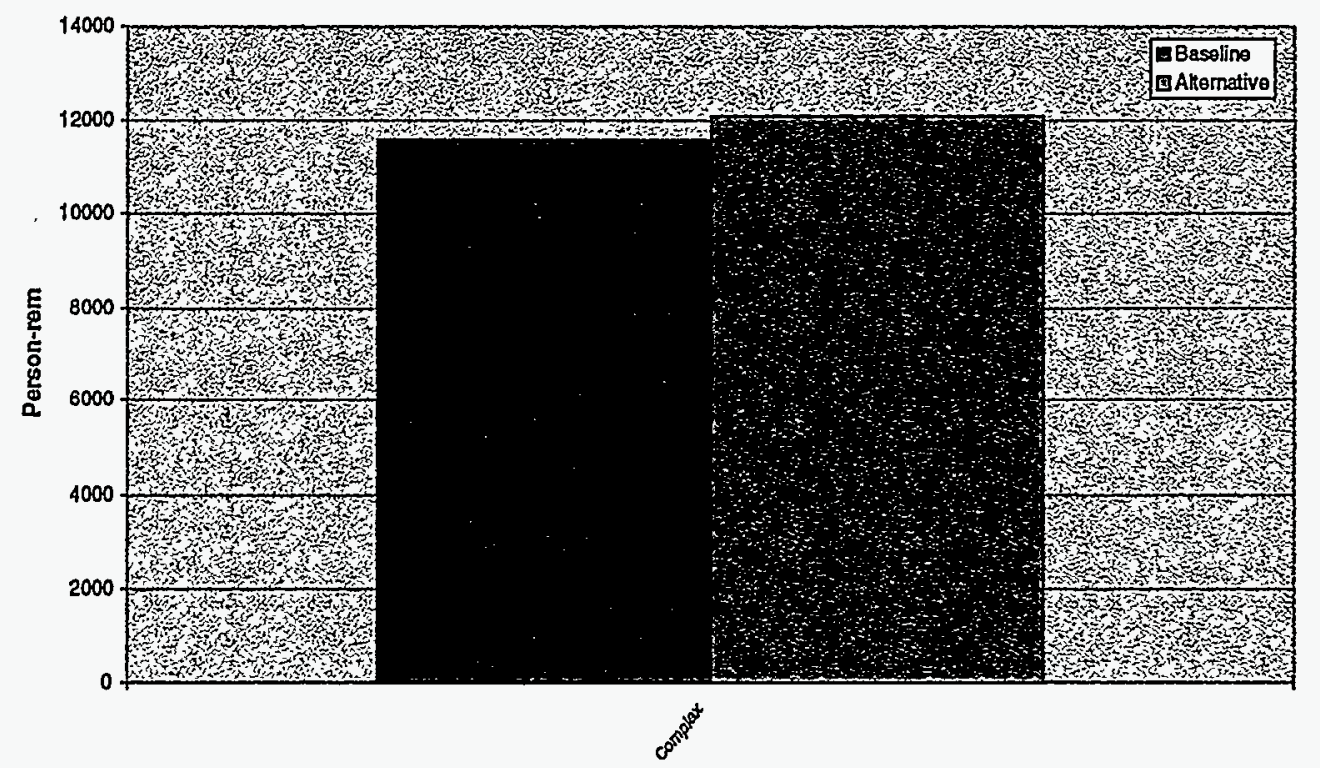

Figure 6-26. DOE complex-wide TRUW risk results.

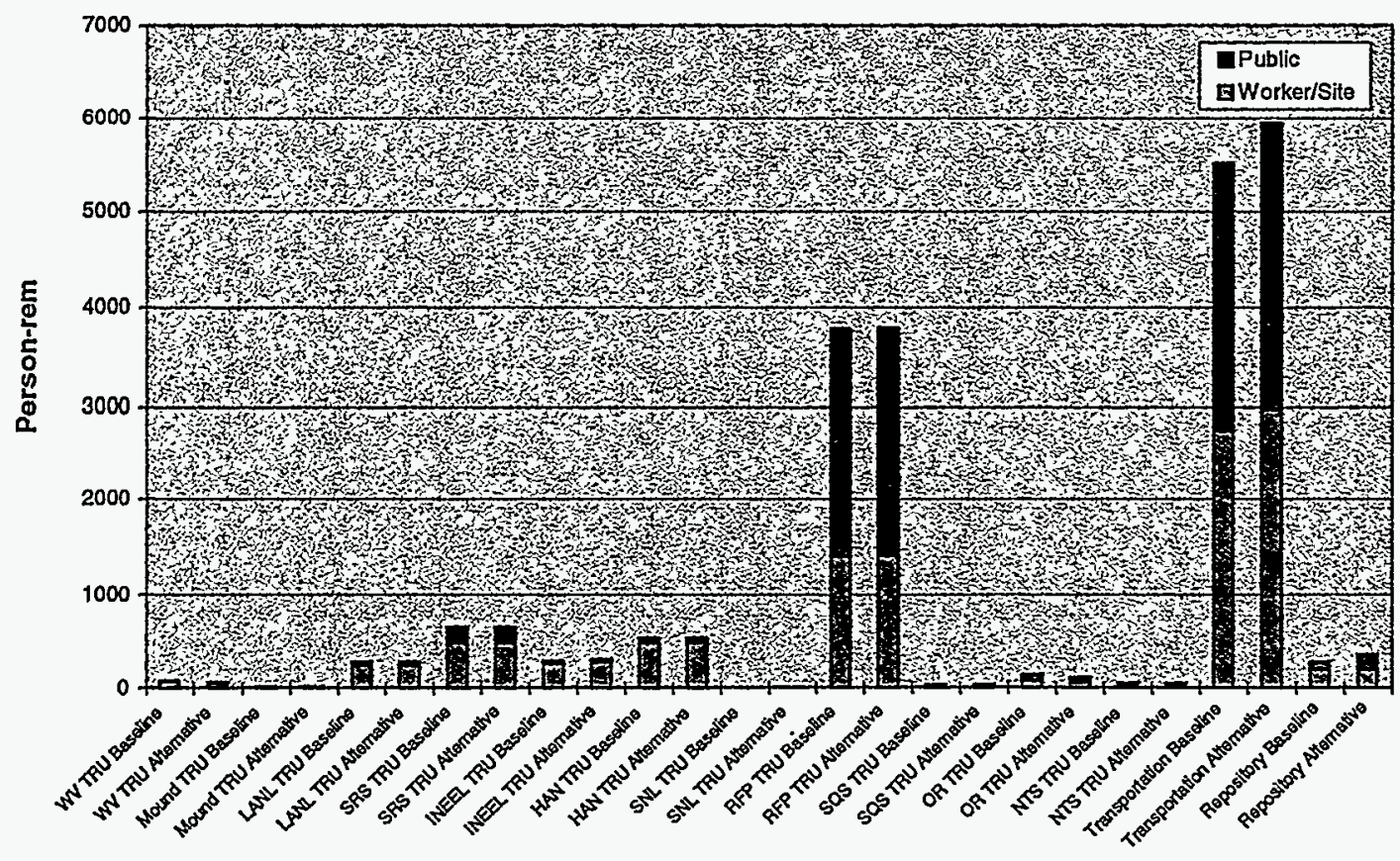

Figure 6-27. DOE TRUW risk results by site (worker/site versus public). 


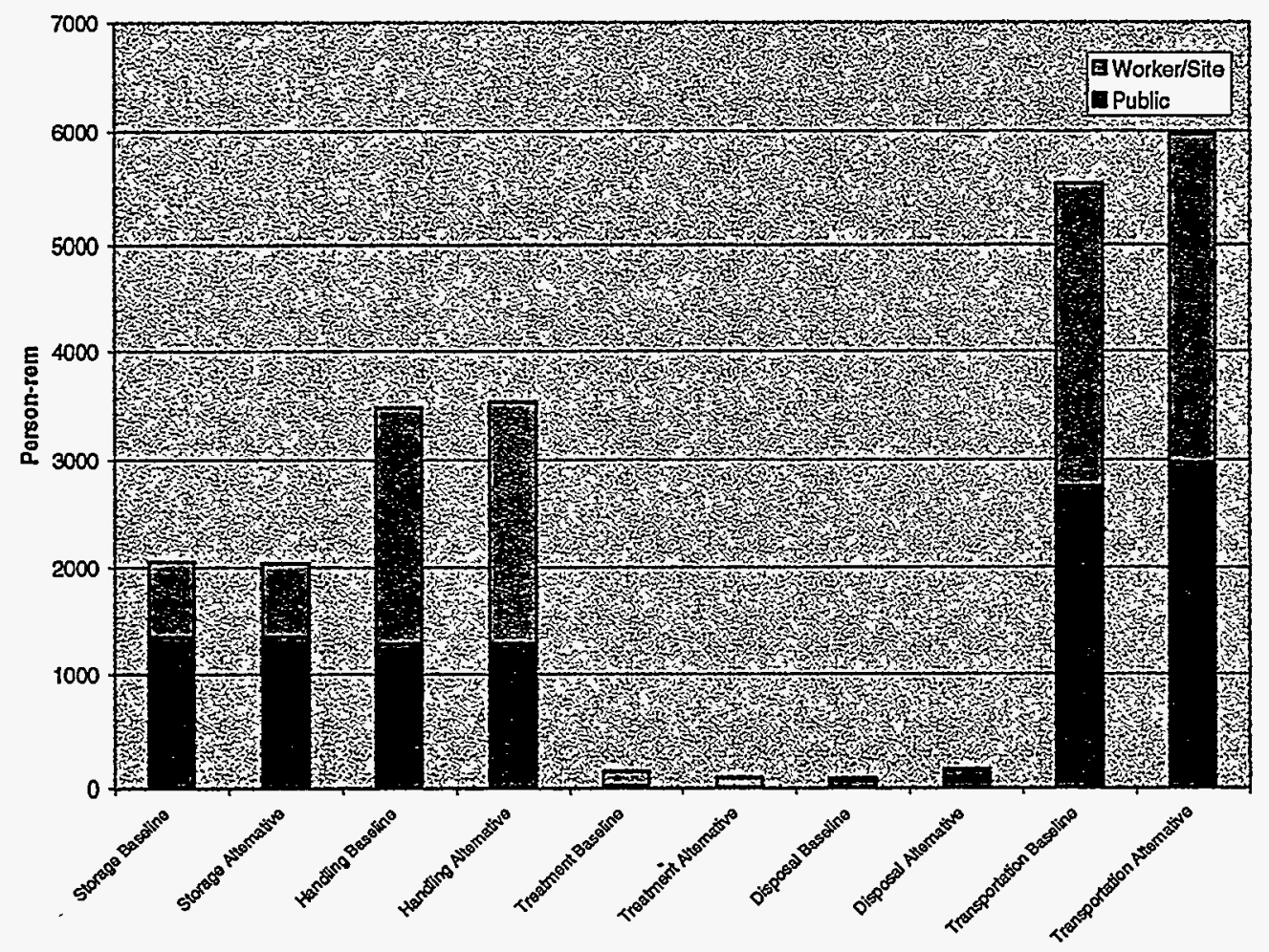

Figure 6-28. DOE complex-wide TRUW risk results by activity type (worker/site versus public).

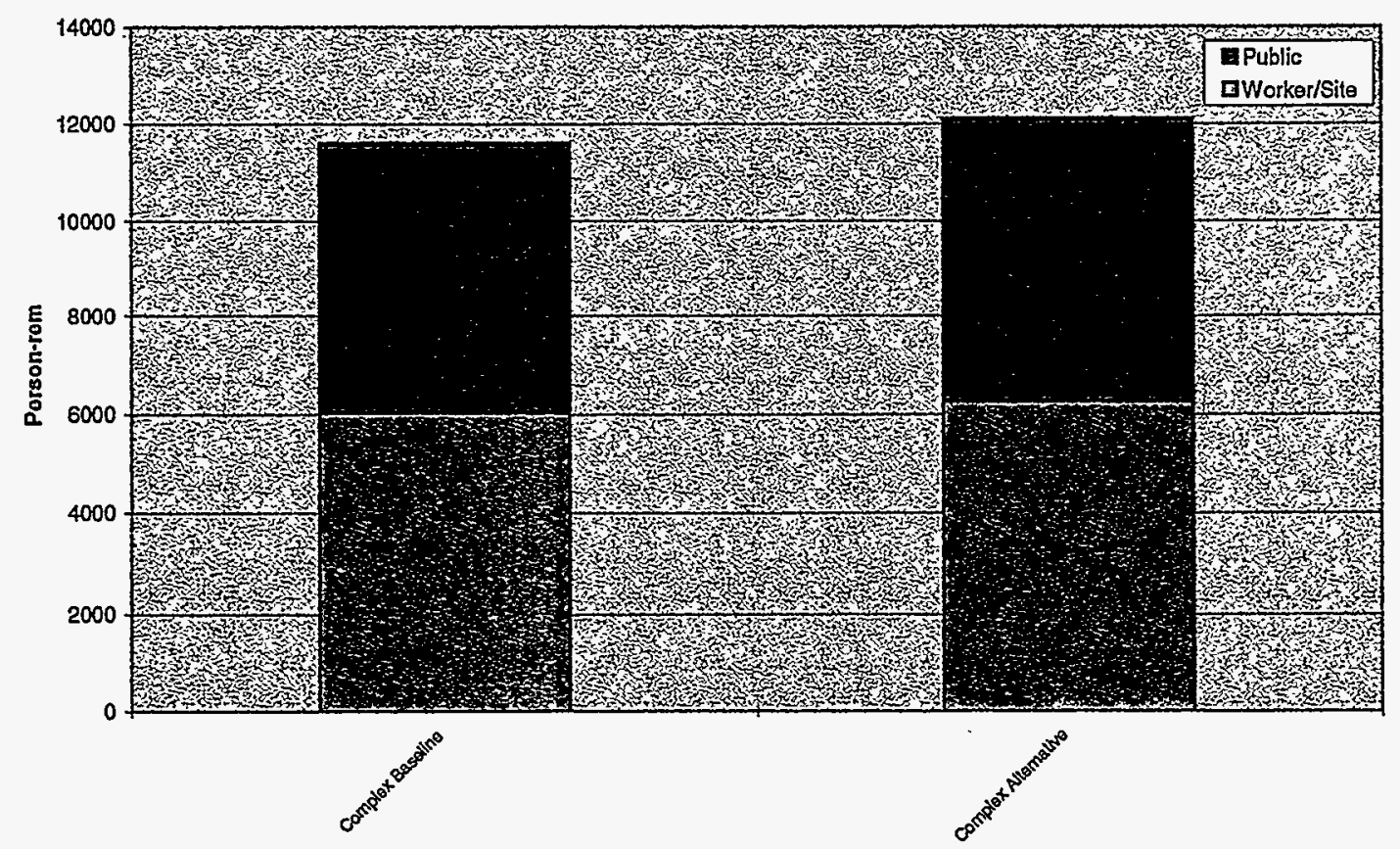

Figure 6-29. DOE complex-wide TRUW public and worker risk breakdown. 




Figure 6-30. DOE TRUW risk results by site (accident versus normal).

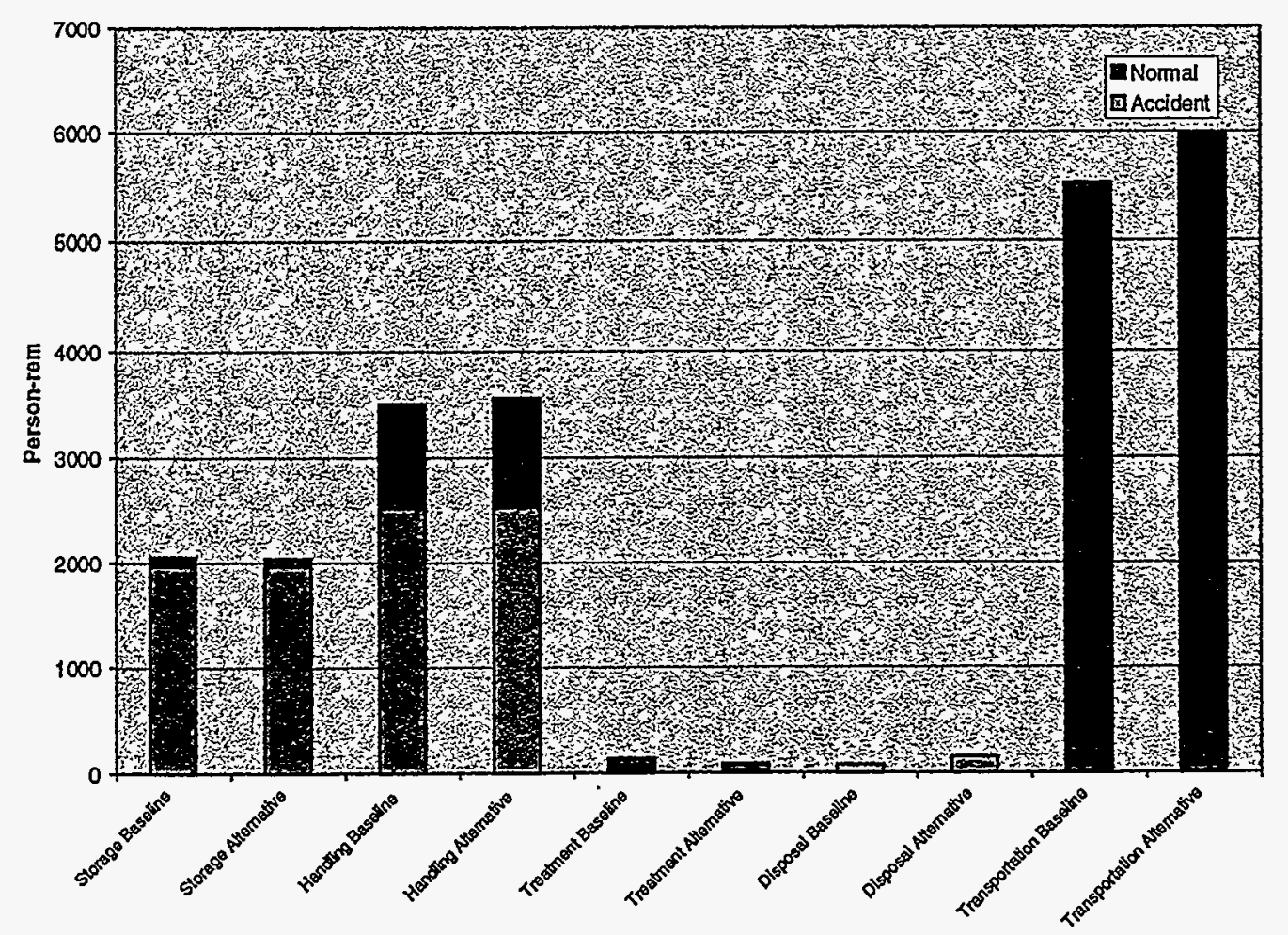

Figure 6-31. DOE complex-wide TRUW risk results by activity type (accident versus normal). 


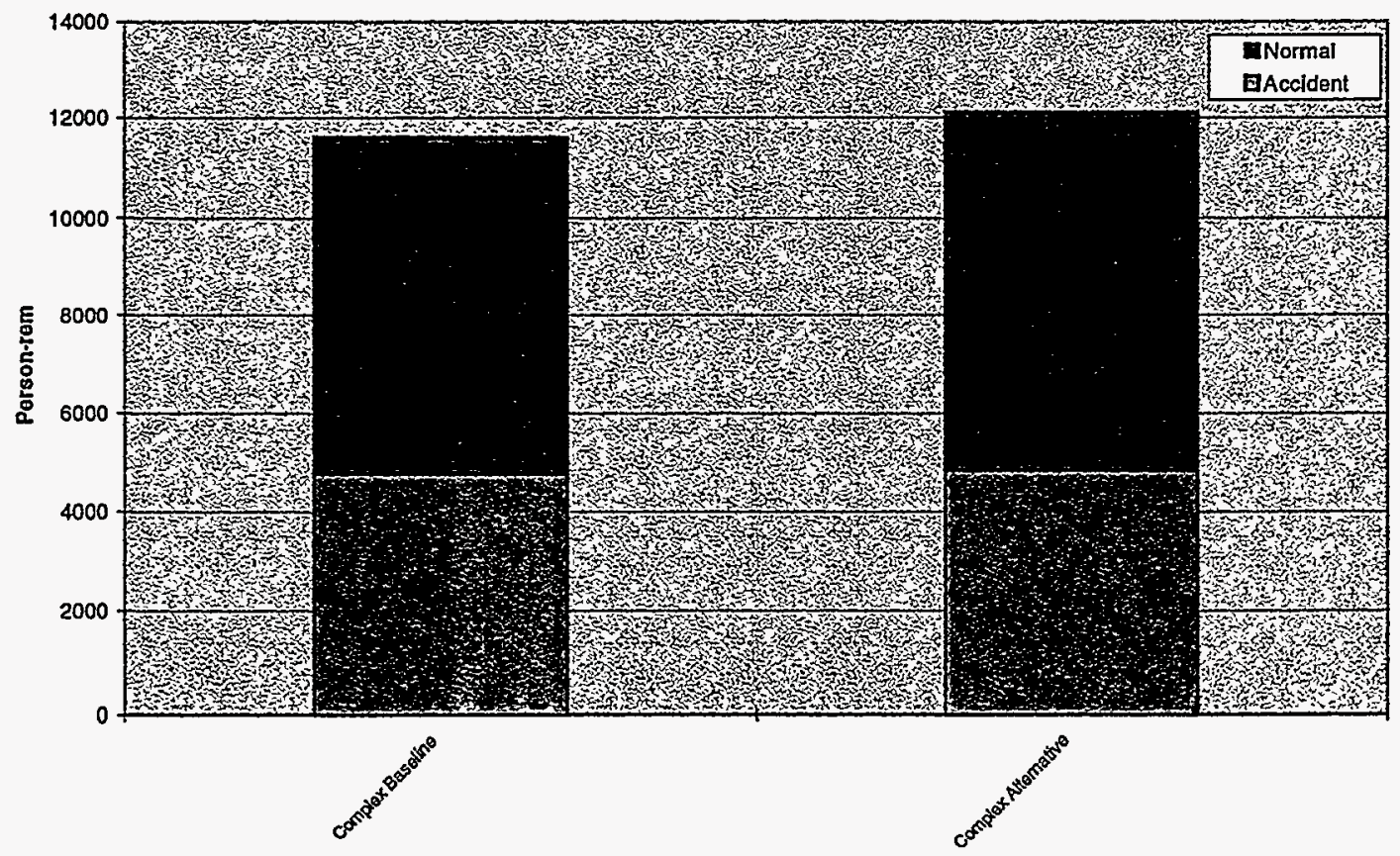

Figure 6-32. DOE complex-wide TRUW risk results (accident versus normal).

Because the SRM TRU model is computerized, sensitivity studies can be performed - relatively easily. In addition, if more opportunities are identified in the future, the SRM analyses can be performed efficiently. Finally, existing SRM TRU results can be broken down in many different ways to respond to questions from stakeholders.

The SRM risk results were compared with other risk estimate sources to ensure that the risk predictions are consistent with more detailed analyses. Comparisons were made with results from the Final Waste Management Programmatic Environmental Impact Statement (WM-PEIS) ${ }^{6}$ and the Savannah River Site Waste Management Final Environmental Impact Statement (SRSEIS). ${ }^{7}$ Table 6-2 shows the correlation between the other risk estimates and the SRM risk results.

In general, the limited comparisons discussed above indicate that the SRM is adequately predicting TRUW human health risk. However, the comparisons do not cover all parts of the SRM. An important contributor to SRM TRU risk is the exposure (radiological and chemical) of workers if accidents occur. Little information is available from more detailed risk assessments, so the SRM results in this area are not validated. Also, there is no detailed risk assessment of the entire DOE TRU baseline program, so no overall comparison can be made with the SRM results. 
Table 6-2. Comparison of SRM risk results with other sources.

\begin{tabular}{|c|c|c|c|c|c|c|c|}
\hline \multirow[b]{2}{*}{ Site } & \multirow[b]{2}{*}{ Activity } & \multicolumn{2}{|c|}{$\begin{array}{c}\text { Public } \\
\text { (person-rem) }\end{array}$} & \multicolumn{2}{|c|}{$\begin{array}{c}\text { Worker } \\
\text { (person-rem) }\end{array}$} & \multirow[b]{2}{*}{ Reference } & \multirow[b]{2}{*}{ Comments } \\
\hline & & Source & SRM & Source & $\mathrm{SRM}$ & & \\
\hline All & Transportation & 2940 & 2752 & 2890 & 2752 & $\begin{array}{l}\text { WM-PEIS, } \\
\text { page E-74 } \\
\text { (Region. } 2 \\
\text { Alternative) }\end{array}$ & $\begin{array}{l}\text { Both studies used } 3 \\
\text { mrem/hour (CH-TRUW) } \\
\text { and } 7 \text { mrem/hour (RH- } \\
\text { TRUW) for the shipping } \\
\text { cask dose rate. Doses are } \\
\text { based on routine operations. } \\
\text { Accidents are not } \\
\text { significant for } \\
\text { transportation. }\end{array}$ \\
\hline SRS & Waste Storage & - & - & 72.6 & 22 & $\begin{array}{l}\text { SRS EIS } \\
\text { page E-44 }\end{array}$ & $\begin{array}{l}\text { SRS value in reference is } \\
\text { an annual dose. Multiplied } \\
\text { by } 33 \text { years to correlate to } \\
\text { the SRM value. }\end{array}$ \\
\hline SRS & Retrieval & - & - & 8.8 & 40 & $\begin{array}{l}\text { SRS EIS } \\
\text { page E-44 }\end{array}$ & $\begin{array}{l}\text { SRS value in reference is } \\
\text { an annual dose. Multiplied } \\
\text { by } 10 \text { years to correlate to } \\
\text { the SRM value. }\end{array}$ \\
\hline SRS & Characterization & 4.19 & 3 & 83.6 & 20 & $\begin{array}{l}\text { SRS EIS } \\
\text { page E-44 } \\
\text { and page } \\
\text { E-46 }\end{array}$ & $\begin{array}{l}\text { SRS value in reference is } \\
\text { an annual dose. Multiplied } \\
\text { by } 10 \text { years to correlate to } \\
\text { the SRM value. }\end{array}$ \\
\hline
\end{tabular}




\section{LOW LEVEL WASTE ANALYSIS}

DOE LLW is presently stored at 27 sites, of which nine were the focus of the LLW alternatives development. The nine sites are Fernald, Hanford, INEEL, LANL, ORNL, RFETS, SNL, SRS, and WVDP. DOE plans to consolidate LLW disposal operations by sending waste to the NTS and Hanford, providing a final disposition path for special case LLW, and minimizing storage and treatment of LLW by direct disposal and processing the waste only when cost effective or required. The baseline program and alternative for $L L W$ for each of the nine sites are outlined in the disposition maps presented in Figures 7-1 through 7-9. The baseline disposition maps for the nine sites show the process by which the stored LLW is retrieved (if applicable), processed for shipment (when necessary), and sent for disposal. The alternatives involve less processing, off-site disposal of LLW (when necessary) at Hanford or the NTS, schedule changes and other activities.

The SRM model was developed by subdividing the disposition map boxes into activities (risk states) such as storage, retrieval, loading and unloading, on-site and off-site transport, various types of waste processing steps and disposal. The subdivision of the disposition maps into activities is shown in Figures 7-1 through 7-9, where the numbers in the parentheses refer to specific activities in question. Figures 7-10 through 7-18 list the specific activities for each site.

The SRM requires knowledge of the radionuclide curie and chemical flow through the disposition maps. The curie information was generally obtained from the report Integrated Database Report - 1995: U. S. Spent Nuclear Fuel and Radioactive Waste Inventories, Projections, and Characteristics. ${ }^{5}$ Initial curie totals for each of the four sites are shown in Table 7-1. Additional information required for the SRM, such as waste form, types of on-site and off-site transport, and schedules were obtained from the subject matter experts. In cases where information was not available, assumptions were made. Chemicals were not modeled due to lack of available information.

Table 7-1. DOE site LLW radiological and chemical inventory estimates.

\begin{tabular}{lccl}
\hline \multicolumn{1}{c}{ Site } & Actinides $(\mathrm{Ci})$ & Nonactinides $(\mathrm{Ci})$ & Chemicals $(\mathrm{kg})$ \\
\hline Fernald & $4.1 \mathrm{E}+1$ & $7.9 \mathrm{E}+3$ & Not modeled \\
Hanford & $2.2 \mathrm{E}+4$ & $4.5 \mathrm{E}+6$ & Not modeled \\
INEEL & $2.6 \mathrm{E}+5$ & $4.2 \mathrm{E}+6$ & Not modeled \\
LANL & $5.3 \mathrm{E}+3$ & $1.1 \mathrm{E}+6$ & Not modeled \\
RFETS & $4.6 \mathrm{E}+3$ & $9.1 \mathrm{E}+5$ & Not modeled \\
ORNL & $9.9 \mathrm{E}+2$ & $2.0 \mathrm{E}+5$ & Not modeled \\
SNL & $1.0 \mathrm{E}+1$ & $2.0 \mathrm{E}+3$ & Not modeled \\
SRS & $1.2 \mathrm{E}+3$ & $2.3 \mathrm{E}+5$ & Not modeled \\
WV & $8.5 \mathrm{E}+3$ & $1.7 \mathrm{E}+6$ & Not modeled \\
\hline
\end{tabular}

SRM human health risk results (person-rem) for activities at each of the nine DOE sites are presented in Figures 7-10 through 7-18. Each figure shows the baseline program and the alternative. Examination of the results indicates that for $L L W$, off-site transportation, treatment and unloading and placement associated with disposal are generally high risk activities relative to other activities such as storage of LLW, loading LLW and unloading (not for disposal) LLW. It should be noted that the activities modeled for each site present all of the important steps in the baseline program (or alternative), from initial storage through final disposal. 

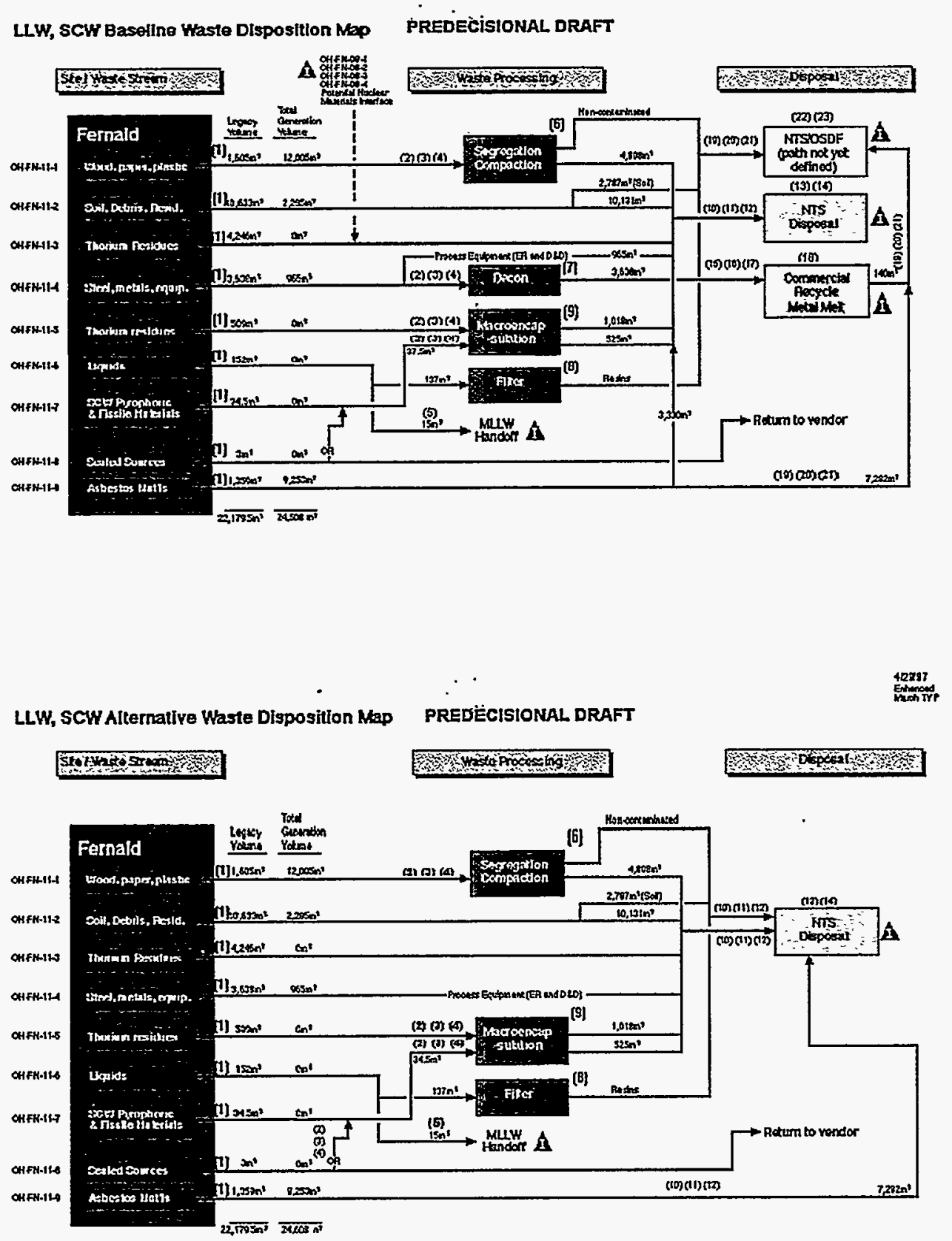

Figure 7-1. Fernald LLW disposition maps (baseline and alternative). 

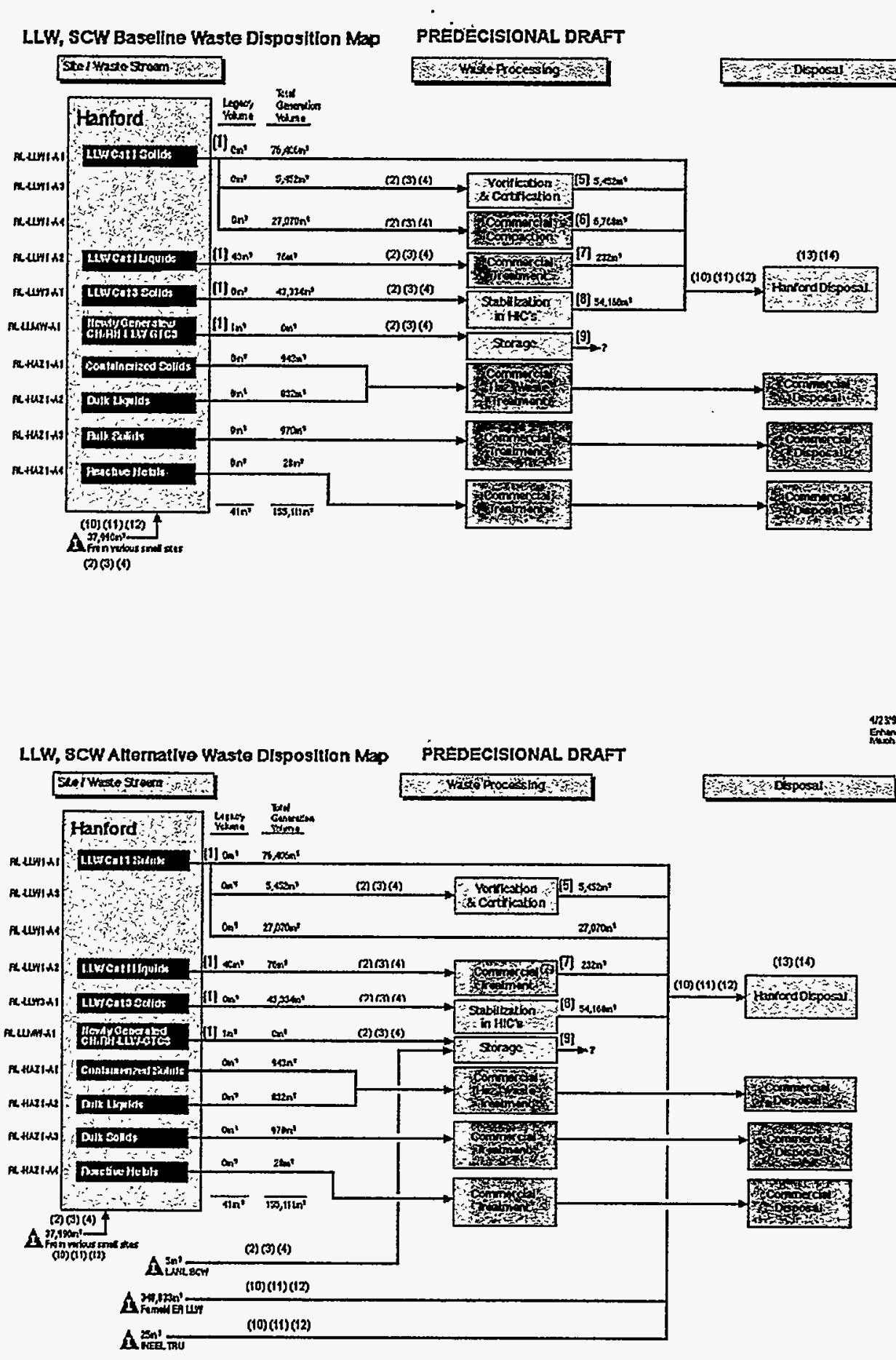

Figure 7-2. Hanford LLW disposition maps (baseline and alternative) 
LLW Enhanced March Baselina Waste Disposition Map
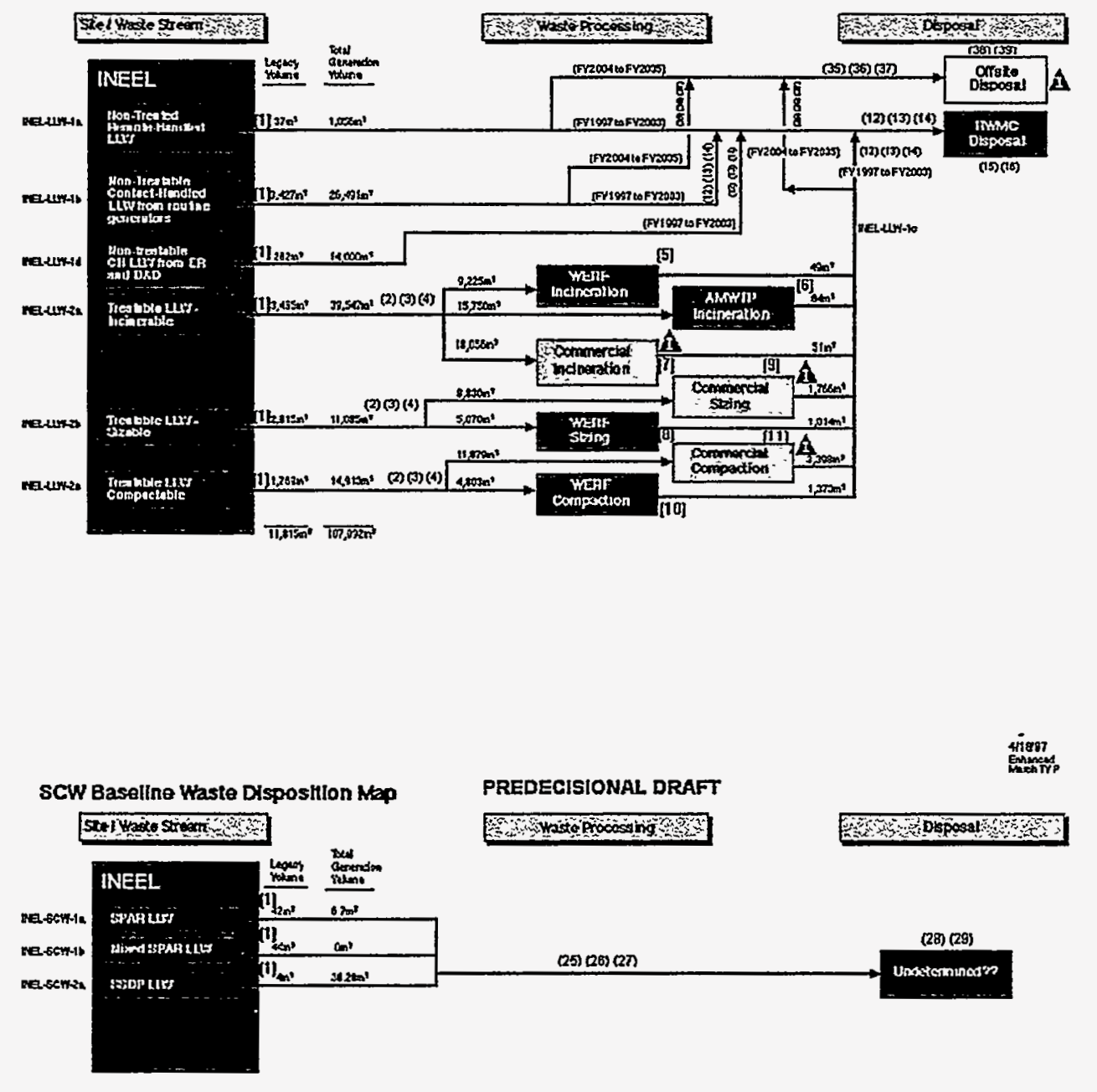

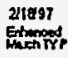

Figure 7-3. INEEL LLW disposition maps (baseline and alternative). 
LLW ALTERNATIVE WASTE DISPOSITION MAP
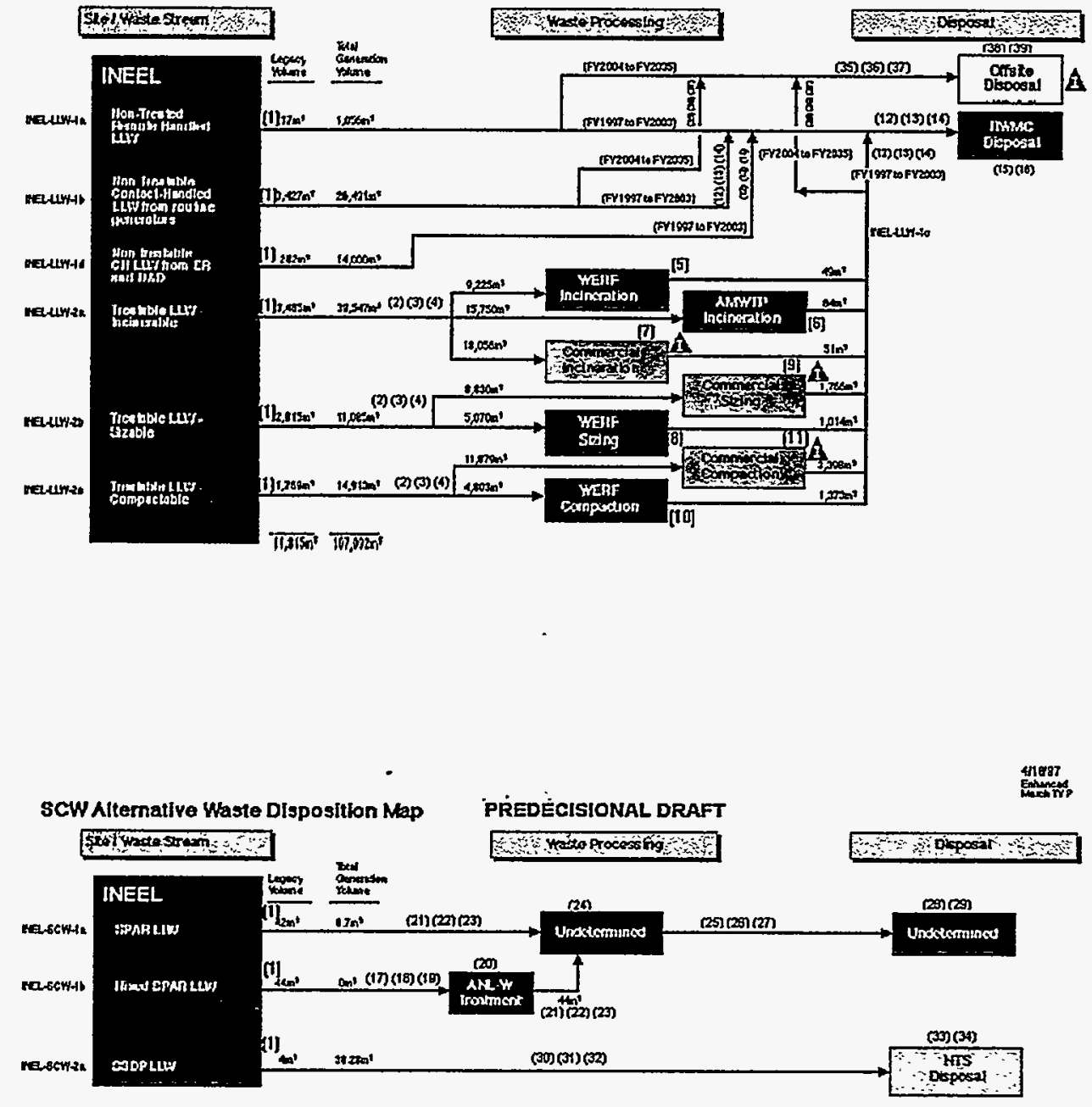

Figure 7-3. INEEL LLW disposition maps (baseline and alternative) (continued). 
LLW, SCW Baseline Waste DIsposition Map PRĖDECISIONAL DRAFT

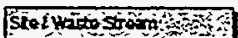

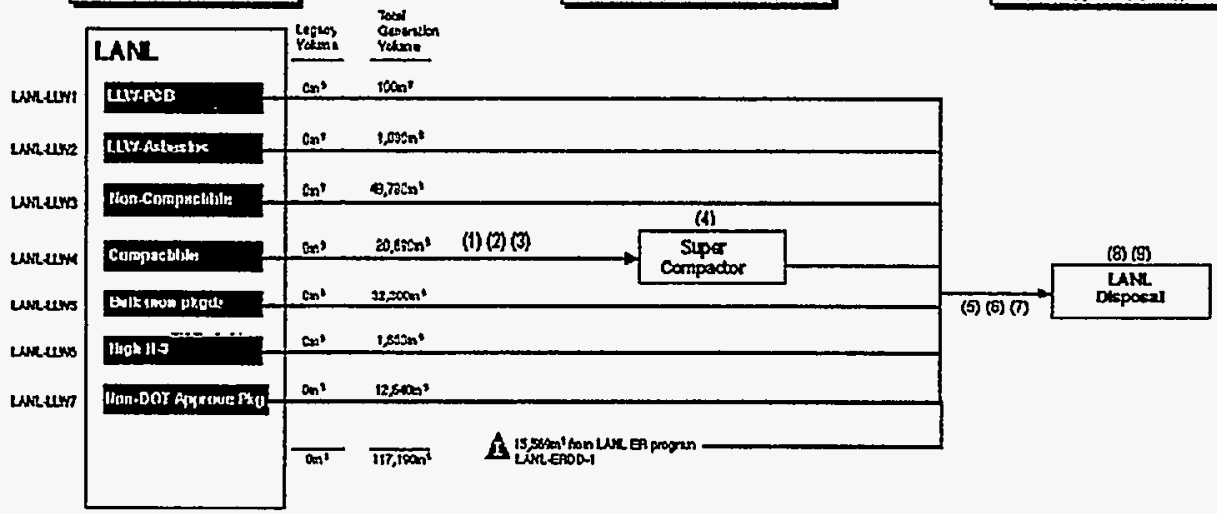

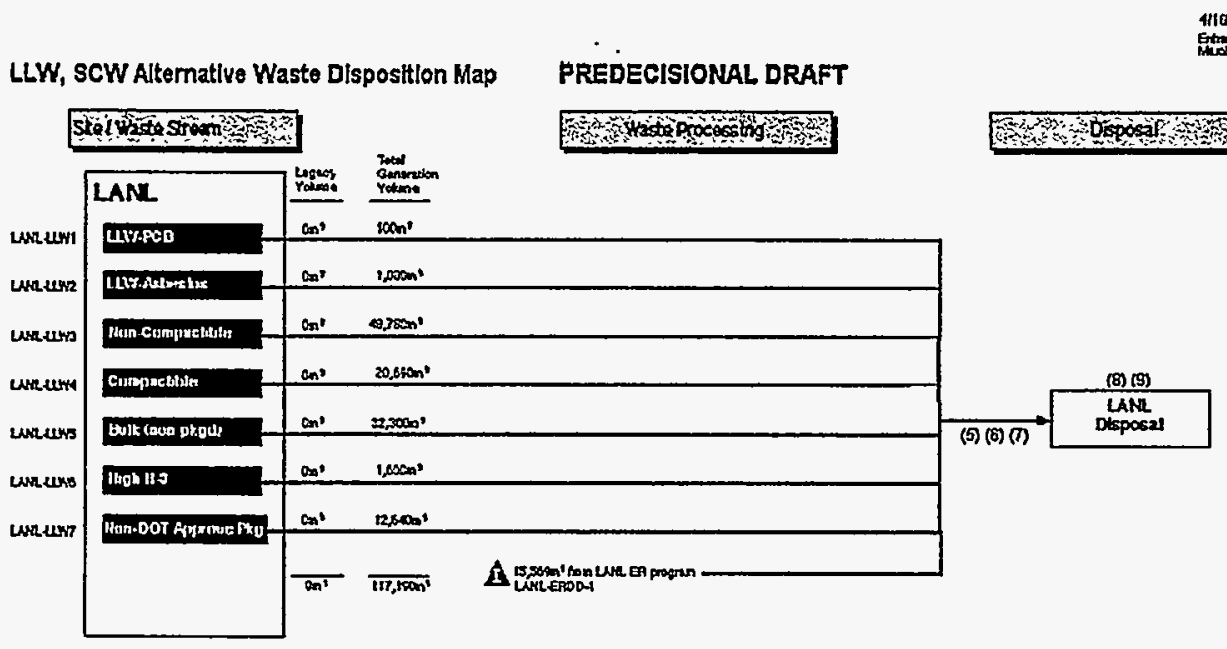

Figure 7-4. LANL LLW disposition maps (baseline and alternative). 

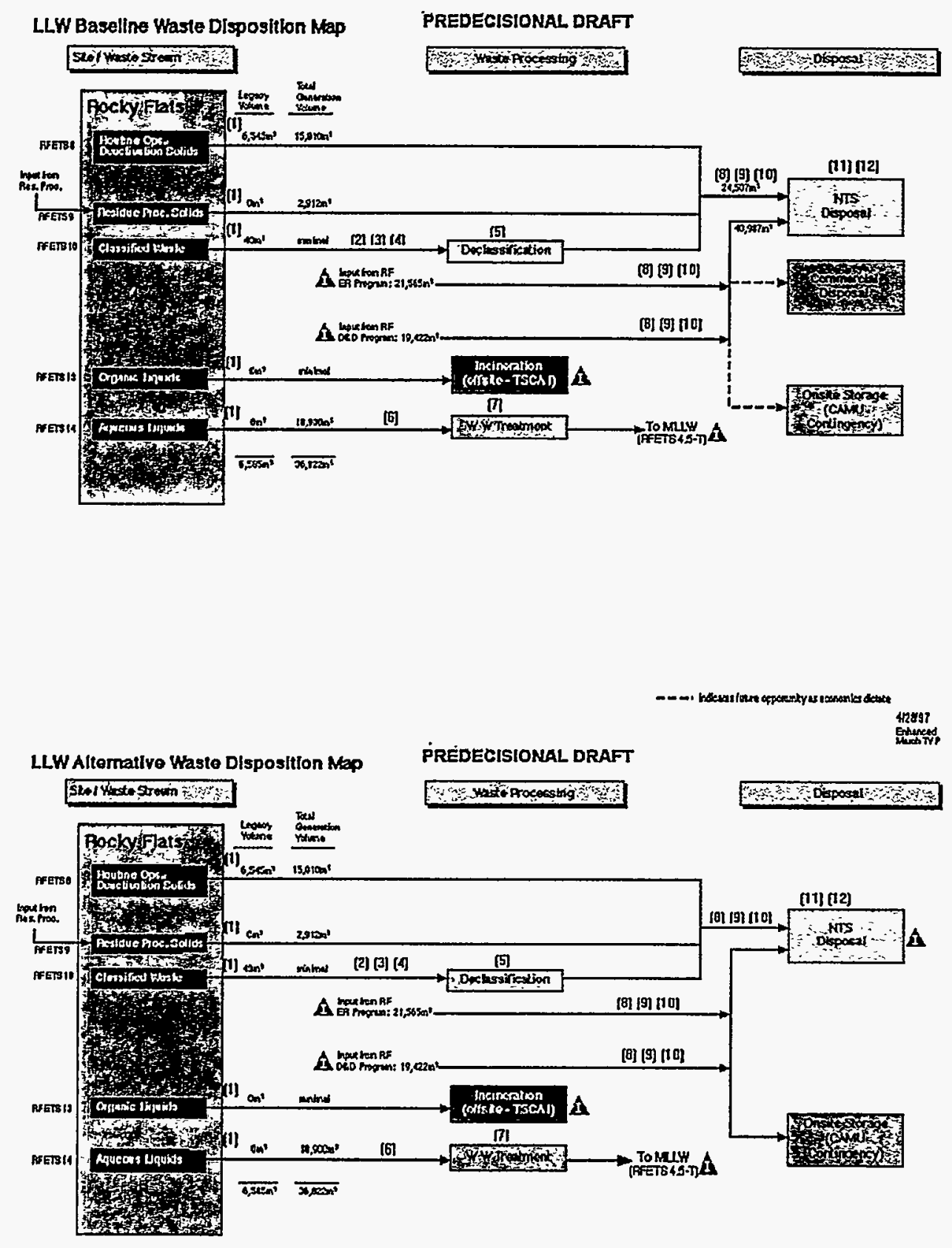

Figure 7-5. RFETS LLW disposition maps (baseline and alternative). 


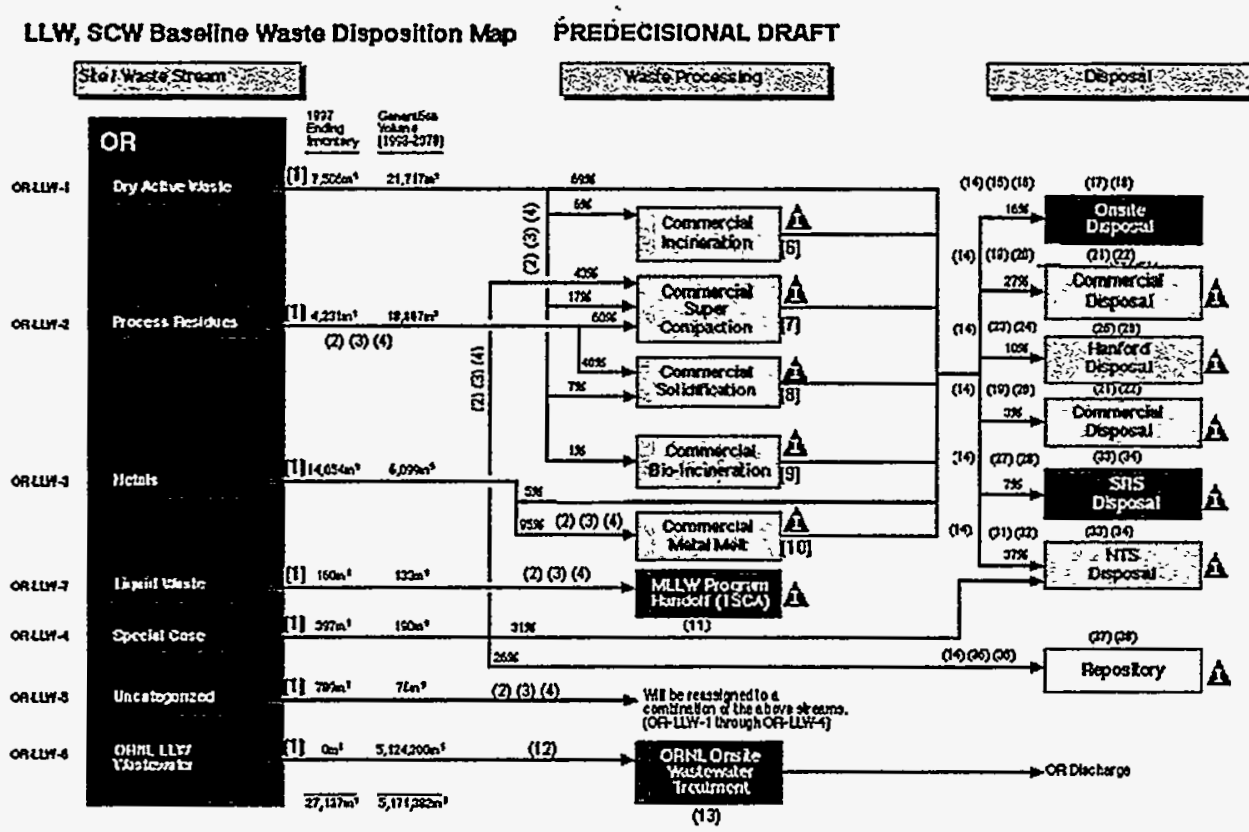

LW, SCW Allernalive Waste Disposition Nap PREDECISIONAL DRAFT

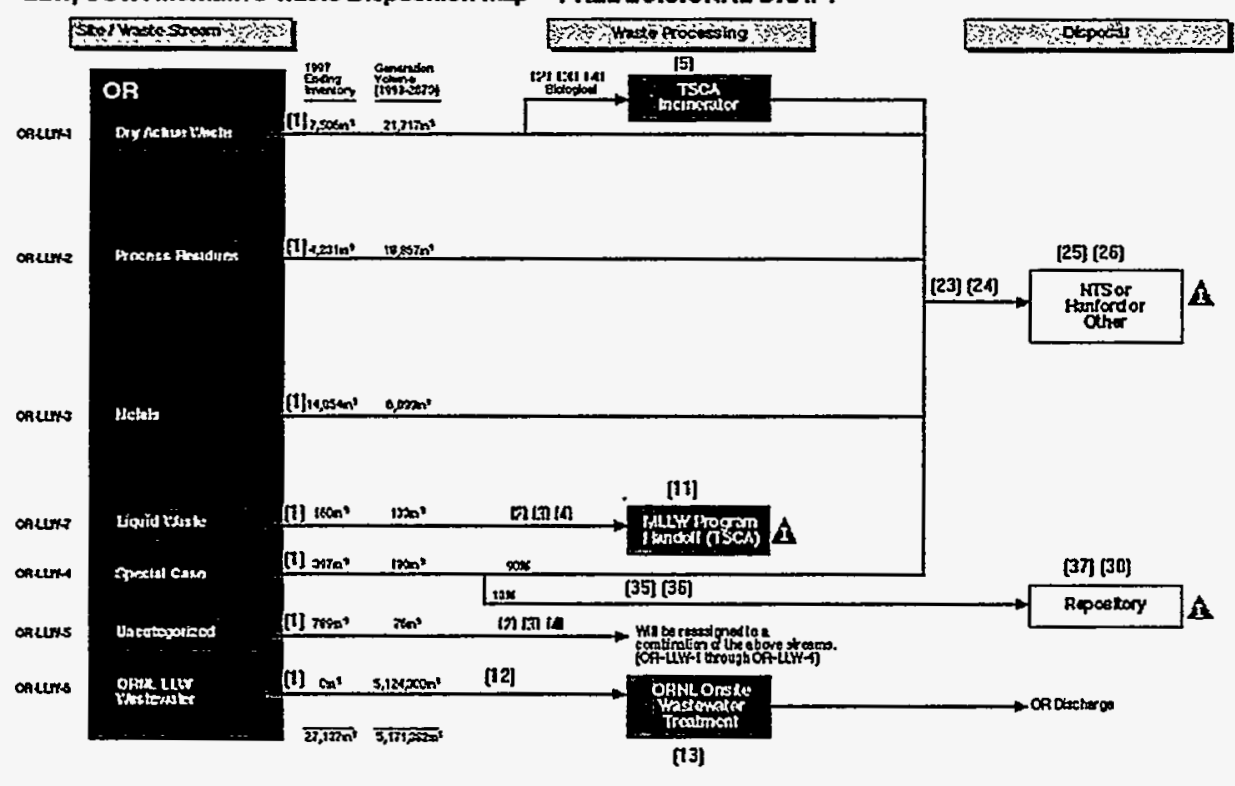

Figure 7-6. ORNL LLW disposition maps (baseline and alternative). 

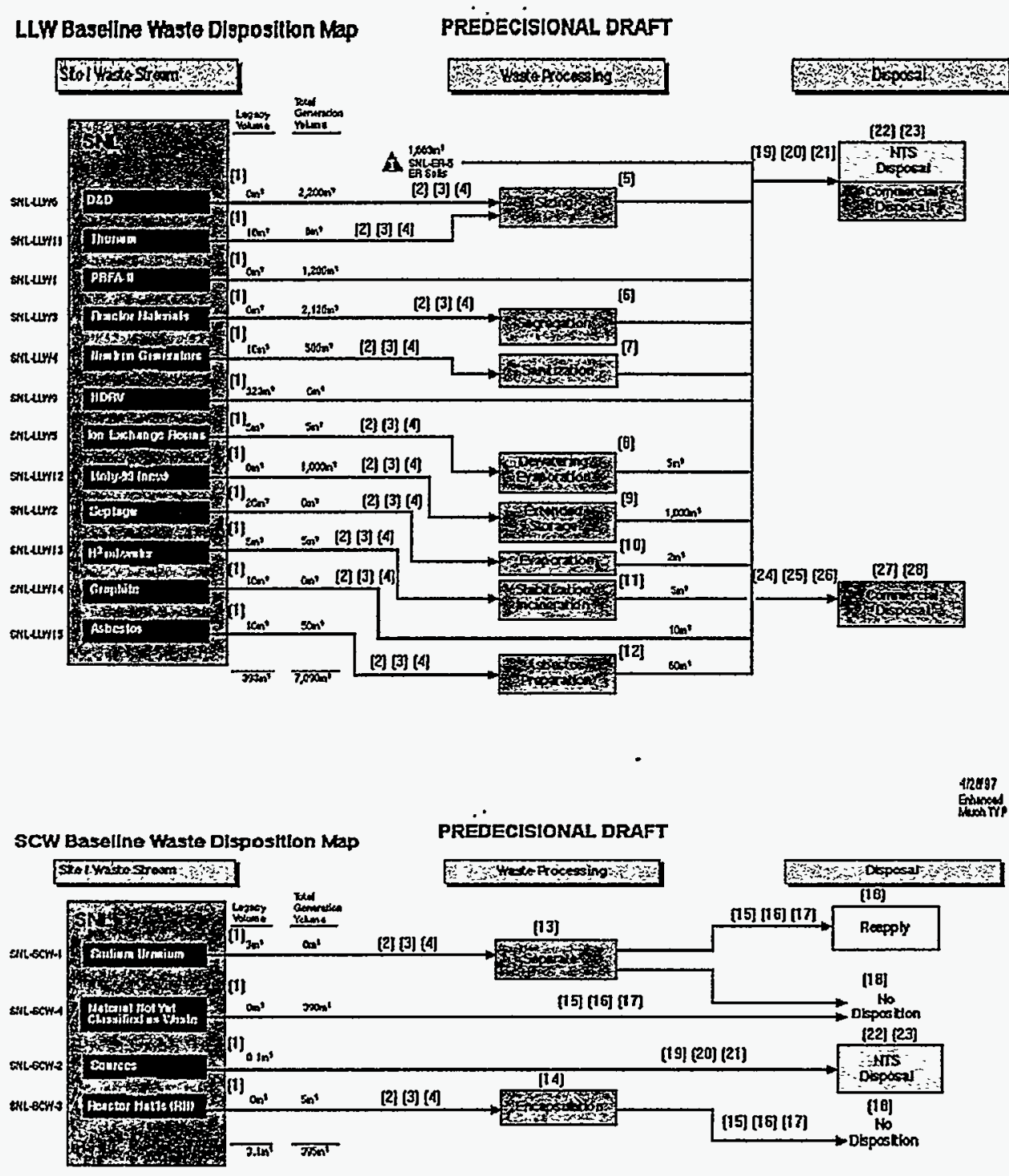

Figure 7-7. SNL LLW disposition maps (baseline and alternative). 

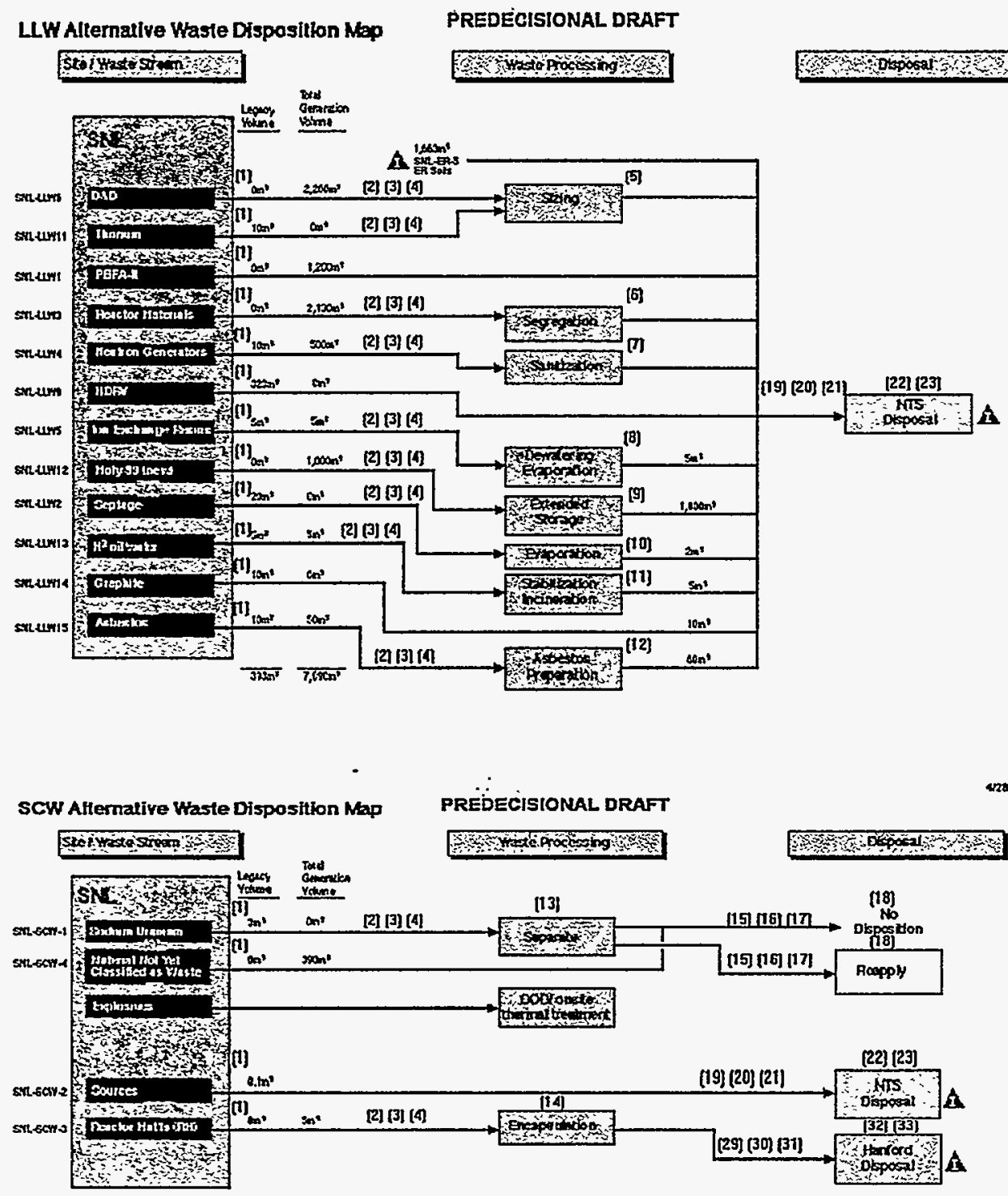

Figure 7-7. SNL LLW disposition maps (baseline and alternative) (continued). 

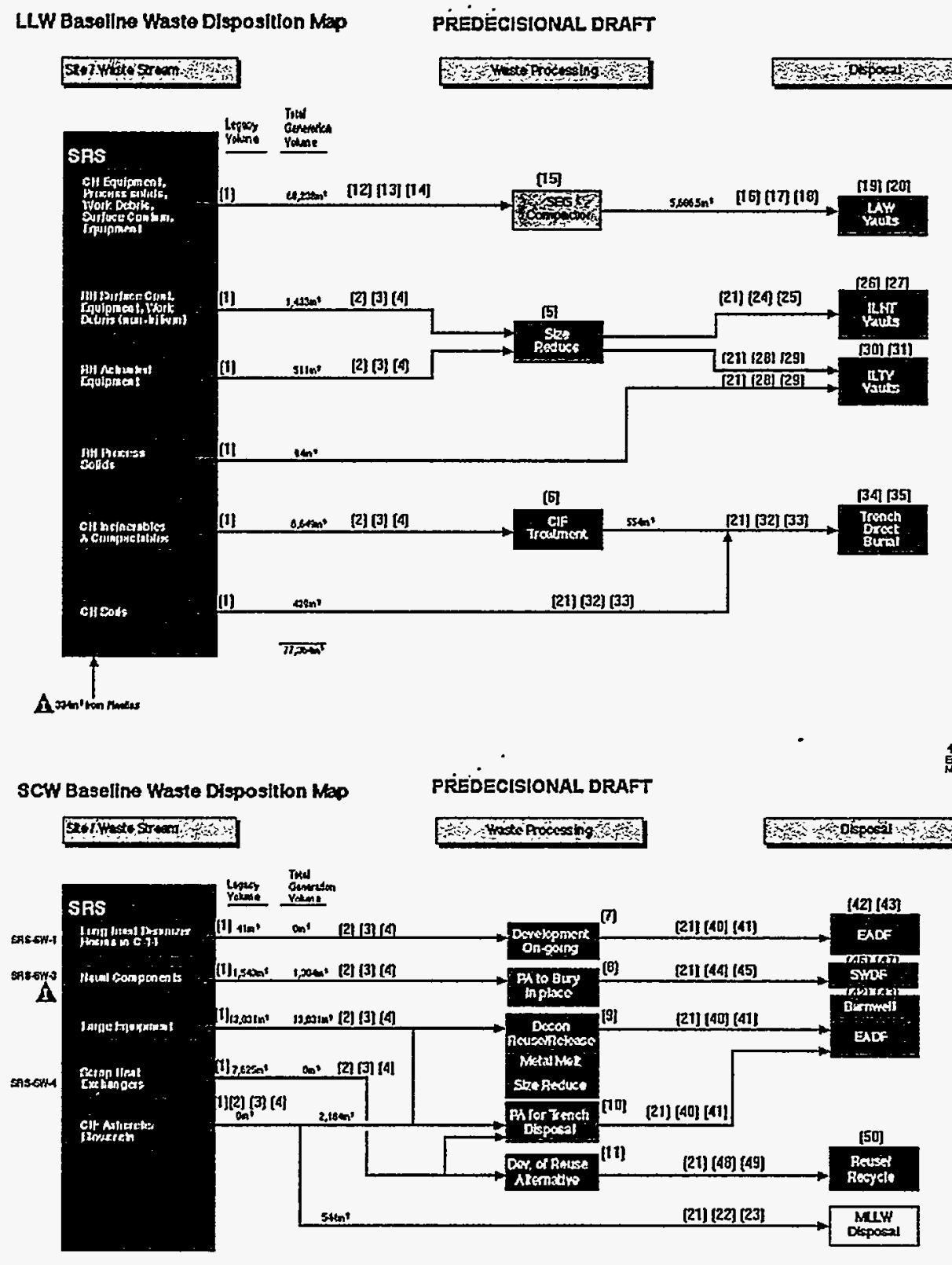

Figure 7-8. SRS LLW disposition maps (baseline and alternative). 

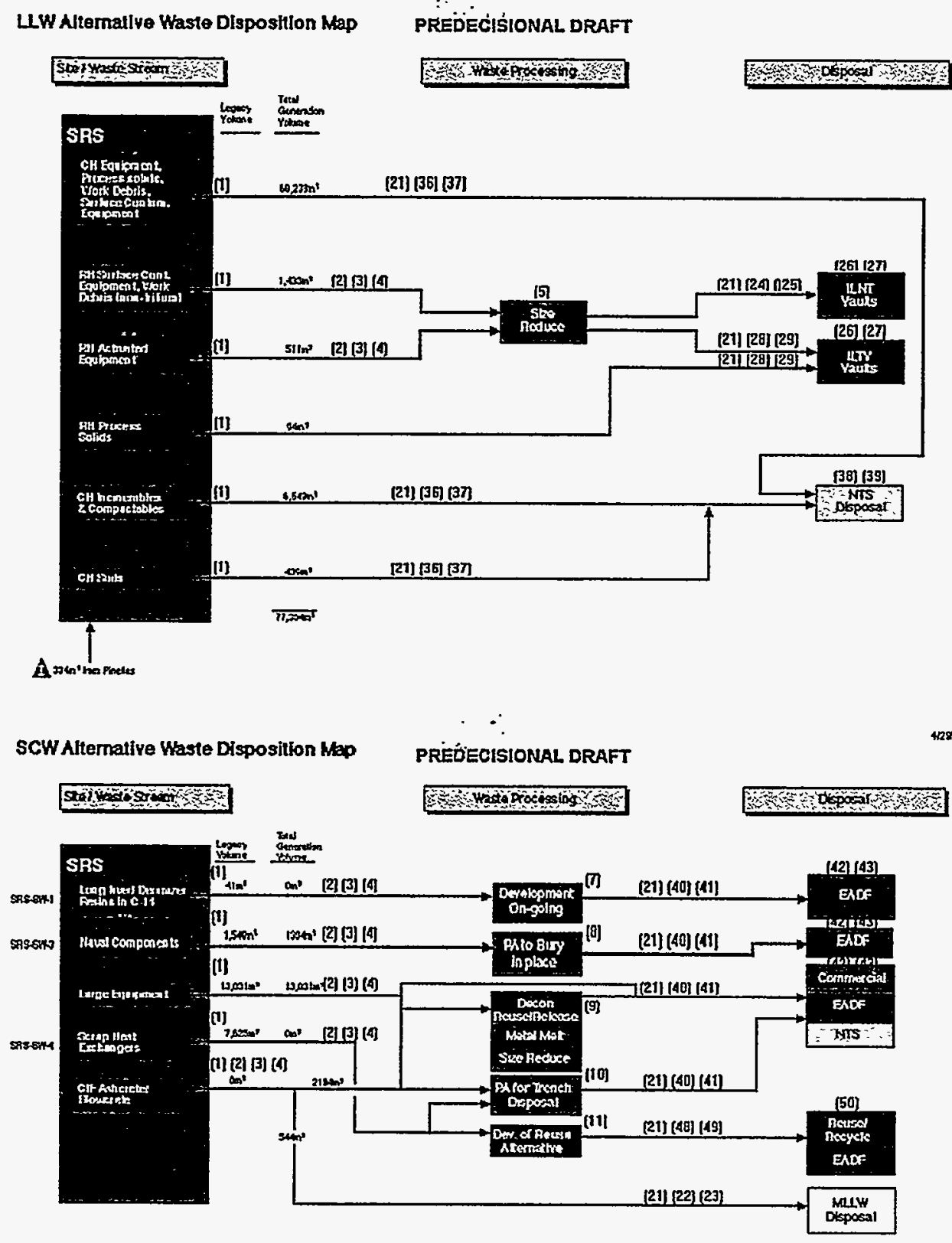

Figure 7-8. SRS LLW disposition maps (baseline and alternative) (continued). 

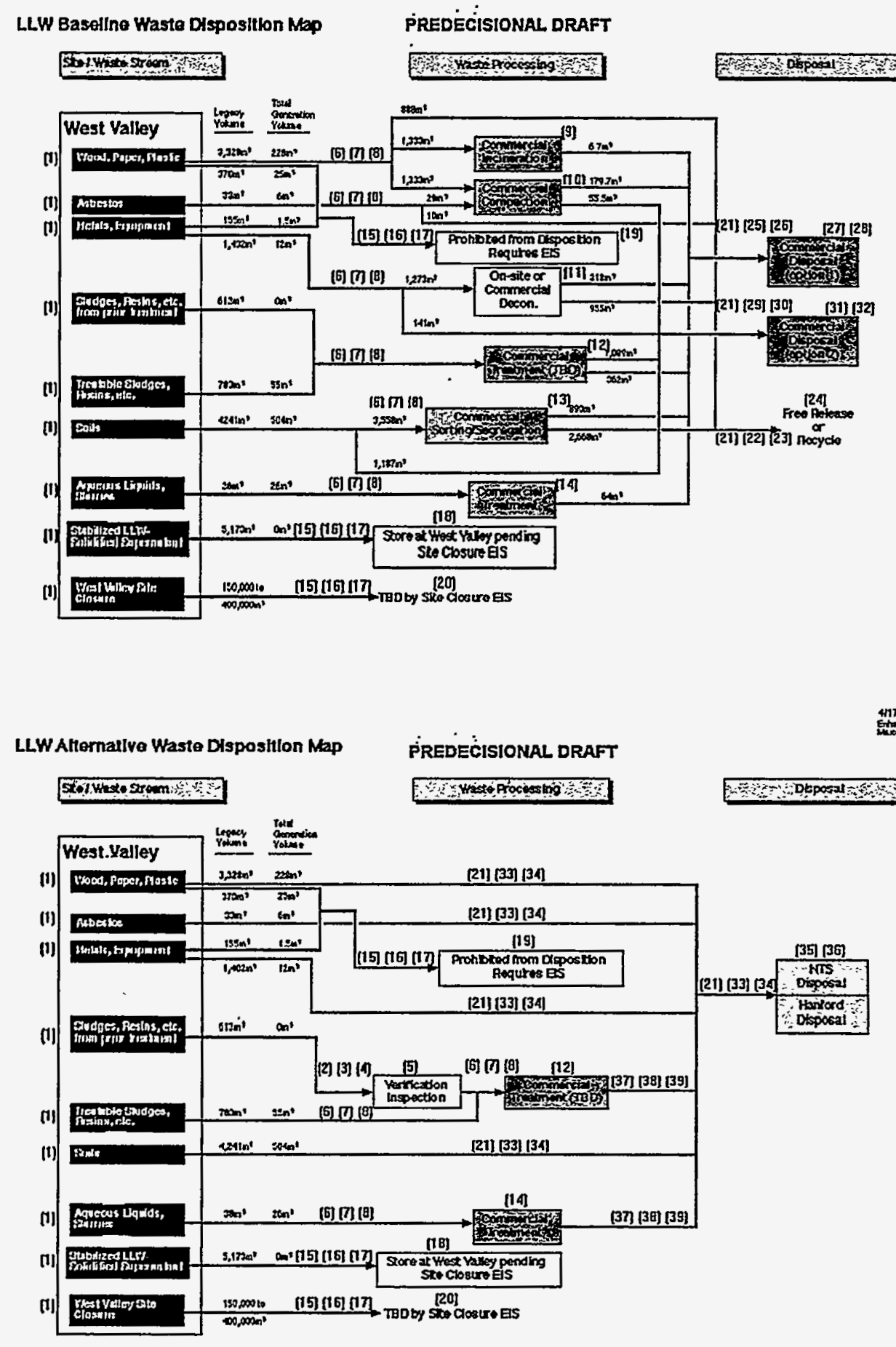

417ะ

Figure 7-9. WVDP LLW disposition maps (baseline and alternative). 


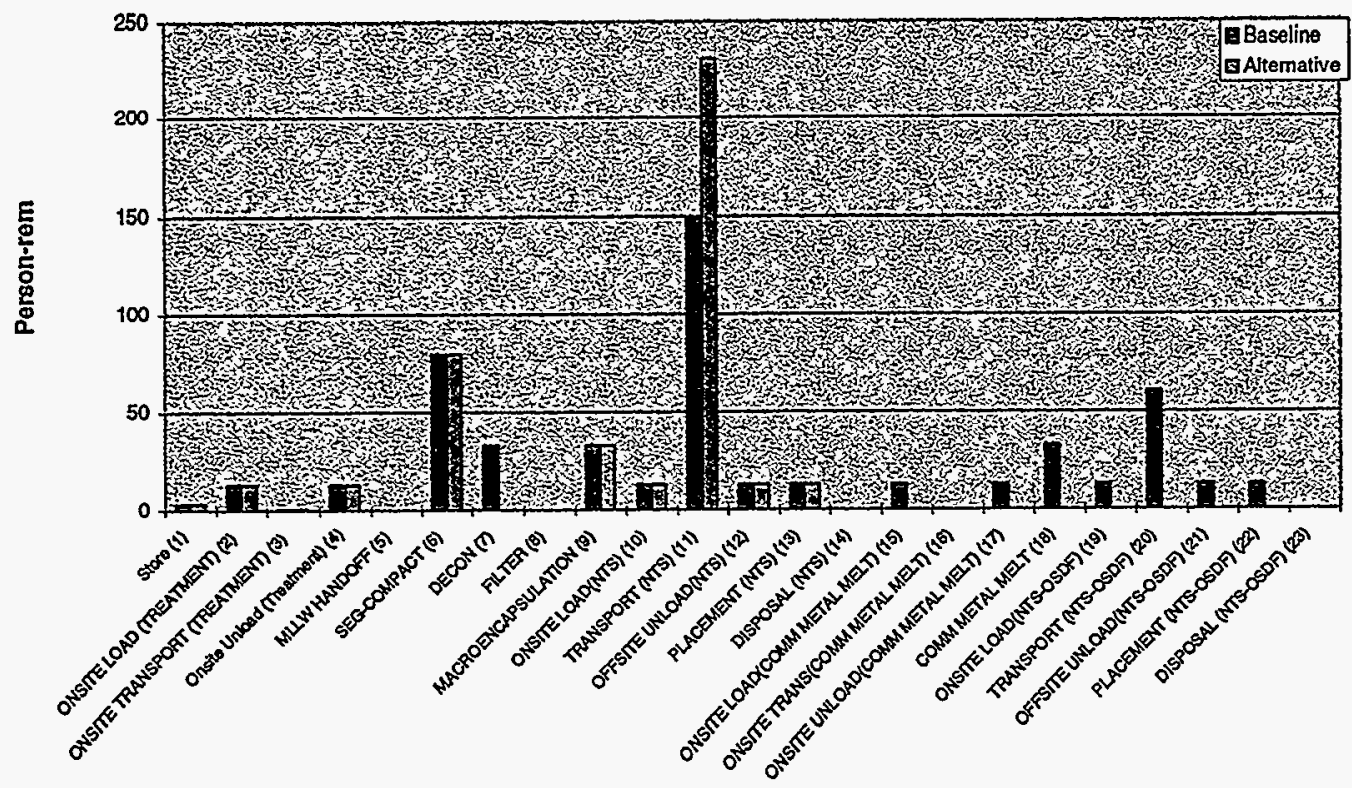

Figure 7-10. Fernald LLW risk results by activity.

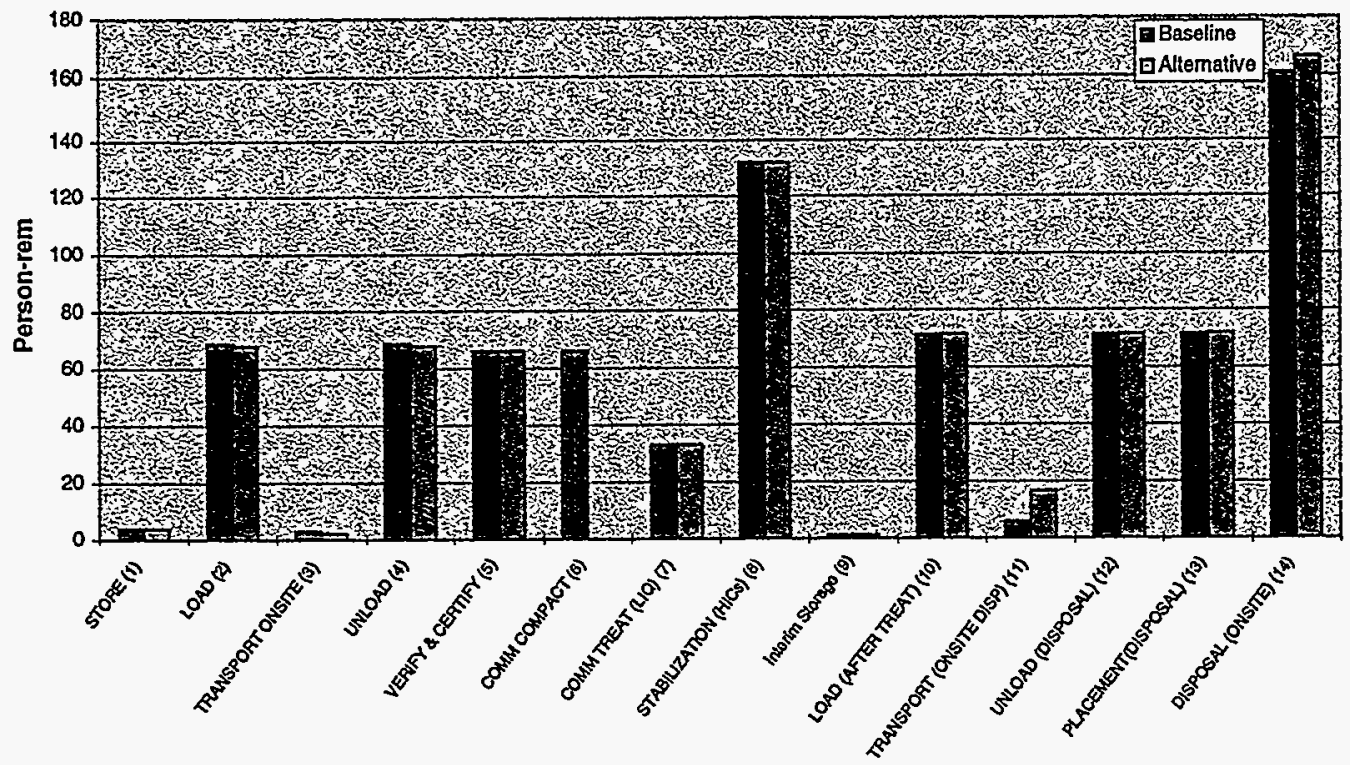

Figure 7-11. Hanford LLW risk results by activity. 


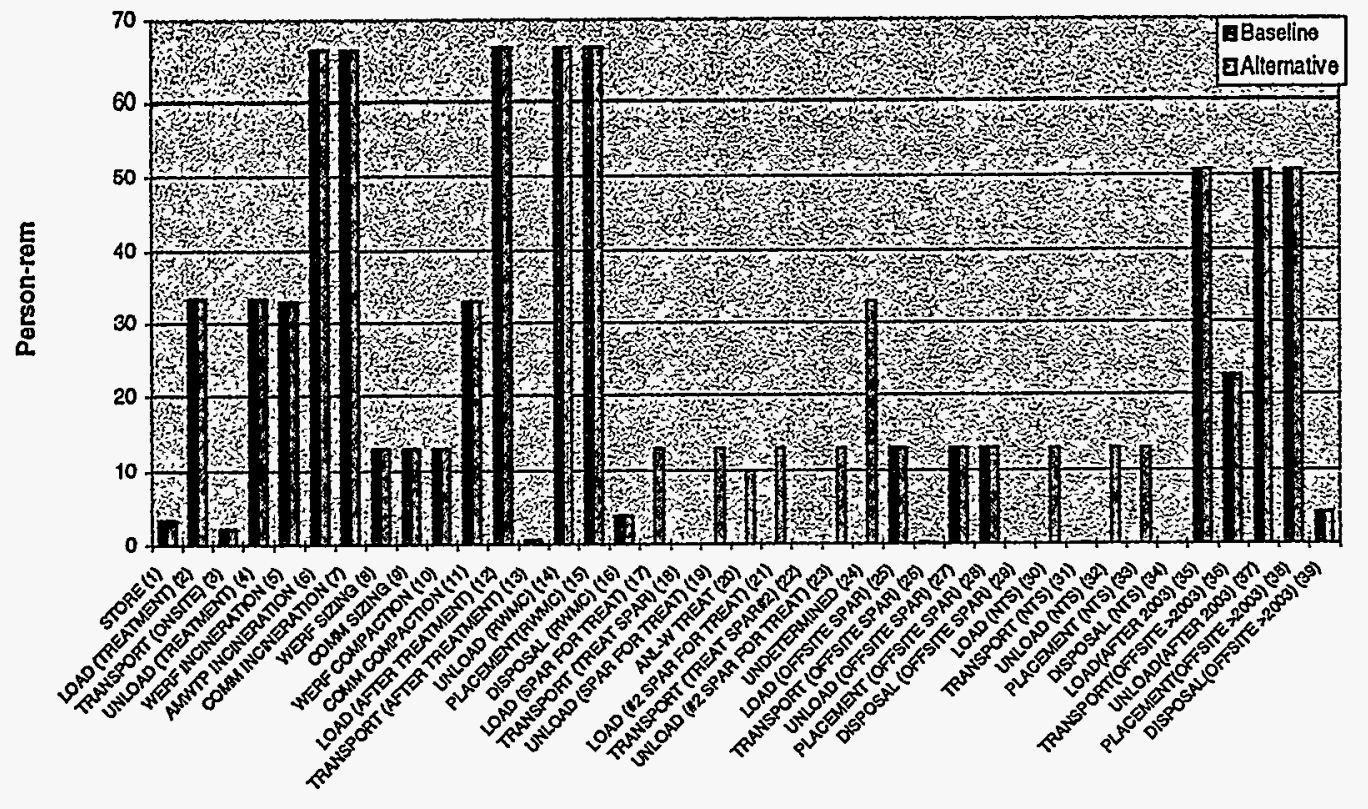

Figure 7-12. INEEL LLW risk results by activity.

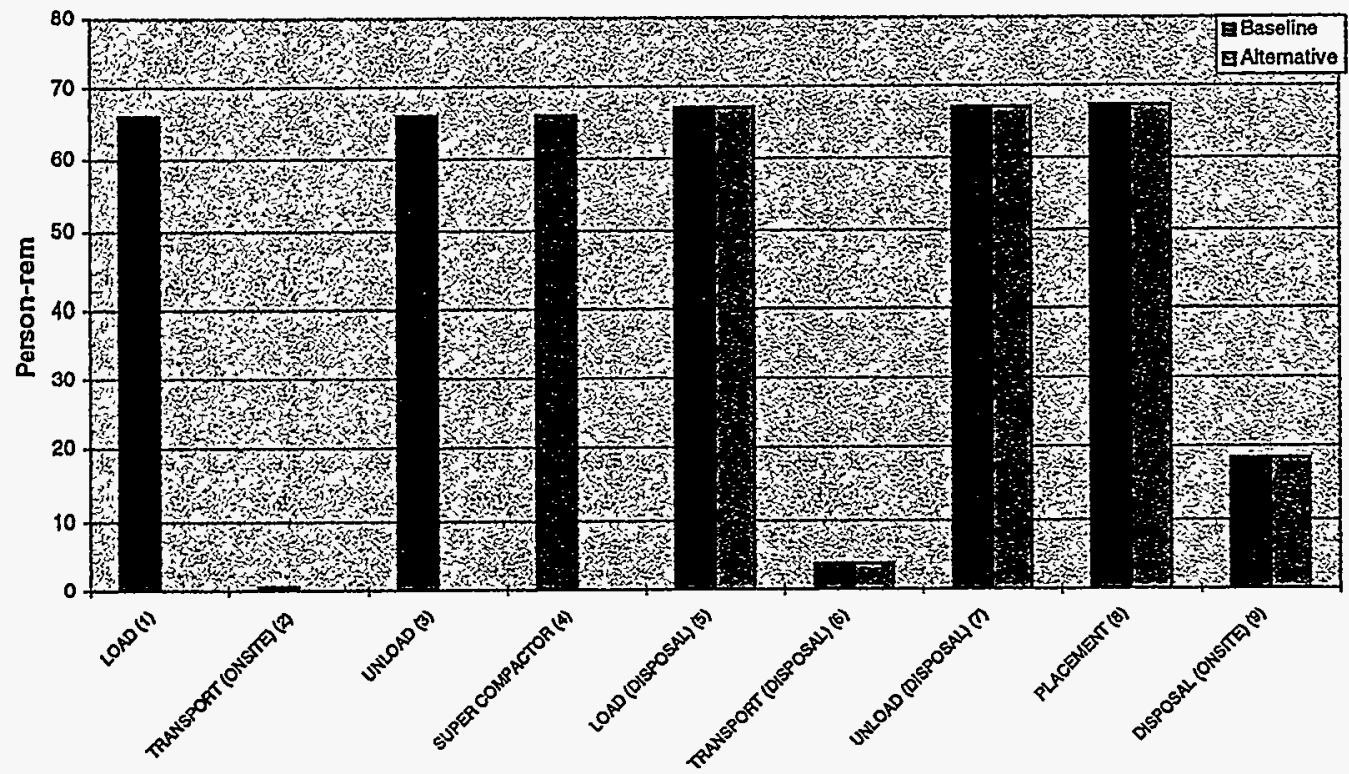

Figure 7-13. LANL LLW risk results by activity. 


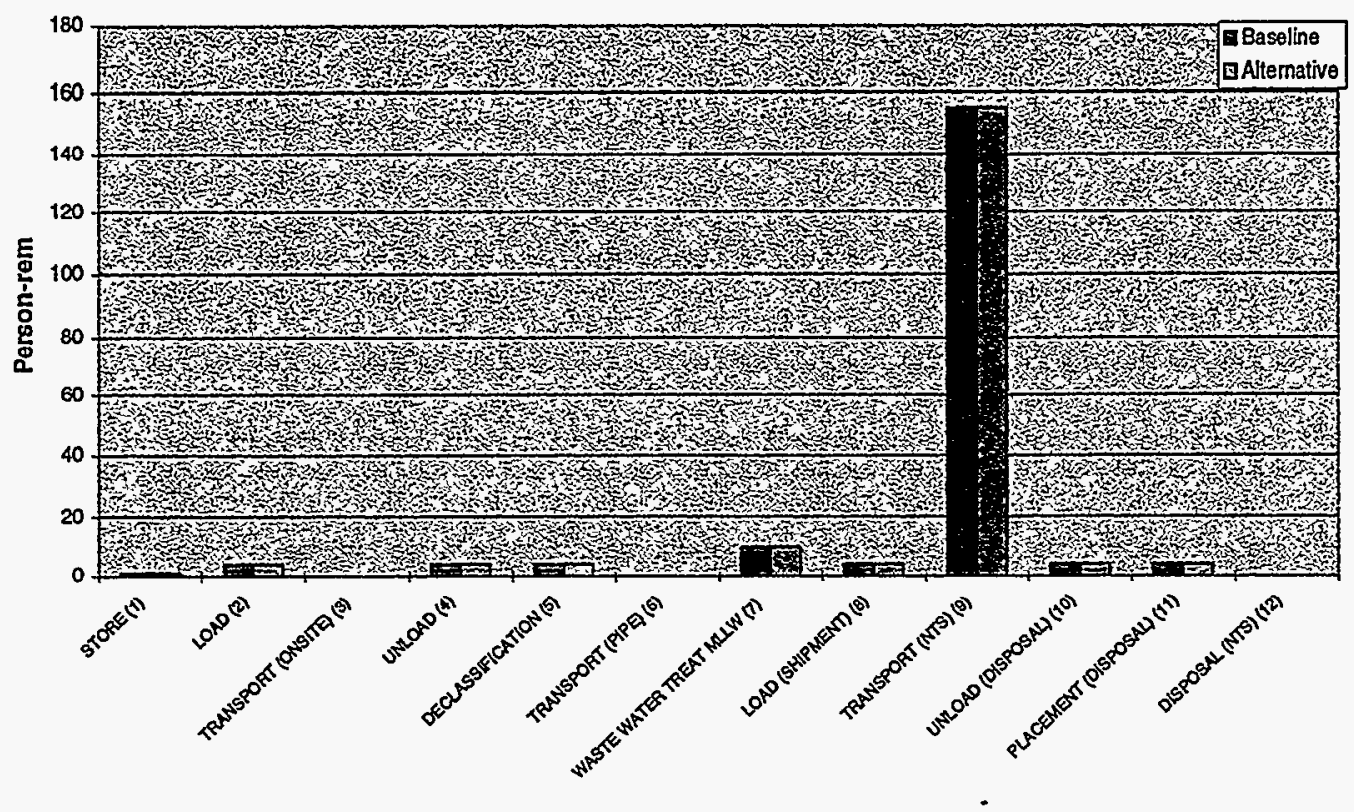

Figure 7-14. RFETS LLW risk results by activity.

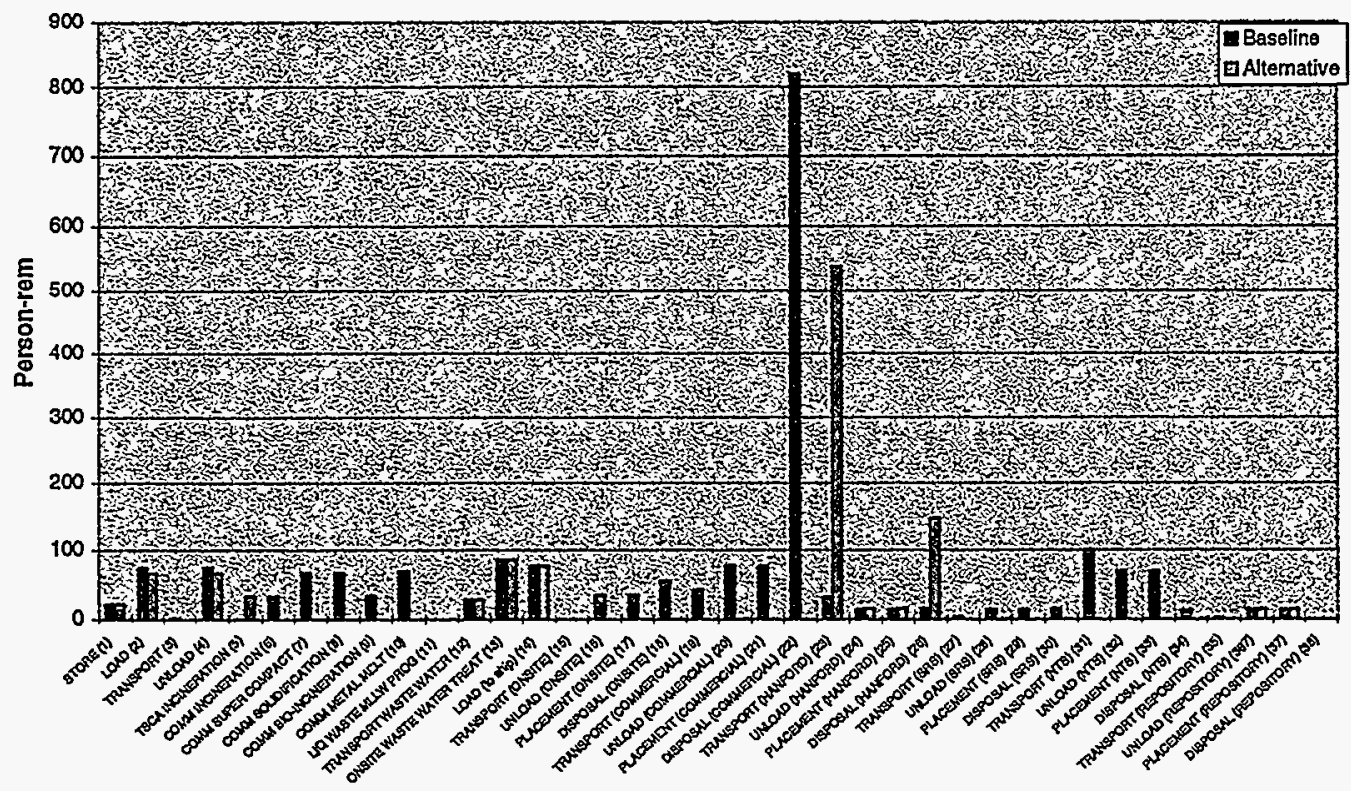

Figure 7-15. ORNL LLW risk results by activity. 


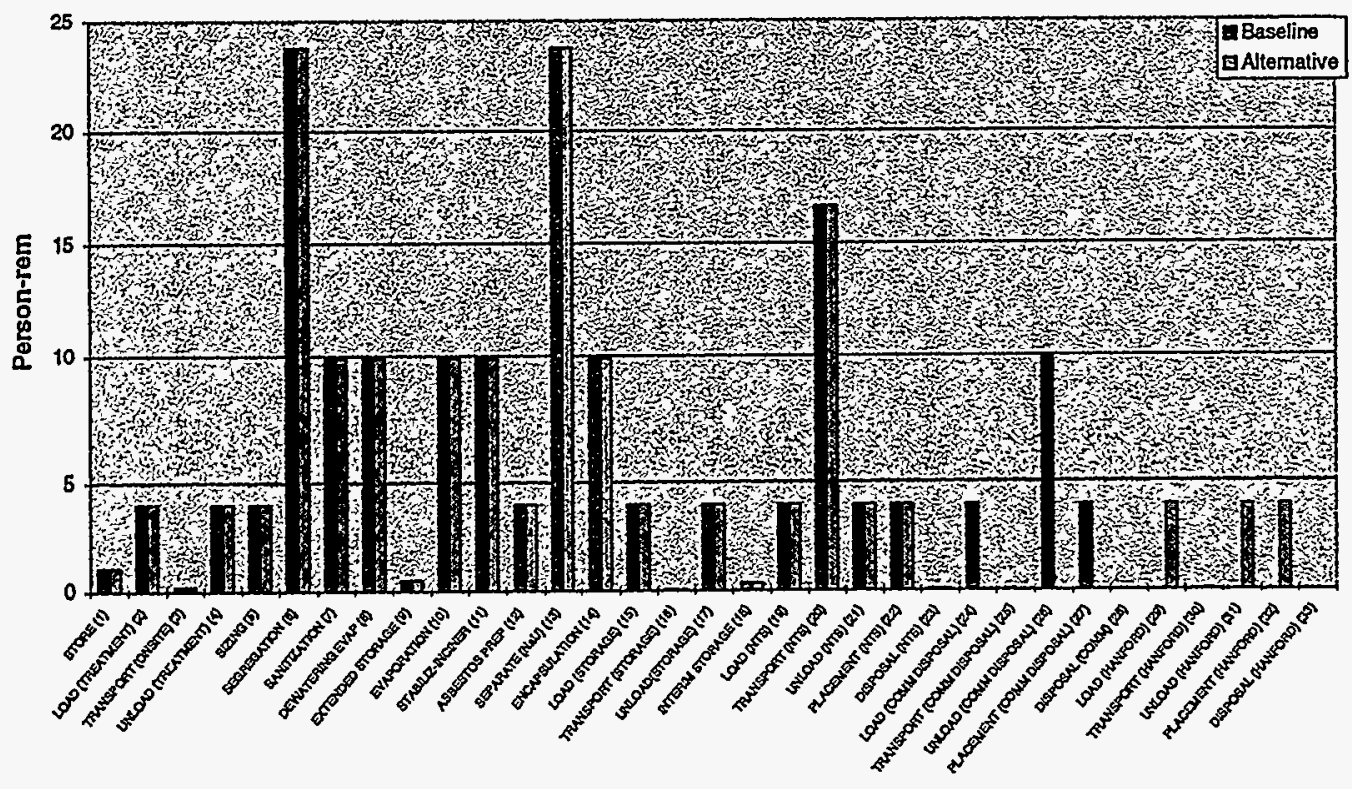

Figure 7-16. SNL LLW risk results by activity.

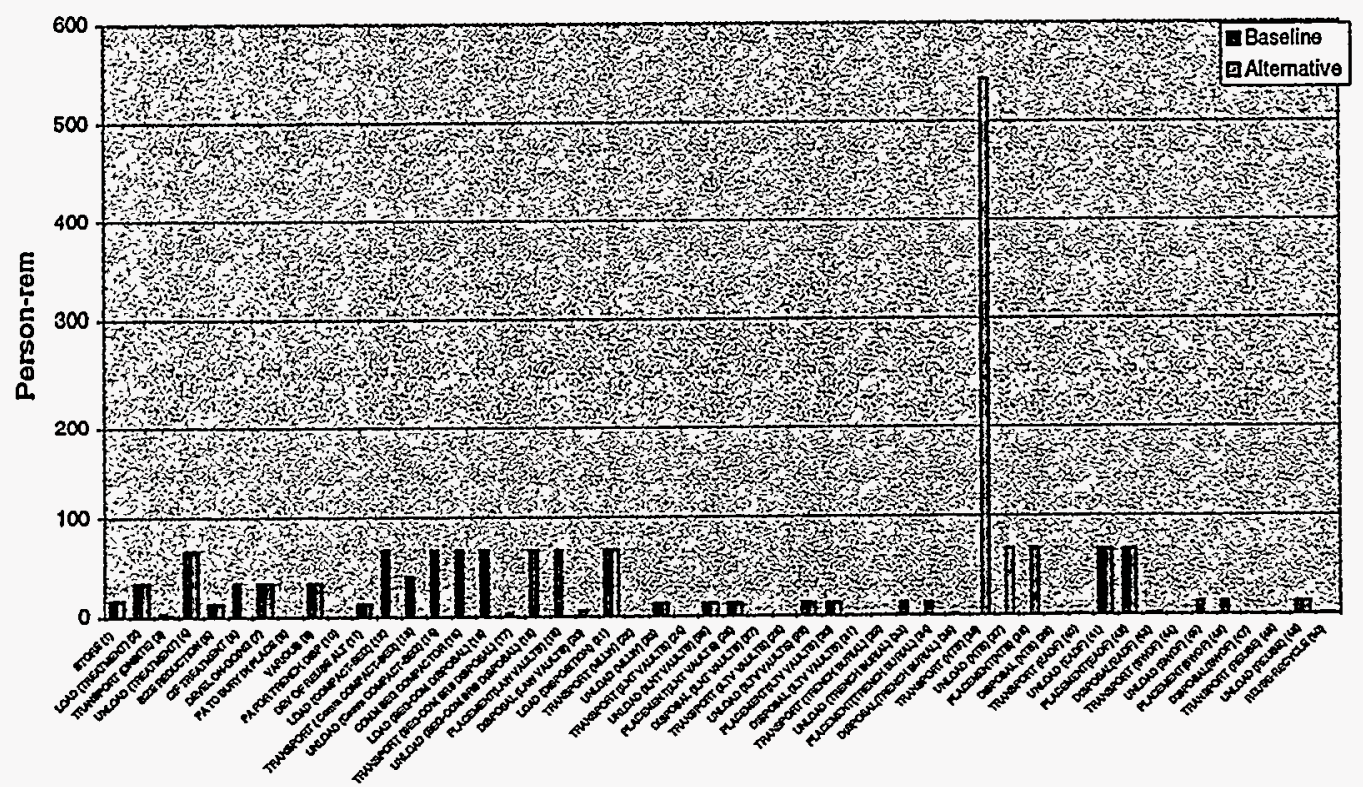

Figure 7-17. SRS LLW risk results by activity. 


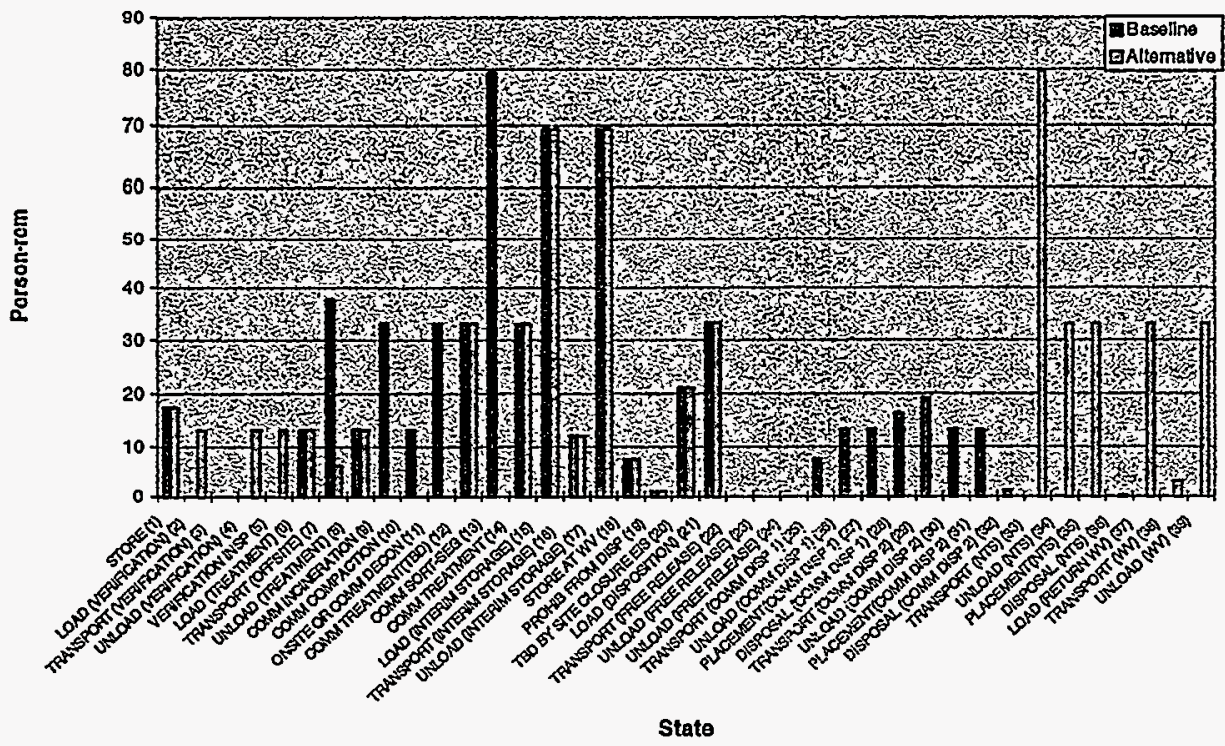

Figure 7-18. WVDP LLW risk results by activity.

Figure 7-19 is a summary of the total risk (person-rem), baseline program and alternative, for each of the nine sites, plus off-site transportation, final disposal, and commercial processing. The SRS has the highest baseline risk of any of the analyzed facilities because it has the most curies and it has a higher offsite population than Hanford or the INEEL. The highest risk of all comes from commercial facility processing. This is mainly due to the large volumes of LLW processed by these facilities in the base case. Transportation is the second highest because of the large volume of LLW shipped and the distances covered.

Figure 7-20 summarizes the DOE complex-wide LLW results by type of activity: storage, handling, treatment, transportation, and disposal. Handling of LLW is a significant contributor to the overall LLW risk. Treatment and transportation are also significant contributors to the overall LLW. The other two types of activities are smaller contributors.

Figure 7-21 presents the total DOE complex-wide LLW risk for the baseline program and the alternative. The total risk for the LLW baseline program is approximately 6700 person-rem, while the alternative case is approximately 5500 person-rem. This decrease in risk for the alternative case is small, given the accuracy of the SRM. Therefore, both the baseline program and the alternative are considered to have comparable risks.

Figures 7-22 through 7-24 are similar to Figures 7-19 through 7-21, but show the breakdown of risk into public and worker/site contributions. Overall, except for transportation, the risk to the workers is two times or more than the risks to the public.

Finally, Figures 7-25 through 7-27 are similar to Figures 7-19 through 7-21, but show the breakdown of risks from accident and normal, incident-free operation. Overall, the risk from normal, incident-free operation is two or more times higher than the risks from accidents. 


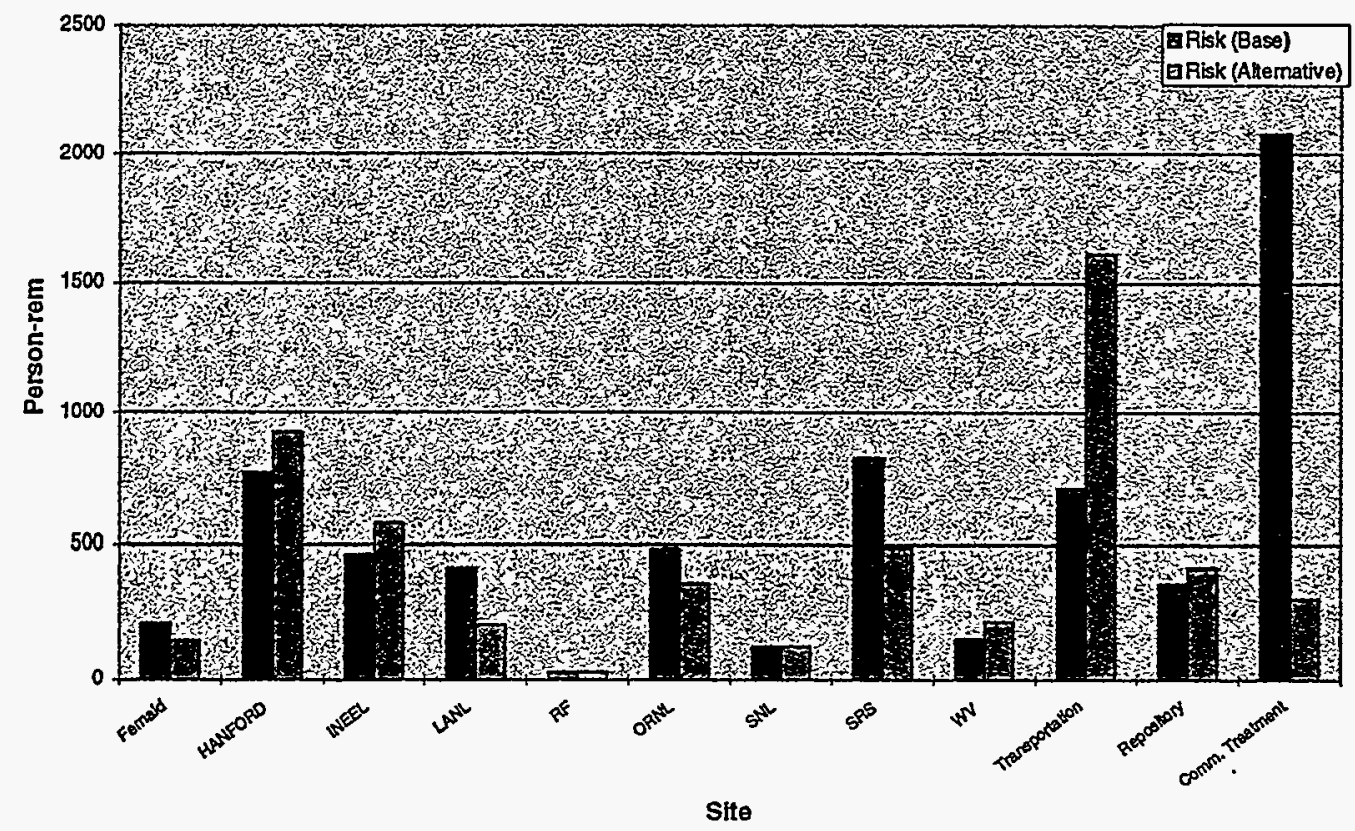

Figure 7-19. DOE LLW risk results by site.

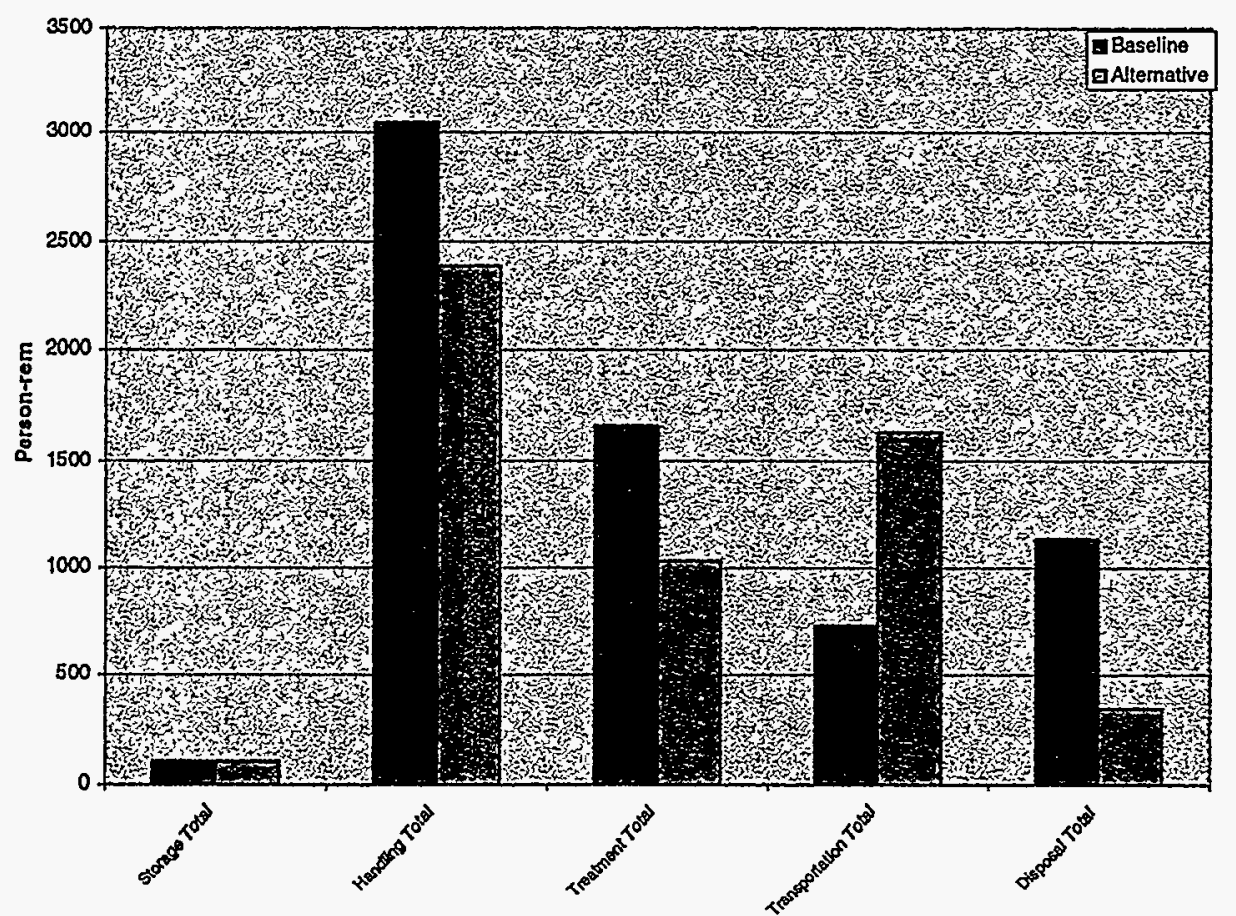

Figure 20. DOE complex-wide LLW risk results by activity type. 


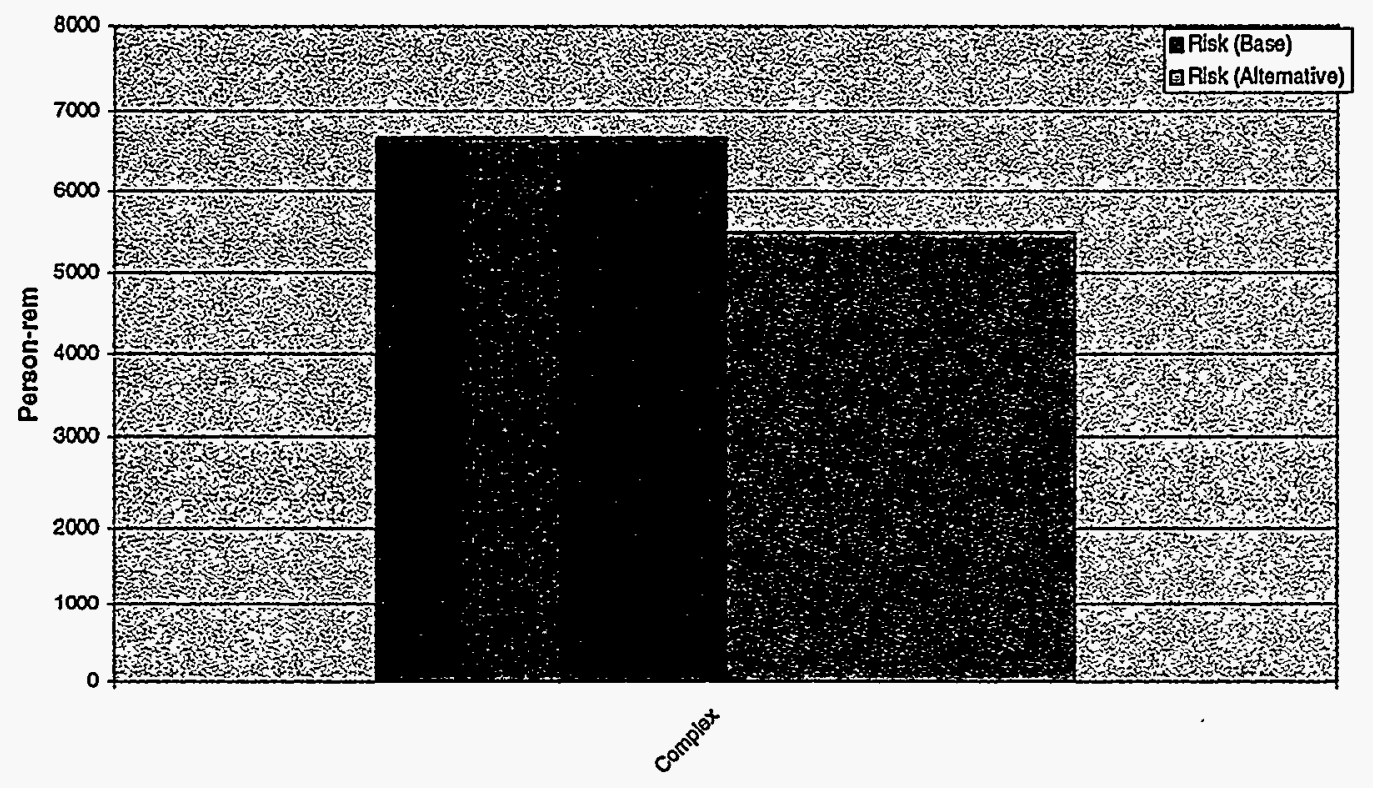

Figure 7-21. DOE complex-wide LLW risk results.

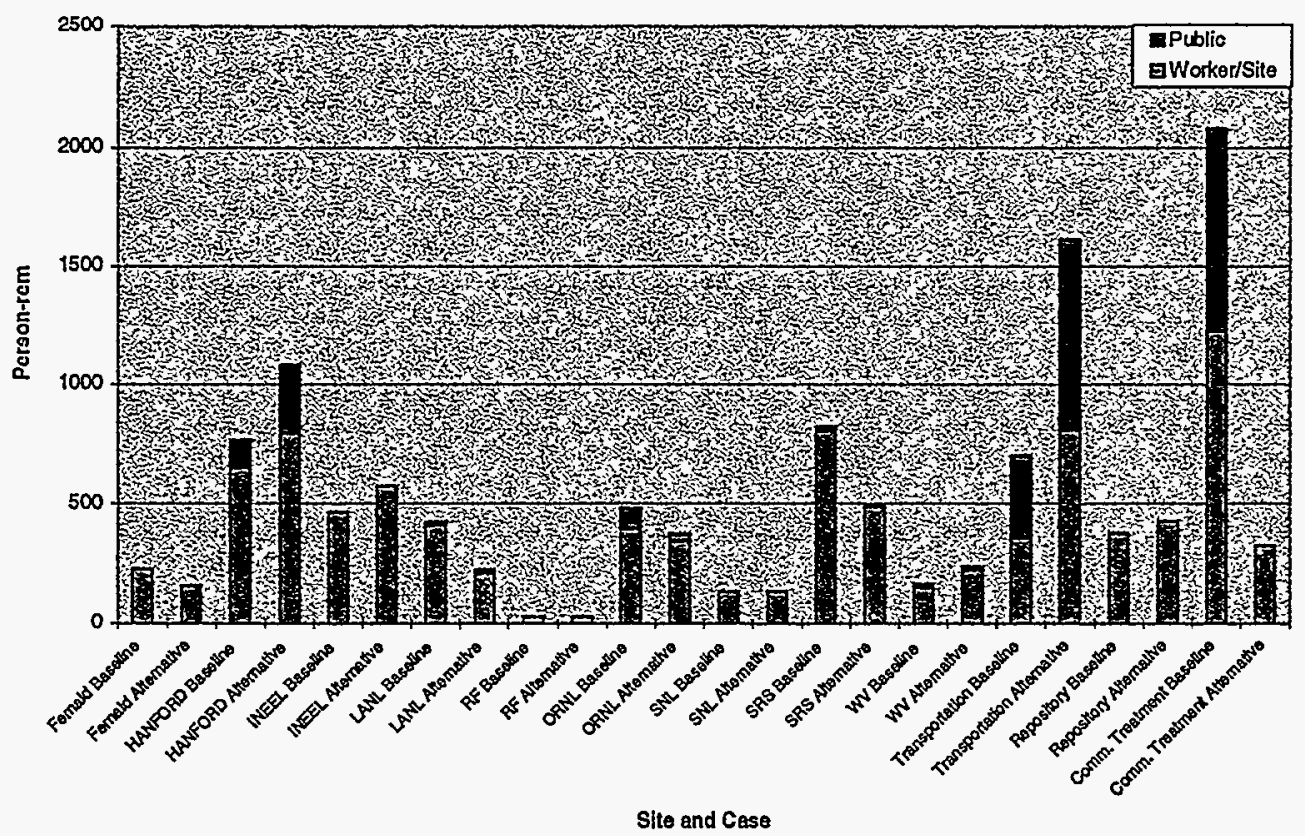

Figure 7-22. DOE LLW risk results by site (worker/site versus public) 


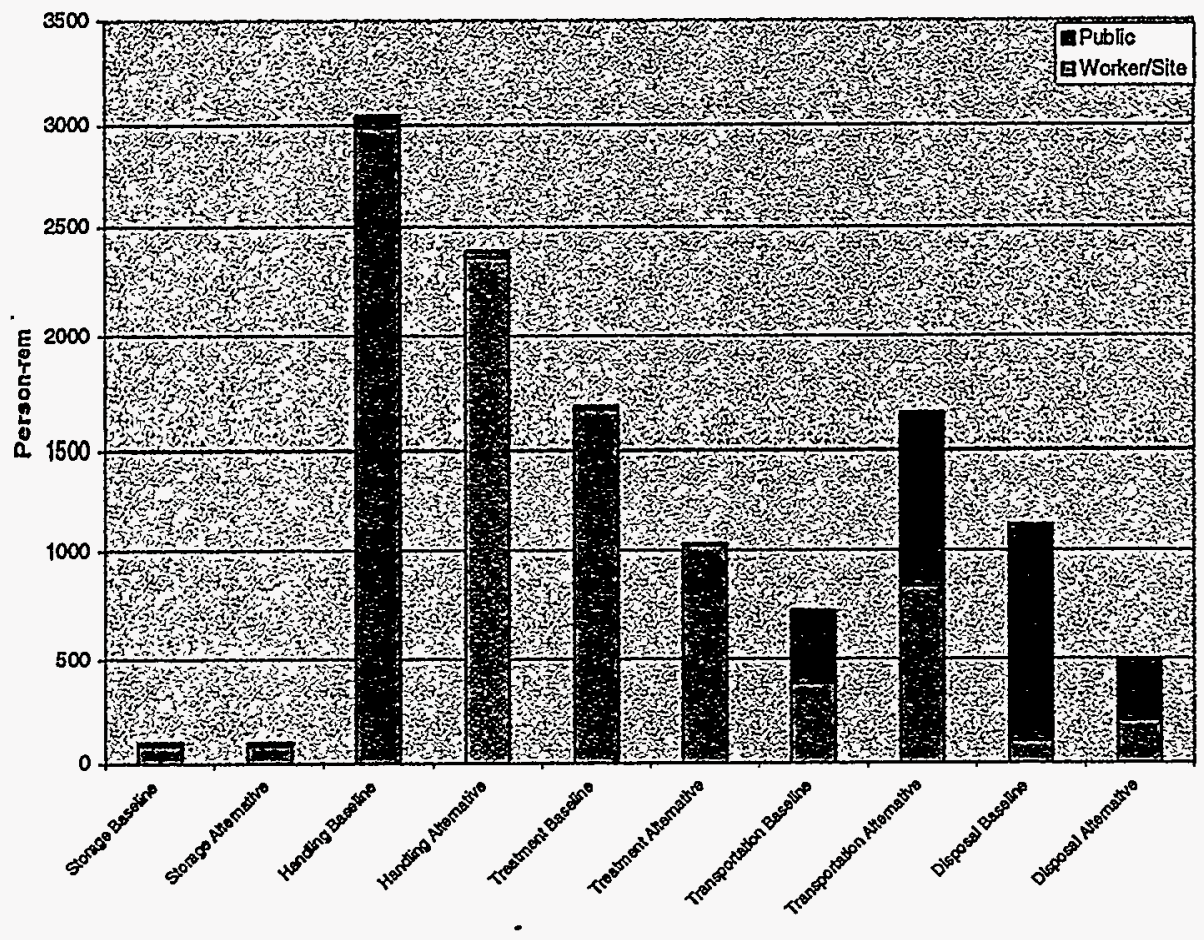

Figure 23. DOE complex-wide LLW risk results by activity type (worker/site versus public).

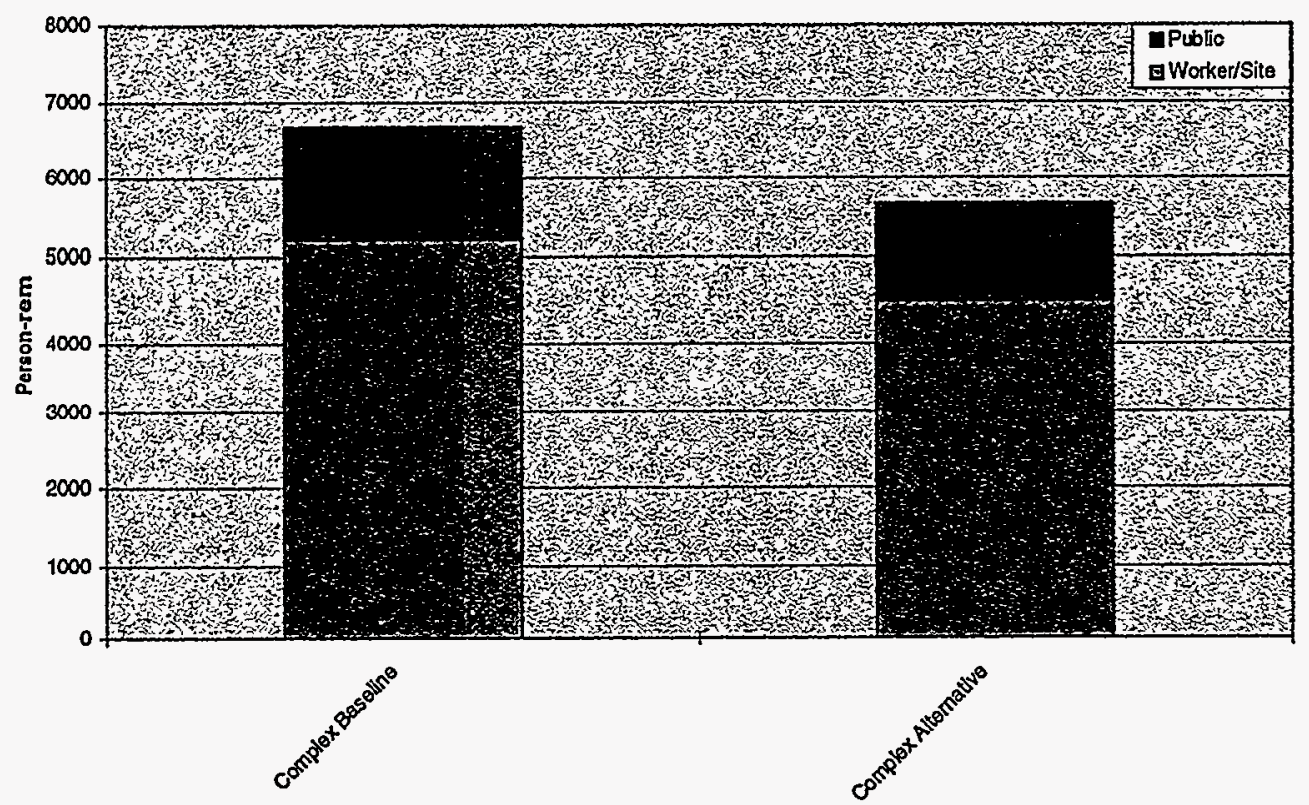

Figure 7-24. DOE complex-wide LLW risk results (worker/site versus public). 


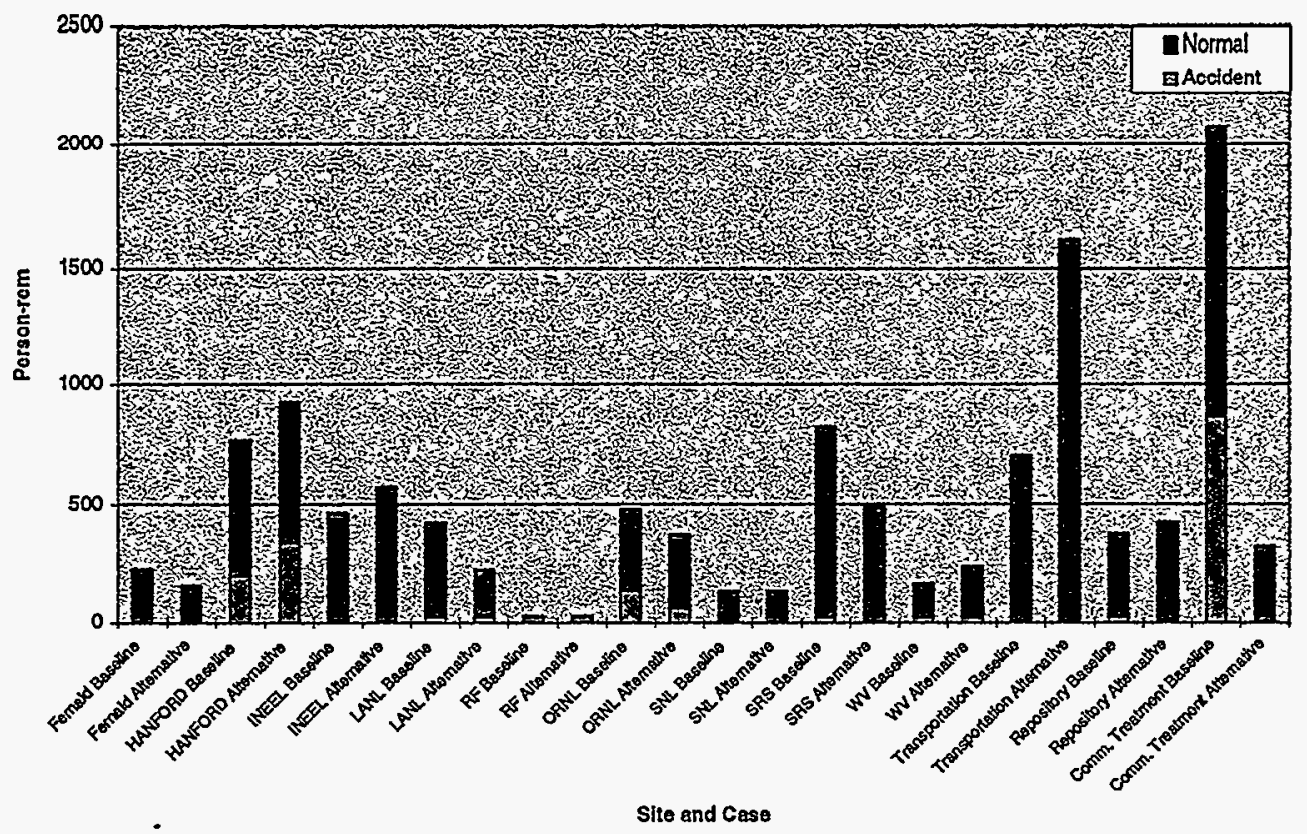

Figure 7-25. DOE LLW risk results by site (accident versus normal).

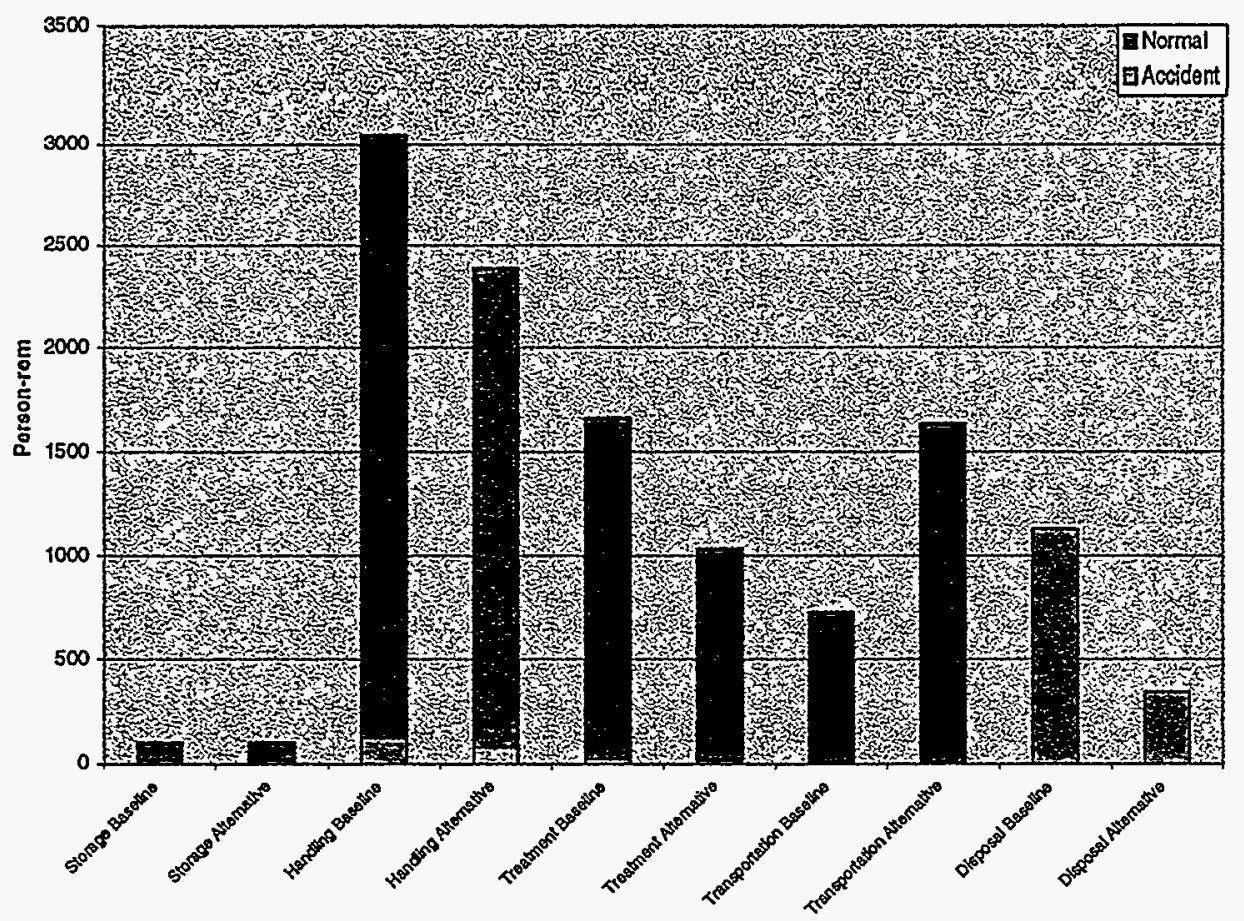

Figure 26. DOE complex-wide risk results by activity type (accident versus normal). 


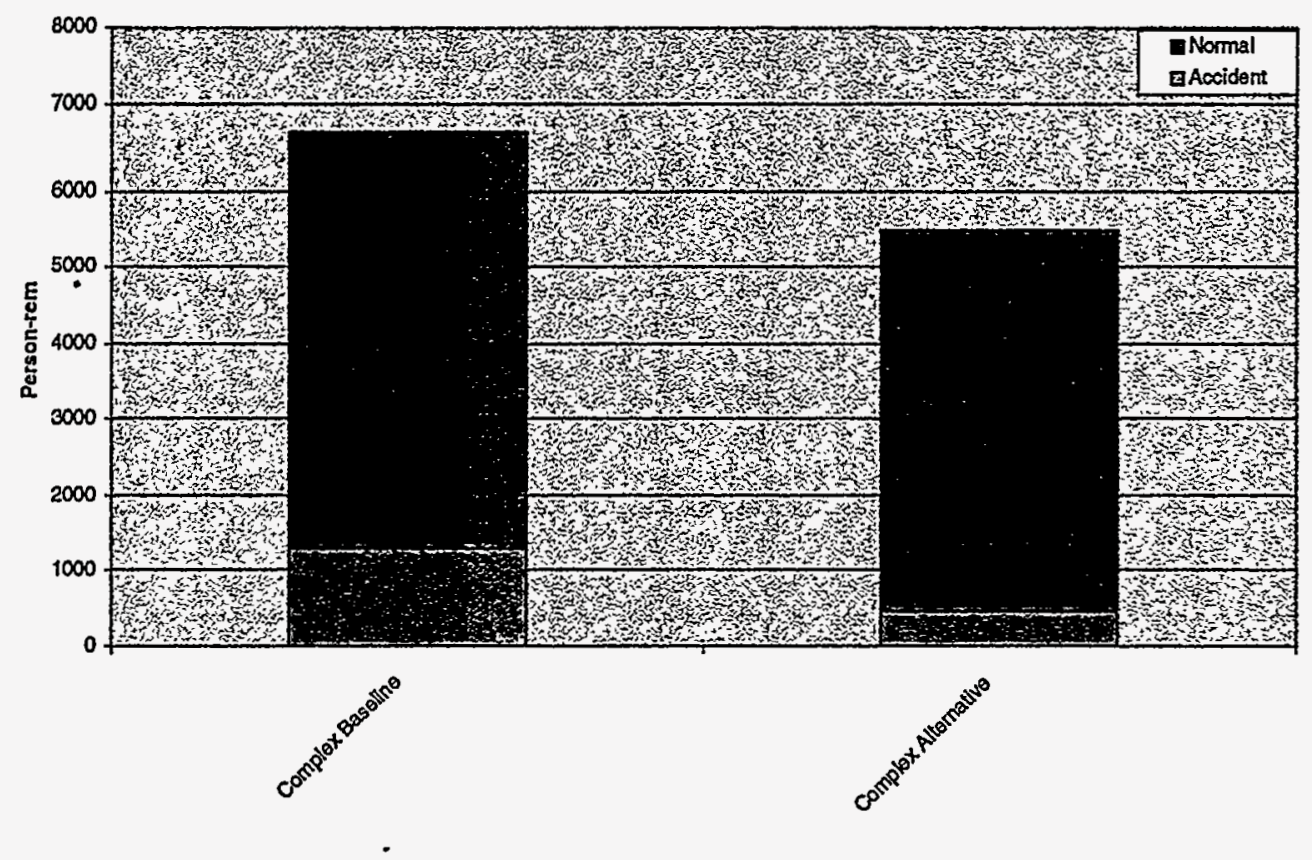

Figure 7-27. DOE complex-wide LLW risk results (accident versus normal).

The complete SRM LLW model is in EXCEL ${ }^{\text {TM }}$ workbooks, with separate spreadsheets for each of the activities summarized in Figures 7-10 through 7-18. The spreadsheets contain detailed risk information on the following: accident risk (airborne) to workers, DOE site personnel, and the public, broken down into contributions from actinides, non-actinides, and chemicals; groundwater ingestion risk to the public from actinides, non-actinides, and chemicals; offgas risk (airborne) to DOE site personnel and the public, broken down into contributions from actinides, non-actinides, normal exposure (direct radiation) to workers; and normal and accident risk to the crew and public for transportation. All of these contributors (as applicable to the activity in question) are summed in order to estimate the total risk from the activity.

Because the SRM LLW model is computerized, sensitivity studies can be performed relatively easily. Also, if more alternatives are identified in the future, the SRM analyses can be performed efficiently. Finally, existing LLW results can be broken down into many different ways to respond to questions from stakeholders.

The SRM risk results were compared with other risk estimate sources to ensure that the risk predictions are consistent with more detailed analyses. Comparisons were made with the results from the Final Waste Management Programmatic Environmental Impact Statement ${ }^{6}$ (WM-PEIS), and individual site Environmental Impact Statements (EISs). The WM-PEIS total risk can be directly compared to the SRM total risk in person-rem. The LLW in the WM-PEIS has fourteen alternatives for waste processing. The alternatives are "No Action", "Decentralized", seven "Regionalized", and five "Centralized". The alternatives that correspond to the closest to the baseline and alternative cases in the SRM are the decentralized and number seven of the regionalized alternatives respectively. In order to do a fair comparison of the SRM and WM-PEIS results the transportation results for the WM-PEIS have been 
adjusted by total miles traveled. For the base case alternative, the WM-PEIS transportation results were multiplied by the factor $(12,548,629 / 8,630,000)$ and for the alternative case (Regionalized 7$)$ multiplied by the factor $(31,745,329 / 125,000,000)$. Using the transportation results combined with treatment and disposal results, the comparison is as follows:

\section{SRM (Person-Rem) \\ Base Case}

6672
WM-PEIS (Person-Rem)

Base Case Alternative

8403

7747

Comparison of off-site transportation is as follows:

SRM (Person-Rem)
Base Case

706
Alternative Case

1611
WM-PEIS (Person-Rem)

Base Case Alternative

903

2147

The overall complex results are within $21 \%$ for the overall base case risk and within $29 \%$ for the alternative case. The transportation results are within $22 \%$ for the base case and $25 \%$ for the alternative. These estimates agree well with the SRM results. Therefore the complex-wide SRM model corresponds well with the WM-PEIS and so does the SRM transportation model.

The SRS EIS presents a risk estimate that can be compared with the SRM SRS LLW results. LLW disposed of in the Consolidated Incineration Facility for Alternative C (Full Treatment) is about $72,718 \mathrm{~m}^{3}$ for a 30 -year run. For 33 years the amount of waste disposed of is $79,990 \mathrm{~m}^{3}$. The amount of waste disposed of for the baseline for the SRS over 33 years is $6649 \mathrm{~m}^{3}$. The worker exposure for the EIS alternative over 33 years is (33years) x (9.135 person-rem/year) or 301.5 person-rem. The fraction of this value that is equivalent to the baseline for the SRS is $\left(6649 \mathrm{~m}^{3}\right) /\left(79990 \mathrm{~m}^{3}\right)$, which results in 25.1 personrem for a 33-year period. The value predicted by the SRM is 33 person-rem, which agrees well with the SRS EIS.

In general, the limited comparisons above indicate that the SRM is adequately predicting LLW human health. However, further comparisons from detailed risk assessments are needed to validate all areas of the SRM, especially risk from accident exposure. 


\section{MIXED LOW-LEVEL WASTE ANALYSIS}

DOE MLLW is presently stored at a number of sites: Fernald, Hanford, INEEL, LANL, Mound, NTS, ORNL, RFETS, SNL, and SRS. Included in the model are sites for the commercial and national treatment and disposal projects.

DOE plans to stabilize this waste, which is mostly in solid form (e.g., items such as protective clothing, paper rags, glass, miscellaneous tools, and equipment). The DOE MLLW includes MLLW for which the hazardous component of the waste is subject to regulation under either the Resource Conservation and Recovery Act (RCRA) or the Toxic Substances Control Act (TSCA) or both. A significant volume of MLLW is associated with environmental restoration activities. For example, most of the radioactive asbestos results from decommissioning and/or renovation of old structures. In addition, remediation of former near surface disposal sites used for disposal of radioactively contaminated materials can result in large quantities of RCRA MLLW. The baseline program and alternative for MLLW for each of the sites are outlined in the disposition maps presented in Figure 8-1 to Figure 8-9. The baseline disposition maps for the DOE sites show the process by which the stored MLLW is retrieved, stabilized, and sent for disposal. The alternatives involve additional separations activities, transport of MLLW to other sites for processing or interim storage, schedule changes, and other activities.

The SRM MLLW model was developed by subdividing the disposition map boxes into activities (risk states) such as storage, retrieval, loading and unloading, on-site and off-site transport, various types of waste processing steps, and disposal. The subdivision of the disposition maps into activities is shown in Figure 8-1 to Figure 8-9, where the numbers in parenthesis refer to specific activities for the site in question. Figure 8-10 through Figure 8-22 indicate the word description associated with each number.

The SRM requires knowledge of the radionuclide curie and chemical flow through the disposition maps. The curie information was indirectly obtained from the report Integrated Data Base (IDB) Report 1995: U. S. Spent Nuclear Fuel and Radioactive Waste Inventories, Projections, and Characteristics. ${ }^{5}$ Since the IDB Report does not list curies for the MLLW, the assumption was made that the curie per cubic meter ratio in the LLW section is similar to the curie per cubic meter ratio in the MLLW unique to each site. Table 8-1 shows the site curie estimates. The actinides are assumed to be $0.5 \%$ of the total curies at each site or state, estimated as a composite of other LLW actinide mixtures. Additional information required for the SRM, such as the waste form (liquid, sludge, grout, glass, etc.), characteristics of storage and processing facilities, types of on-site and off-site transport, and schedules were obtained from the site subject matter experts. In cases where such information was not available, assumptions were made.

Chemical inventories were estimated based on Table 6.4-13 in the Final Waste Management Programmatic Environmental Impact Statement. ${ }^{6}$ The average chemical inventory $\left(\mathrm{kg} / \mathrm{m}^{3}\right)$ was calculated over all sites in this table. For each site, representative chemicals were chosen based on waste stream descriptions, or an average chemical pair was picked. 
Table 8-1. DOE site MLLW curie inventory estimates.

\begin{tabular}{|c|c|c|c|c|c|c|c|}
\hline Site & $\begin{array}{l}\text { Specific Activi } \\
\text { LLW at Variou }\end{array}$ & $\begin{array}{l}\text { (Ci/m3) of } \\
\text { s Facilities } \\
\text { Newly } \\
\text { generated } \\
\text { (1995) }\end{array}$ & \multicolumn{2}{|c|}{$\begin{array}{c}\text { Volume of MLLW at Sites } \\
\text { New }\end{array}$} & \multicolumn{3}{|c|}{$\begin{array}{c}\text { Curies of MLLW at Sites } \\
\text { New }\end{array}$} \\
\hline$\overline{F e r n a l d}^{\circ}$ & 4.089 & 5.358 & 786 & 1,945 & 3,214 & 10,422 & 13,636 \\
\hline Hanford $^{b}$ & 4.089 & 16.163 & 8,209 & 59,573 & 33,563 & 962,863 & 996,426 \\
\hline INEEL & 0.026 & 9.906 & 967 & 733 & 25 & 7,261 & 7,286 \\
\hline LANL $^{b}$ & 4.089 & 1.418 & 524 & 441 & 2,142 & 625 & 2,768 \\
\hline NTS ${ }^{\circ}$ & 4.089 & 5.358 & 293 & 0 & 1,198 & 0 & 1,198 \\
\hline ORNL & 217.437 & 2.223 & 14,738 & 27,292 & $3,204,587$ & 60,671 & $3,265,258$ \\
\hline RFETS & 0.005 & 5.358 & 15,737 & 115,987 & 72 & 621,485 & 621,557 \\
\hline $\mathrm{SNL}^{\mathrm{b}}$ & 4.089 & 5.358 & 87 & 20 & 354 & 108 & 468 \\
\hline SRS & 196.783 & 2.424 & 4,147 & 1,836 & 816,117 & 4,452 & $820,56 s$ \\
\hline
\end{tabular}

a. IDB Table 4-11 \& 4-12

b. Specific activity based on the "Others" column in IDB.

c. Volumes from waste disposition maps.

SRM human health risk results (person-rem) for activities at each of the DOE sites are presented in Figure 8-10 through Figure 8-22. Each figure shows the baseline program and the alternative. It should be noted that the activities modeled for each site represent all of the important steps in the baseline program (or alternative), from initial storage through final disposal.

Figure $8-23$ is a summary of the total human health risk (person-rem), baseline program and alternative, for each of the nine sites, plus off-site transportation and final disposal. Transportation in the alternative shows the highest level of risk because of the normal exposure to the workers and the public during shipment.

Figure 8-24 summarizes the DOE complex-wide MLLW risk results by activity type: storage, handling, treatment, transportation, and disposal. Handling and transportation (in the alternative) are significant contributors to the overall MLLW risk. Treatment also contributes significantly. Handling and transportation are primarily contributing through the normal exposure of site workers through the exposure to direct radiation.

Figure 8-25 summarizes the total DOE complex-wide MLLW risk for the baseline program and alternative. The total risk for the MLLW baseline program is approximately 1580 person-rem, while the alternative case is approximately 2040 person-rem. This is a relatively small increase in risk for the alternative, given the accuracy of the SRM. Therefore, both the baseline program and the alternative are considered to have similar total risks. 
MLW Baseline Waste Disposition Map

\section{PREDECISIONAL DRAFT}

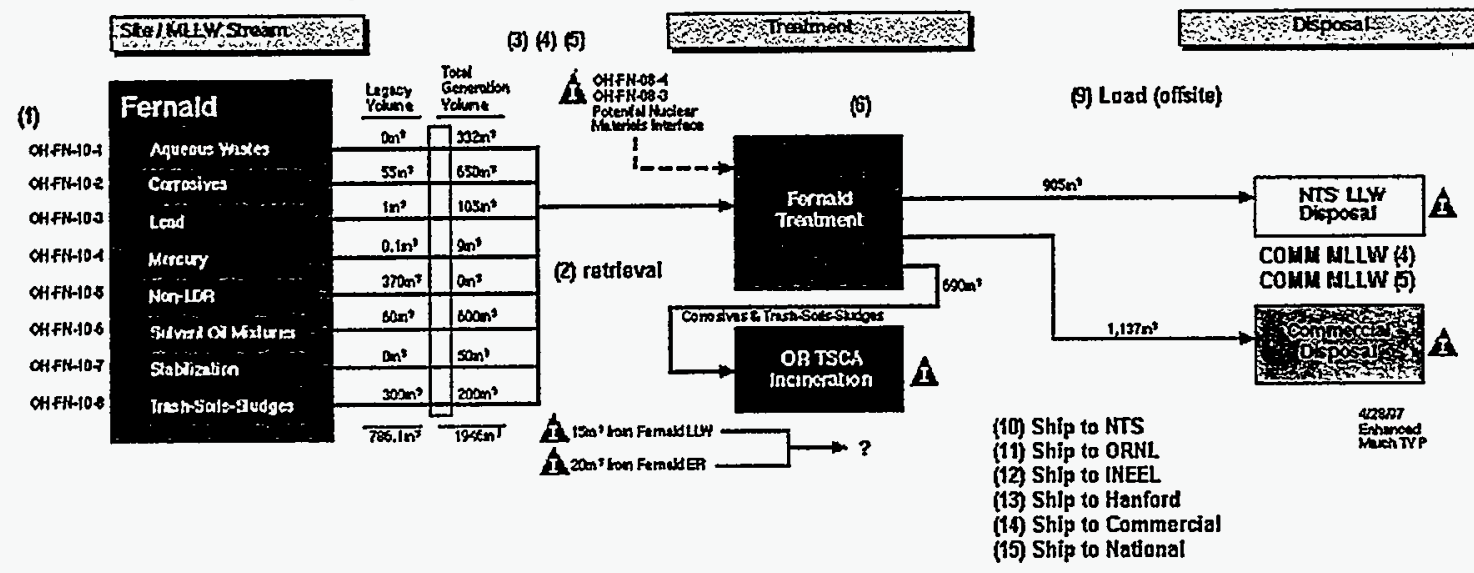

MLW Alternative Waste Disposition Map

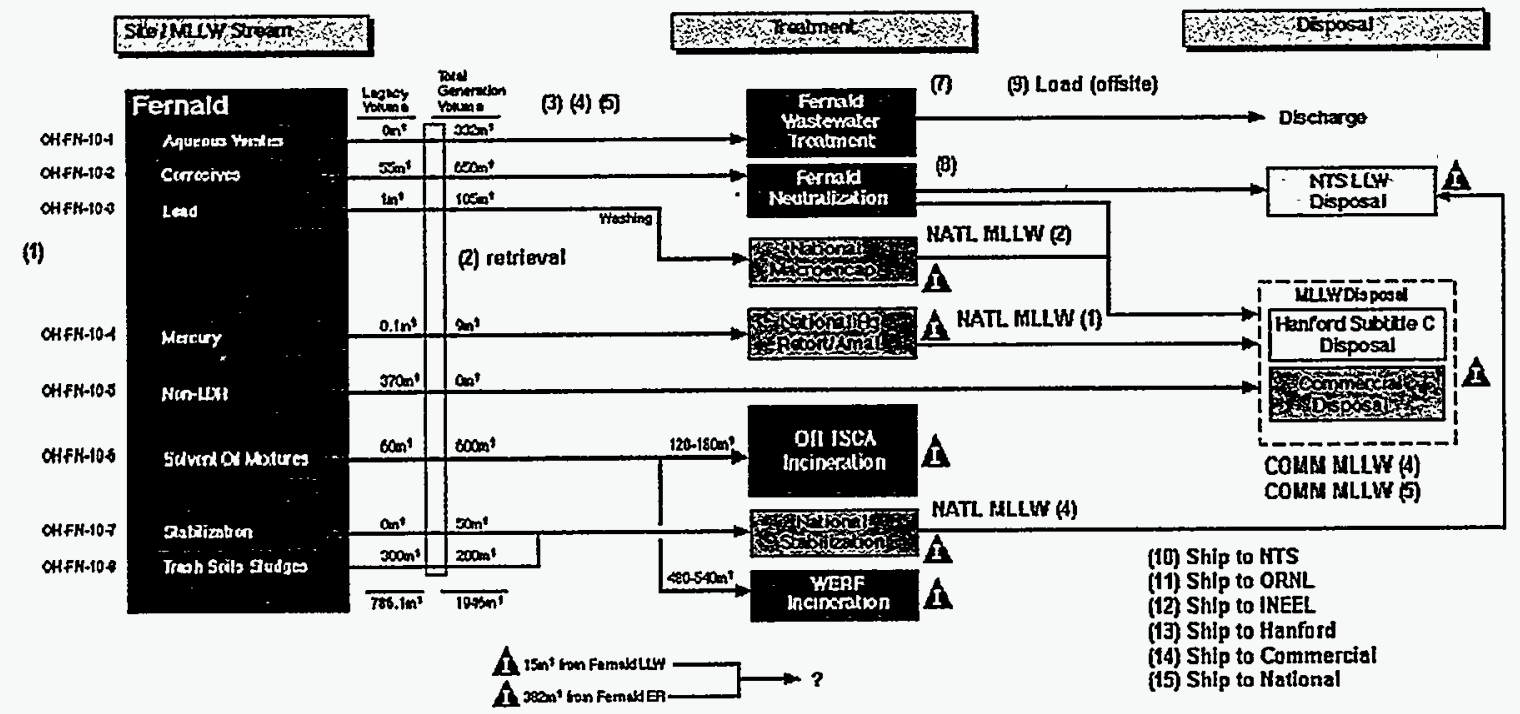

Figure 8-1. Fernald MLLW disposition maps (baseline and alternative). 
MLW Baseline Waste Disposition Map

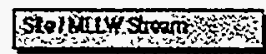

PREDECISIONAL DRAFT

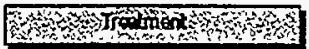

Fos

(19) (14)

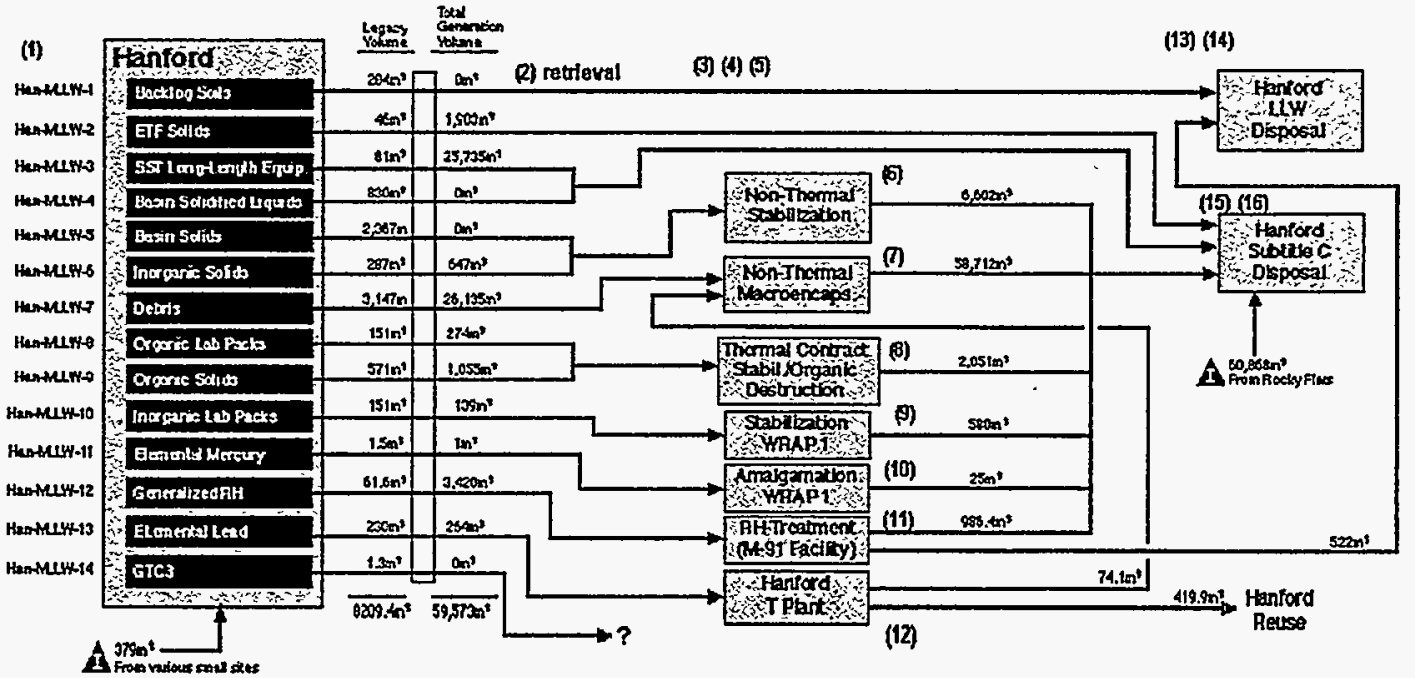

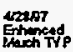

\section{MLW Alternative Waste Dlsposition Map}

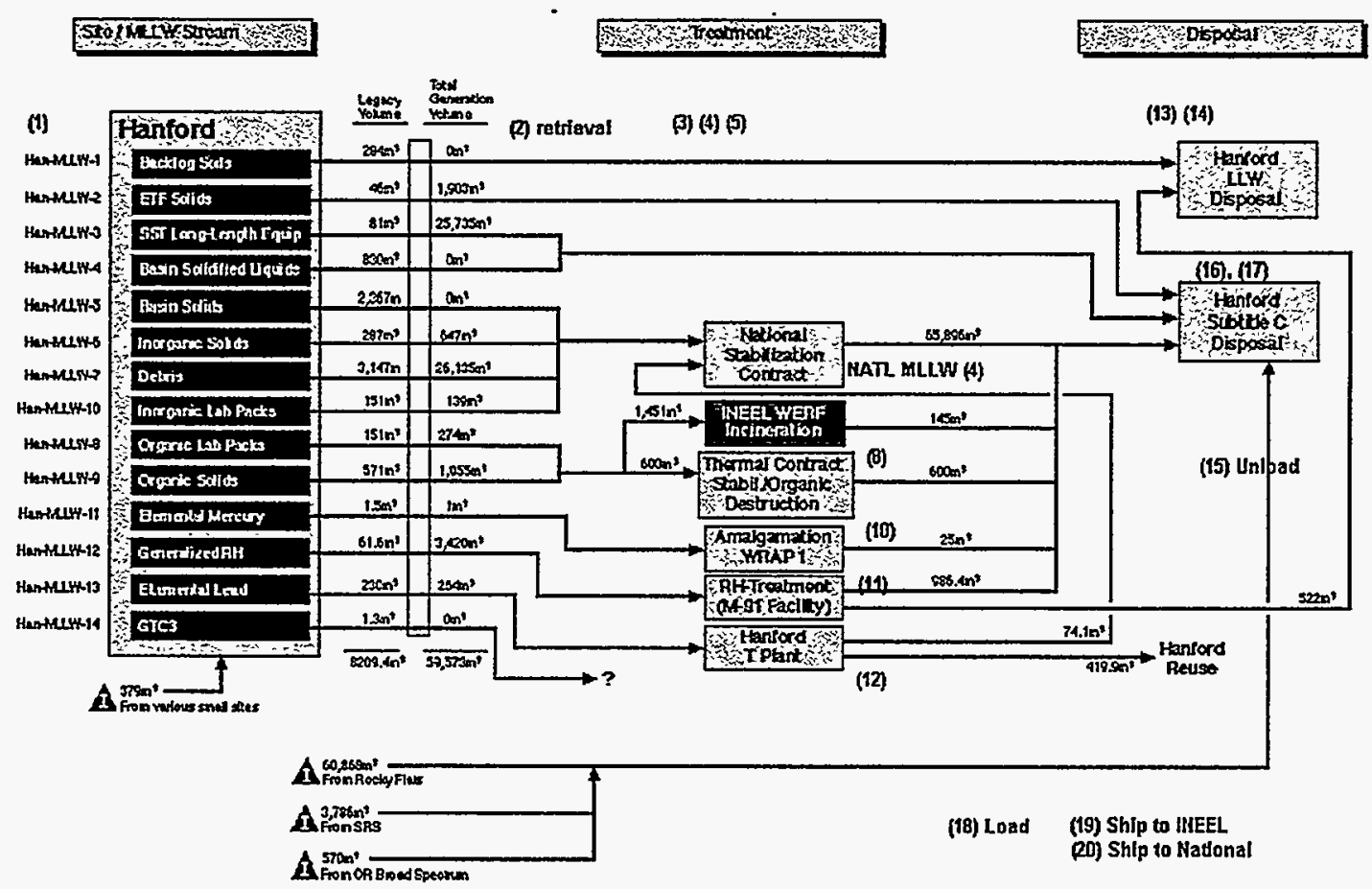

Figure 8-2. Hanford MLLW disposition maps (baseline and alternative). 


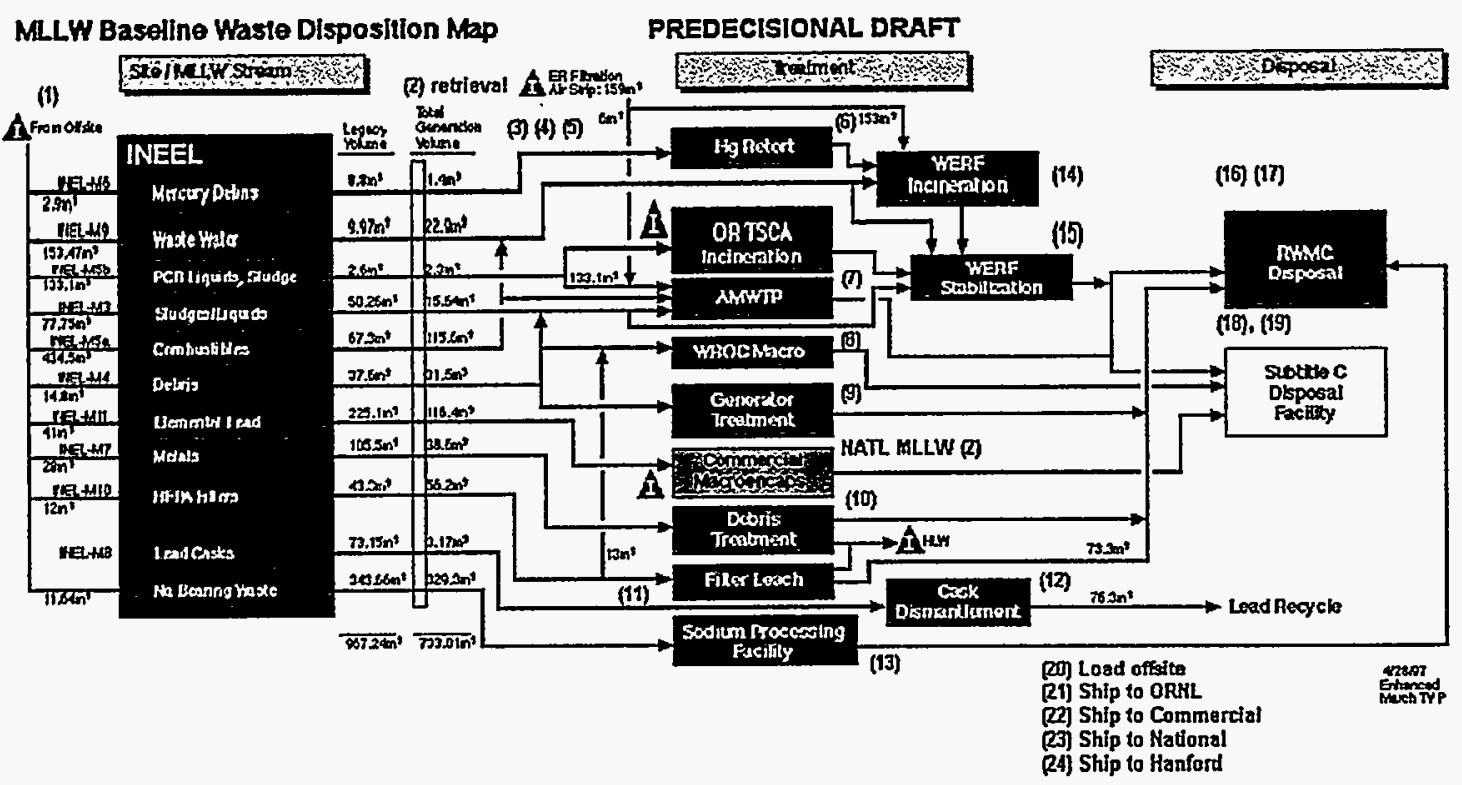

MLLW Alternalive Waste Disposition Map

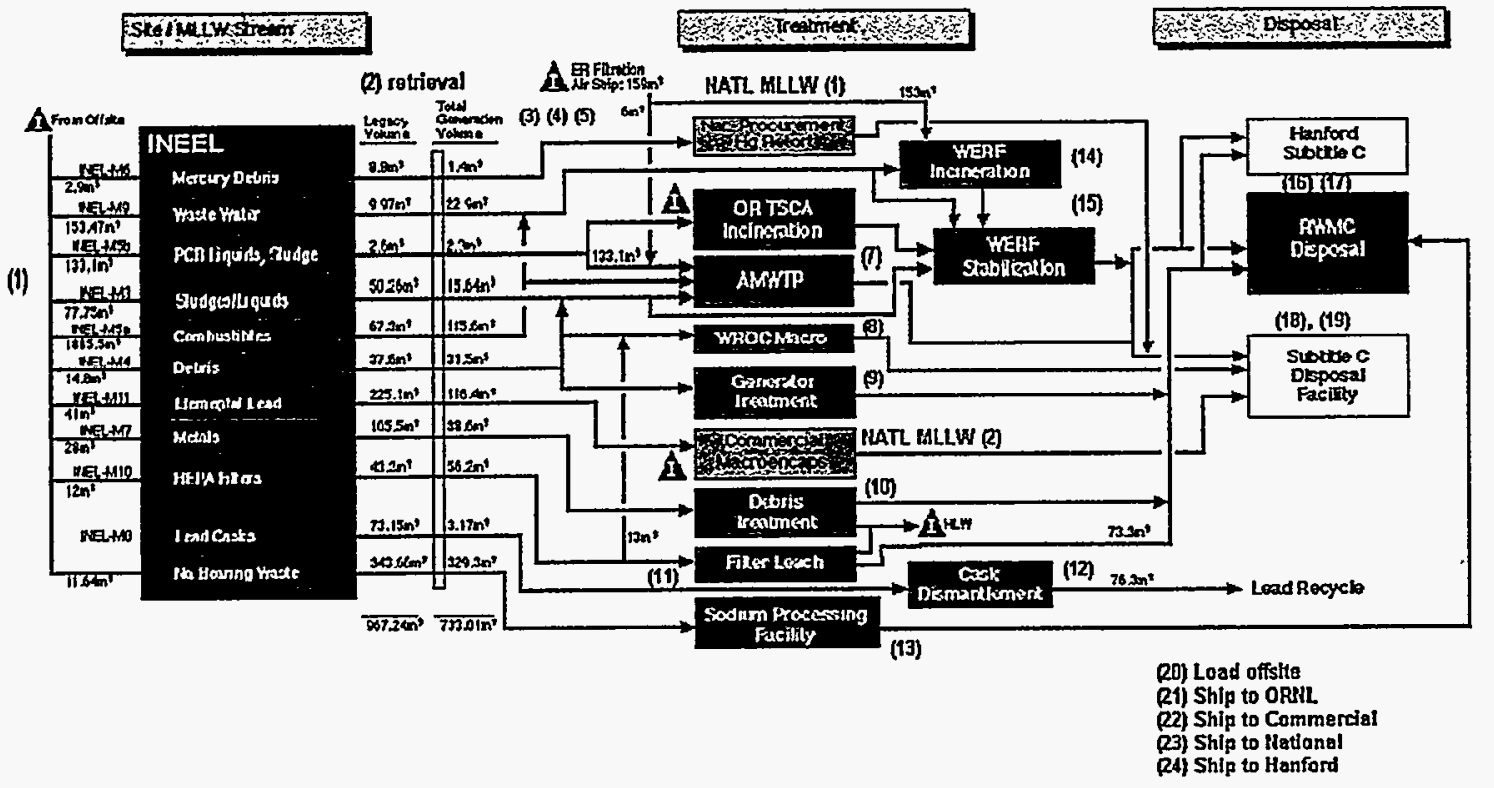

Figure 8-3. INEEL MLLW disposition maps (baseline and alternative). 
MLLW Baseline Waste Disposition Map

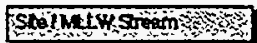

PREDECISIONAL DRAFT

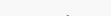

Qjos

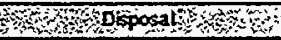

(1)

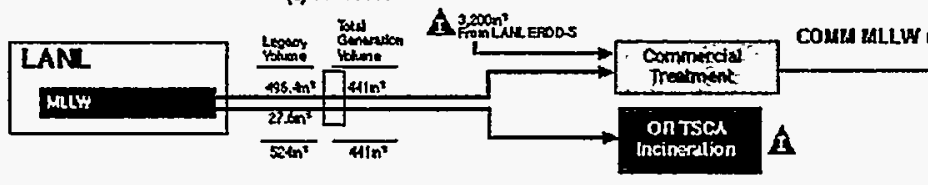

Dad offiste

(8) Ship to Commarcial Estancer

(9) Ship to ORNL

(fO) Ship to IKEEL.

COaㅕ AILLW (4) COMM MLLW (j)

(11) Ship to Hational

MLW Alternatuve Waste Dlsposition Map

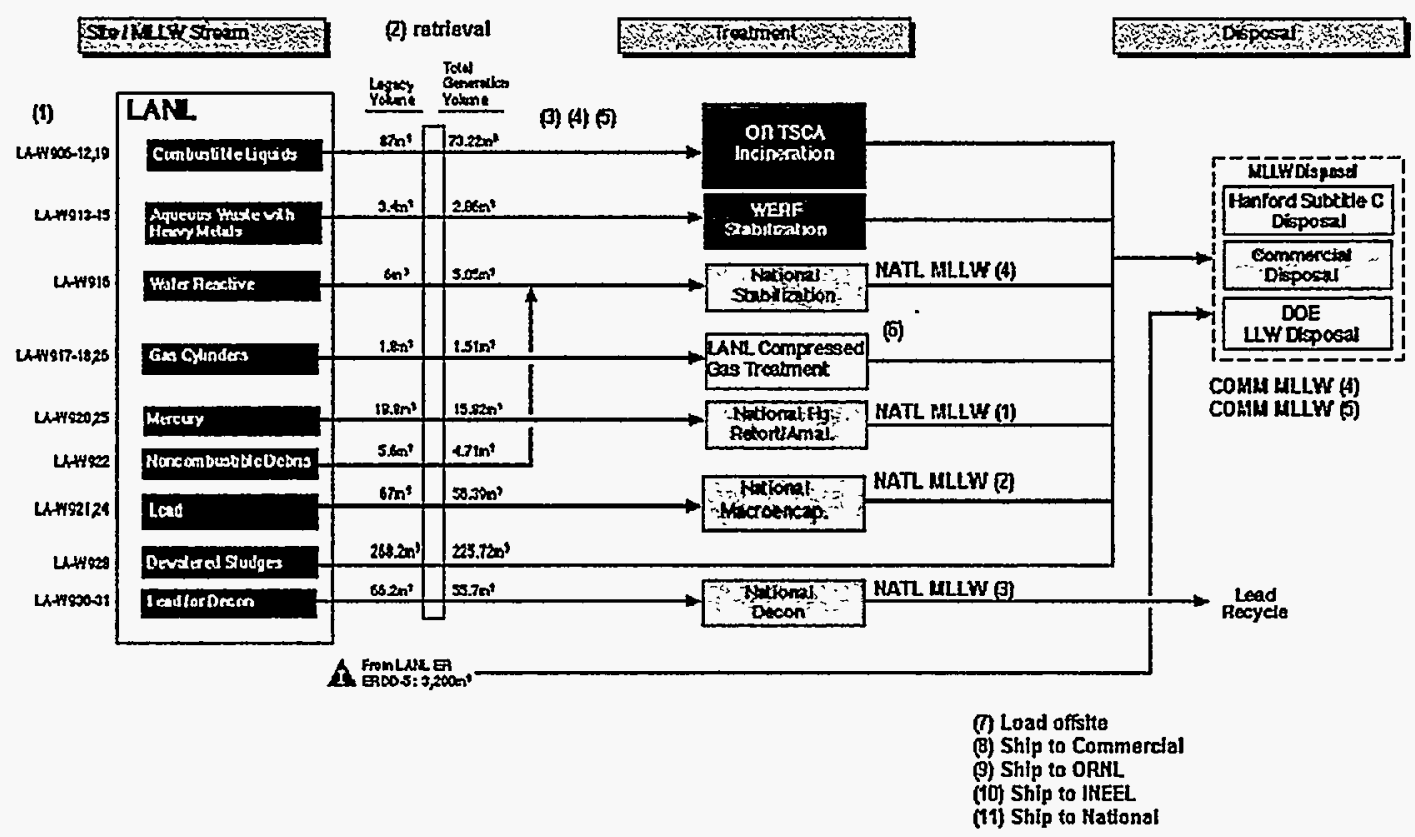

Figure 8-4. LANL MLLW disposition maps (baseline and alternative). 
MLLW Baseline Waste Disposition Map

PREDECISIONAL DRAFT

Stormet stoon

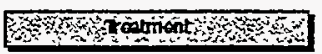

Fyososing

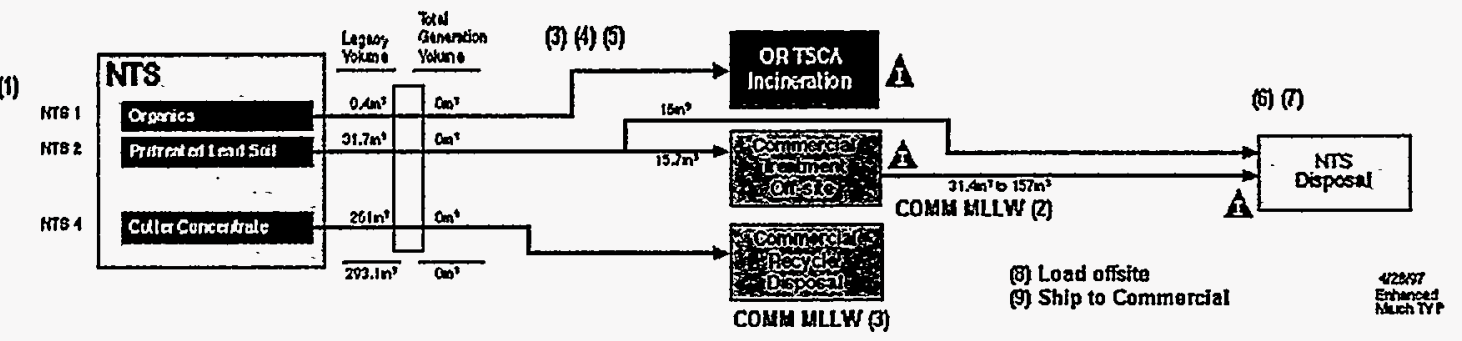

MLLW Alternative Waste Disposition Map

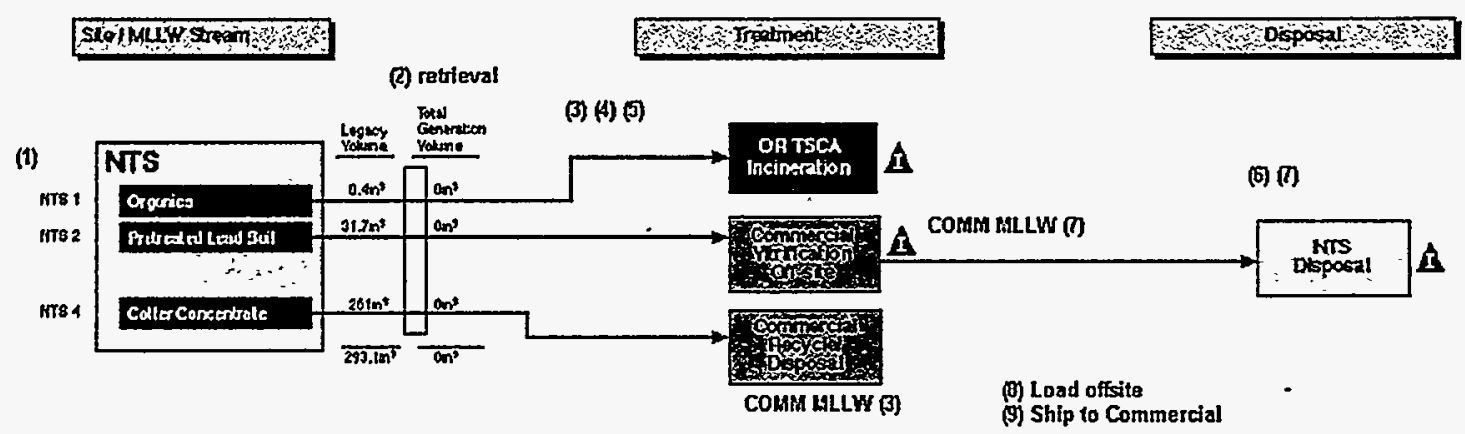

Figure 8-5. NTS MLLW disposition maps (baseline and alternative). 


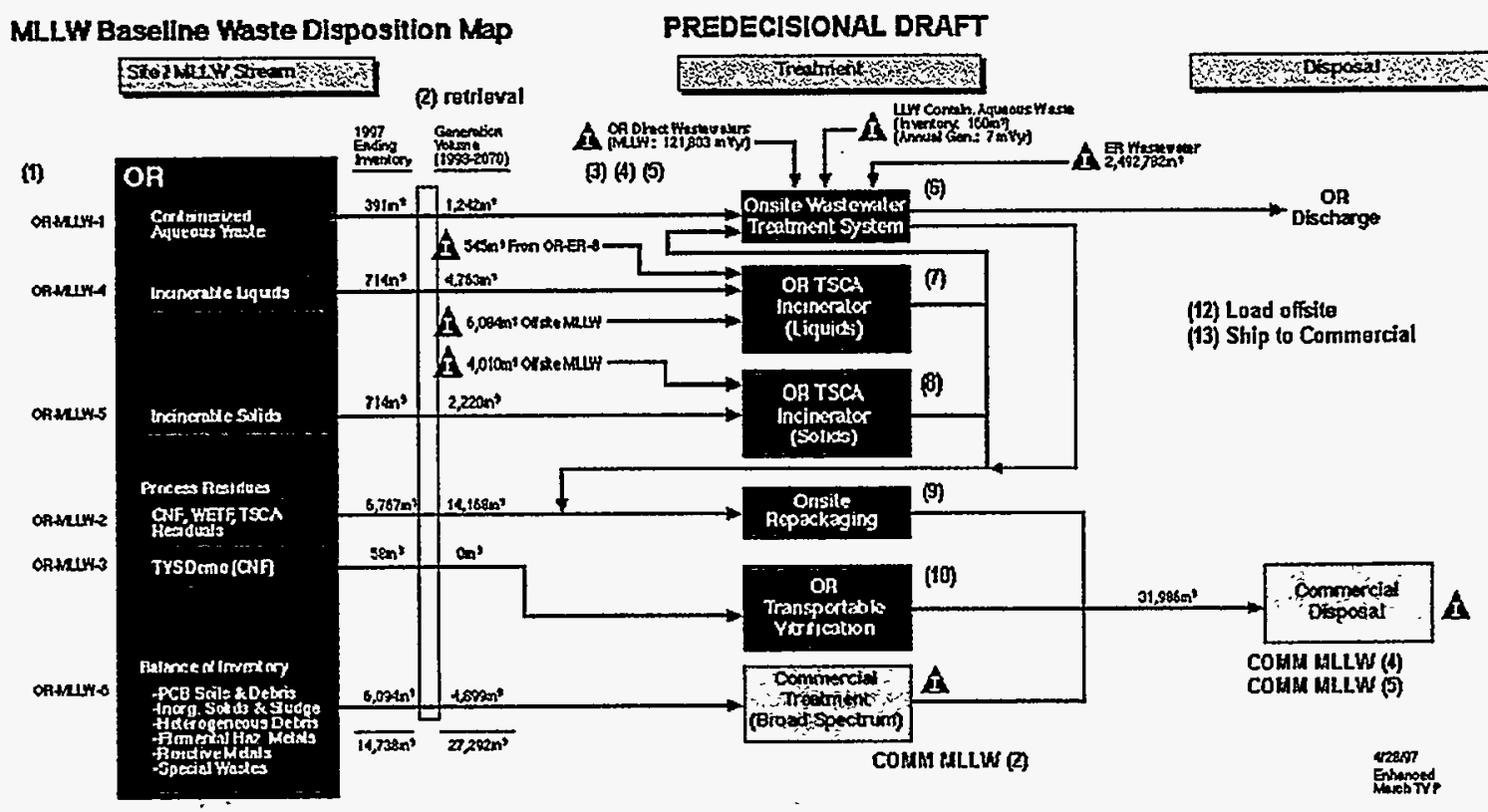

\section{MLLW Alternative Kaste Disposition Map}

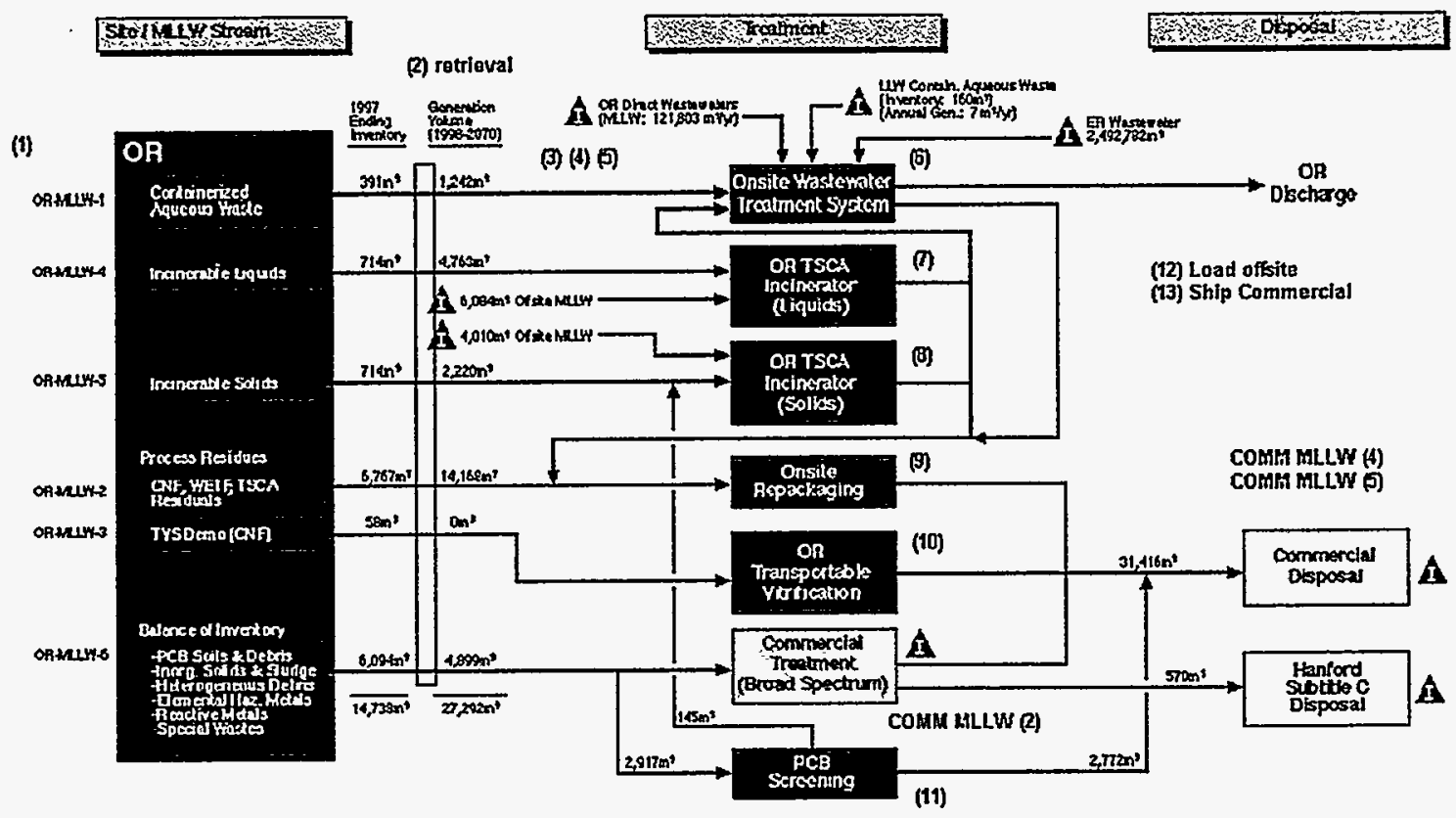

Figure 8-6. ORNL MLLW disposition maps (baseline and alternative). 


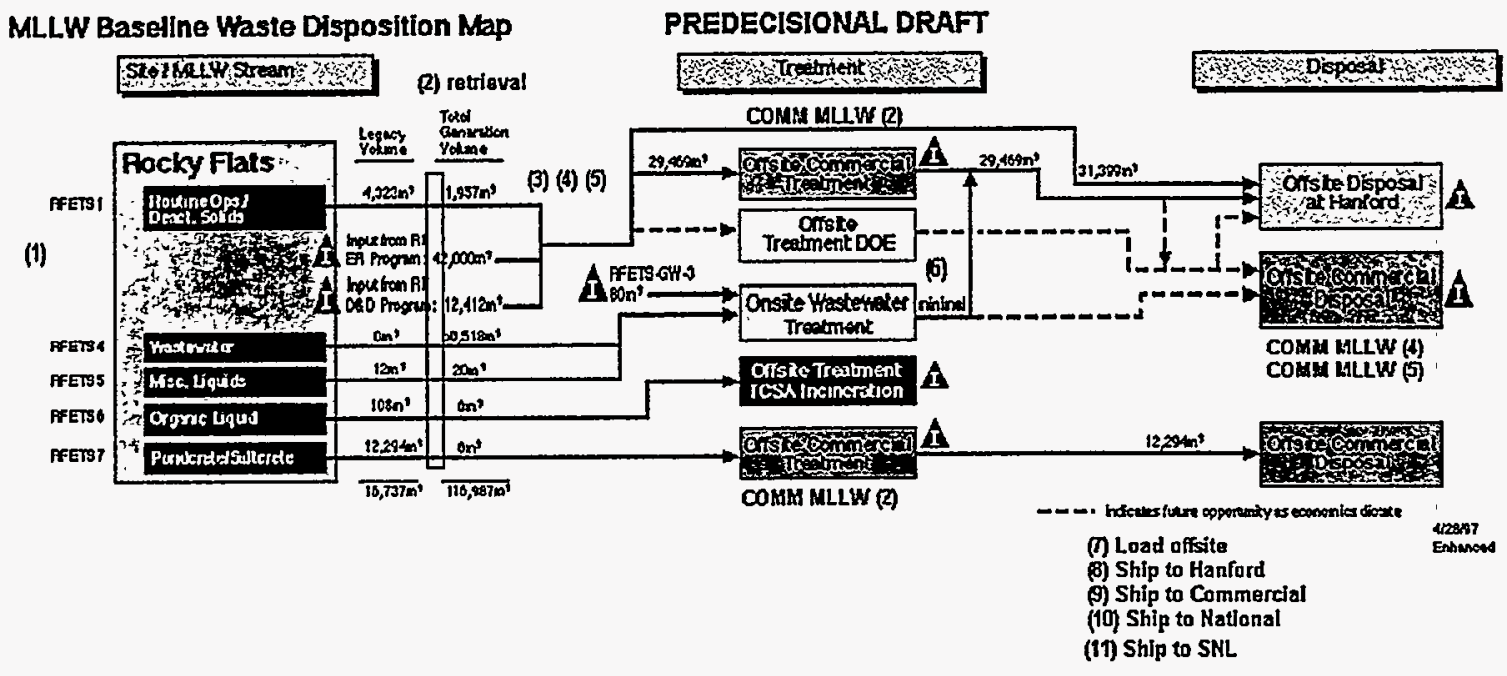

MLLW Altemative Waste Disposition Map

STolMCLFofing

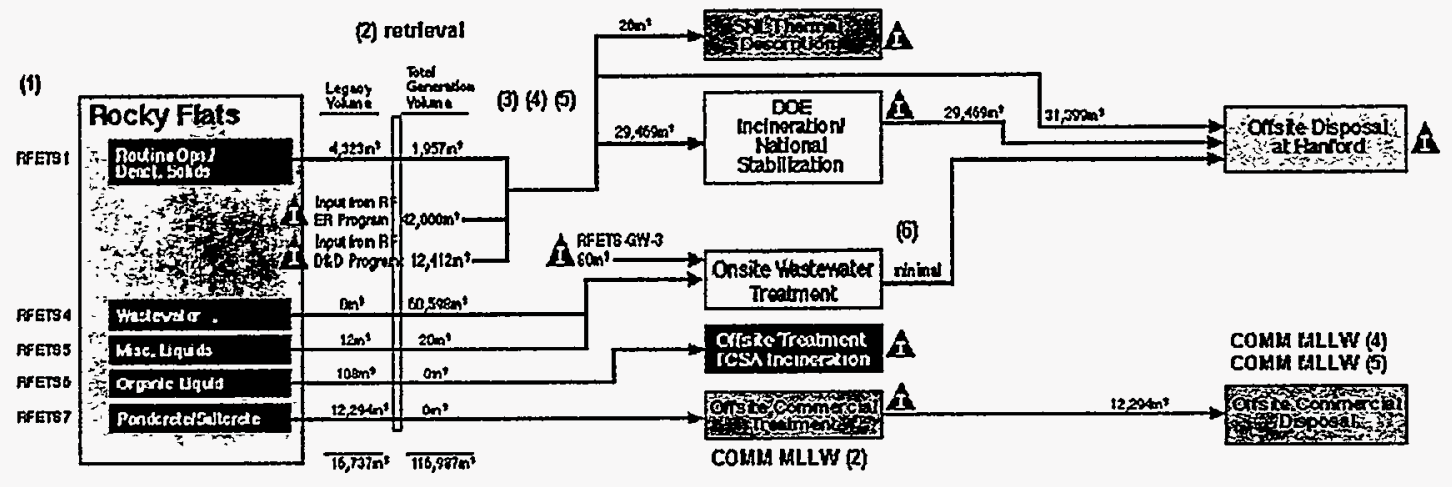

(1) Load offita

(B) Ship to Hanford

(9) Ship to Commercial

(10) Ship to Nationa!

(11) Ship to Sill.

Figure 8-7. RFETS MLLW disposition maps (baseline and alternative). 


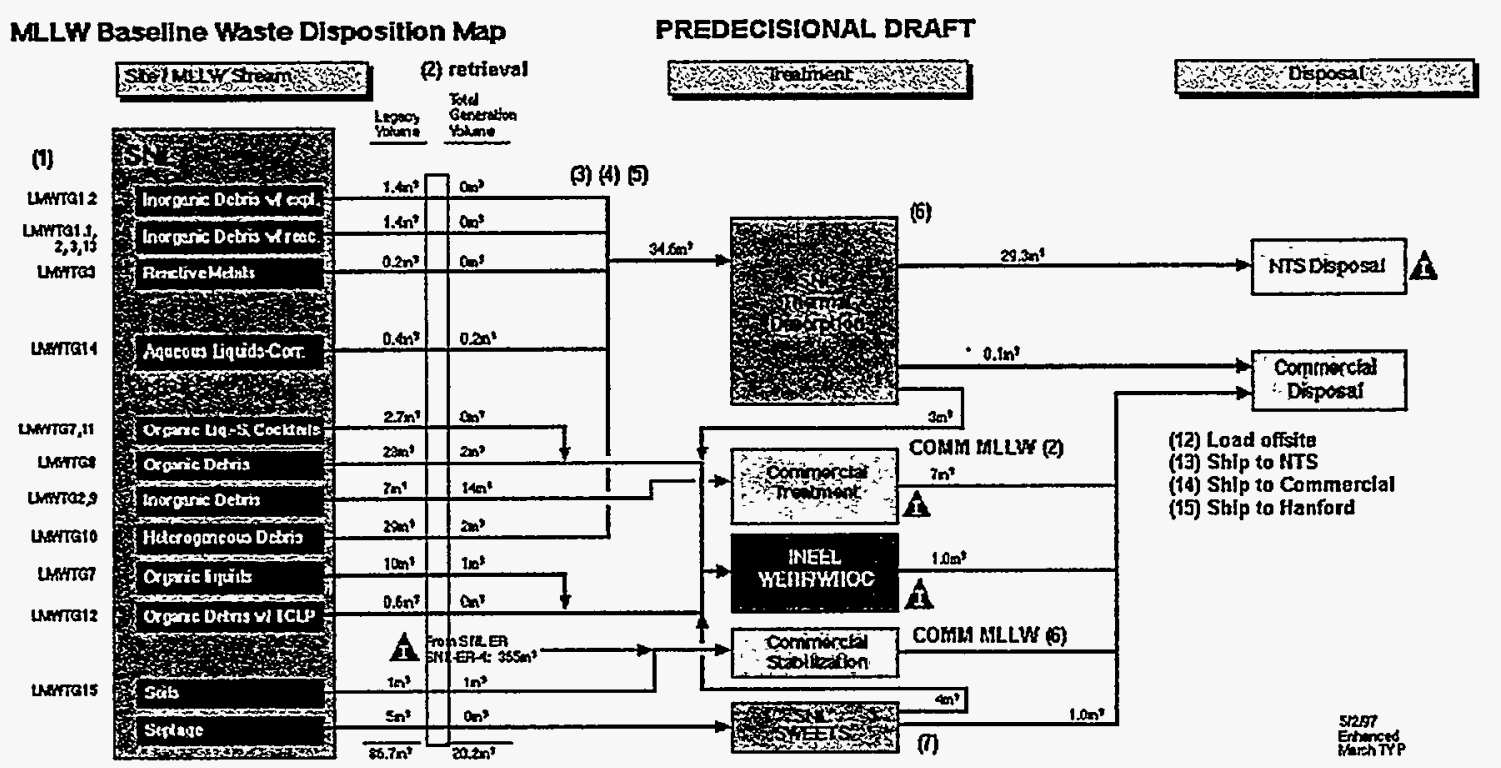

MLW Alternative Waste Disposition Map

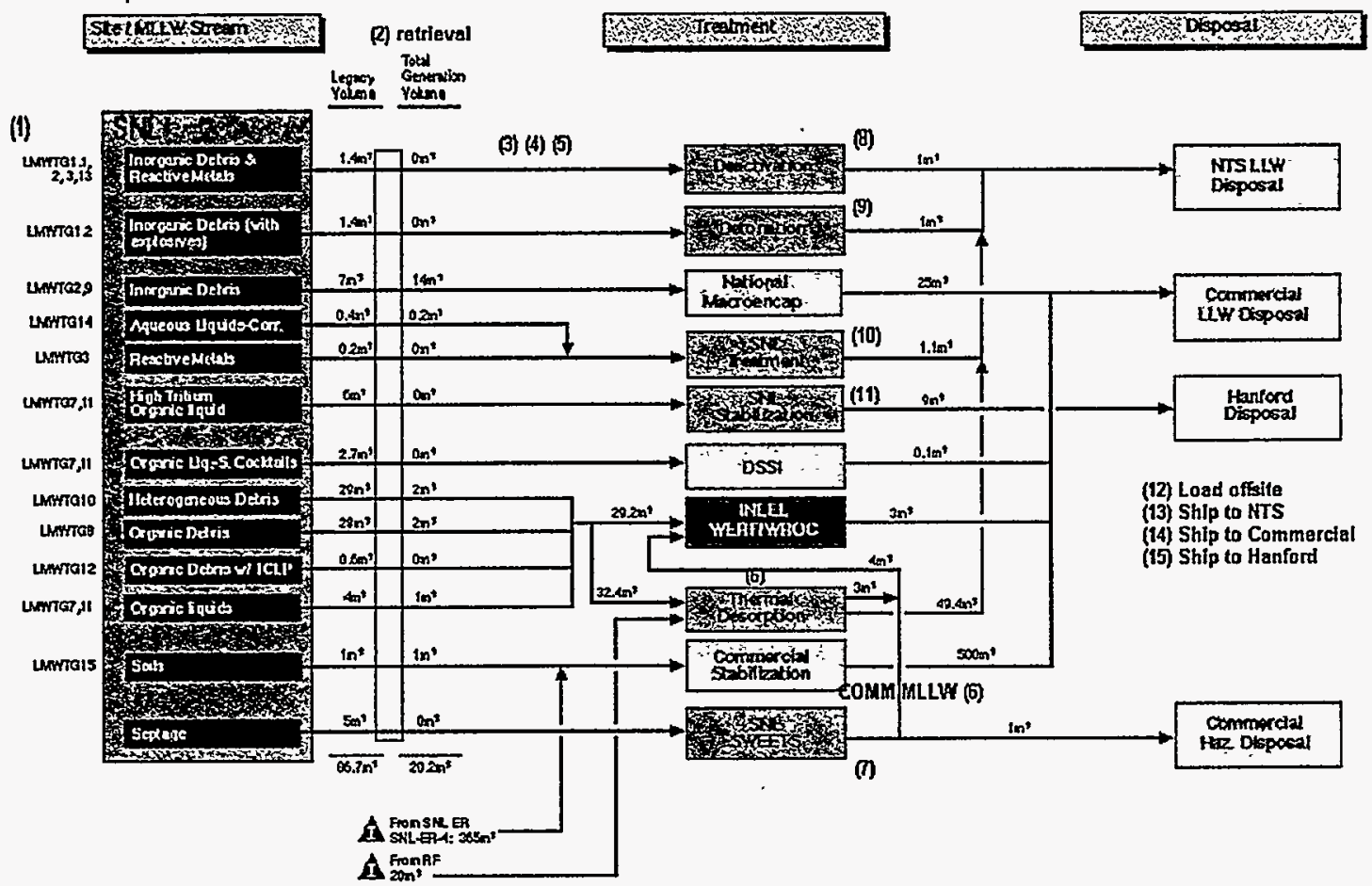

Figure 8-8. SNL MLLW disposition maps (baseline and alternative). 


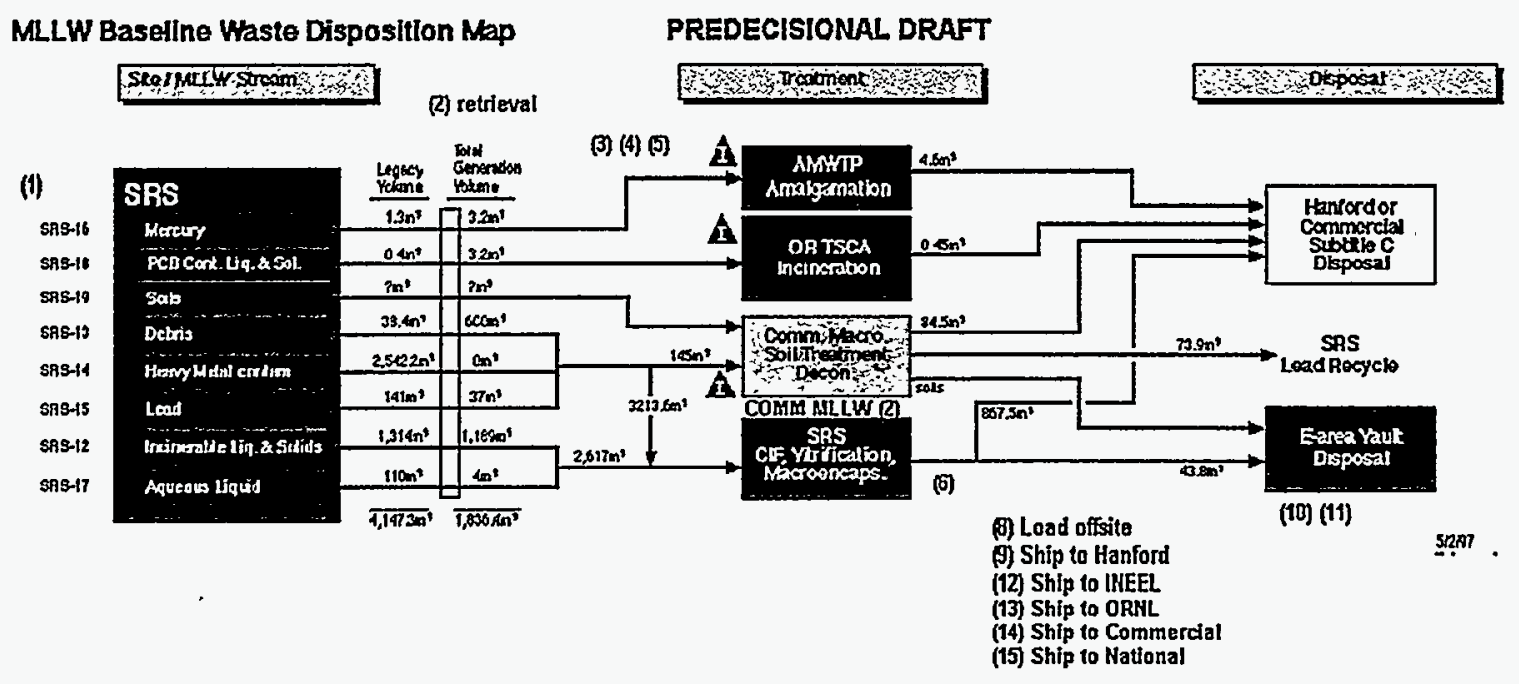

MLLW Alternative Waste Disposition Map

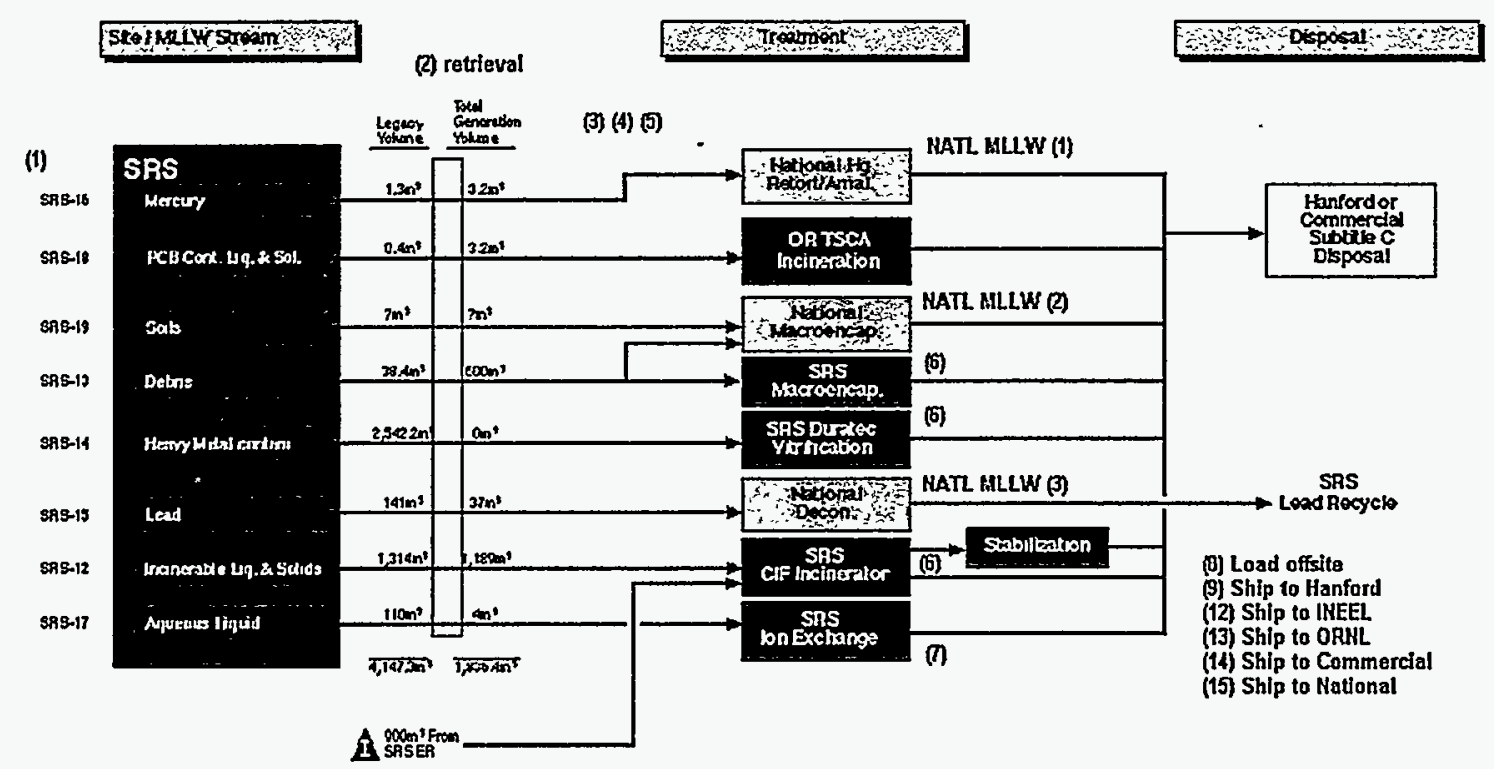

Figure 8-9. SRS MLLW disposition maps (baseline and alternative).

Figure 8-26 through Figure 8-28 show the breakdown of risk into public and worker/site contributions.

Finally, Figure 8-29 through Figure 8-31 show the breakdown of risk from accidents and normal, incident-free operation. Overall, the risk from normal, incident-free operation is much higher compared to the risk from accidents, but if the contribution from transportation were set aside, the risk would be largely due to accidents.

The complete SRM MLLW model is an EXCEL ${ }^{\mathrm{TM}}$ workbook, with separate spreadsheets for each of the activities summarized in Figure 8-10 through Figure 8-22. The spreadsheets 
contain detailed risk information on the following: accident risk (airborne) to workers, DOE site personnel, and the public, broken down into contributions from actinides, non-actinides, and chemicals; groundwater ingestion risk to the public from actinides, non-actinides, and chemicals; offgas risk (airborne) to DOE site personnel and the public, broken down into contributions from actinides, non-actinides, and chemicals; normal exposure (direct radiation) to workers; and normal and accident risk to the crew and public for transportation. All of these contributors (as applicable to the activity in question) are summed in order to estimate the total risk from the activity.

Because the SRM MLLW model is computerized, sensitivity studies can be performed relatively easily. Also, if more opportunities are identified in the future, the SRM analyses can be performed efficiently. Finally, existing SRM MLLW results can be broken down in many different ways to respond to questions from stakeholders.

The SRM risk results were compared with other risk estimate sources to ensure that the risk predictions are consistent with more detailed analyses. Comparisons were made with results from the Final Waste Management Programmatic Environmental Impact Statement (WM-PEIS). ${ }^{6}$ A review of the WM-PEIS alternatives indicated that Regional Alternative 2 most closely matched the HLW baseline program outlined in the disposition maps. For Regional Alternative 2, the WMPEIS lists 1441 person-rem (p. 6-38) for treatment, 1300 person-rem (p. 6-37) for disposal, and 188 person-rem (p. E-83) for transportation. The total is 2929 person-rem. In comparison, the SRM baseline risk result for MLLW is 1581 person-rem. To compare only transportation results, the WP-PEIS results must be multiplied by a factor of 2.1 to account for the additional shipping in the baseline program. The WM-PEIS transportation result is then 403 person-rem, while the corresponding SRM result is 297 person-rem.

The SRM has been used to comprehensively and consistently model human health risk from radionuclides (and to a limited extent, chemicals) for the entire DOE MLLW baseline program and opportunities. The model predicts approximately 1580 person-rem for the baseline program, covering initial storage all the way through final disposal. The difference in risk between the alternative program and the baseline program, approximately 460 person-rem, can be attributed to more transportation in the alternative.

Limited comparisons indicate that individual portions of the SRM are generally matching the results from more detailed risk assessments and actual exposure data. However, no detailed risk assessment covers all of the activities included in the SRM MLLW model, so the overall SRM MLLW risk results cannot be compared. It should be noted that a comparison of volumes listed in the WM-PEIS and the volumes identified on the waste disposition maps show some discrepancies. 


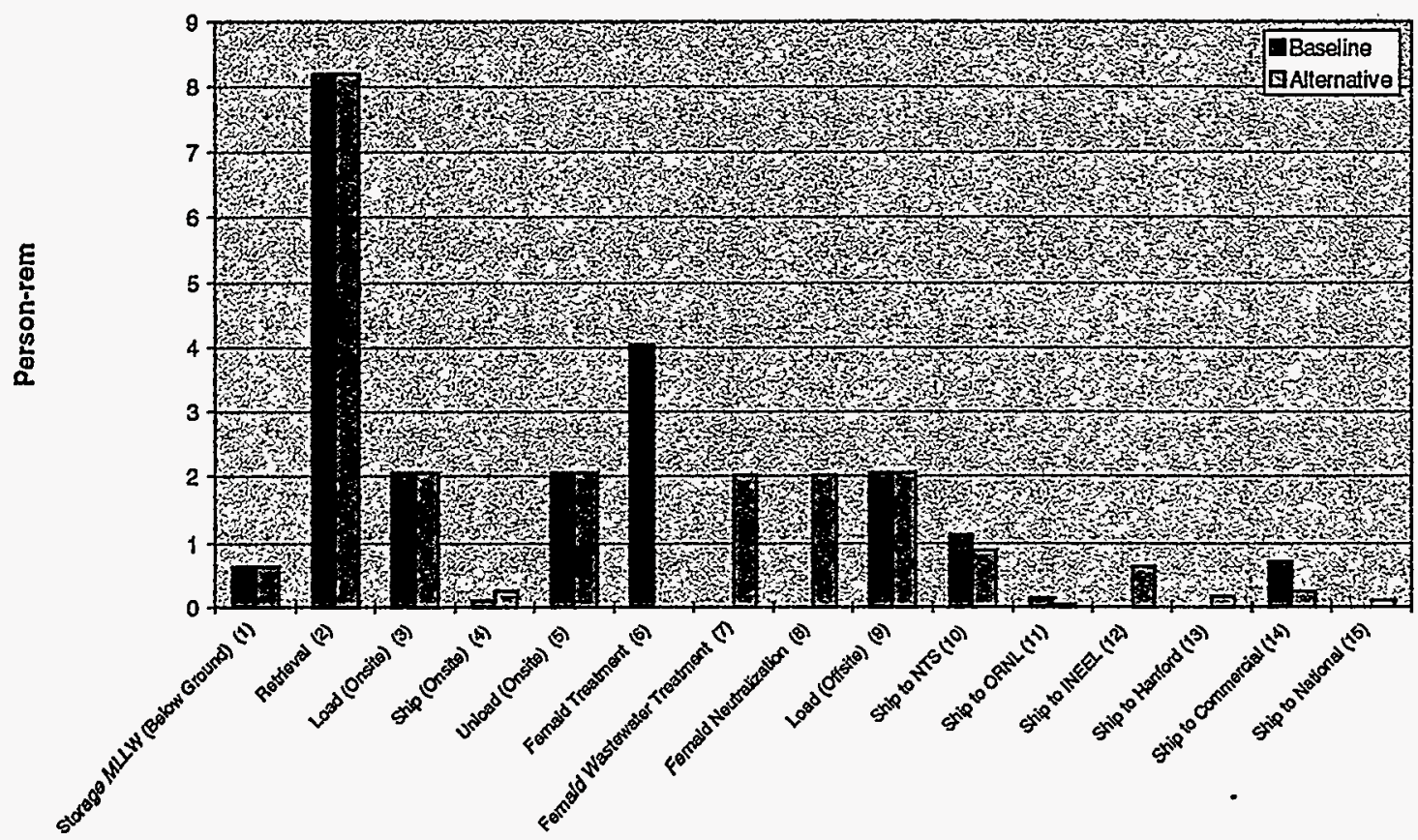

Figure 8-10. Fernald MLLW risk results by activity.

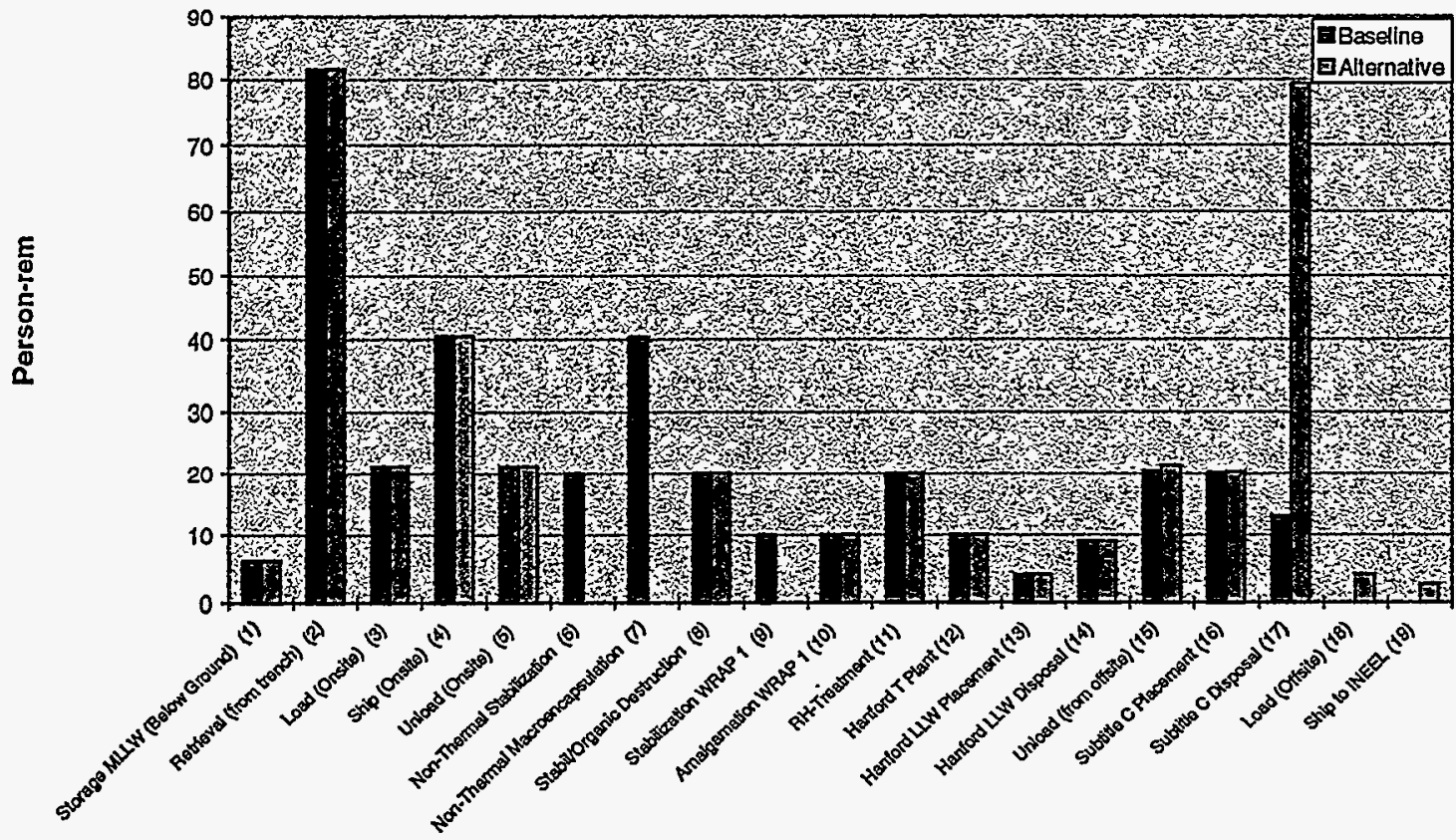

Figure 8-11. Hanford MLLW risk results by activity. 


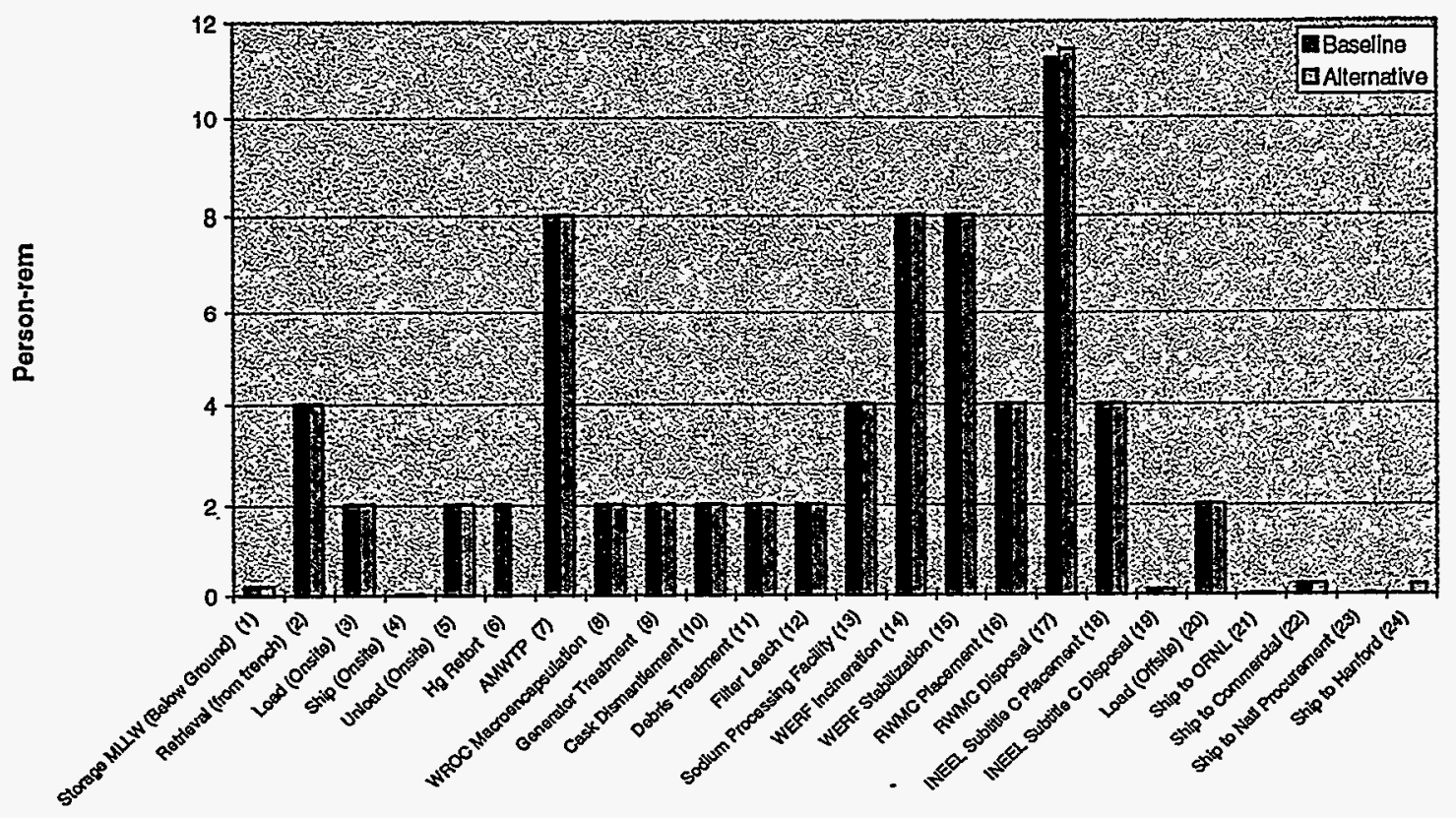

Figure 8-12. INEEL MLLW risk results by activity.

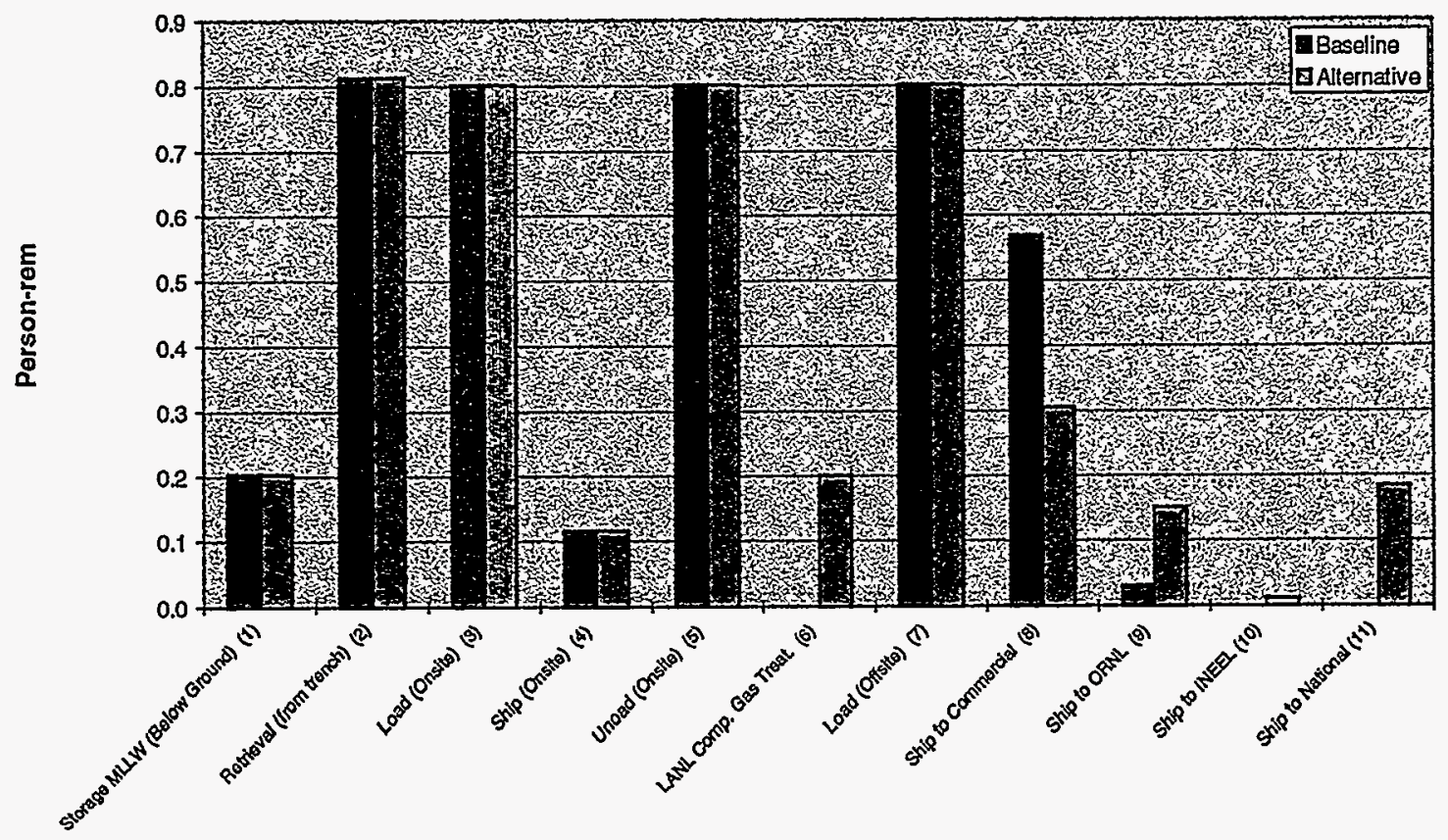

Figure 8-13. LANL MLLW risk results by activity. 


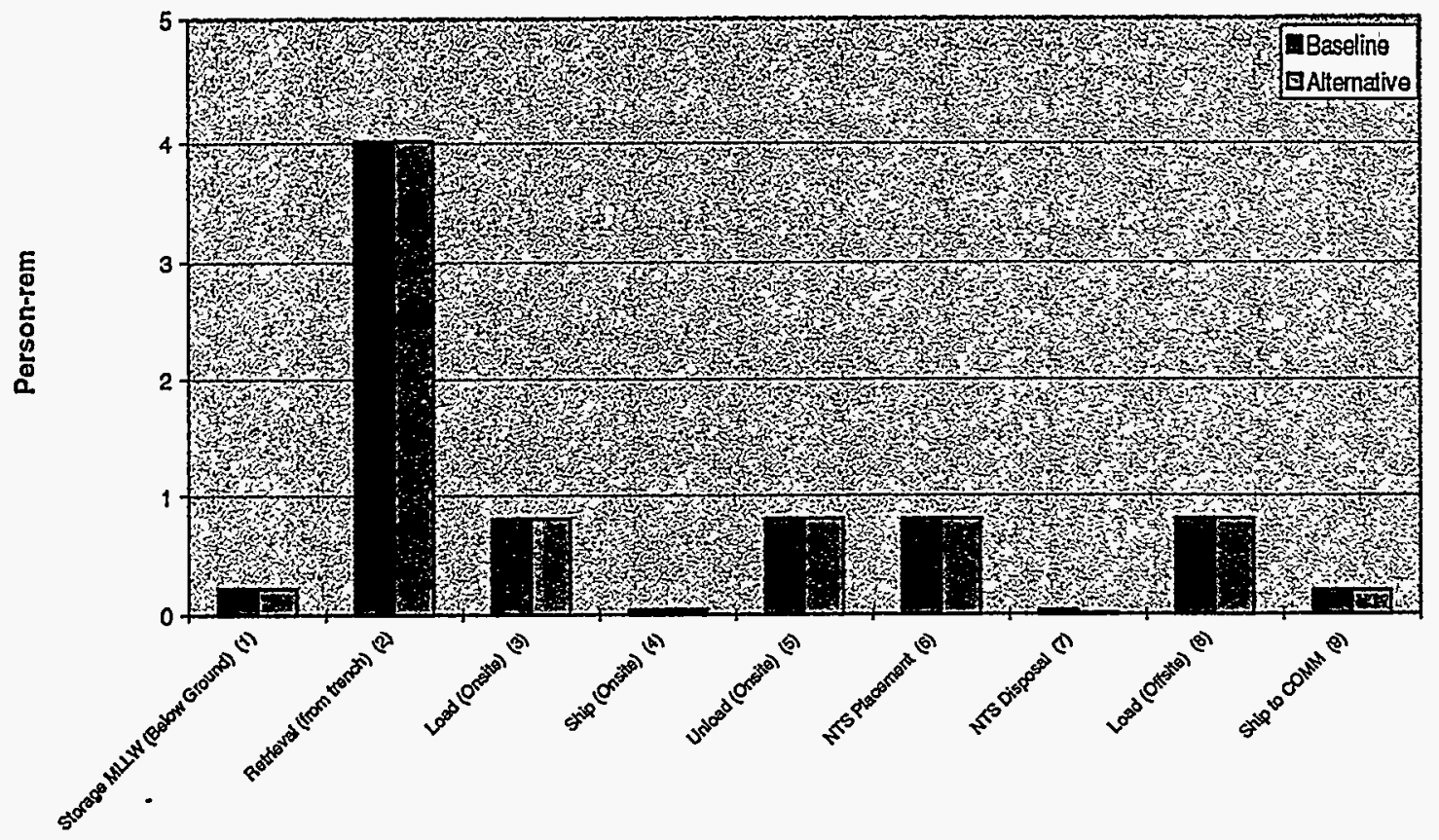

Figure 8-14. NTS MLLW risk results by activity.

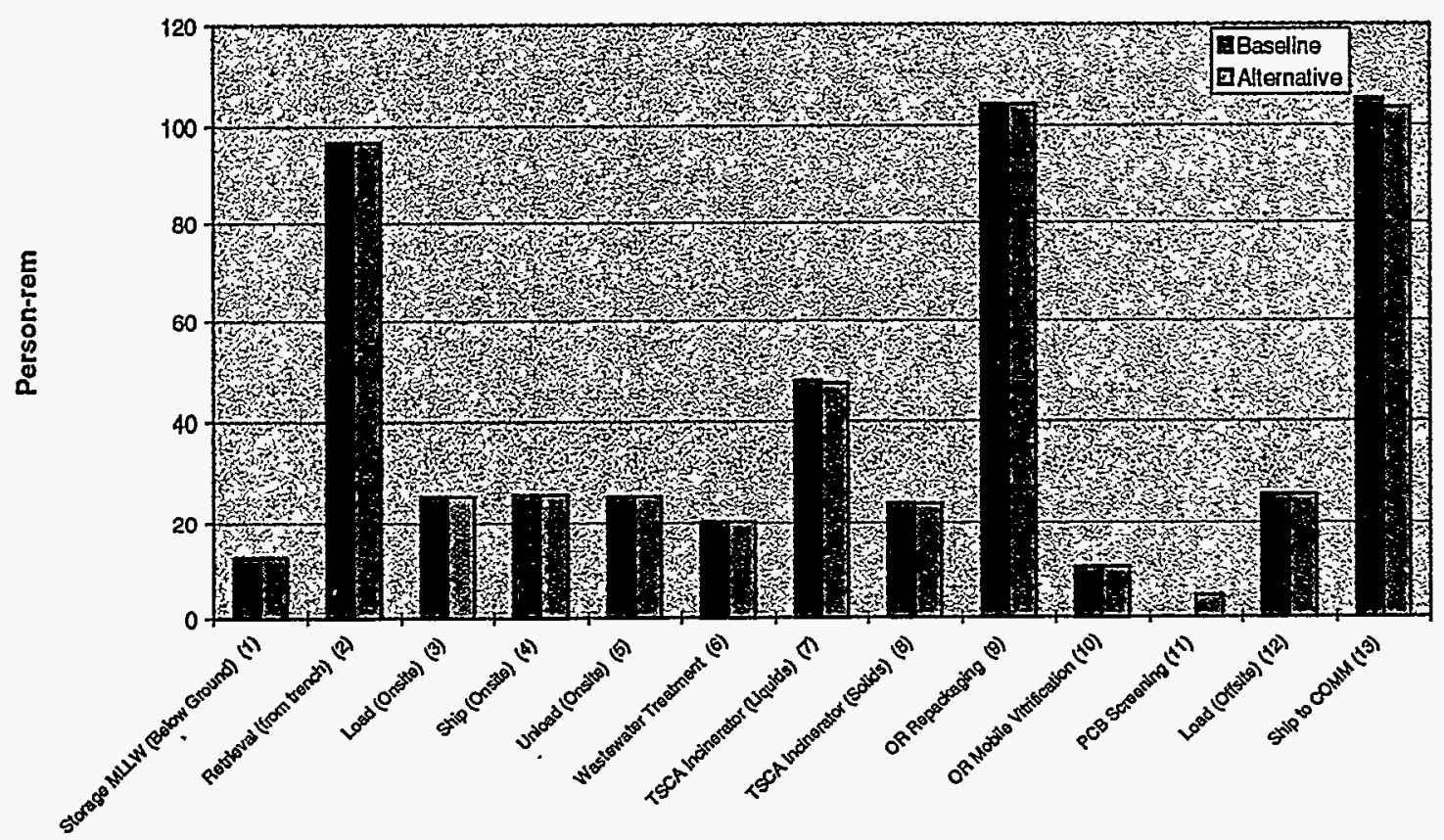

Figure 8-15. ORNL MLLW risk results by activity. 


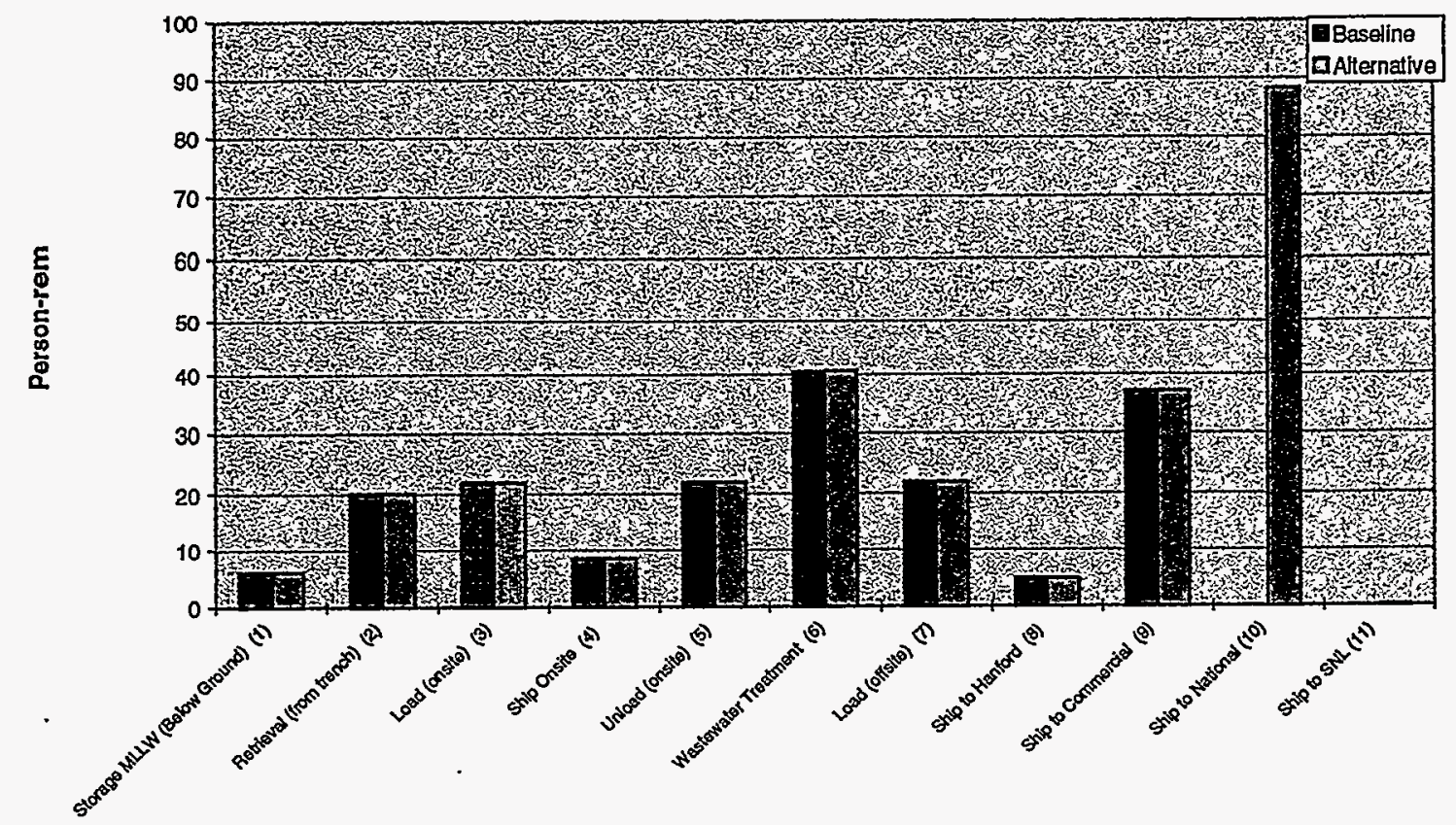

Figure 8-16. RFETS MLLW risk results by activity.

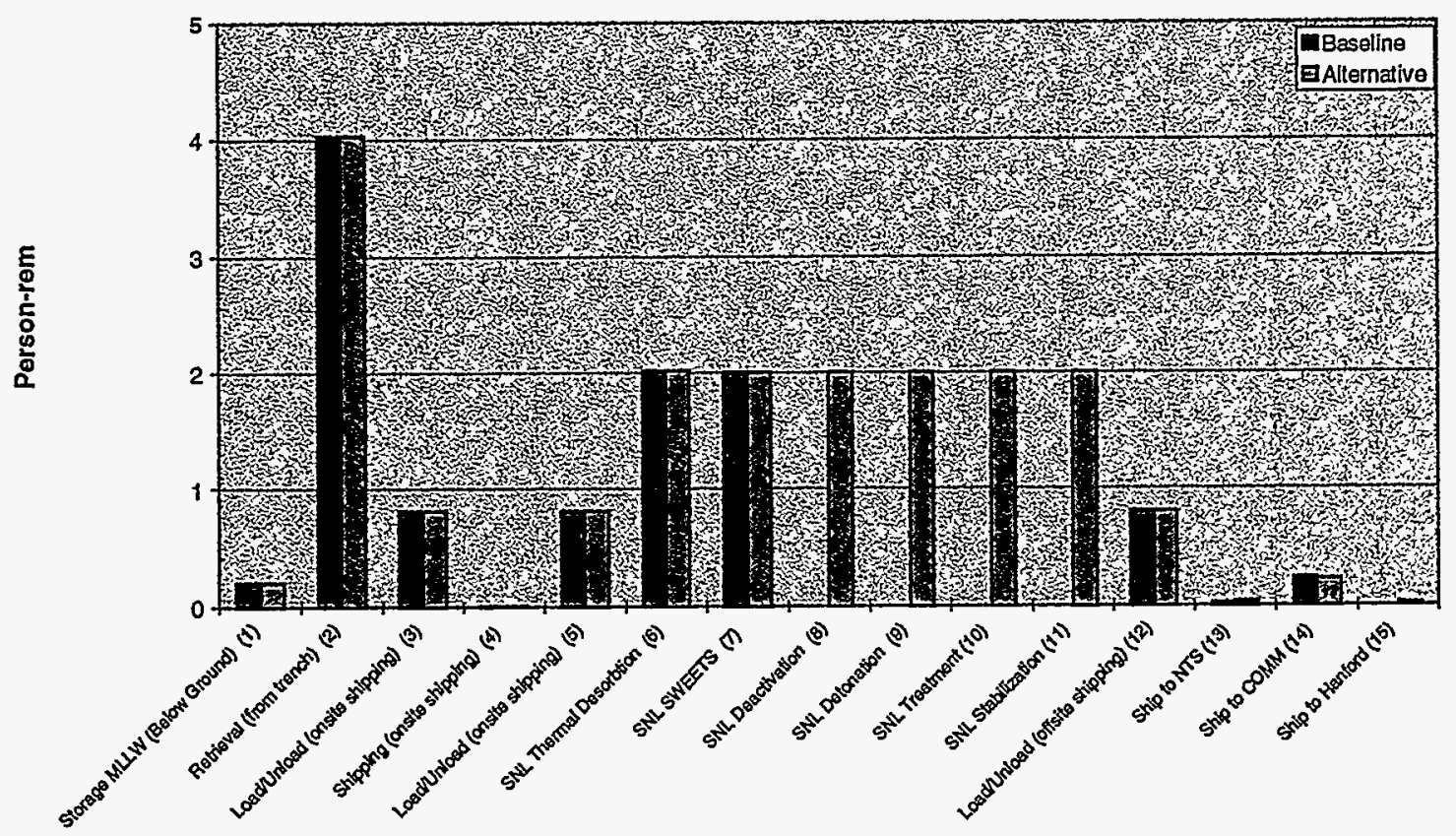

Figure 8-17. SNL MLLW risk results by activity. 


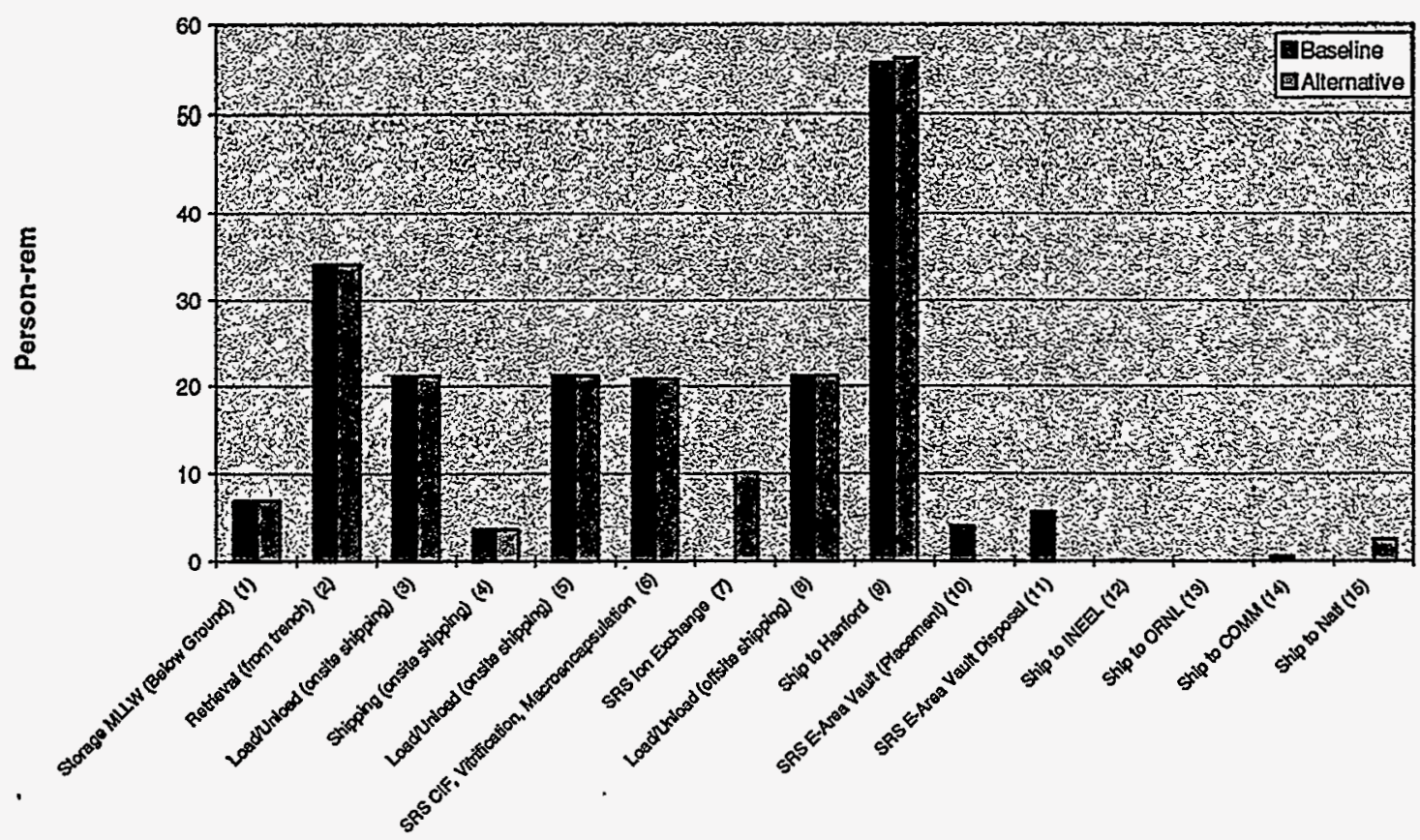

Figure 8-18. SRS MLLW risk results by activity.

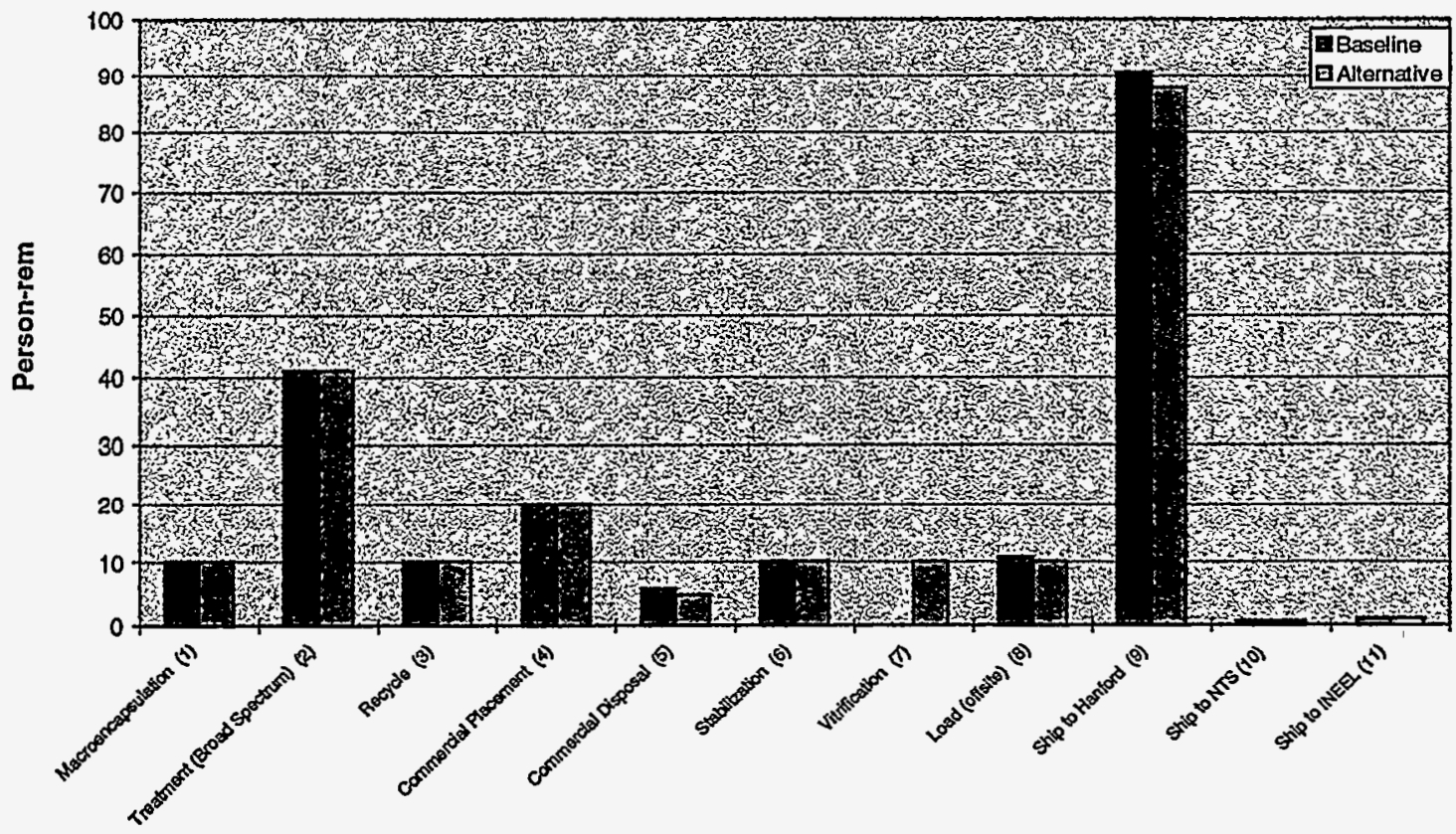

Figure 8-19. Commercial MLLW risk results by activity. 


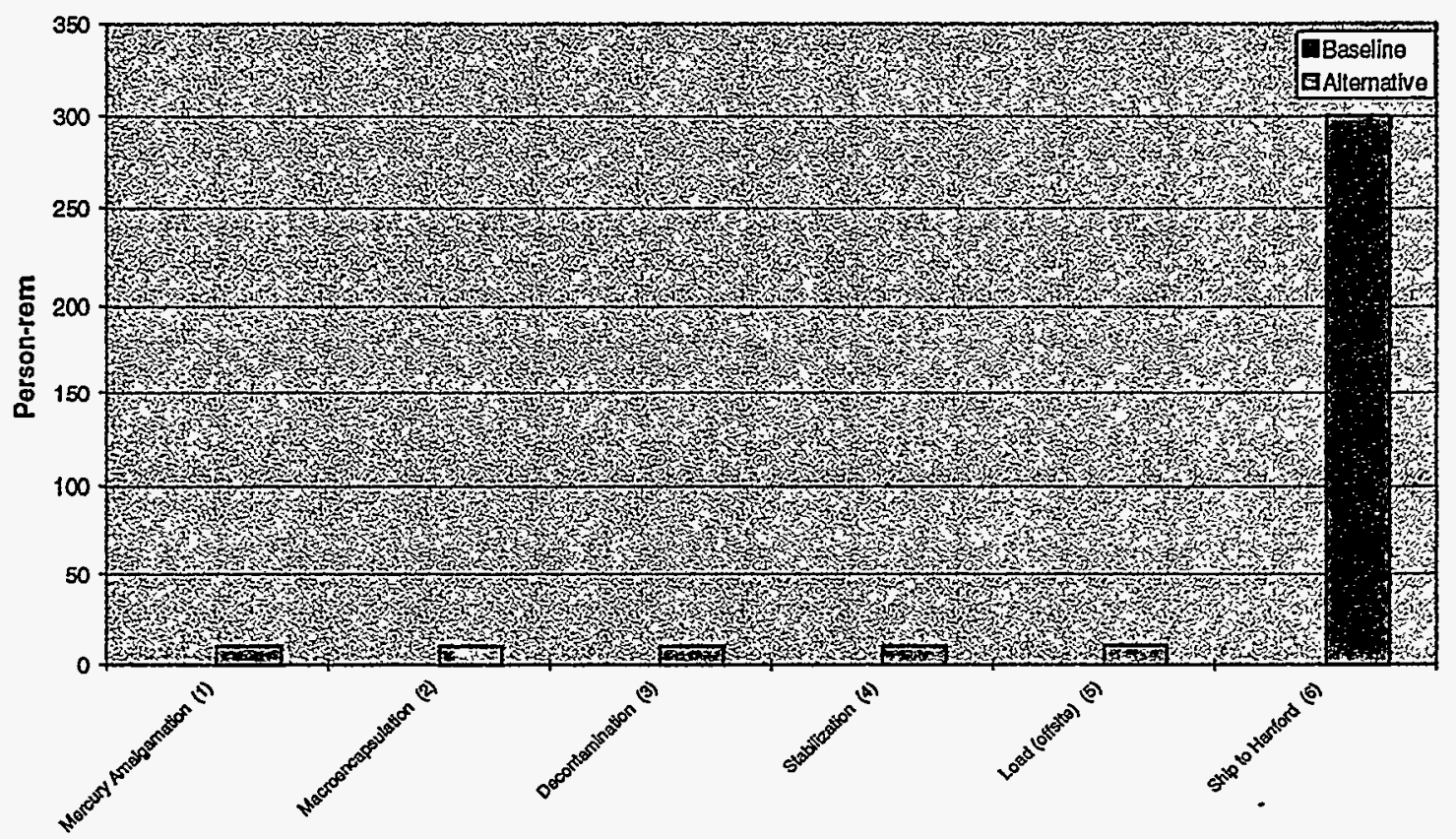

Figure 8-20. National MLLW risk results by activity.

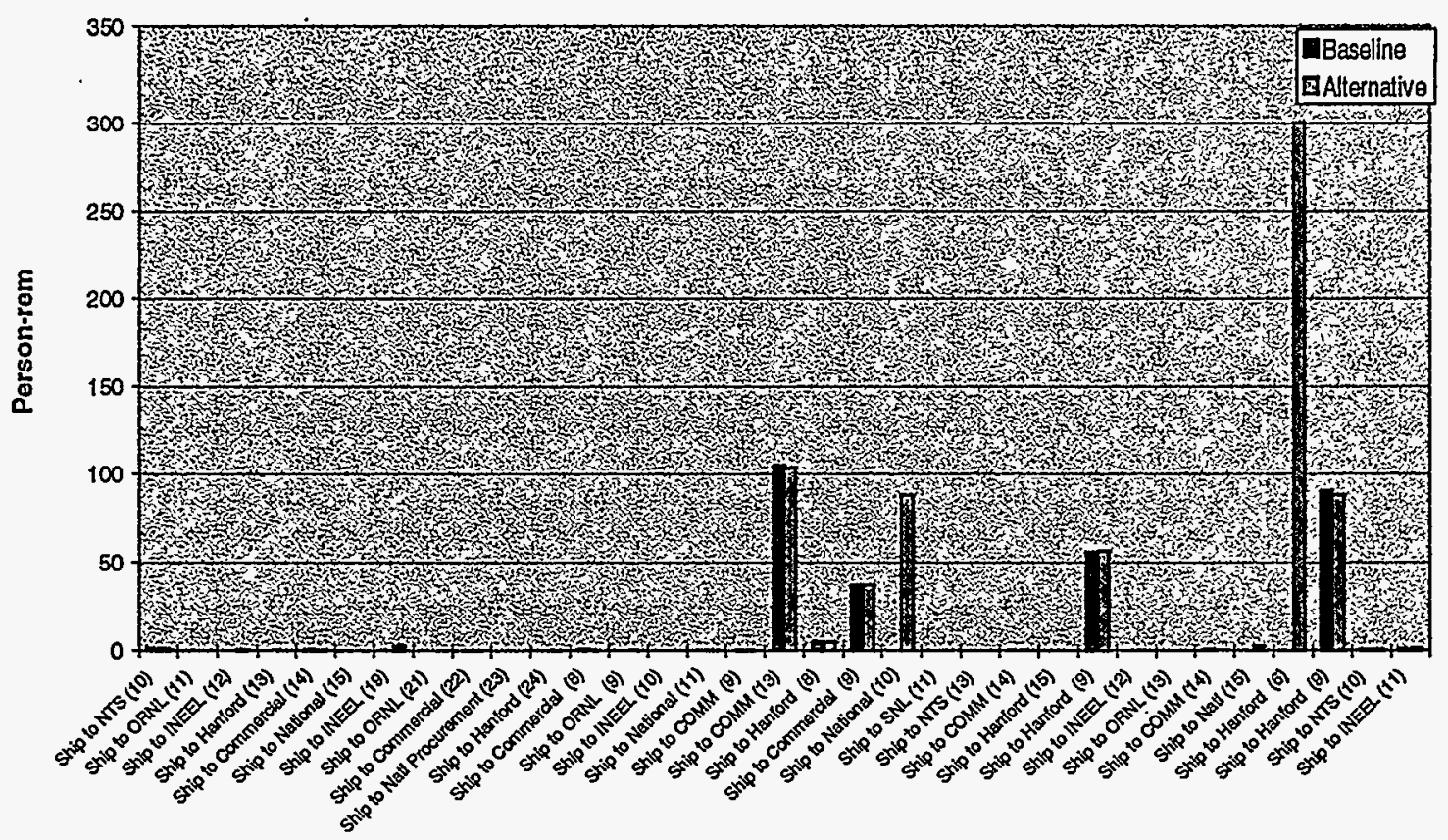

Figure 8-21. Transportation MLLW risk results by activity. 


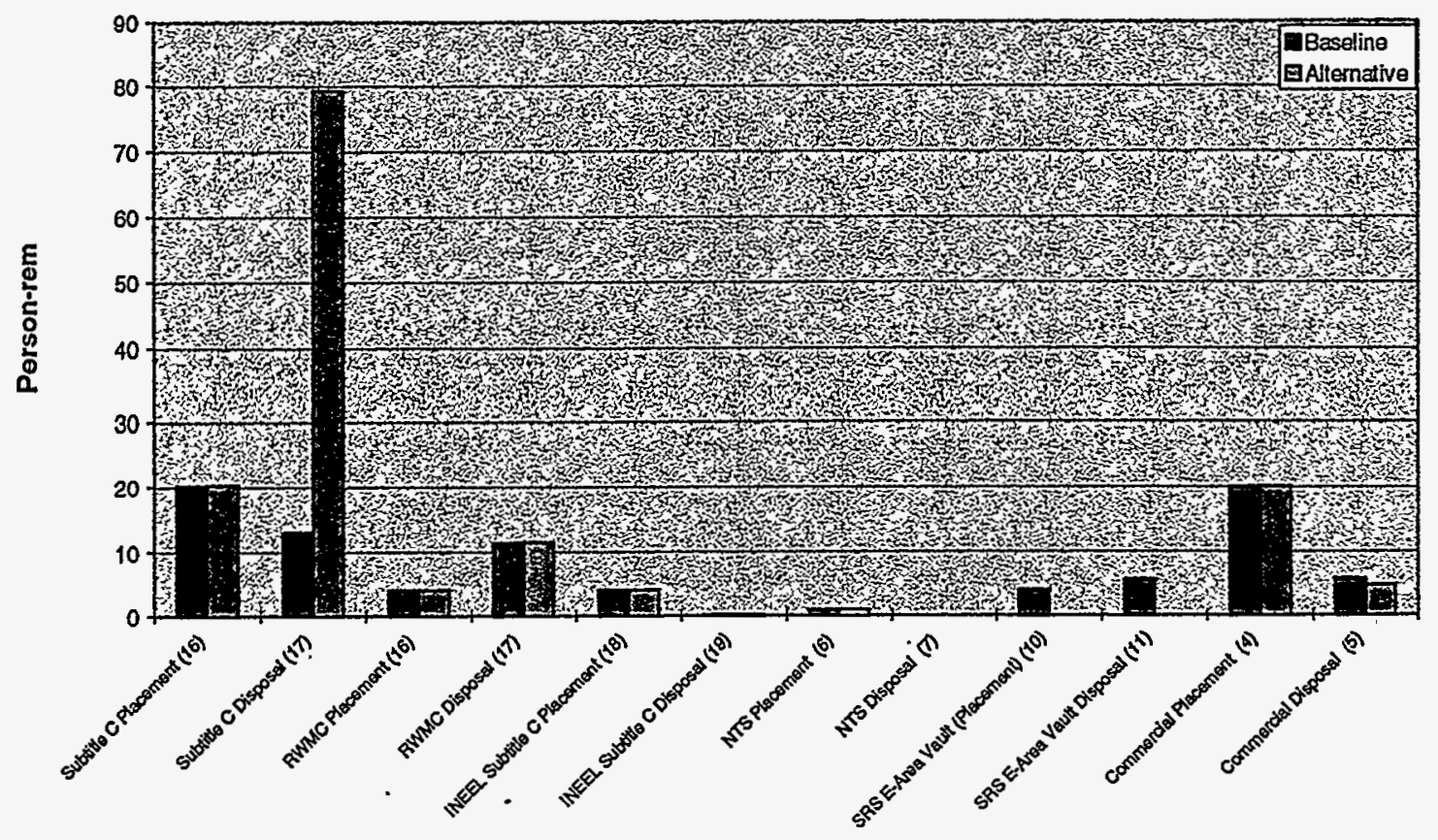

Figure 8-22. Repository MLLW risk results by activity.

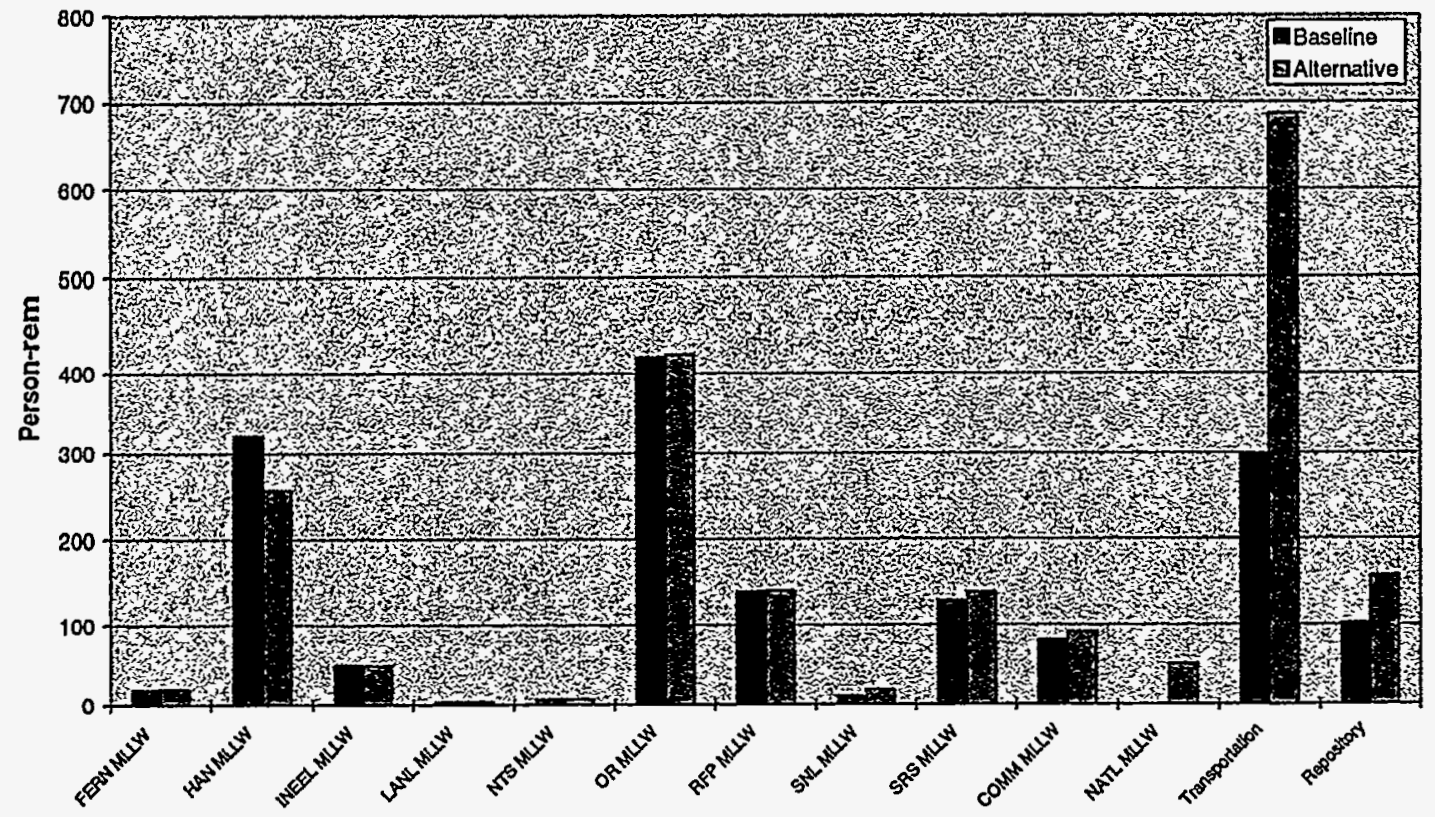

Figure 8-23. DOE MLLW risk results by site. 


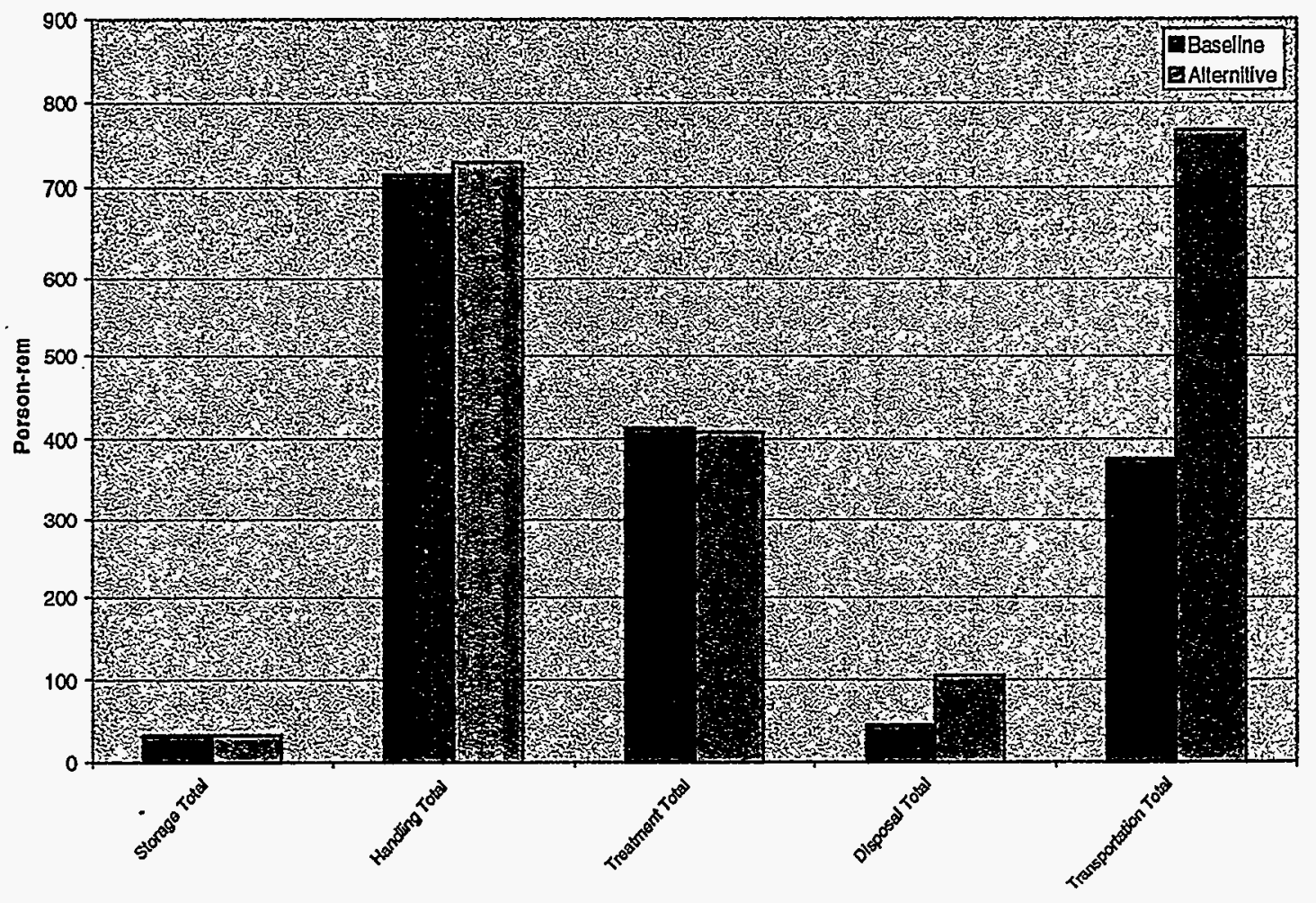

Figure 8-24. DOE complex-wide MLLW risk results by activity type.

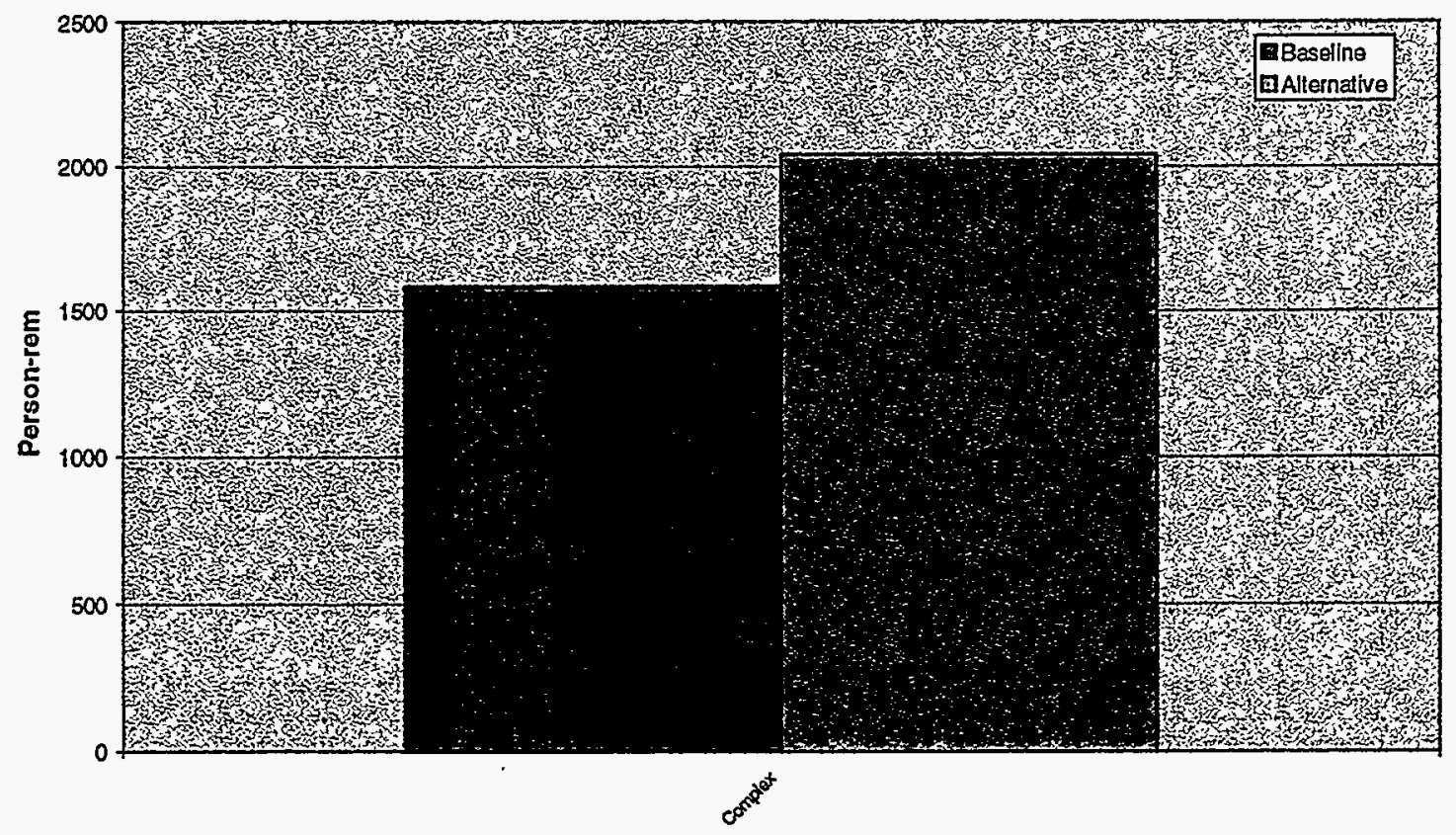

Figure 8-25. DOE complex-wide MLLW risk results. 


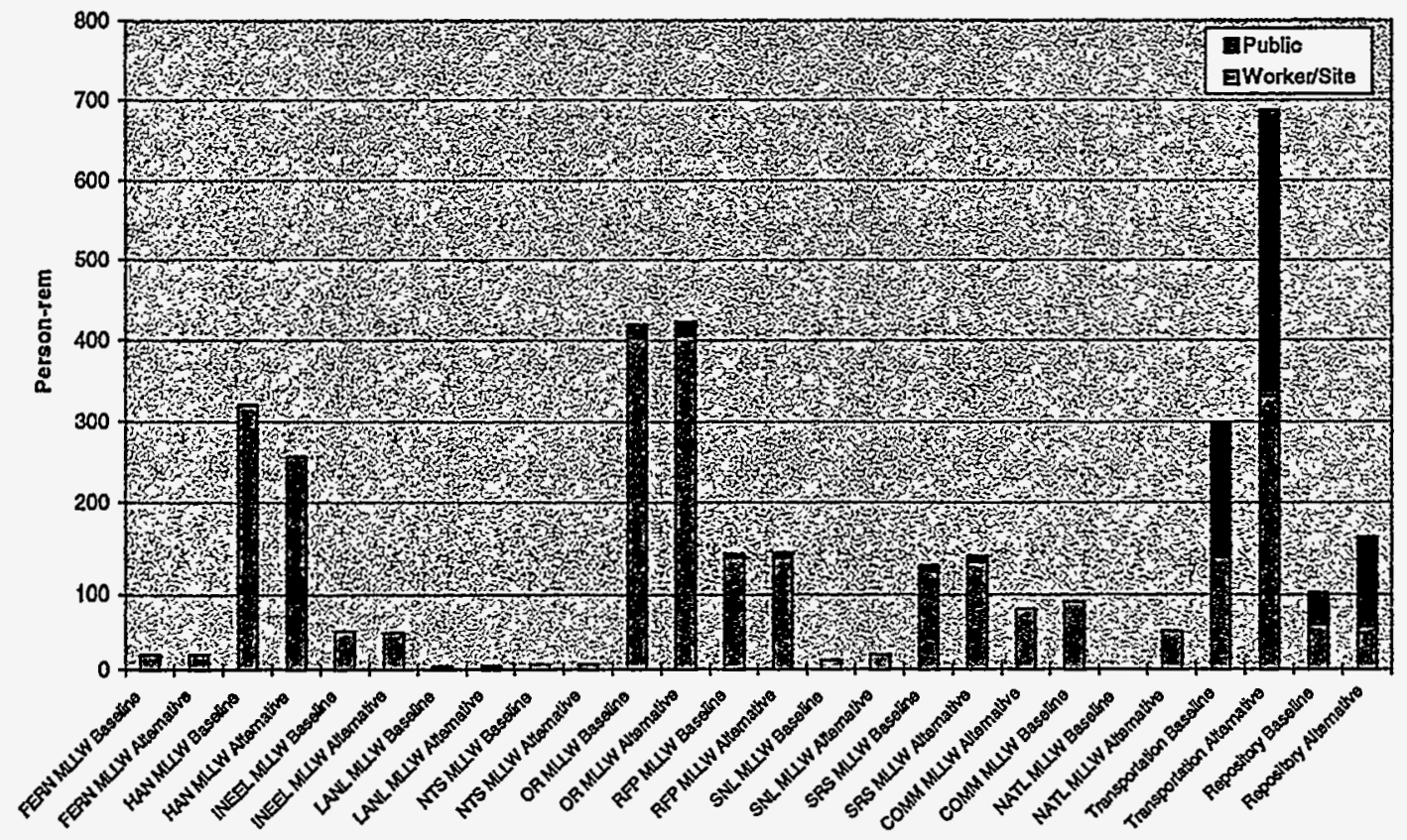

Figure 8-26. DOE MLLW risk results by site (worker/site versus public).



Figure 8-27. DOE complex-wide MLLW risk results by activity type (worker/site versus public). 


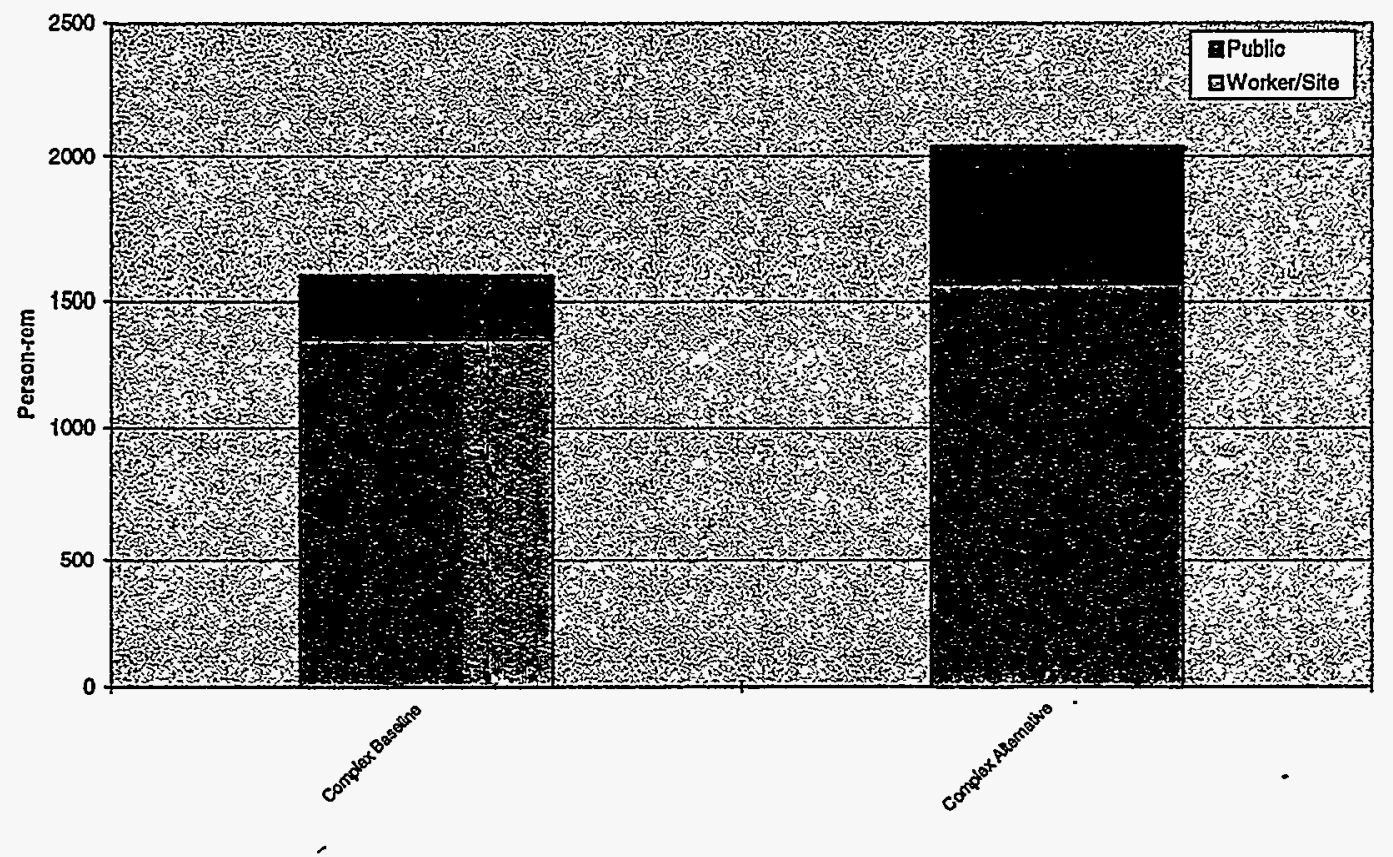

Figure 8-28. DOE complex-wide MLLW risk results (worker/site versus public).

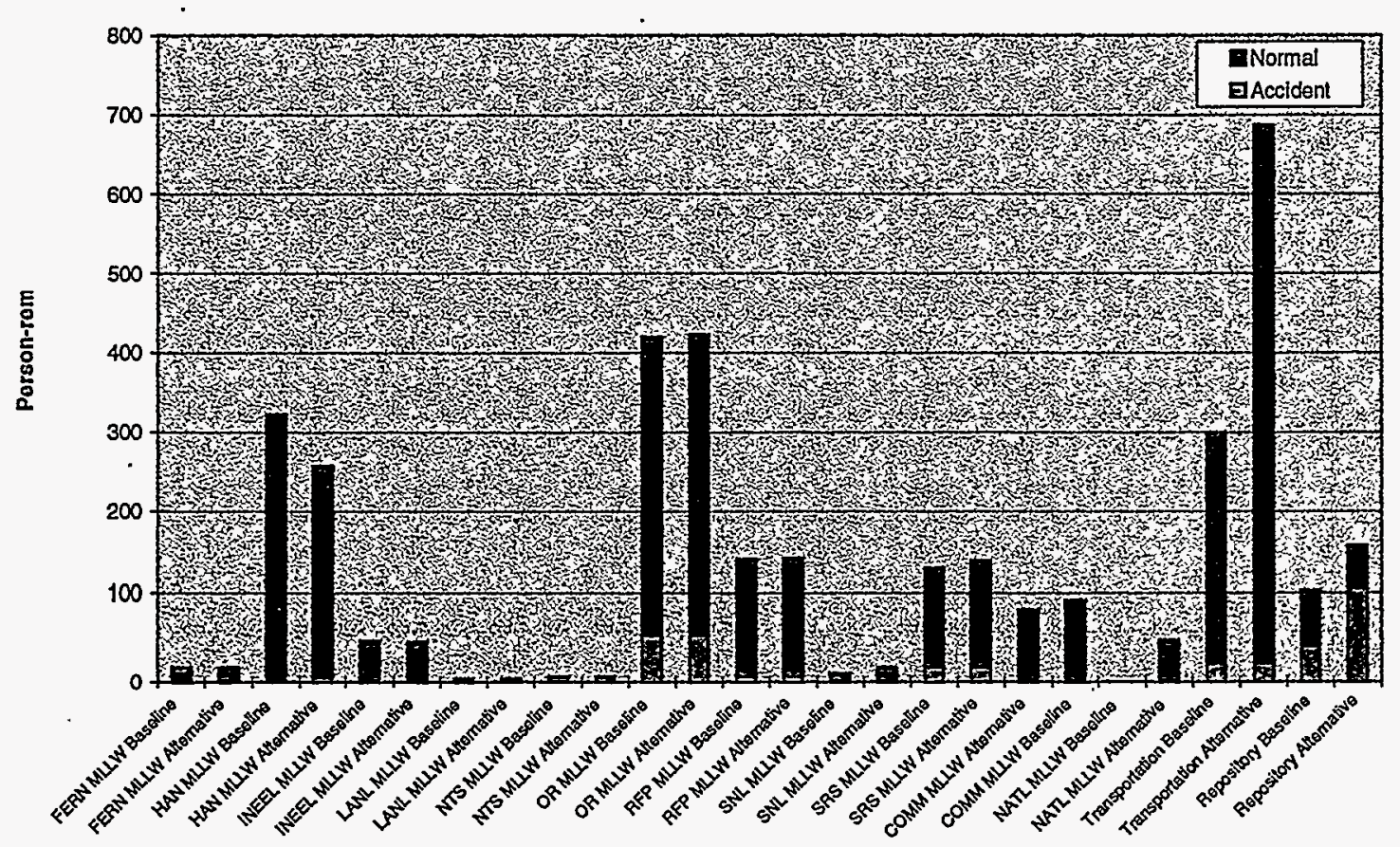

Figure 8-29. DOE MLLW risk results by site (accident versus normal). 


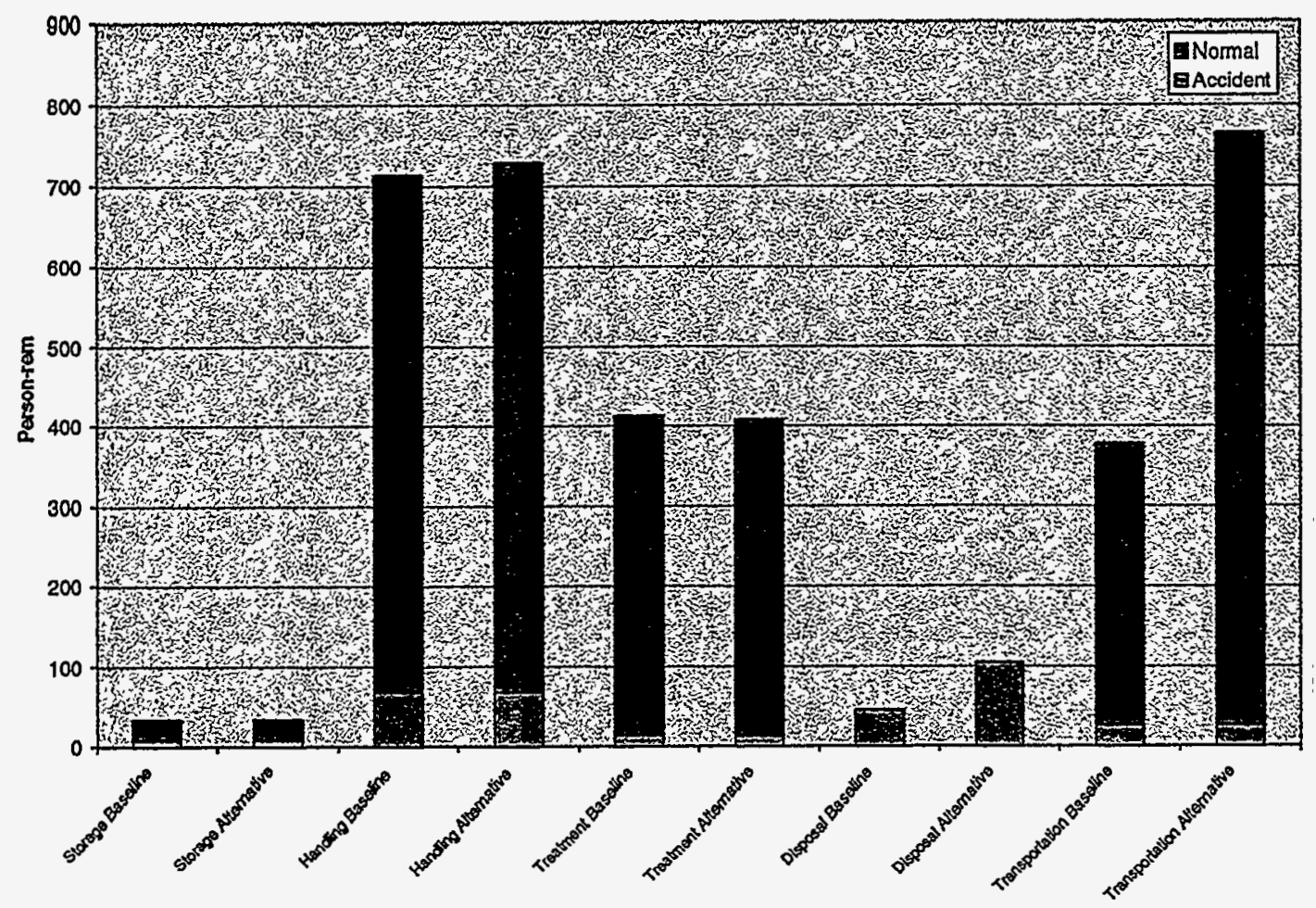

Figure 8-30. DOE complex-wide MLLW results by activity type (accident versus normal).

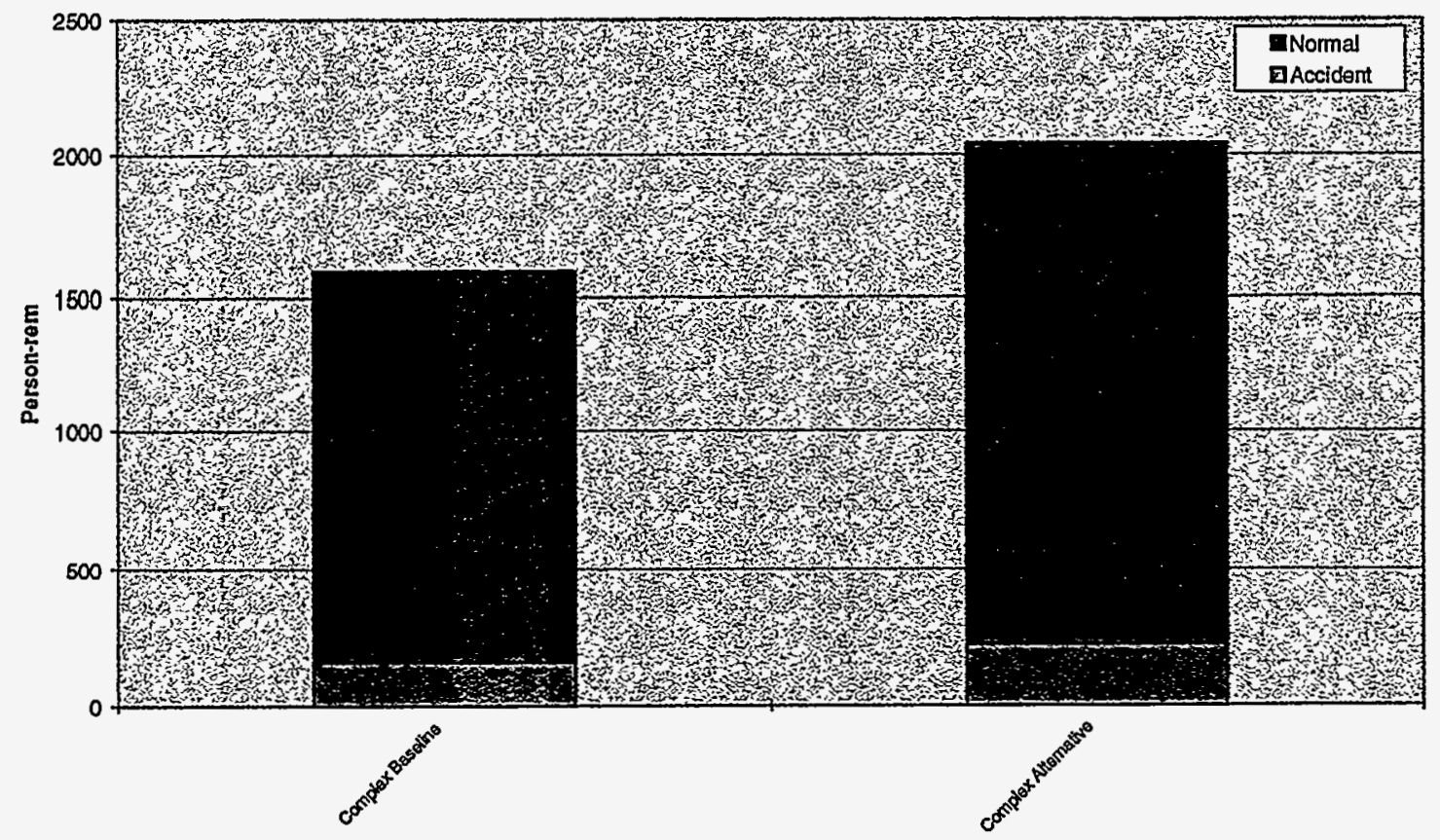

Figure 8-31. DOE complex-wide MLLW risk results (accident versus normal). 


\section{SPENT NUCLEAR FUEL ANALYSIS}

DOE SNF is presently stored at five sites of which four have become the focus of the SNF alternatives development. The four sites are Hanford, INEEL, ORNL, and the SRS. SNF from the fifth site, WVDP, will be shipped to INEEL for storage prior to disposal actions. DOE plans to consolidate SNF disposal operations, sending the SNF to a national high level waste and spent nuclear fuel repository such as Yucca Mountain. The baseline program and alternative for SNF for each of the four sites are outlined in the disposition maps presented in Figures 9-1 through 9-4. The baseline disposition map for the four sites show the process by which the stored SNF is retrieved, stabilized, and sent for disposal. The alternatives involve additional separation, repackaging, treatment and other activities.

The SRM model was developed by subdividing the disposition map boxes into activities (risk states) such as storage, retrieval, loading and unloading, on-site and off-site transport, and various types of waste processing steps and disposal. The subdivision of the disposition maps into activities is shown in Figures 9-1 through 9-4, where the numbers in the parentheses refer to specific activities in question. Figures 9-5 through 9-8 list the specific activities for each site.

The SRM requires knowledge of the radionuclide curie and chemical flow through the disposition maps. The curie information was generally obtained from the report Integrated Database Report - 1995: U. S. Spent Nuclear Fuel and Radioactive Waste Inventories, Projections, and Characteristics. ${ }^{5}$ Initial curie totals for each of the four sites are shown in Table 9-1. Additional information required for the SRM, such as waste form, types of on-site and off-site transport, and schedules were obtained from the subject matter experts. In cases where information was not available, assumptions were made

Table 9-1. DOE site SNF radiological and chemical inventory estimates.

\begin{tabular}{lccl}
\hline \multicolumn{1}{c}{ Site } & Actinides (Ci) & Nonactinides $(\mathrm{Ci})$ & Chemicals $(\mathrm{kg})$ \\
\hline Hanford & $3.2 \mathrm{E}+6$ & $3.2 \mathrm{E}+7$ & Not modeled \\
INEEL & $8.4 \mathrm{E}+6$ & $8.9 \mathrm{E}+7$ & Not modeled \\
ORNL & $2.6 \mathrm{E}+5$ & $4.2 \mathrm{E}+6$ & Not modeled \\
SRS & $5.3 \mathrm{E}+5$ & $1.9 \mathrm{E}+7$ & Not modeled \\
\hline
\end{tabular}

Chemicals were not modeled due to lack of available information.

SRM human health risk results (person-rem) for activities at each of the four DOE sites are presented in figures 9-5 through 9-8. Each figure shows the baseline program and the alternative. Examination of the results indicates that for SNF, packaging and treatment are generally high risk activities relative to other activities such as transportation and final disposal. It should be noted that the activities modeled for each site present all of the important steps in the baseline program (or alternative), from initial storage through final disposal. 
SNF Baseline Disposition Map

PREDECISIONAL DRAFT

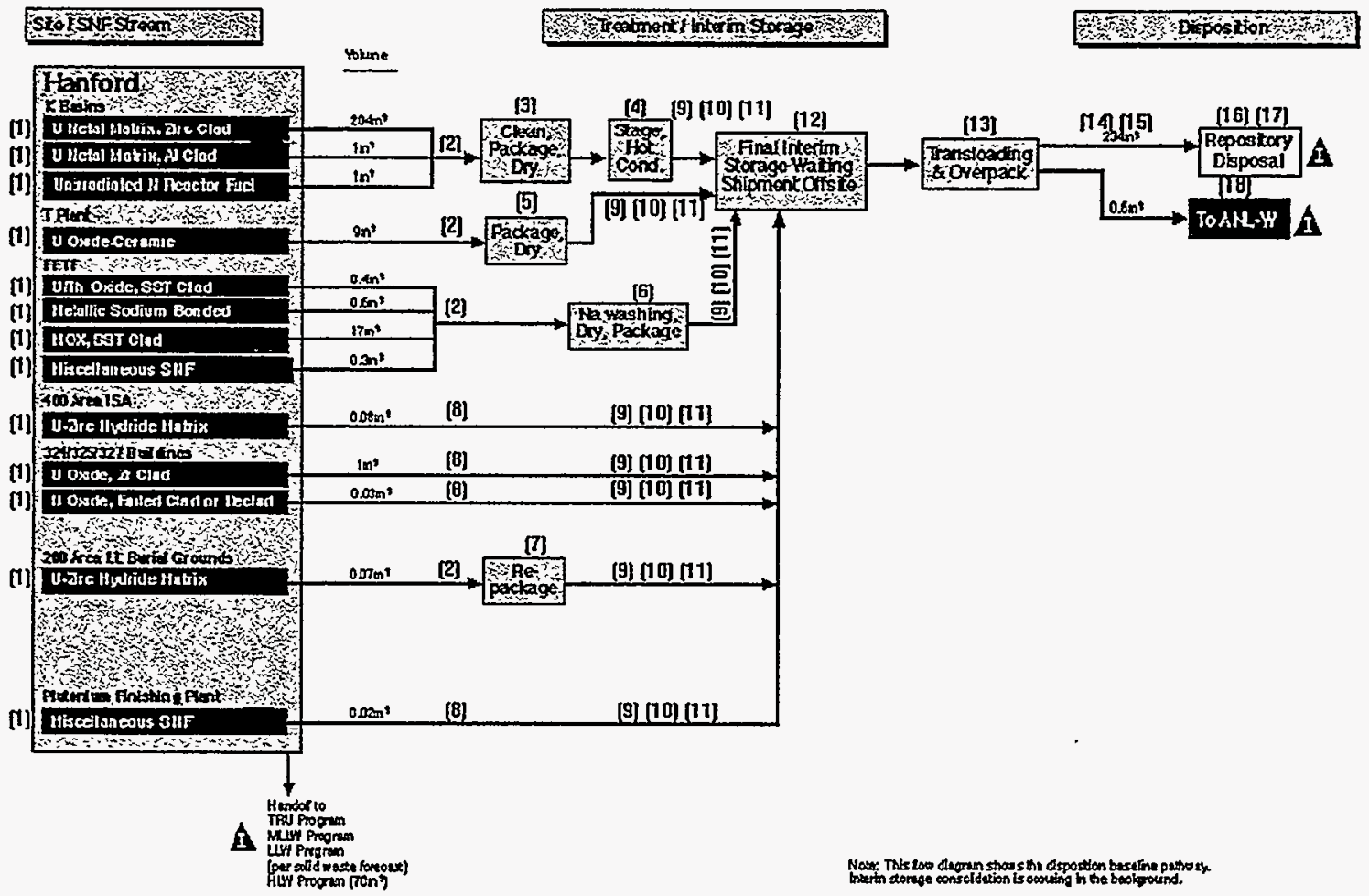

(and

42897

Enheroed

SNF Alternative Disposition Map

PREDECISIONAL DRAFT

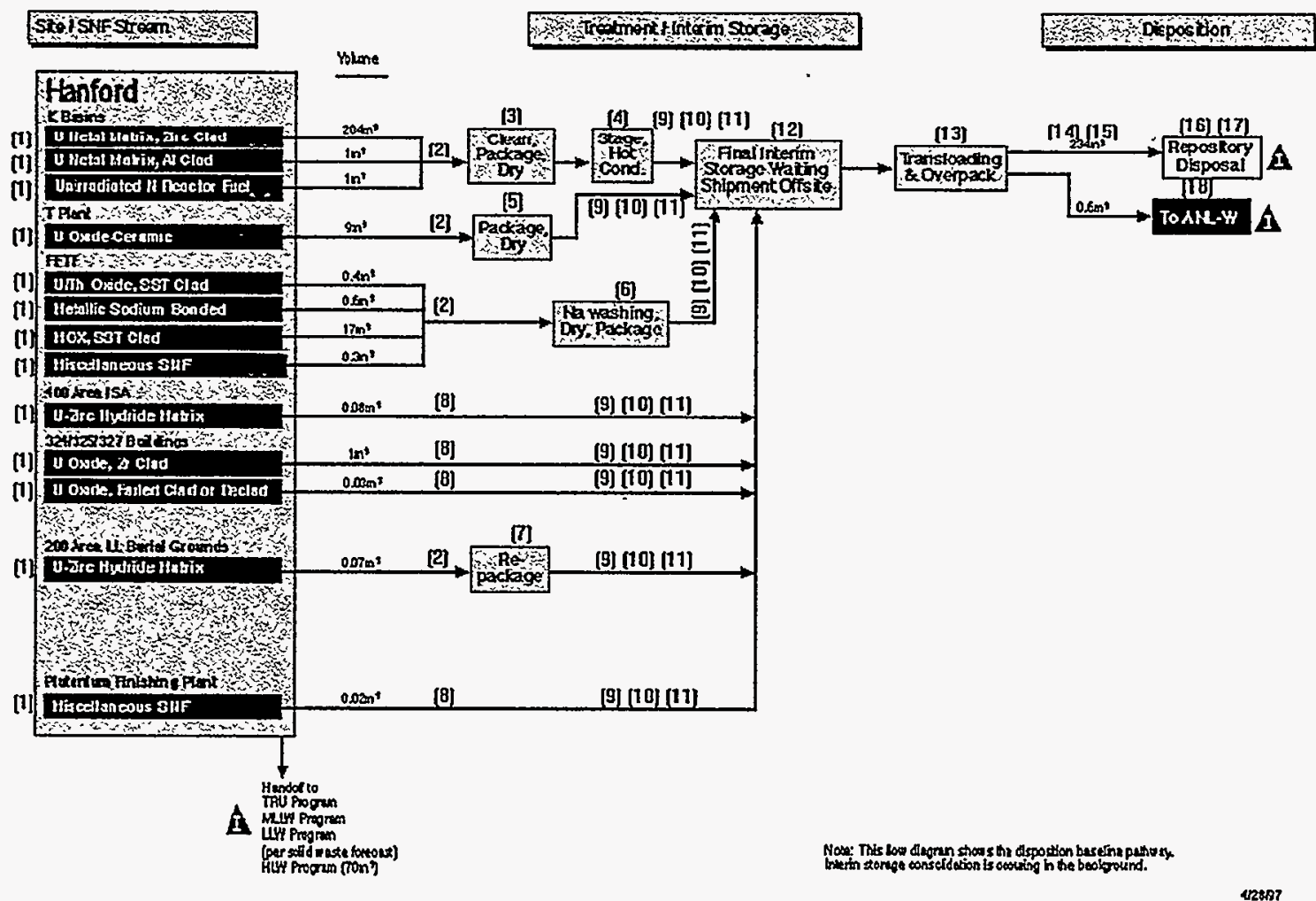

Figure 9-1. Handford SNF disposition maps (baseline and alternative). 
SNF Baseline Disposition Map

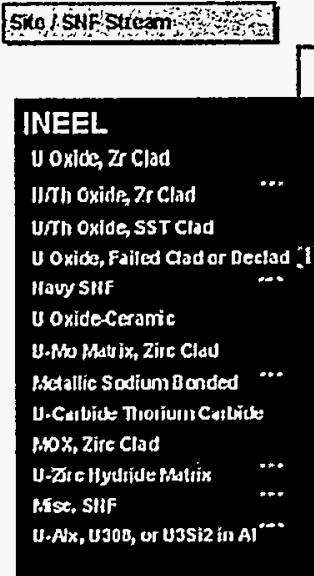

\section{PREDECISIONAL DRAFT}

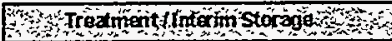

\section{- Progortion uw I}

(27) (28) (44)

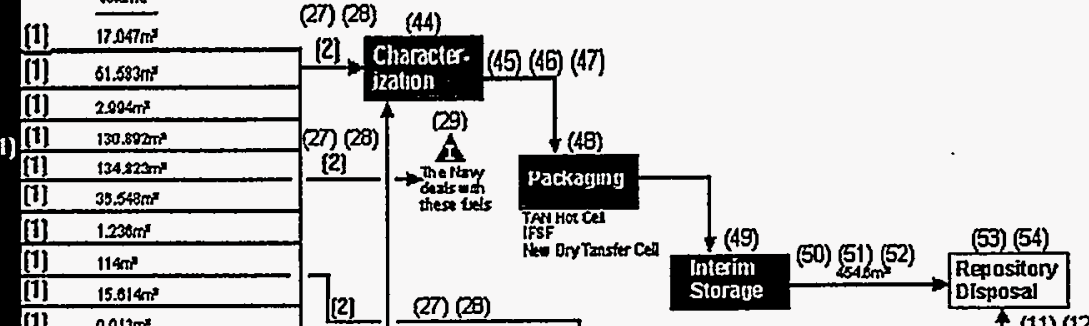

(1) $0.013 \mathrm{~m}^{2}$

[1] $1250 m^{2}$

[1] $\quad 14.274 \mathrm{~m}^{2}$

$36 \mathrm{Atam}^{3}$

$63075 \mathrm{~m}^{2}$

(18) A From Harrod (21) (25) (28)

(B) 1 Fromwes Vesley (24) (25) fig

(19) A FroinsRs (22)(25)(26)

(20) $\mathrm{A}$ [romor

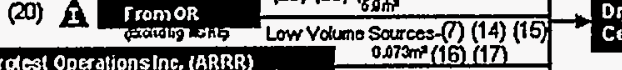

Argonnollotionaltiah - Ead

Amed forces Rad Rescarch ins.

Babcock \& Wilcox

Comell University

Dow Chemical Co, USA

Gencrol Atonics Co.

Kansas State Uriversity

Pikcledan Air Force B ase

Ilorth Cardina State U niversity

oregon state Unversty

Pemsyluania State University

Reou College

Sandia, Lannzann at Kinthand AFB

State University of Ilew York, Butfolo

Traas AsMll niversity

US Depe of intarlor (USGS)

Iniugreity of Atizona

Unlucrsty of Califomla - Irvine

Univer sity of ulinois at Urbans

Unlucrsty or maryond

University of Texas at Austin

Univer sity of Utals

Univessity of Wisconsin

Veteraus Aduninistraliou llospitus

Washington State University

Folt Saint Vrain in Coloradu

\begin{tabular}{l|l}
$0.206 \mathrm{~m}^{2}$ \\
\hline $0.070 \mathrm{~m}^{2}$ \\
\hline $0.02 \mathrm{em}$
\end{tabular}$\rightarrow$ IFSF

$0.028 \pi$

$0.125 \mathrm{~m}$

$0.08 \mathrm{~m}^{\mathrm{m}}$

$0.195 \mathrm{~m}^{2}$

$0.6 \mathrm{~m}^{3}$

$0.6 \mathrm{~m}^{3}$

$0.16 \mathrm{mx}$

$0.18 \pi^{2}$

$0.068 \mathrm{~m}^{*}$

$1.22 m^{2}$

$\frac{1.12 \pi}{0.1345}$

$0.37 \mathrm{ans}^{2}$

$0.166 \mathrm{~mm}^{2}$

$0.081 \mathrm{im}^{2}$

$0.004 \pi^{2}$

$0.004 \pi^{2}$

$0.164 \mathrm{~m}^{2}$

$0.132 \pi^{2}$

$0.164 \pi)^{2}$

$0.312 \pi r^{2}$

0.045ms

$0.302 \pi \pi^{3}$

$130.207 \mathrm{~m}^{\circ}(\bar{C}$

$6.44 \pi$

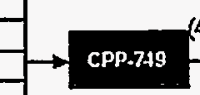

Foreign Research Reactor Fucts

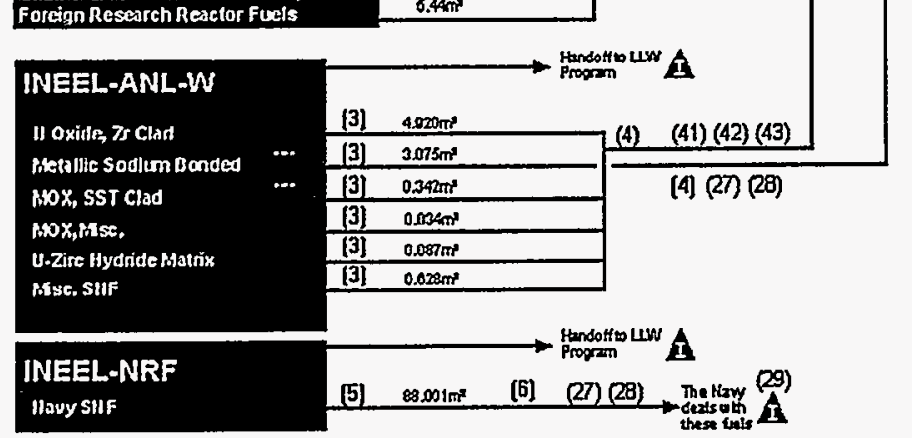

Figure 9-2. INEEL SNF disposition maps (baseline and alternative).

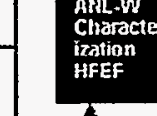




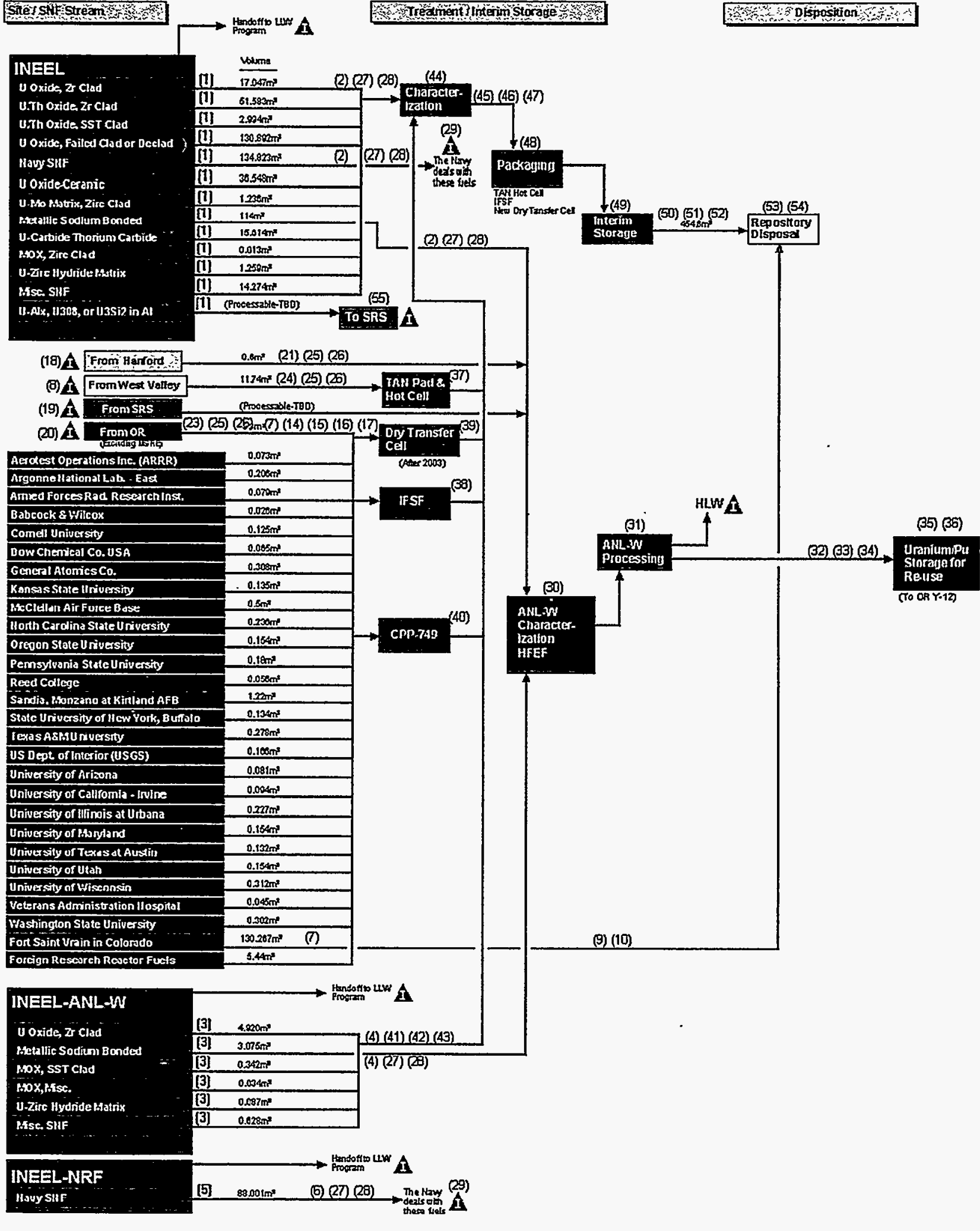

Figure 9-2. INEEL SNF disposition maps (baseline and alternative) (continued). 

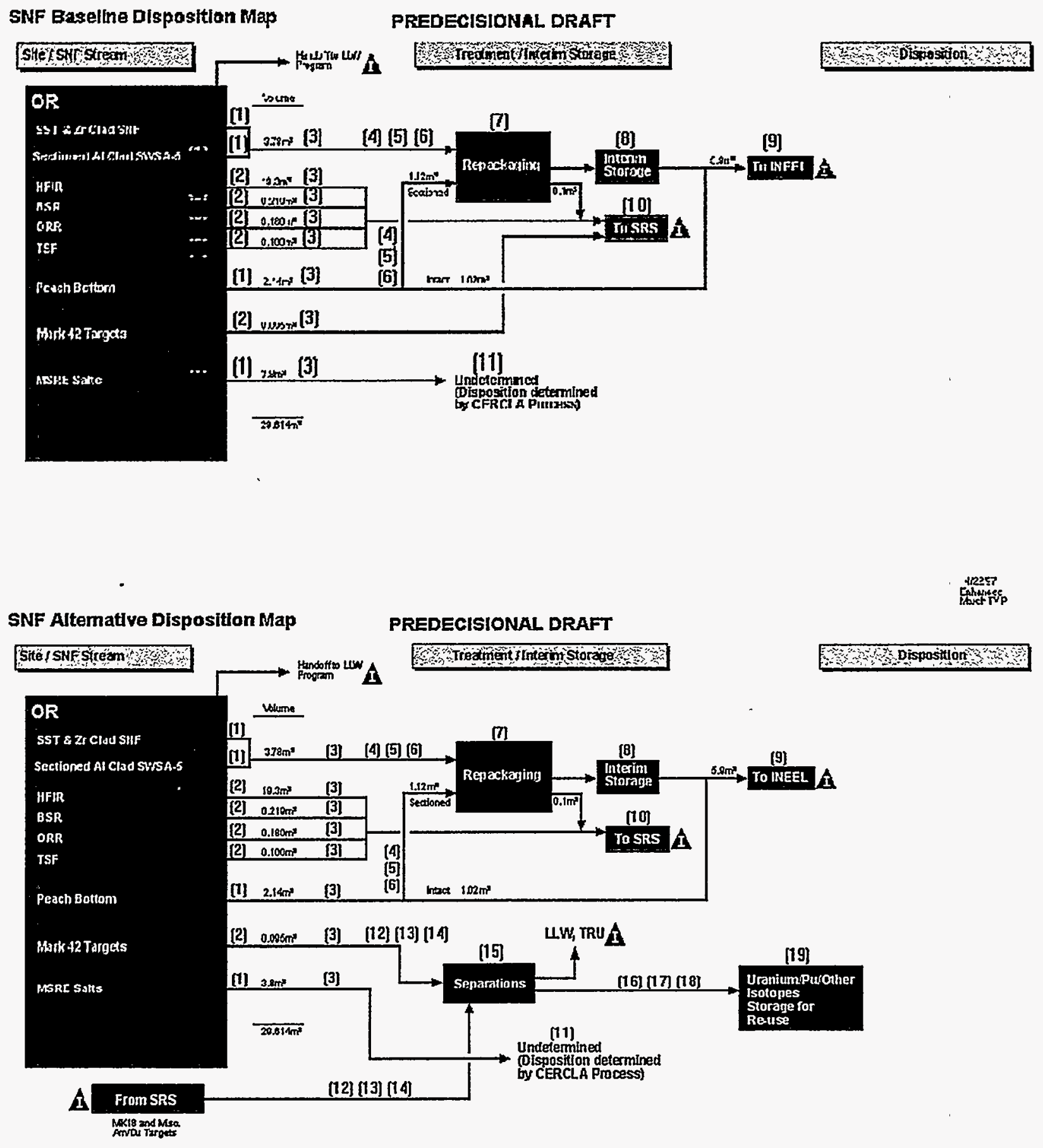

Figure 9-3. ORNL SNF disposition maps (baseline and alternative). 


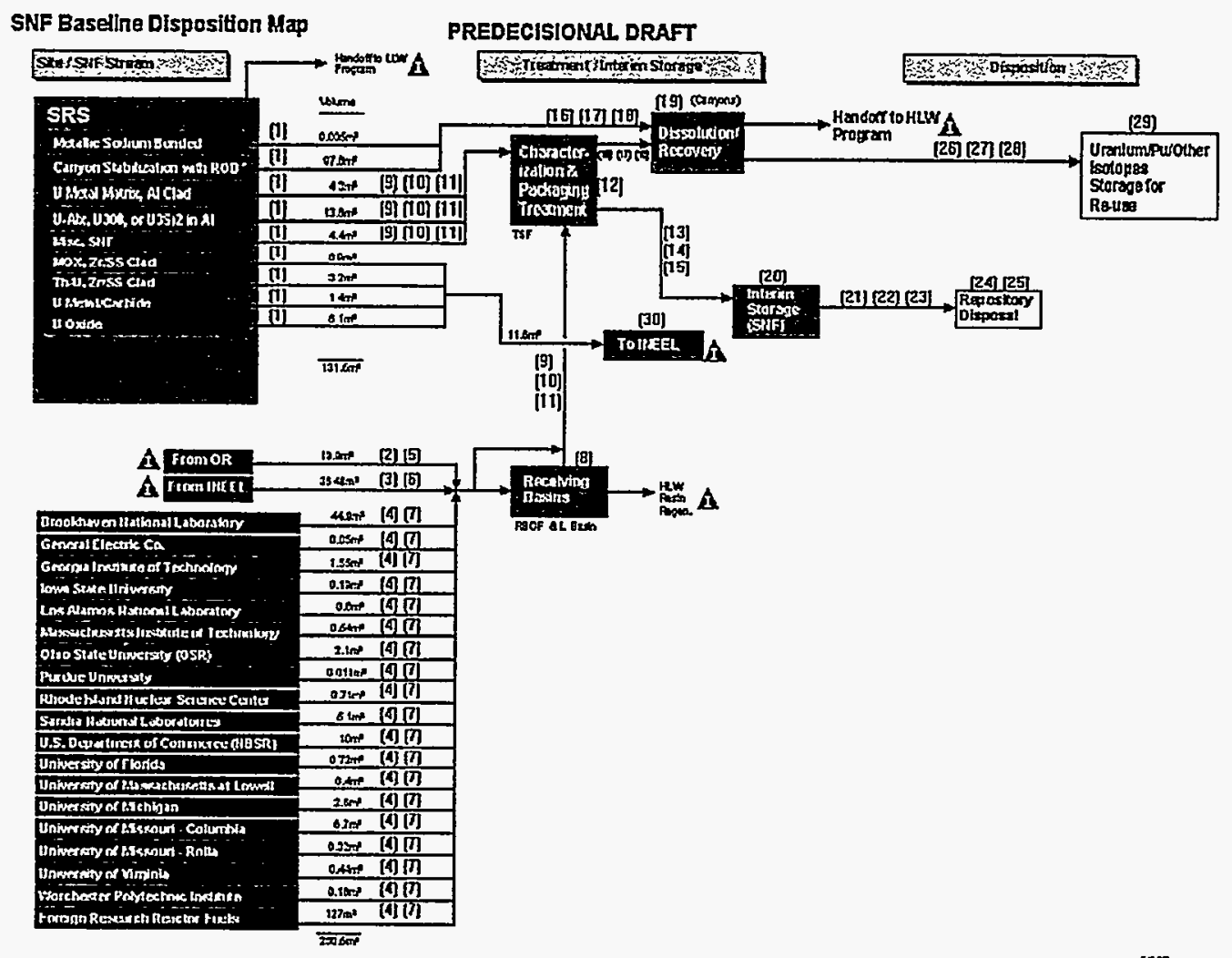

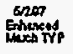

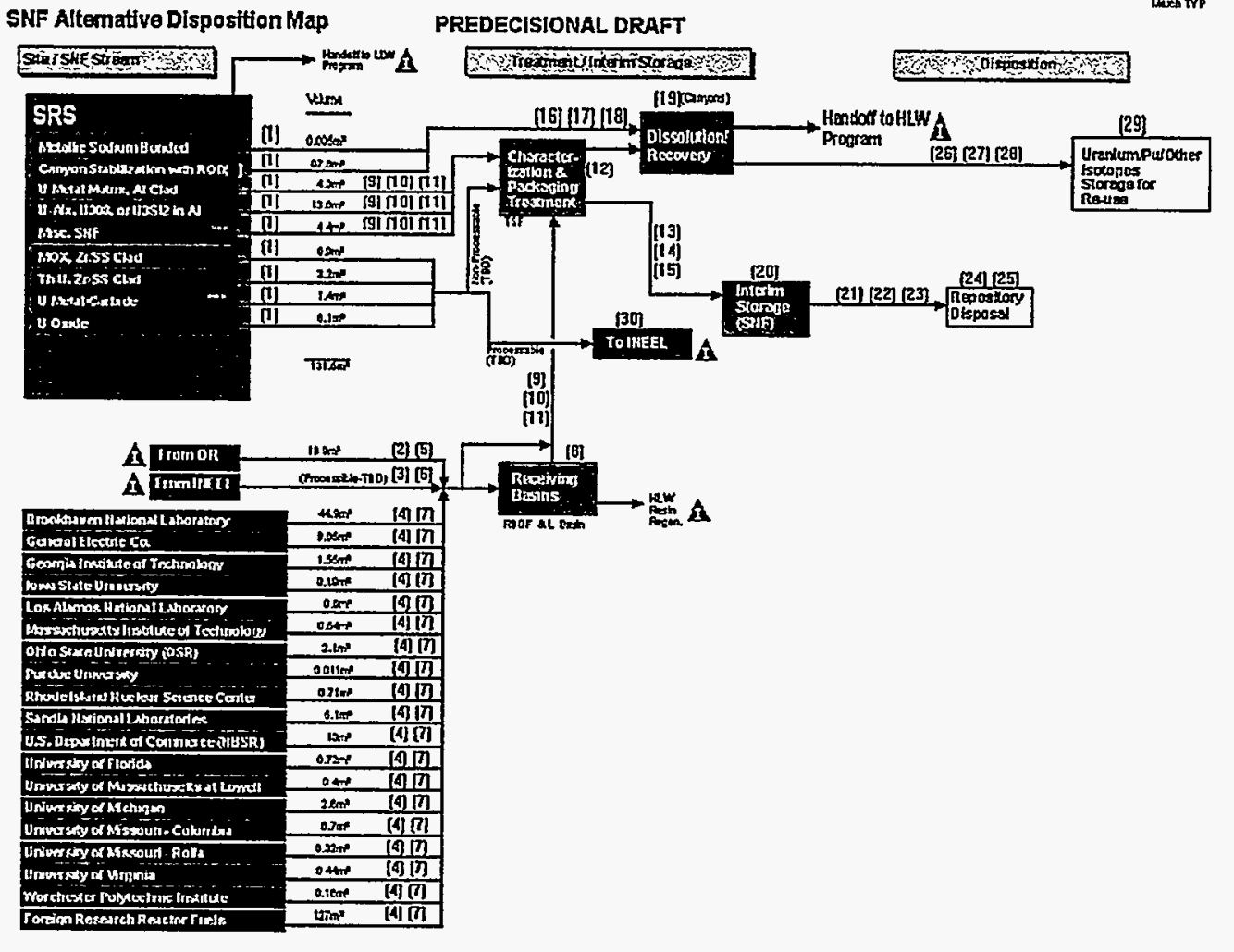

Figure 9-4. SRS SNF disposition map (baseline and alternative). 


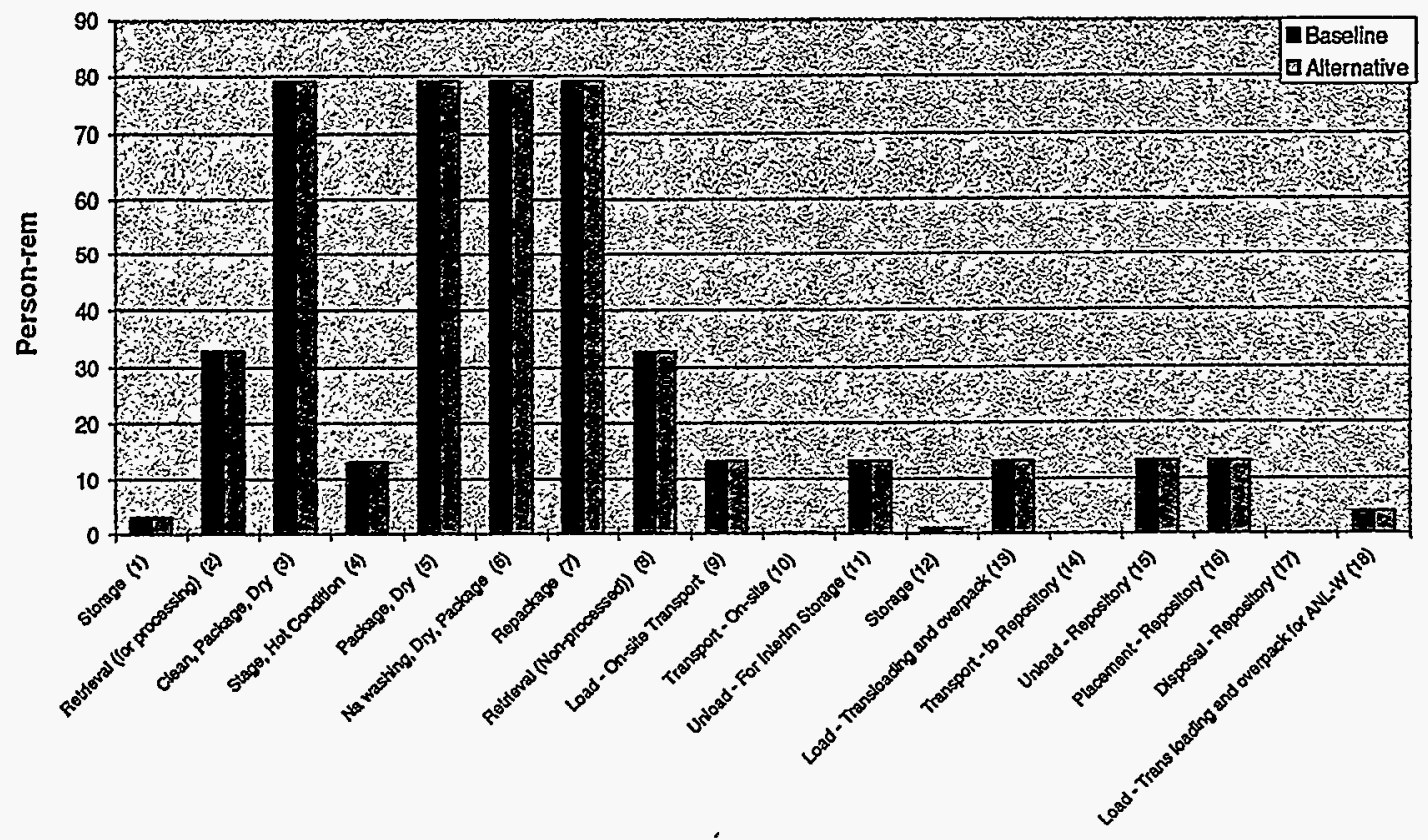

Figure 9-5. Hanford SNF risk results by activity.

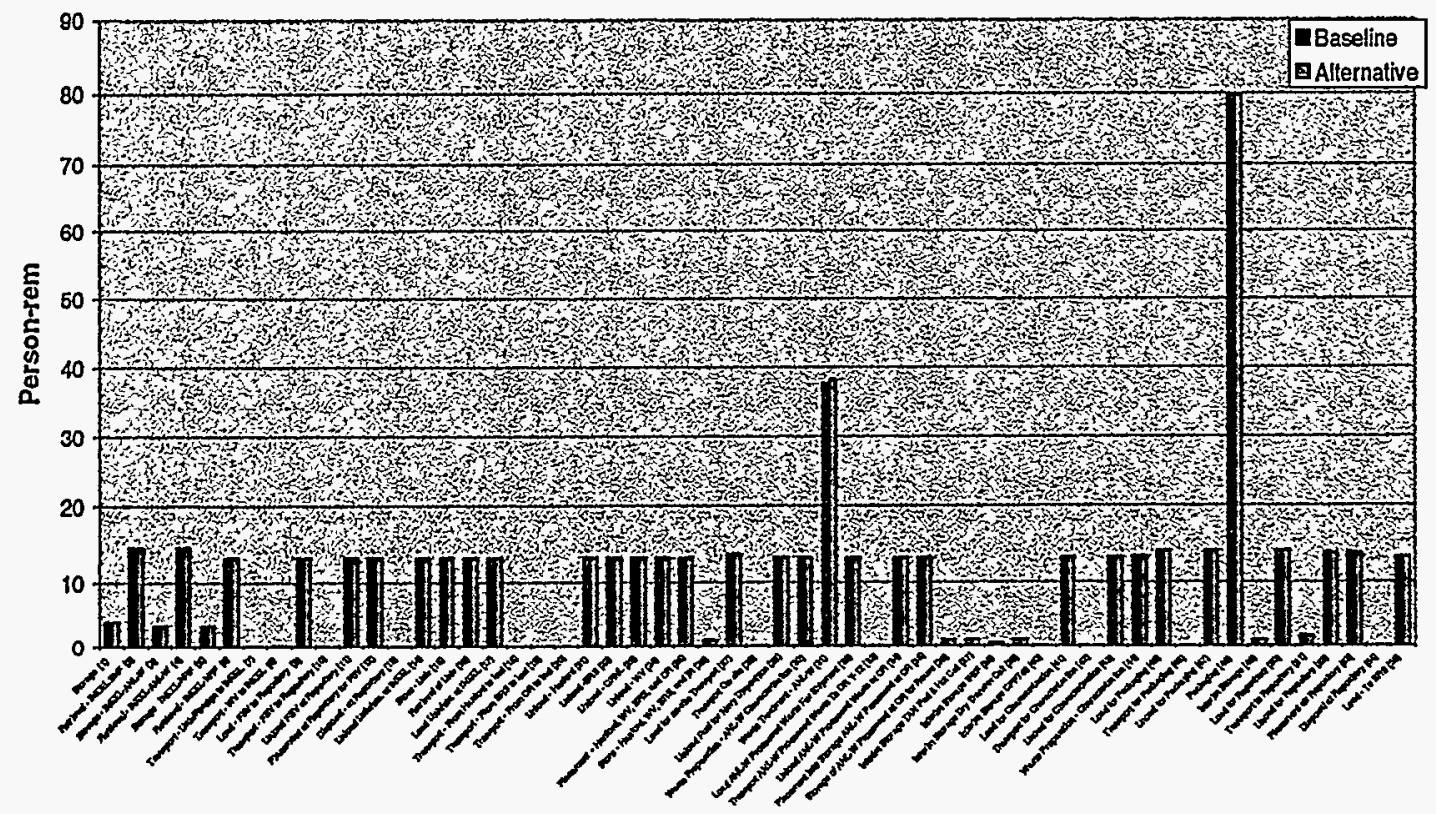

Figure 9-6. INEEL SNF risk results by activity. 


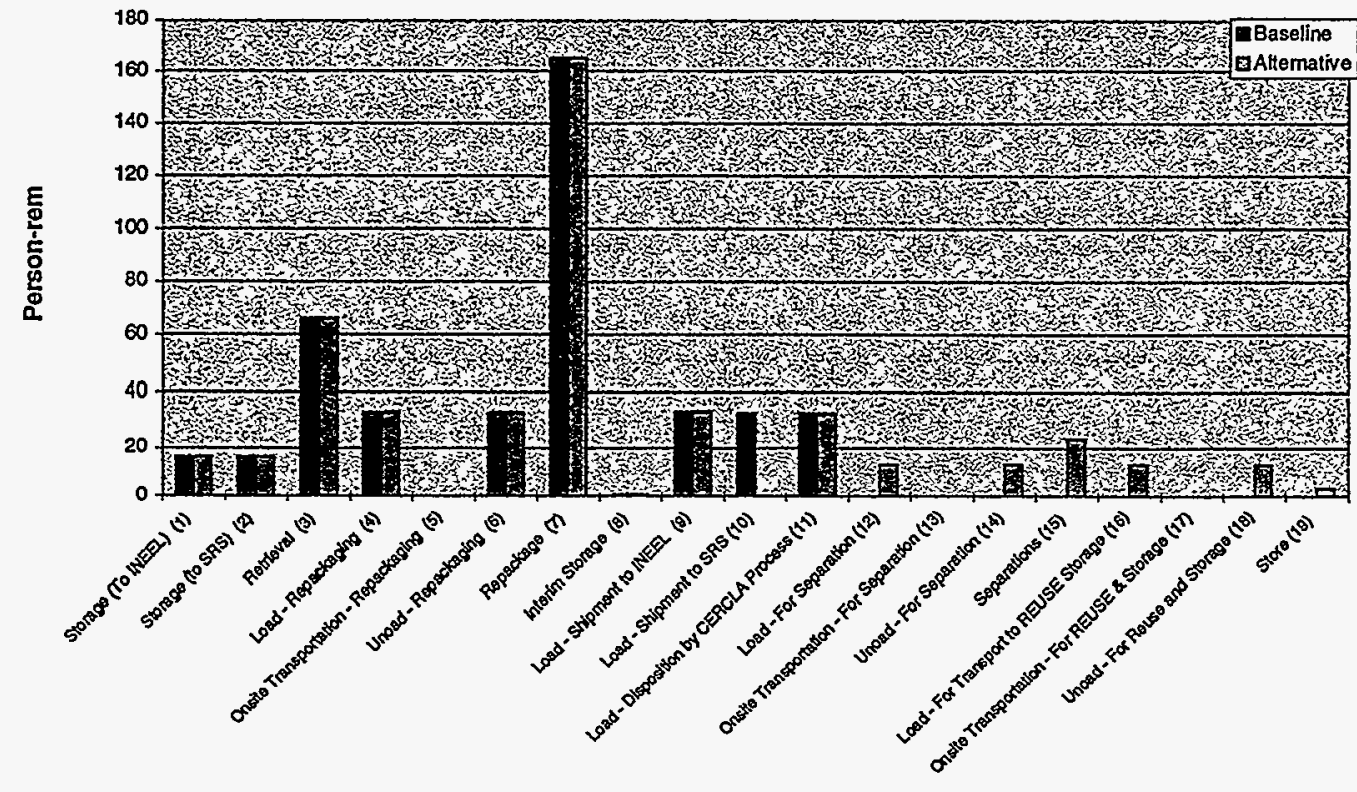

Figure 9-7. ORNL SNF risk results by activity.

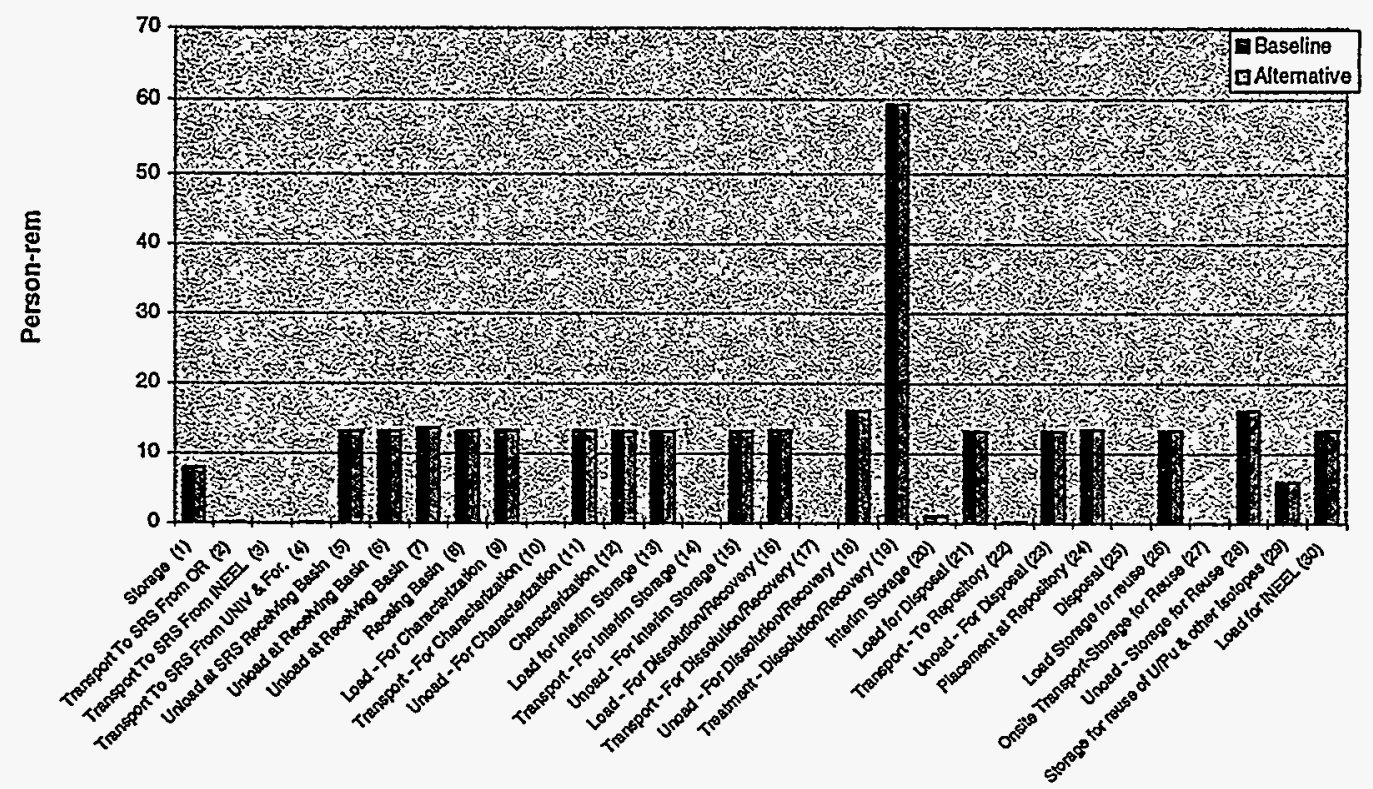

Figure 9-8. SRS SNF risk results by activity, 
Figure 9-9 is a summary of the total risk (person-rem), baseline program and alternative, for each of the four sites plus off-site transportation and final disposal (at Yucca Mountain). The INEEL site has the most risk because it has the most curies, with SNF from some of the other DOE sites and the foreign, university and other small sites processed though the INEEL.

Figure 9-10 summarizes the DOE complex-wide SNF risk results by type of activity: storage, handling, treatment, transportation, and disposal. Handling of SNF is a significant contributor to the overall SNF risk. Treatment of SNF also contributes significantly. The other three types of activities are smaller contributors.

Figure 9-11 presents the total DOE complex-wide SNF risk for the baseline program and the aiternative. The total risk for the SNF baseline program is approximately 1750 person-rem, while the alternative case is approximately 1800 person-rem. This small increase in risk for the alternative is negligible, given the accuracy of the SRM. Therefore, both the baseline program and the alternative are considered to have comparable risk.

Figures 9-12 through 9-14 are similar to Figures 9-9 through 9-11, but show the breakdown of risk into public and worker/site contributions. Except for transportation, the worker/site risk is six or more times higher than the public risk.

Finally, Figures 9-15 through 9-17 are similar to Figures 9-9 through 9-11, but show the breakdown of risks from accident and normal incident free operation. Overall, the risk from normal, incident free operation is nine or more times greater than the risks from accidents.

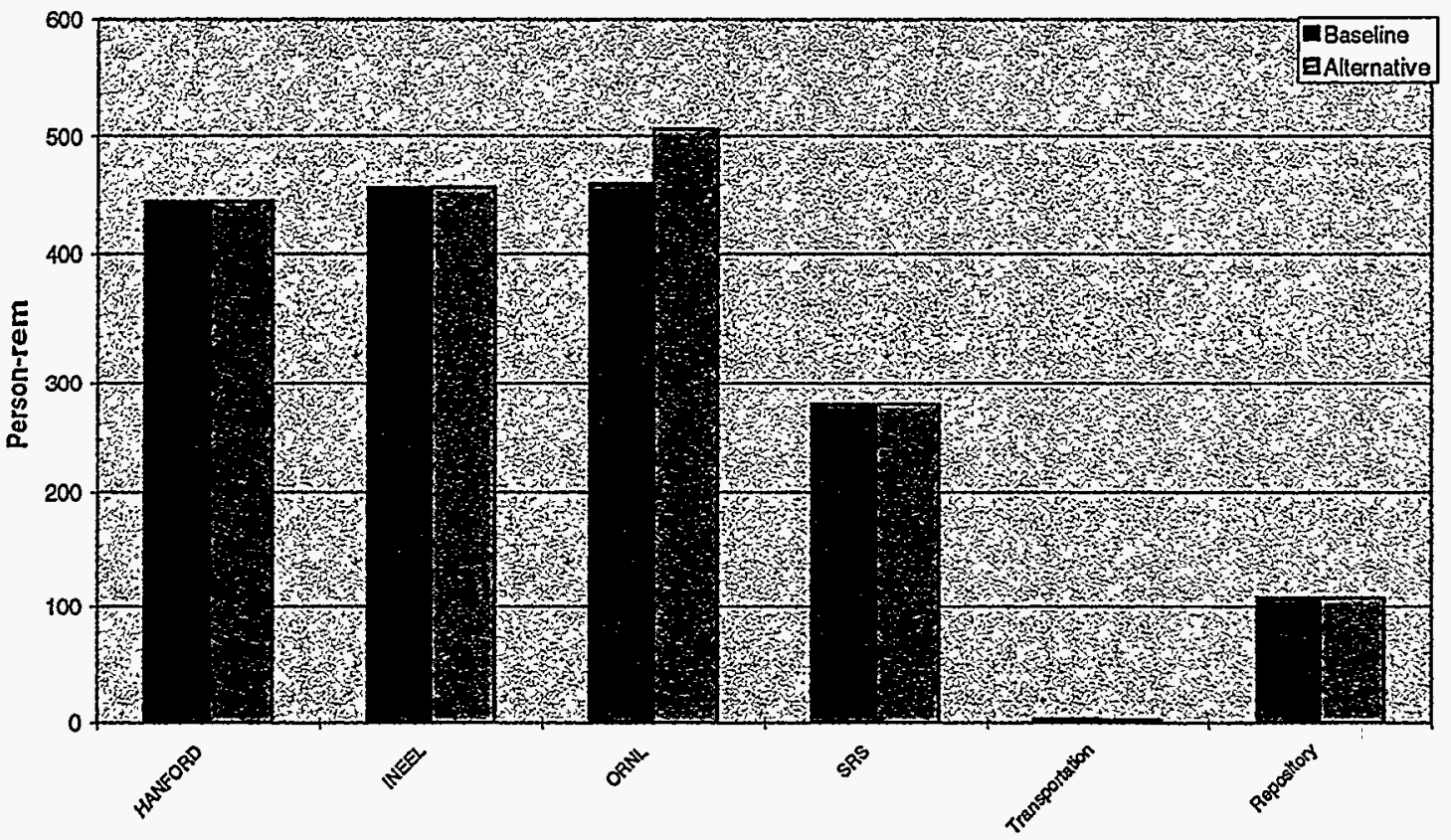

Figure 9-9. DOE SNF risk results by site. 


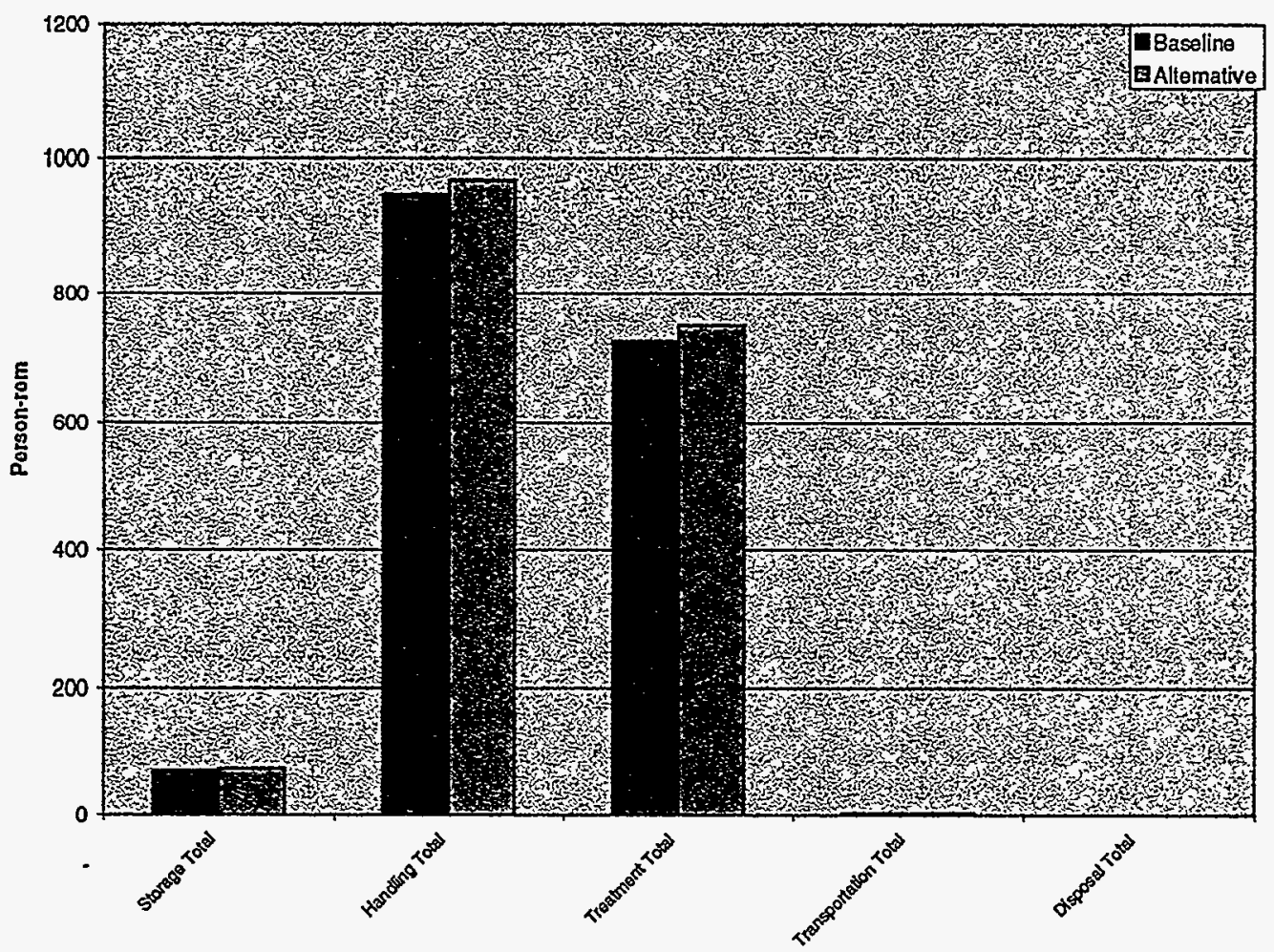

Figure 9-10. DOE complex-wide SNF risk results by activity type.

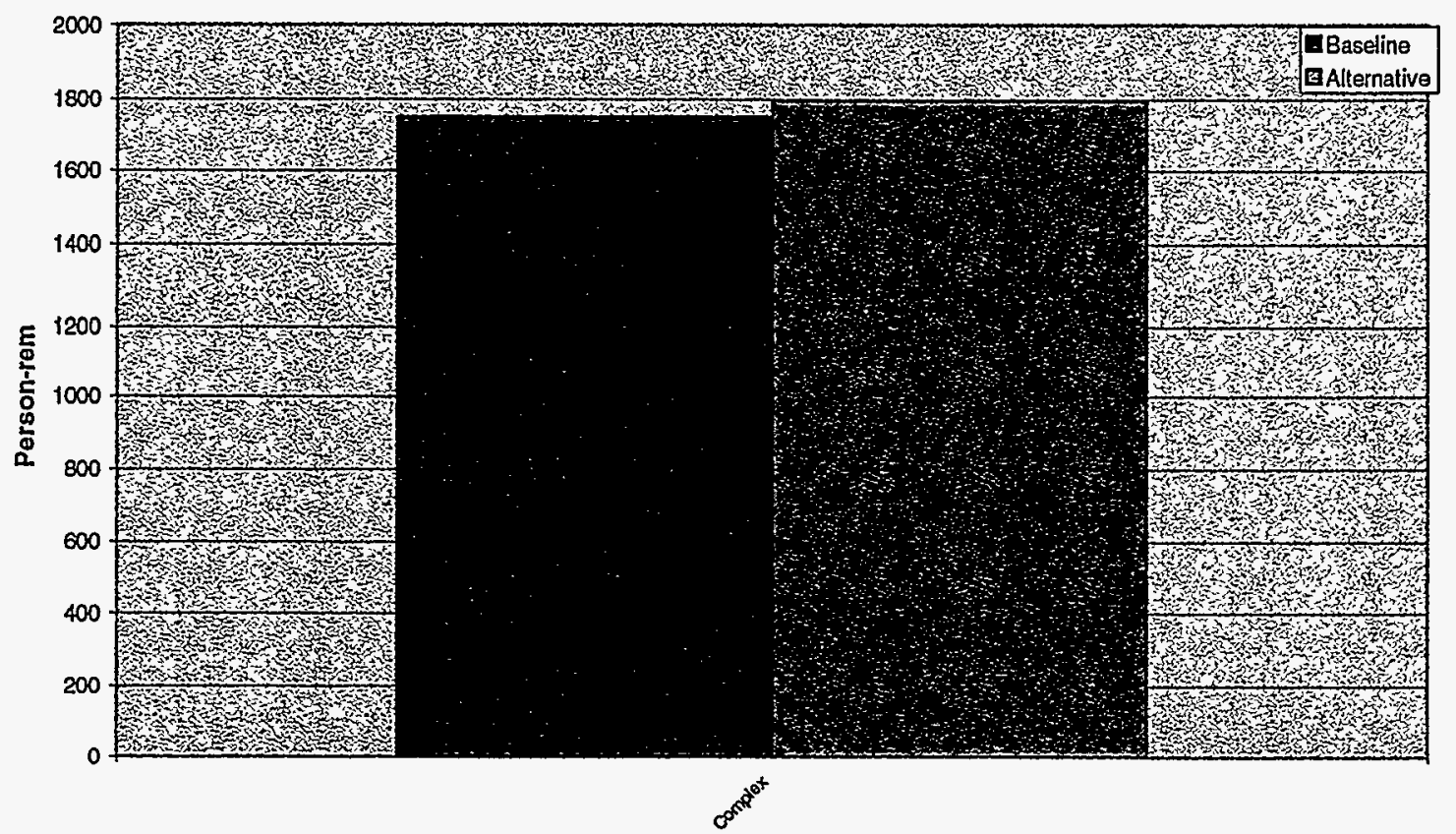

Figure 9-11. DOE complex-wide SNF risk results. 




Figure 9-12. DOE SNF risk results by site (worker/site versus public).

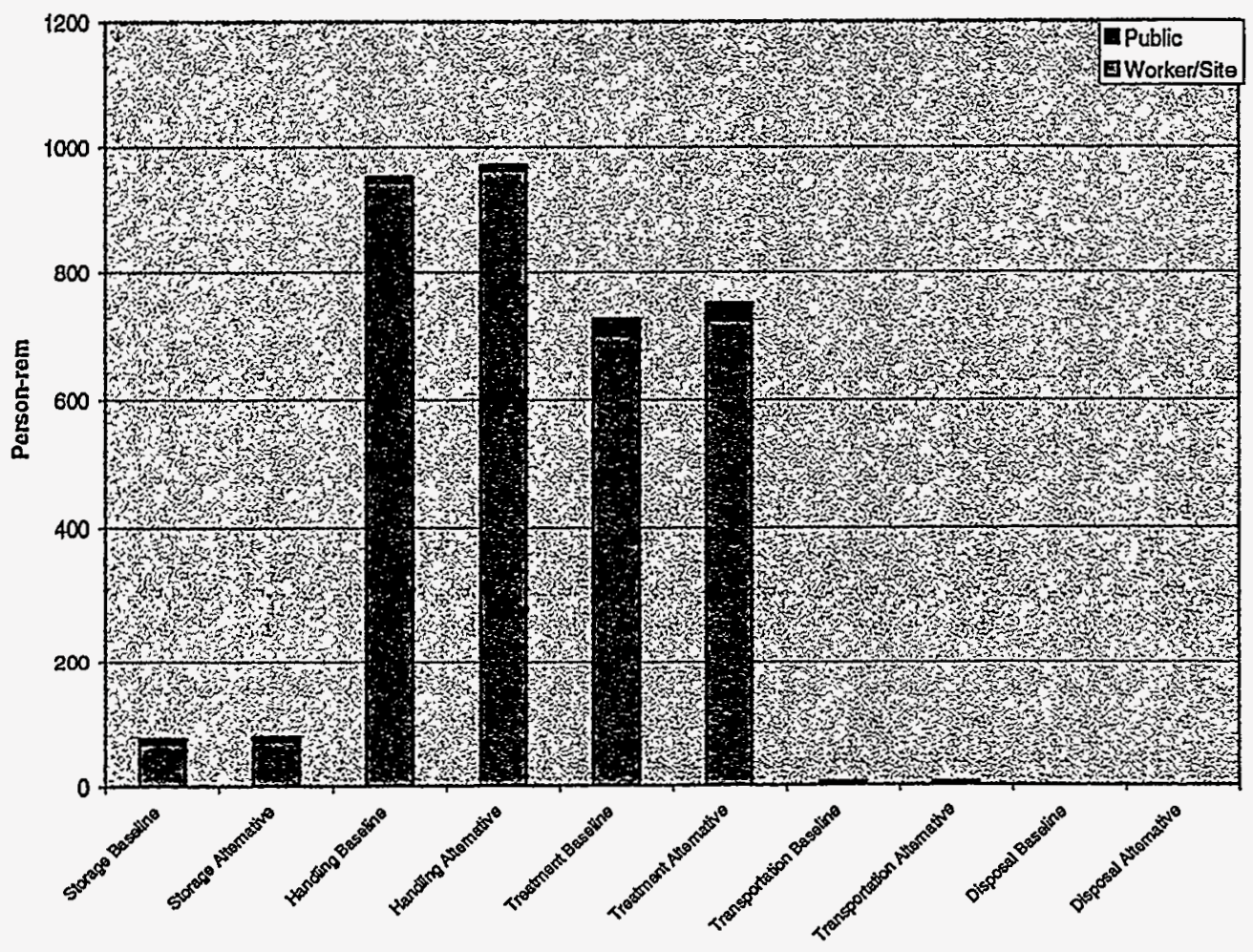

Figure 9-13. DOE complex-wide SNF risk results by activity type (worker/site versus public). 


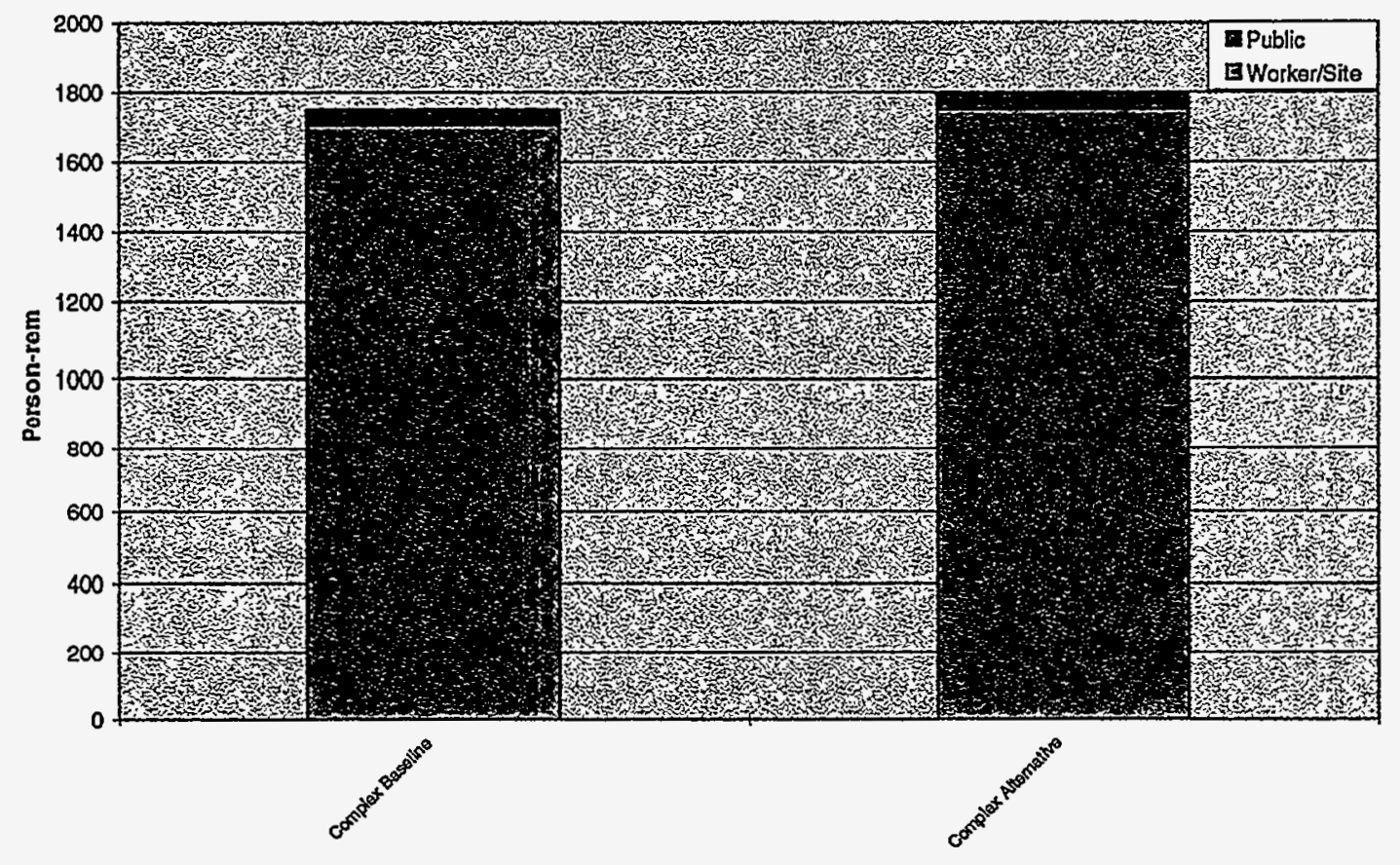

Figure 9-14. DOE complex-wide SNF risk results (worker/site versus public).

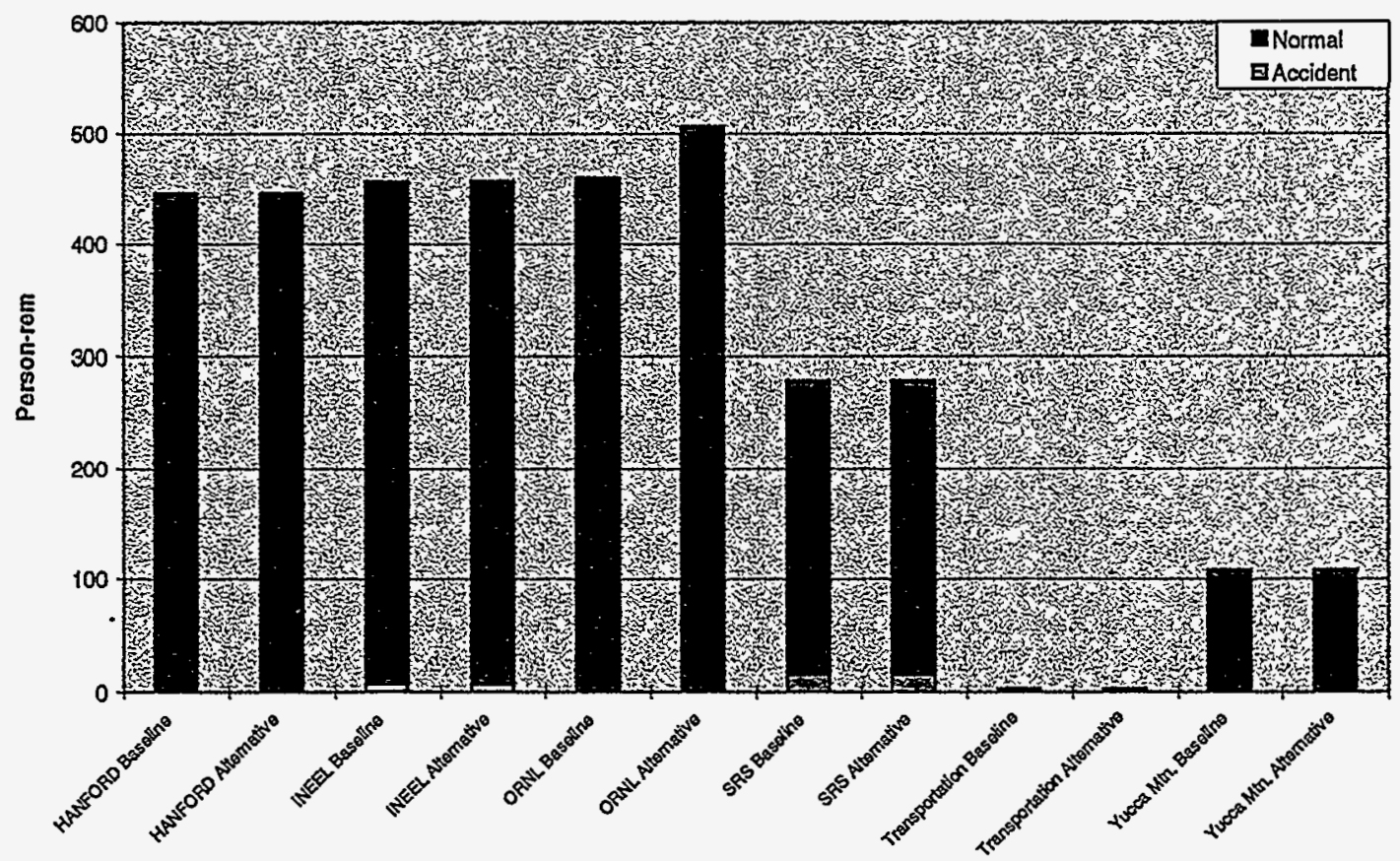

Figure 9-15. DOE SNE risk results by site (accident versus normal). 


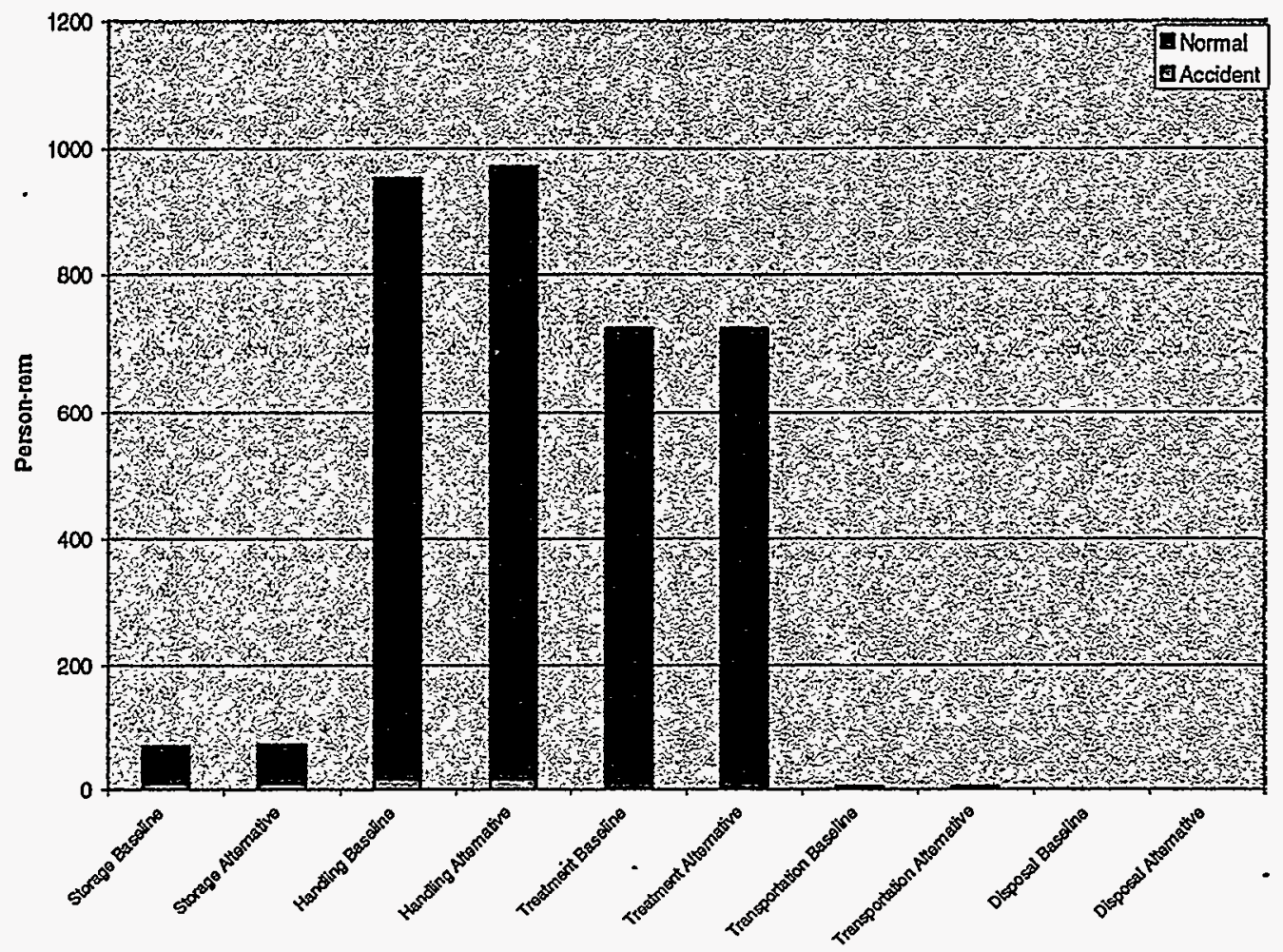

Figure 9-16. DOE complex-wide SNF risk results by activity (accident versus normal).

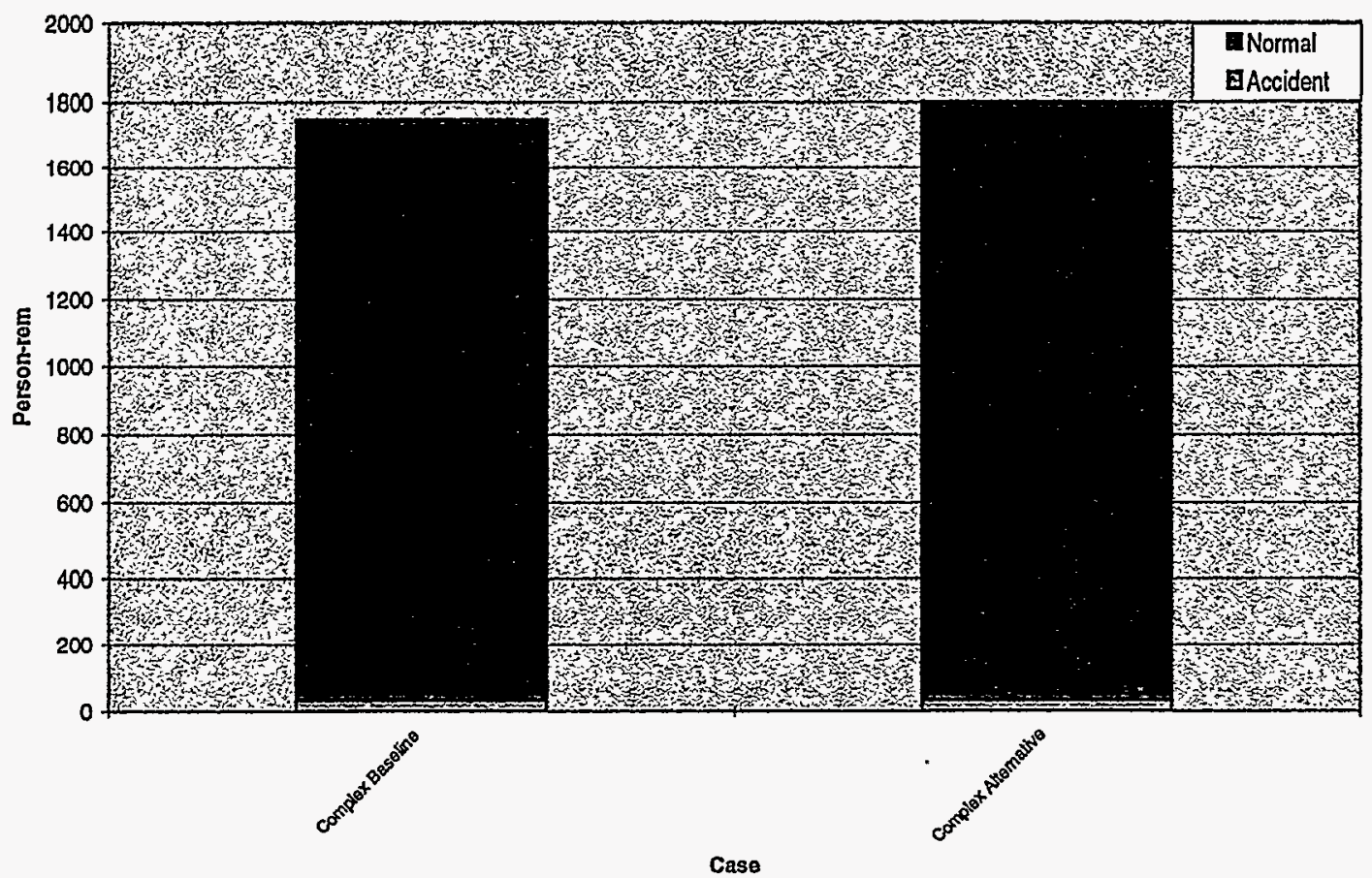

Figure 9-17. DOE complex-wide SNF risk results (accident versus normal). 
The complete SRM SNF model is in EXCEL ${ }^{\text {TM }}$ workbooks, with separate spreadsheets for each of the activities summarized in Figures 9-5 through 9-8. The spreadsheets contain detailed risk information on the following: accident risk (airborne) to workers, DOE site personnel, and the public, broken down into contributions from actinides, non-actinides, and chemicals; groundwater ingestion risk to the public from actinides, non-actinides, and chemicals; offgas risk (airborne) to DOE site personnel and the public, broken down into contributions from actinides, non-actinides, normal exposure (direct radiation) to workers; and normal and accident risk to the crew and public for transportation. All of these contributors (as applicable to the activity in question) are summed in order to estimate the total risk from the activity.

Because the SRM SNF model is computerized, sensitivity studies can be performed relatively easily. Also, if more opportunities are identified in the future, the SRM analyses can be performed efficiently. Finally, existing SNF results can be broken down into many different ways to respond to questions from stakeholders.

The SRM risk results were compared with other risk estimate sources to ensure that the risk predictions are consistent with more detailed analyses. Comparisons were made with the results from the report Department of Energy Programmatic Spent Nuclear Fuel Management and Idaho National Engineering Laboratory Environmental Restoration and Waste Management Programs Final Environmental Impact Statement. ${ }^{10}$ The SNF in this document has 21 alternatives for disposition of SNF. The Planning Basis alternative was used for comparison. The results of the comparison are presented in Table 9-2.

Table 9-2. Summary of EIS risk results (Planning Basis Alternative) ${ }^{1}$

\begin{tabular}{llll}
\hline \multicolumn{1}{c}{ Site } & EIS Total (person-rem) & SRM Total (person-rem) & Comparison \\
\hline Hanford & $352-492$ & 445 & $-21 \%$ to $11 \%$ \\
INEEL & 230 & 456 & $-50 \%^{3}$ \\
SRS & 206 & 280 & $-27 \%$ \\
ORNL & 582 & 506 & $15 \%$ \\
Offsite Transportation & $280(20)^{2}$ & 3 & $>100 \%^{4}$ \\
\hline
\end{tabular}

1. Obtained from Appendices A, B, C, and F of EIS. Planning Basis Alternative used.

2 EIS used $14 \mathrm{mrem} / \mathrm{h}$ at $1 \mathrm{~m}$. Divide by 14 to compare with SRM results. Also, EIS result includes naval fuel.

3. The Planning Basis Alternative is not a very good comparison for the INEEL since the SRM has more material shipped to INEEL than in the Planning Basis Alternative.

4. The transportation totals for the SRM do not include Naval Spent Nuclear Fuel which is a significant contributor to the transportation totals. Also the number of spent fuel shipments in the Planning Basis Alternative differ from the number of shipments in the SRM.

In general, the limited comparison above indicates that the SRM is adequately predicting SNF human health for this comparison. However, further comparisons from detailed risk assessments are needed to validate all areas of the SRM, especially risk from normal worker/site exposure. 


\section{CONCLUSIONS}

As indicated in the introduction to this report, the goals of the SRM analyses of HLW, TRUW, LLW, MLLW, and SNF were the following:

- provide a consistent, comprehensive, and quantitative human health risk picture for all of the important activities involved in the baseline programs and alternatives

- evaluate the alternative program risk relative to the baseline program risks

- provide a simplified risk model that can be exercised to answer stakeholder questions about risk.

Each of these goals was met.

The SRM risk structure, with its standardized risk matrix approach for modeling individual activities at each site and its standardized look-up tables for determining values for elements of the risk equations, was developed to ensure consistent, comprehensive, and quantitative analyses of human health risk. The SRM analyses of the DOE complex-wide programs for HLW, TRUW, LLW, MLLW, and SNF consistently and comprehensively cover these material types from initial storage through final disposal or disposition. Essentially all of the activities associated with these material types (e.g., storage, retrieval, loading and unloading, sorting, repackaging, various treatment processes, on-site and off-site transportation, and disposal) were modeled, even though some of the activities may have negligible human health risks for some of the material types. The quantitative risk results from the SRM analyses, expressed in terms of person-rem, are available for individual site activities associated with a specific material type up through summary results for the entire DOE complex for all five material types.

SRM human health risk results were generated for both the baseline programs and alternatives. Again, these results are available for individual site activities up through summaries of the entire DOE complex. At the DOE complex-wide program level for each material type, the differences in risk between the baseline program and the alternative are less than $33 \%$, with the alternative risks lying above or below the baseline risks, depending upon the material type. When all five material type risks are combined at the DOE complex-wide level, the alternative risks are less than $0.1 \%$ different from the baseline risks. Therefore, given the accuracy of the SRM, the baseline and alternative programs are considered to be comparable with respect to human health risk.

Finally, the SRM risk matrices provide significant risk detail at the site activity level. Included are risk estimates for the following types of contributors: accident risk (airborne pathway) to workers, site personnel, and the public, broken down into contributions from actinides, nonactinides, and chemicals; groundwater ingestion risk to the public from actinides, nonactinides, and chemicals; offgas risk (airborne pathway) to site personnel and the public, broken down into contributions from actinides, nonactinides, and chemicals; normal exposure (direct radiation) to workers; and normal and accident risk to the crew and public for transportation. All of these risk contributors were included in the SRM because they have been shown to be significant in one or more of the activities typically modeled. These risk matrices are EXCEL $^{\mathrm{TM}}$ spreadsheets, which can be summarized and combined in various ways to answer a wide range of human health risk questions from stakeholders. Also, if changes are made to the material type baseline or alternative programs, these changes can be quickly incorporated into the existing SRM risk models. 


\section{REFERENCES}

1. U.S. DOE Complex-Wide EM Integration Team, A Contractor Report to the Department of Energy on Environmental Management Baseline Programs and Integration Opportunities (Discussion Draft), INEL-EXT-97-00493, May 1997.

2. S. A. Eide et al., A Simplified Method for Quantitative Assessment of the Relative Health and Safety Risk of Environmental Management Activities, INEL-95/0645, September 1996.

3. R. G. Peatross and S. A. Eide, User's Guide for the Simplified Risk Model (SRM), INEL-96/0397, October 1996.

4. DOE Order 5480.23, "Nuclear Safety Analysis Reports," U.S. Department of Energy, April 10, 1992.

5. Oak Ridge National Laboratory, Integrated Data Base Report -- 1995: U.S. Spent Nuclear Fuel and Radioactive Waste Inventories, Projections, and Characteristics, DOE/RW-0006, Rev. 12, December 1996.

6. U.S. Department of Energy, Office of Environmental Management, Final Waste Management Programmatic Environmental Impact Statement, DOE/EIS-0200-F, May 1997.

7. U.S. Department of Energy, Savannah River Operations Office, Savannah River Site Waste Management Final Environmental Impact Statement, DOE/EIS-0217, July 1995.

8. S. Eide personal communication with K. Malone of West Valley, February 1997.

9. D. R. MacFariane, Probabilistic Safety Assessment for Hanford High-Level Waste Tanks, LA-UR-95-1900, April 1995.

10. U.S. Department of Energy, Office of Environmental Management, Idaho Operations Office, Programmatic Spent Nuclear Fuel Management and Idaho National Engineering Laboratory Environmental Restoration and Waste Management Programs Final Environmental Impact Statement, DOE/EIS-0203-F, April 1995. 